\title{
Towards a new theory of VET policy evaluation and engagement:
}

A multiple stakeholder approach

by

Lois Elaine Parkes

\begin{abstract}
A thesis
submitted to the Victoria University of Wellington in fulfilment of the requirements for the degree of Doctor of Philosophy
\end{abstract}

Victoria University of Wellington 


\begin{abstract}
Much current policy analysis assumes that in order to build theory on vocational education and training (VET) policy evaluation, it is useful to explore evaluation from the perspectives of its stakeholders. However in practice this does not always happen. This thesis addresses the limitations that arise in policy analysis on VET when stakeholders' perspectives are ignored or assumed. Industry Training in New Zealand is used as an example of a VET policy that has experienced increasing participation by stakeholders, but limited evaluation that largely ignores stakeholders' views.
\end{abstract}

Taking an inclusive, qualitative approach, this research seeks to unearth how different stakeholders in the state and tourism sectors evaluate the impact of Industry Training and how value is created for each from Industry Training engagement. Fifty semistructured interviews were completed with a cross-section of stakeholders representing policy makers, various industry interest groups, as well as employers/managers and trainees from four state and tourism sector organisations. Secondary data, where available, were also analysed, in order to improve the level of data triangulation.

An analytical framework was developed from the VET, human capital, human resource development, critical human resource development and policy evaluation literatures. This framework consists of two broad paradigms of evaluation:

(1) The Strategic HRD/VET policy logic of skills investment equals increased socioeconomic prosperity. This views the outcomes of VET policy as largely value-free, quantifiable facts that are mutually beneficial to all stakeholders, and which exist separately from these stakeholders; and,

(2) The Critical HRD/Stakeholder logic that views the outcomes of VET policy as value-laden, not necessarily mutually beneficial to all stakeholders, nor existing separately from its stakeholders. 
Responses from interviewees were compared against these paradigms and among different stakeholder groups to answer the main research question: How do stakeholders evaluate the impact of a VET policy?

The main research outcome is the development of a new framework and theory of VET policy evaluation, based on a comparative understanding of value creation from multiple stakeholders' perspectives. 


\section{ACKNOWLEDGEMENTS}

My $\mathrm{PhD}$ journey would not have been possible without the help and support of a number of persons. The support provided by the Victoria Management School, both its academic and administrative staff has been exceptional. Special thanks to my supervisors, Jane Bryson and Richard Norman, who provided not only excellent supervision, but friendship and support beyond the call of duty, particularly during my times of illness.

Without the financial support provided by the Commonwealth Scholarship awarded by the New Zealand Agency for International Development, this research would not have materialised.

I also thank my fellow PhD students, who provided laughter, a sounding board, stress relief and shoulder to cry on, all of which allowed me to maintain my sanity during this process.

My interview participants as well as numerous other persons from the Industry Training sector in New Zealand, gave generously of their time, knowledge and insights. Without their input, this thesis would not exist.

Special mention must be made of my friends at Arise Church, who provided me with love, balance and emotional support during my time in New Zealand.

I am indebted also to my employer, the Public Service Commission of Jamaica, as well as work colleagues at the Cabinet Office of Jamaica, who provided me with financial support, as well as many of the initial ideas for this research.

My family in Jamaica and elsewhere have also been a source of strength and support throughout. A very special thanks must be given to my father, Wilbert Parkes, the world's best single father, who quite literally taught me how to study. 


\section{TABLE OF CONTENTS}

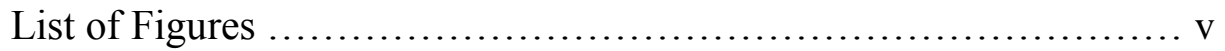

List of Tables.................................................... vi

List of Abbreviations........................................... vii

Definition of Key Terms.................................... viii

Chapter 1 - Introduction.......................................

Chapter 2 - Literature Review....................................4

Chapter 3 - New Zealand Context - Industry Training.................52

Chapter 4 - Methodology........................................... 75

Chapter 5 - Data Analysis - Findings from Policymakers and Industry Interest Groups...........................................99

Chapter 6 - Data Analysis - Findings from Tourism Organisations.....126

Chapter 7 - Data Analysis - Findings from State Sector Organisations...............................160

Chapter 8 - Discussion and Conclusion..............................205

Appendix A - List of Respondents ................................236

Appendix B - Research Questions Map ...........................238

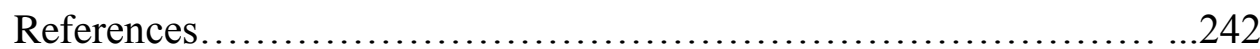




\section{LIST OF FIGURES}

Figure 2.1 - The Strategic HRD/VET policy logic.........................47

Figure 2.2 - The Stakeholder Theory Logic................................48

Figure 2.3 - The Critical HRD/Stakeholder Logic..........................50

Figure 3.1 - Key players in the Industry Training System...................53

Figure 5.1 - Factors leading to value creation from Industry Training policymakers and industry interest group perspectives....................... 16

Figure 5.2 - Programme Logic for value creation from Industry Training Perspectives of policymakers and industry interest groups................... 125

Figure 6.1 - Programme Logic for Value Creation - Tourism organisations......157

Figure 7.1 - Programme Logic for Value Creation - State Sector perspective....203

Figure 8.1 - Revised programme logic for VET policy implementation .230 


\section{LIST OF TABLES}

Table 2.1 - Dominant forms of skills provision across different countries: Initial VET and Further VET...................................................... 18

Table 2.2 - Emerging paradigms from the literature......................... 45

Table 2.3 - Human Capital/VET Policy logic..................................45

Table 2.4 - Strategic HRD Logic...........................................46

Table 2.5 - Critical HRD Logic..........................................49

Table 4.1 - Numbers of Interviewees and Stakeholder Groups Represented........83

Table 4.2 - Comparative Analytical Framework.................................86

Table 5.1 - Industry Interest Groups and Policymakers' Perspectives of

Pedagogical Issues Affecting Industry Training................................ 101

Table 5.2 - Summary of Findings - Policymakers and Industry

Interest Groups......................................................... 124

Table 6.1 - Industry Training Qualifications pursued in Company B..............128

Table 6.2 - How value is determined by managers/employers - Tourism

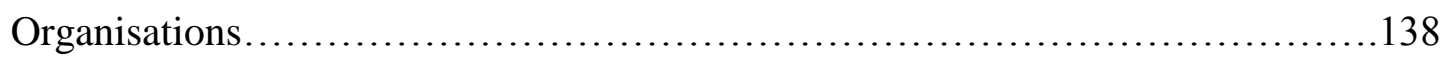

Table 7.1 - Description of Trainee Respondents for Department X................164

Table 8.1 - Characteristics of the Strategic HRD/VET logic and the Critical

HRD/Stakeholder Logic.................................................223

Table 8.2 - Evaluation methods employed by multiple stakeholders of VET........227

Appendix A: List of Respondents............................................236

Appendix B: Research Questions Map........................................238 


\section{LIST OF ABBREVIATIONS}

ATTTO - Aviation, Travel, Tourism Training Organisation

EU - European Union

HR - Human resources

HRD - Human Resource Development

HRM - Human Resource Management

HSI - Hospitality Standards Institute

ILO - International Labour Organisation

ITF - Industry Training Federation

ITO - Industry Training Organisation

KPI - Key performance indicator

LCP - Limited credit programme

NQF - National Qualifications Framework

NVQ - National Vocational Qualification

NZQA - New Zealand Qualifications Authority

OECD - Organisation for Economic Cooperation and Development

PI - Performance indicator

PSITO - Public Sector Industry Training Organisation

PTE - Private training establishment

SME - Small and medium enterprise

STM - Standard training measure

TEC - Tertiary Education Commission

UK - United Kingdom

USA - United States of America

VET - Vocational education and training 


\section{DEFINITION OF KEY TERMS}

Competitive Advantage: At the level of firms, it refers to the ability to sustain above average profits vis-à-vis other competitor firms (Barney, 1991). At the level of countries, it refers to the ability of a nation to sustain above average levels of GDP and standard of living vis-à-vis other competitor nations (Dunning, 1992).

Human Capital: "The knowledge, skills, competencies and attributes embodied in individuals that facilitate the creation of personal, social and economic well-being" (OECD 2001, p. 18, cited by (Le, Gibson \& Oxley, 2005, p. 6).

Human Resource Development (HRD): "the study and practice of increasing the learning capacity of individuals, groups, collectives, and organisations through the development and application of learning-based interventions for the purpose of optimising human and organisational growth and effectiveness" (Chalofsky, 1992, p. 179).

Industry Training: This is the term used to describe New Zealand's largest vocational education and training policy. It was enacted through the passing of the Industry Training Act of 1992, which allowed for local industries to establish Industry Training organisations with responsibility for the design, assessment and organisation of Industry Training within the national qualifications framework. It describes the learning and skill development interventions linked to the needs of workers, workplaces and industry ("Key facts about industry training," 2008).

Logic Model: This is a diagrammatic representation of a programme theory (Julian, Jones, \& Deyo, 1995; S. Kaplan \& Garrett 2005).

Programme Theory: This term refers to the underlying assumptions about how a policy initiative or a set of policy actions will work to accomplish the outcomes intended (Bickman, 2000; Owen, 1998). 
Skills: "People's capabilities, abilities, knowledge, understanding, motivation, willingness and ability to use their capabilities and knowledge. It is broken down in the following categories:

- "foundation skills - things we need to know, understand and be able to do in order to do most other things

- generic skills - skills that we can apply in a range of contexts, and often enable use to make use of other skills

- technical skills - skills that are often specialised and required for particular activities” (“Key facts about Industry Training,” 2008, p. 2).

Vocational Education and Training (VET): This is defined as formal, post secondary, government skills initiatives directed specifically at the employed labour force. This is distinct from skills initiatives directed at the unemployed or utilised to foster smoother school to work transitions for youth (Wolf, 2002).

Workplace Learning: This describes all learning that takes place within the contexts of work, and includes learning acquired through formal training, as well as informal and tacit learning acquired through work performance and interaction with others in the work environment (Hager, 2000; Kitching \& Blackburn, 2002; Rainbird, Fuller, \& Munro, 2004). This definition also acknowledges that the boundary of the workplace is permeable, and learning external to the workplace can and does impact learning within the workplace. 


\section{CHAPTER 1 - INTRODUCTION}

This research has its genesis in a critique of the promises of vocational education and training (VET) policies promulgated in both developed and developing nations. The essence of these promises often articulated in VET policy literature is that greater investment in VET will provide the vehicle that organisations, individual workers and economies can utilise to arrive at the destination of a number of 'highs' - high skills, high wage jobs, high levels of productivity, and improved levels of socio-economic performance, along with improving equity outcomes for the disadvantaged in the labour market. The critique stems from the failure of many economies and individuals to arrive at this 'high' destination. Additionally, the VET policy literature often fails to articulate and analyse the distinction among various types of VET interventions. The factors contributing to the achievement of VET outcomes are often assumed, and in fact have been under-researched, particularly the roles that various stakeholders play in the VET engagement process. Finally, VET policies often suffer from numerous challenges in their evaluation, being limited to the use of a small range of quantitative indicators, such as numbers of trainees and completion rates for VET qualifications, underpinned by the assumption that these indicators reflect the mutually beneficial outcomes for all VET stakeholders. VET policy research suffers from a paucity of examination of the underlying assumptions of VET, the absence of the exploration of stakeholders' perspectives, and critical analysis of VET policy evaluative practice. This research seeks to fill these gaps in our understanding of these issues.

The Industry Training system in New Zealand was chosen as the object of this research as it represented a VET policy that is managed in a decentralised manner, involving a number of stakeholders. It is also an example of a policy that carried with it many promises and aspirations. Over the past twenty years, policymakers in developed countries have advocated for the expansion of VET policies, with a vision of creating high-wage, high-skill, and highly productive economies. In New Zealand, the Industry Training Strategy has been touted as one of the main vehicles for achieving this goal. Eighteen years since its introduction, New Zealand has seen an expansion in Industry Training and higher education, but not necessarily the other 'highs': high wage, high productivity (Harvey \& Harris, 2008; Working Smarter: 
Driving productivity growth through skills, 2008, p. 8). Throughout its implementation, evaluation of this strategy has been largely limited to a few quantitative indicators - such as numbers of trainees - with very little connection between the evaluation findings and accomplishment of the vision. Additionally, these indicators have been by and large developed by policymakers and industry interest groups. There is an unspoken assumption that such indicators effectively represent the value of Industry Training to all stakeholders concerned.

A few words must be said about the timing of this research. The actual research began in 2007 and ended in 2010. During that period, two critical events took place - the change from a Labour-led government to a National-led government and the global economic recession, which saw New Zealand going from having the lowest unemployment rate internationally to experiencing job losses and higher levels of unemployment. During this three-year period, there were renewed debates around the role not only of Industry Training, but of skills in general. This is exemplified in the discussions surrounding the attempts to develop a Unified Skills Strategy, the focus on the role of workplaces in this process, and the current interest in low completion rates for Industry Training and the wider tertiary education programmes (New Zealand Skills Strategy Discussion Paper, 2008; Ryan, 2007; Tertiary Education Strategy 2010-15; 2010). At the heart of these debates lie three fundamental questions: what is the value of Industry Training, how is that value realised, and how is that value assessed.

This research seeks to shed light on the answers to these questions. At one level, the contribution of this research is practical and pragmatic. It is hoped that providing further illumination on these issues will assist practitioners and policymakers in improving the implementation of Industry Training and skills policies in general.

This research however is also comparative in nature, and is seeking to further enrich the debate by examining value from multiple stakeholder perspectives. The research assumes that different stakeholders may value Industry Training differently, and may view the process of value creation through different lenses. This divergence of views is probably most pronounced among end users, such as employees and employers/managers. 
A qualitative, inclusive approach is used in this research to explore how different stakeholders evaluate the impact of the Industry Training Strategy and how value is created for each from strategy engagement. This research is unique in that it seeks to take a multiple stakeholder perspective to the evaluation of Industry Training, whereas previous evaluative research has either ignored these perspectives, or has been limited to only comparing a small range of stakeholders' perspectives.

Another unique aspect of this research is its analytical framework, which has been derived from programme theories on evaluation from the literature. This then provides another layer of comparative analysis, which seeks to examine the data through the lens of these programme theories. The result of this research is an expanded theory of VET policy evaluation and VET effectiveness, from a multiple stakeholder perspective. The academic contribution of this research will be to VET policy evaluation literature, with applications to the HRD literature, Critical HRD literature and the wider policy analysis field.

The following chapter covers the review of the relevant literature, which seeks to establish the specific knowledge gaps that this research is seeking to address. This provides the rationale for the research and informs the analytical framework employed. Chapter 3 is a continuation of the review of the literature which examines the New Zealand Industry Training context. This provides a historical perspective of Industry Training, its genesis and an analysis of its evaluation. Chapter 4 describes the methodology used for this research: the research paradigm used, the research questions, the methods of analysis, data sources, data collection methods, ethical considerations and research limitations. Chapters 5 and 6 capture the research findings against the various research questions. In the final chapter the research findings are discussed, with the research conclusions and recommendations for future research. 


\section{CHAPTER 2 - LITERATURE REVIEW}

New Zealand is not unique in its pursuit of VET initiatives with the expectation of attaining an economy characterised by highly skilled, high wage jobs and socioeconomic prosperity. Its experience mirrors international developments in the area of VET policy, particularly within the OECD. It is therefore important to examine the literature on the various (but reinforcing) schools of thought that have influenced countries along similar paths. Drawing mainly on literature from the United Kingdom, Europe, the United States, Australia and New Zealand, I will first discuss the concept of globalisation, and attendant ideas about changes in the world economy and changes in the nature of work. Next, the logic underpinning these attendant ideas will be explored, particularly in terms of assumptions about the definition and benefits of VET, and the challenges these pose. The roles of various theories including human capital, labour economics, employability theory and HRD theories will be examined to unearth and critique their influences on the ascendancy of VET policies in macroeconomic development and the benefits and beneficiaries of VET investment at the societal, organisational and individual levels. The literature on how VET investment is expected to create beneficial outcomes is next explored, with emphasis on pedagogical issues relating to VET, and the roles of VET stakeholders and varieties of institutional arrangements in this process, as manifested in differences in VET policy solutions that have emerged. The challenges of evaluation of VET policies are then critiqued, drawing on VET evaluation analyses, policy and HRD evaluation literature. This chapter ends with a synthesis of the literature, proposing that there are two underpinning and competing theories or logic models that define how VET investment creates outcomes for stakeholders. These two models propose different approaches to how VET investment is or ought to be evaluated.

\section{Globalisation, the New Economy and the Nature of Work}

The prominence of VET and skills more generally in the policy arena stems from the rise of dominant perceptions about globalisation and its attendant changes in world trade, competition, information and communication technology, the production of goods and services, and ultimately in the way people work. All these factors together have given rise to what has been dubbed the 'new economy'. This new economy is a 
direct symptom or consequence of globalisation, which can be defined from an economic perspective as the growing integration and inter-connection of markets, market competition, investment, production networks and strategic alliances (Strugeon, 2000, pp. 4-5). Prior to the emergence of the new economy, developed countries were characterised as having industrialised economies, whose hallmark was Fordist production methods and the bureaucratic organisation of work, where work was distilled into discrete tasks, each requiring limited skills (Briggs \& Katay, 2000; Gilbert, 2005). Within the industrial economy, manufacturing sectors were the major employers of labour, providing high income levels for low skilled and mainly permanent manufacturing jobs.

Although it can be argued that the process of globalisation began centuries ago, since the Second World War, the world has witnessed, and continues to witness, an accelerated pace of change in information and communication technologies, technology generally and trade liberalisation. Other nations, particularly from Asia, began to provide competition to developed Western nations; they could provide similar and sometimes better products more cheaply (Buchanan et al, 2000). With trade liberalisation and greater mobility of capital, low skill production plants could be set up in these countries, where labour costs were cheaper than in developed nations. The recommended policy response of developed countries to these challenges was to pursue initiatives which encouraged constant innovation to improve their ability to produce high quality products and services. (Aldcroft, 1992, Boshier, 1980; Crocombe et al, 1991; Flude \& Siemenski, 1999; Harbison, 1973; Lange et al, 2000; Tight, 2002). The underlying policy assumption or programme theory is that these initiatives would result in the continued economic survival and competitiveness of developed countries. This would also result in a fundamental shift in the labour market to the creation of a greater number of jobs which would require higher levels of skills and thus command higher wages - the creation of the 'high-skill, high-wage vision' or the 'knowledge society' (S. Porter, 2006).

Advances in technology and particularly in information and communication technologies have led to a decline in heavy manufacturing jobs, and a major change in the nature of work. Work is now predominantly characterised as less labour-intensive, white-collar, professional jobs in the service sector (Naswall et al., 2008). These 
service sector jobs differ from traditional manufacturing jobs in that job tasks are less discrete, and employees now have more control and self-direction over work outcomes, the outcome being more knowledge intensive work. The requirement for organisations to constantly improve services and products in order to remain competitive necessitated a more highly skilled and flexible workforce in order to adapt to these continuous changes (Rudman, 2000).

Any discussion about the ascendancy of skills in the policy sphere would be incomplete without discussion of the changes that took place in labour relations in many developed countries. Increased liberalisation and market competition fundamentally altered the perception of the labour market. Faced with increased competition, businesses needed to become more flexible in order to manage their staffing levels and costs. In many developed countries, particularly the USA, Britain, Australia and New Zealand, legislation was enacted to bring an end to multi-employer bargaining, and thus began a dramatic decline in union membership and union density. This also brought about a dramatic change in the psychological contract between employers and employees. In an industrialised economy dominated by mass produced manufacturing goods operating in a relatively stable world economy, the psychological contract was characterised by lifelong employment in exchange for employee loyalty (Hodkinson \& Bloomer, 2002). In the new economy of openness of trade, increased competition, and world economic instability, lifelong employment was no longer a guarantee. The decline in manufacturing in developed countries, and the subsequent increases in unemployment bolstered the need for a change in the nature of the employment relationship (Rudman, 2000). The dominant theory characterising the new psychological contract was the employability theory. The central tenet of the employability theory is that workers' survival in the new economy depended on them increasing and adapting their skill levels, so that they would always be able to find employment and avoid social exclusion (Devins \& Johnson, 2003; Rainbird, 2002; Tight, 2002). This became part of the motivating force behind public policy in many developed countries for expanding government skill development initiatives and education in general.

A major proponent of the philosophy of the new economy has been Robert Reich, former Labour Secretary in the United States, who argued that improved performance 
in VET and higher education generally was the new source of competitive advantage (Reich, 1992). He theorised that national corporations would give way to multinational corporations, and that the fastest growing occupational group would be that of symbolic analysts (also called knowledge workers by other writers), who would have the ability to create value through exploitation of knowledge and skills. According to Reich, the best policy response in this context was to expand VET, and to attract and retain symbolic analysts to the economy. Piore and Sabel (1984) in their work, The Second Industrial Divide, examined the decline of manufacturing in the United States. They concluded that, in light of the increased competition developed nations faced from developing countries in the area of mass produced goods, the only way for developed countries to maintain high wage economies and competitiveness was through continuous innovation, which required a highly skilled workforce as a major input (Briggs \& Katay, 2000).

In the UK, the National Institute of Economic Studies compared the performance of matched cases of British and German firms in basic metalworking products, kitchen furniture, women's outer wear and hotel sectors, and examined the relationship between VET performance and firm performance (Daly et al, 1985; Prais, 1989). The conclusion drawn in all the cases was that German firms consistently outperformed their British counterparts, and the source of Britain's underperformance was the weaknesses in its skill development strategies. This provided further evidence to support calls for an increase in skill investment through the improvement and expansion in VET as well as higher education.

In summary, the increasing competition in trade, led to labour market liberalisation, which has manifested itself in more flexible work arrangements such as workers changing jobs more frequently and being generally more mobile, and the growth of more flexible work arrangements such as the contract work, temporary work and contingent workforces (Naswall et al., 2008). Hence, skills and education is seen as the new guarantee of employment security and the path to increasing competitiveness, not only in the labour market, but also among organisations and nations, as higher skilled workers would be able to produce high end goods and services that are in greater demand globally. 
There are a number of assumptions that underpin the arguments as outlined above, that need to be analysed in turn. The first concerns the precise nature of the skills and education investment that is required to create this outcome of socio-economic growth for societies and its workers. The second relates to how these outcomes are created, and the assumptions about the roles of different stakeholders engaged in the process. The third relates to how these outcomes are evaluated.

\section{The nature of skills and education investment}

The merit of the logic that the acquisition of skills and education is highly beneficial to workers and societies is supported by a great deal of socio-economic data. In most societies, those who are more highly skilled and educated experience lower levels of unemployment, higher wages and better health outcomes, to name a few beneficial outcomes (Dyson \& Keating, 2005; Harbison, 1973). However, the VET policy rhetoric refers to the benefits of skills and education in very generalised terms, often lumping a variety of skills initiatives with other forms of higher education such as diploma and degree programmes. Further, there is often no attempt made to identify differing types of VET initiatives in terms of goals, content, design, quality or quantity. Yet, it is assumed that all types of VET, irrespective of differing characteristics, lead to highly skilled workforces earning increased wages.

The use of VET as an all encompassing term to cover all aspects of post-secondary training and learning, poses a challenge for policy evaluation purposes, as the distinction is not made between different types of post-secondary training provisions, and their distinct purposes. Grubb and Ryan (2000) rightly argue that distinguishing among the different types of VET provisions is critical to effective VET policy evaluation. To this end, they offer a useful typology of VET provisions that is outlined below:

- Pre-employment VET that is targeted at preparing secondary school leavers for entry into the labour market

- Upgrade training that provides learning opportunities for the employed for job advancement and other purposes 
- Retraining for displaced workers to assist them in finding alternative employment

- Remedial VET which provides learning opportunities to individuals who have been marginalised in the mainstream education sector and labour force (Grubb \& Ryan, 2000, p. 10).

Grubb and Ryan (2000) further argue that the different types of VET provisions have differing goals and target different segments of the labour force. Therefore, there is a need to make those distinctions clear in the policy dialogue, and identify the implications for policy evaluation. For example, using the employment rate of trainees to assess upgrade training can lead to exaggerated conclusions of successful programme performance, as this type of VET provision targets the employed. Thus VET policy dialogue would benefit from greater specificity in programme and goal definition to improve evaluation in the field.

In the literature, there is a proliferation of terms covered by evaluation studies on skills for example, human capital, formal and informal training and learning. All these terms have varied and ever-changing meanings, and are not easily defined. Firstly, the meaning of skill, particularly within the policy dialogue of the new economy, is changing. It has moved from describing the ability to perform discrete tasks to meaning cognitive abilities and personal attributes, such as the ability to work in teams and analytical skills (Fenwick \& Hall, 2006; Payne, 2004). This change from a more technical perspective of skill, to embracing cognition and personal attributes has its genesis in the altered occupational structures created by the new economy. With the fall in manufacturing, the service industry is now the fastest growing segment of the economies of all developed countries, and with it has come the growth of what is dubbed service work (Keep \& Payne, 2004). Service work is by no means a homogenous employment categorisation; however, service work is characterised by increased interface with customers and increased use of creativity and work teams, making the use of cognitive abilities and personal attributes more critical to job performance. Stasz et al in examining the outcomes of VET policy in the UK context offer an interesting typology of skills outcomes: academic skills, social skills, and generic skills (Stasz et al, 2004). Warhurst and Nickson have further expanded on this concept, to include what they call aesthetic labour, which is especially evident in the 
retail and hospitality industries, where service work places emphasis on factors such as image, appearance and dress codes (Warhurst \& Nickson, 2007). This expanding definition of skills is a highly contested issue in the literature for several reasons. For some, this expansive definition of skills has led to confusion, and to skills becoming a catch all phrase, meaning everything and nothing (Keep \& Payne, 2004). Additionally, there is the question of whether these cognitive and personal skills can be developed adequately using formal skill development interventions, such as VET programmes. Evidence from the UK reveals that national vocational qualifications in service work tend to be of lower quality and of lower value and status. There is however a counter argument that the downplaying of these kinds of 'service' skills represents a gendered view of skills, in that these skills and the jobs that utilise them are mainly occupied by women, often in exchange for low pay and poor working conditions. It is further argued that these skills and their attendant qualifications are viewed as low status because work dominated by women is undervalued in society (Korczynski, 2005).

Notwithstanding the debate about the value, or lack thereof, of the expanded meaning of skill, this expansion presents an evaluation dilemma. This dilemma is centred on several unknowns. The first is what exactly is meant by skills; given the changing definition of skills, new skills, such as social skills (example being customer service skills) are not readily observable or described, thus evaluation of such skills is challenging. A further question is how are skills, given their variety, best developed. Payne, for example, postulates that many of these new skills are best developed within the work context (a point to be discussed later in this chapter); however, in the context of the UK voluntarist VET system, the responsibility for the development of these skills has shifted to educational institutions (Payne, 2004). As pointed out by Keep, there is a need to acknowledge that VET policy is possibly better geared at developing technical skills rather than service skills (Keep, 2007). Within competency based national qualifications systems (which are discussed later in this chapter), qualifications are used as a proxy for skills. However the efficacy of this proxy has been questioned, particularly by proponents of signalling theory (Bassanini et al., 2005). Such proponents argue that skills are properly acquired through experience on the job, and qualifications are not indicators of skill level. Rather, qualifications serve as a signal to employers on the abilities (usually of the more cognitive nature) of 
prospective workers; those with qualifications are considered more able, and possibly have the capacity to learn the necessary skills on the job, and those without are less capable (Correa, 2004). Moreover, the use of qualifications as a proxy for skills can ignore quality concerns, such as whether the relevant skills were taught, and more importantly, whether the trainees actually learn, and use what they have learnt, as this is what then actually translates into performance (Rainbird et al., 2004).

The other problematic terms in the literature are formal and informal training and learning. Kitching makes a useful distinction between training and learning, the former being what is done to the employee, and the latter being what the employee actually does (Kitching, 2007). Thus training refers to attempts to equip employees with certain skills and knowledge, whether on a formal or informal basis, and learning is an expected outcome of training, but not necessarily a given. Evans and Rainbird make a different distinction between training and learning with training being business focused, while learning addresses a wider range of stakeholders' needs (K. Evans \& Rainbird, 2002). This broader appreciation for meeting a range of stakeholders' need has led to a shift in the policy dialogue to embrace learning, and notions of lifelong learning and the learning society (Fuller et al., 2003).

Human capital suffers from the same problem definition issues as skills. Many definitions with different emphases have been put forward (Kulvisaechana, 2005). One of the most comprehensive ones has been put forward by the OECD, "the knowledge, skills, competencies and attributes embodied in individuals that facilitate the creation of personal, social and economic well-being" (OECD cited by Le at al., 2005 , p. 4). As seen from the definition, human capital has different aspects; the question then arises as to how these elements of human capital are developed, and which aspects are critical, and critical for what - economic development, social development? Many commentators have noted that different proxies have been used for human capital, and this has been cited as the source of the lack of empirical consensus on the contribution of human capital to economic development (David \& Lopez, 2001; Le et al., 2005). Le et al have presented a useful summary and critical analysis of the types of proxies that have been used for human capital: the cost-based, income-based and education-based measures. 
The cost-based measure of human capital is one of the earliest measures and possibly least used today. The measure involves the use of child rearing costs, and human capital investment as a proxy for human capital stocks. This measure has been subject to a number of criticisms, some of which are the inability to distinguish between human capital investment and consumption costs, the effect of depreciation rate on cost based measures, and the failure of the measure to look at the quality of the output (Le et al., 2005, pp. 4-5). The income-based measure of human capital is very popular, and looks at individual as well as national income streams as a proxy for individual and national productivity. Many policy documents on human capital initiatives use the higher earning power of university graduates and graduates of vocational education and training programmes, to justify policy intervention, and government funding for such policies. For example, in the United States in 2004, 83\% of adults between the ages 25 to 64 whose highest level of educational attainment was at the lower secondary level earned at or below the US median income. This compares with the same age group who attained a minimum of a university degree, of which 69\% earned above the US median income (Miller et al, 2007). Another common statistic often used in conjunction with income earnings is the lower unemployment rates of persons with higher levels of educational attainment. So for example in the United States in 2004, $83 \%$ of persons who completed higher education were employed, compared with $57 \%$ of persons whose highest level of educational attainment was lower secondary education or below (Miller et al., 2007). The use of income and employment rate as a proxy has the advantage of readily available data that can be obtained through surveys. However, the measure is not without its disadvantages, one being that it assumes that wages equal productivity, when in fact there could be other structural factors that account for income levels, such as strength of union bargaining power, or the state of the economy or particular industry in which firms operate (Le et al., 2005).

The education-based measure of human capital involves the use of education outputs as proxies for human capital stock. The main proxies used in this category are literacy rates, enrolment rates, years of schooling, and level of educational attainment or qualifications (Le et al., 2005). The use of literacy rates has been criticised for giving insufficient attention to higher level skills, and for not being a particularly useful analytical tool within the context of developed countries, which tend to have higher 
literacy rates. Additionally, it has been difficult to find a consistent measure for literacy, although this gap has been addressed by the introduction of the International Adult Literacy Survey (IALS) (Johnston, 2004; Le et al., 2005). The use of enrolment rates and years of schooling also have their challenges, in that it does not account for quality of output and can be distorted by dropouts and repetitions. The use of qualifications as a proxy for human capital has also been challenged by numerous commentators (Correa, 2004; Nordman et al., 2006; Rainbird et al., 2004). Also it is debated whether years of schooling and qualifications are actual indicators of productive capability, or whether it is merely used as a signalling device to sort job candidates (Correa, 2004; Le et al., 2005; Stroombergen, 2002).

What is clear is that all measures of human capital have shortcomings in terms of their use in evaluation (Hanusek \& Wobmann, 2007; Johnston, 2004; Le et al., 2005). Although the type of proxy for human capital differs among studies, what is common is the pre-eminence of econometric quantitative analyses, all based on certain assumptions about how specific factors operate in the economy. Such econometric models must take into account certain variables, but usually to the necessary omission of others, and there has been the challenge of which factors should be taken into consideration in the various models. Another challenge with these econometric models is that they tend to reveal relationships among variables, but they are usually unable to prove causality between factors, or explain how variables actually work together. Econometric models are also plagued by problems of getting appropriate data, and especially assuring the integrity of data. In particular, cross country analyses can be problematic as variables and data are neither consistently defined nor captured across time and countries; some common examples are the measurement of unemployment, and the definition of youth. Notwithstanding these deficiencies, econometric analyses are constantly improving, and are useful for macro level analyses. However, they inevitably do not tell us how things actually operate, which is the heart of policy analysis and evaluation. Particularly as it relates to VET policy, quantitative analyses do not offer much insight on the relationship between incidence and investment in skills and higher levels of productivity. Moreover, the empirical evidence to support one of the central tenets of human capital theory - that is the link between human capital and economic growth, or human capital and firm performance - is inconclusive (Blundell et al, 1999; Christopoulos, 2007). Indeed Wolf et al point 
to UK research in 1990s where for sectors that had the greatest growth, "shortfalls in training and skill development seem to have been insignificant factors in explaining either decline or revival" (Wolf et al., 2006, p. 556). They further cite evidence that certified training did not lead to increased earnings in the UK context; in fact the evidence pointed to an association between uncertified employer-provided training and higher earnings (Wolf et al., 2006, p. 557).

In summary, the logic that skills and education investment lead to socio-economic development goals such as high wage, high skills jobs and increased productivity requires much qualification. While the logic may not be totally falsified, there is a need to identify the distinctions among different measures being employed, different skills and VET offerings, including their limitations and peculiarities. Depending on the nature of the indicator being used and the type of VET initiatives being examined, different impacts may be experienced by different labour markets, industries and workers.

\section{What are the outcomes expected and how are these created?}

An examination of the relevant literature reveals that, with the exception of the work done by Grubb and Ryan (1999), VET policy literature is often lacks critical analysis of the variety of VET outcomes, the differences in VET offerings and organisation, and the roles the differing VET stakeholders play or may not play in the process of creation of VET outcomes. This section examines firstly the impact of economic theories which have significantly influenced the formulation of VET policies, and the assumptions made about the value creation process of VET, the role of various stakeholders and the gaps in the theories. This section will also examine the literature on the variations in VET models across differing governments, to analyse the roles of stakeholders and the assumptions of these models. HRD theory is also examined, not because the link to VET policies is explicit, but to identify the similarities and differences between these theories, and how they may inform the VET value creation process, and the roles of stakeholders in the process. The section ends with the examination of pedagogical issues related to learning in workplaces, again from the perspective of examining the linkages to VET policy. 
A number of theories, mainly from the field of economics, have underpinned this programme theory of economic growth through skills development. Mournier succinctly summarised the three mutually reinforcing ideologies behind this thinking (Mournier, 2001):

- Neoclassical, endogenous growth, and factors proportion theories where the general consensus is that increasing levels of income and economic growth are dependent on improvement in skills levels in an economy impacted by globalisation, increasing levels of competition and rapid changes in technology.

- Schumpeterian and Neo-Schumpeterian theories which argue "competitive power and corporate results increase according to their innovative capabilities and these in turn are functions of the level of skills of their workforce"; and

- Neoclassical theory of income distribution and human capital theories which assert that the more highly educated have higher income levels and lower levels of unemployment, as "... incomes are related to labour productivity" which in turn "is related to education and skills levels" (Mournier, 2001, p. 1).

It is perhaps human capital theory which has most captured the imagination of policymakers, particularly in New Zealand. One need only look at a list of reports published by the New Zealand Treasury and other government departments to understand the theory's impact; they include titles such as Knowledge, Capabilites and Human Capital Formation in Economic Growth (David \& Lopez, 2001; Human Capital and the inclusive economy: Treasury Working Paper 01/16 2001; Stroombergen, 2002). Gary Becker has been credited for being the economist who contributed most to the development and popularisation of human capital theory. Of particular interest have been his ideas related to on-the-job training as he argued that "it clearly illustrates the effect of human capital on earnings, employment, and other economic variables" (Becker, 1962, p. 2). In a nutshell, Becker argues that firms would not be willing to pay for general training, as the benefits from this will accrue mostly to the worker, who can then utilise the skills and knowledge gained from 
general training to seek other jobs elsewhere. The exception would be if workers were willing to contribute to the cost of general training, by for example, accepting reduced wages. On the other hand, firms would be willing to invest in specific training related to the unique characteristics of that firm, as it is the firm that reaps most of the benefits of specific training, and due to its non-portability, workers would not rationally invest in specific training themselves. Becker also argued that the income differentials could be explained by the differing levels of investment in human capital among individuals, and that the more able "tend to invest more than others" (Becker, 1962, p. 48).

Becker's theory has been critiqued particularly for referring to a context of a perfect labour market, which does not exist. In the perfect labour market, as put forward by Becker, there is virtually no need for government intervention in the provision of certain skills, as these would be provided through the functioning of the labour market. His critics have cited a number of market failures and imperfections in the labour market. Examples cited in the literature include imperfect labour market information, inadequate financing available to workers to facilitate their investment in their skills development, inequitable access to education and training for disadvantaged groups (Acemoglu, 1997, 2003; Bassanini et al., 2005).

These economic theories taken together make certain assumptions about the role and responsibilities of the variety of stakeholders in the value creation process. One set of stakeholders are employees, who have an individual responsibility for their own development and for investing in general training, which is not defined. This fits neatly with the employability theory. However, how this investment in loosely defined general training translates into higher earnings and employability is not explained by these theories. Specifics about the nature of this investment, details on differences among sectors in the economy, and labour market differences do not feature in the arguments, thus making the logic a weak one. Another critical stakeholder identified in these theories is employers, whose motivation is to provide specific training, which will be beneficial in terms of improved organisational performance. Again, there is no distinction made as to the nature of specific training; its interaction with workers' general training is not accounted for. Finally, how specific training creates organisational performance is not specified; rather it is 
assumed. The third stakeholder is the state. Arguments in relation to the role of the state recognise a greater degree of complexity in terms of acknowledging differences among workers, particularly in terms of differences in access to the means to invest in their development. This requires the state to provide access to correct such inequities through skills initiatives. However, initiatives targeted at improving labour market outcomes, and addressing inequity often differ in quality and form, when compared to other types of skills initiatives (Grubb \& Ryan, 1999). Yet, it is argued that all types of state interventions in skills are expected to translate in the accomplishment of equity outcomes as well as socio-economic growth for workers and states.

According to Mournier, these theories together explain the programme theory on skills as conceived by policymakers - workers invest in education in their quest for higher incomes; they then provide firms with more skilled labour, which then positively impacts firms' productivity, the outcome of which is increased national economic growth, ending in higher per capita income (Mournier, 2001). In principle, Becker's critics support his theory of skills being the path to socio-economic development. However they believe that the market failures outlined provide a rationale for government intervention in the area of skill development, in order to have optimal levels of skills investment to support socio-economic development.

What is noteworthy in examining this debate is how it has been shaped by influential policymakers and academics (mainly from the field of economics) (Acemoglu, 2003; Becker, 1962; Daly et al., 1985; Dunning, 1992; Harbison, 1973). Even more striking is how the viewpoint of a powerful few came to be translated virtually wholesale into public policy on skills, without much challenge. Of further interest is the assertion in the skills policy rhetoric that skills would not only deliver the high wage, high skill vision, but that it would do so for all. 


\section{Differences in Institutional Arrangements}

Although governments in developed countries have been captivated with increasing their nation's human capital, there is significant divergence in models on how best to achieve the high-wage, high-skill vision. Table 2.1 below provides a typology of skill provision in VET across a number of countries.

\begin{tabular}{|c|c|c|c|c|}
\hline \multicolumn{5}{|c|}{$\begin{array}{l}\text { Table 2.1: Dominant forms of Skills provision across diffe } \\
\text { Initial VET and Further VET }\end{array}$} \\
\hline Direct State & $\begin{array}{l}\text { Corporatist } \\
\text { Networks }\end{array}$ & $\begin{array}{l}\text { Local Firm } \\
\text { Networks }\end{array}$ & $\begin{array}{l}\text { Institutional } \\
\text { Companies }\end{array}$ & Free Markets \\
\hline \multicolumn{5}{|l|}{ Initial VET } \\
\hline $\begin{array}{l}\text { France } \\
\text { Italy } \\
\text { Sweden } \\
\text { UK }\end{array}$ & $\begin{array}{l}\text { Germany } \\
\text { (Japan) } \\
\text { (Sweden) }\end{array}$ & $\begin{array}{l}\text { Italy } \\
\text { (Japan) }\end{array}$ & $\begin{array}{l}\text { (France) } \\
\text { (Japan) } \\
\text { (Sweden) } \\
\text { (UK) } \\
\text { (USA) }\end{array}$ & $\begin{array}{l}\text { (UK) } \\
\text { USA }\end{array}$ \\
\hline \multicolumn{5}{|c|}{ Further VET } \\
\hline $\begin{array}{l}\text { (France) } \\
\text { Sweden }\end{array}$ & (Sweden) & $\begin{array}{l}\text { Italy } \\
\text { (Japan) }\end{array}$ & $\begin{array}{l}\text { France } \\
\text { Germany } \\
\text { Japan } \\
\text { Sweden } \\
\text { UK } \\
\text { USA }\end{array}$ & $\begin{array}{l}\text { (Germany) } \\
\text { Italy } \\
\text { UK } \\
\text { USA }\end{array}$ \\
\hline
\end{tabular}

Note: Country names in parentheses indicate that this is a minor model within the country in question. Source Crouch et al. 1999; p. 10.

Crouch et al (1999) have provided a useful taxonomy for analysing these models, which I will adopt as a part of my analysis of the VET literature. Essentially, the bases of variation among the models are the institutional frameworks underpinning the employment relations climate of the specific country (and sometimes specific industry), and the programme theory on the role of government in the VET sector. 
At one end of the spectrum, VET is provided directly by the government. Human capital theory has been used to explain and rationalise such direct involvement. The premise is that there is imperfect competition in the marketplace, such as imperfect information on the part of workers, and underinvestment and suboptimal levels of training. This results in market failure, warranting government intervention to fill the gap (Briggs \& Katay, 2000). Critical to this thinking is the notion of VET as a social good, that the government has an obligation to secure. The notion of whether VET constitutes a social or individual good has been much debated, and where commentators and policymakers sit in the debate affects their programme theory of how VET policy ought to be implemented, and how it ought to be funded.

A major criticism of direct state intervention is that successful VET policy ought to deliver training and education that is aligned to the needs of industry, and the state is not in the best position to understand those needs, therefore state-led VET systems have the tendency to be unresponsive to industry needs, leading to lower training numbers as the VET loses validity among workers and employers alike. This was one of the main arguments put forward in the UK and Australia. This resulted in a counter policy response in the form of the free market VET model (Briggs \& Katay, 2000).

The free market model has to be understood within the context of the wider public sector reform agenda of these countries. One programme theory underpinning these reforms is that the market and market type mechanisms were a more efficient and effective way of delivering public services. This philosophy was extended to the VET sector, and led to the introduction of industry-led models, where the responsibility for VET design and to varying extent, VET funding, was subject to market forces, and firms volunteer their participation in VET on the basis of their needs (Chappell et al., 2002; Flude \& Siemenski, 1999; Hayward \& James, 2004; Junor, 1992).

However, it should be noted that even among the countries that pursue the free market model as the dominant path to providing VET, there are variations. One such - which I propose as a major adaptation to the Crouch et al model - is the addition of the market-led competency model, which has been pursued (with variations) in the UK, New Zealand and Australia (Ashton, 2004). The competency based model for VET has its genesis in the broader quality movement in education, and even broader theory 
of the new economy. In this model, it is assumed that skills can be defined as discrete competencies or tasks that can be classified into documented unit standards. This model is underpinned by the development of a National Qualifications Framework to which VET qualifications are attached and defined by unit standards at different levels. This National Qualifications Framework is expected to provide a basis through which both employers and employees in the labour market can identify skills to be utilised both as a sign of employability and signal of productive potential. The state's role in this model is to provide this framework, and to stimulate VET engagement through the provision of funding subsidies to intermediate institutions such as training providers and organisations, and in some jurisdictions, to employers. Another feature of the competency-based model is the flexibility of delivery methods that can be employed. The workplace under this model is viewed as a legitimate site of learning, in addition to traditional institution-based training. This then gave rise the employment of assessors within the workplace to assess learning. The theory of the new economy as explained earlier, espouses the achievement of high skill levels as the path to higher wages, productivity and economic growth. Simultaneously, in developed countries, there has been growing concern about the quality of educational output vis-à-vis competitor nations, particularly in the USA and the UK. The marketled competency model, where it was applied, (UK, New Zealand and Australia) was attractive to policymakers on three counts. Firstly, it sought to improve the quality of VET by ensuring (at least in theory) that VET met specified, documented standards, standards that would and should be developed across various sectors of the economy (Bailey \& Merritt, 1995). Secondly, adequate signals would then be sent to employers on the skill levels of workers, thus signalling adequacy of the supply of skills (Bailey $\&$ Merrit, 1995). Thirdly, it fostered greater ease of measurement of outcomes, in that outcomes could 'easily' be measured in terms of unit standards completed. This again dovetailed with the wider public sector reform agenda, and its focus on performance indicators as a means of evaluating the level and quality of public service delivery (Bailey \& Merrit, 1995; Field, 1991).

This market-led competency model has faced many criticisms. First, it defines the problem as being one of supply of skills, and many commentators have noted that greater emphasis is needed on the demand side of equation, and on public policy encouraging firms to adopt skills-intensive competitive strategies (Finegold \& 
Soskice, 1998; Keep \& Mayhew, 1999). Another criticism is that the actual implementation of the model has undermined the quality of VET. The model, particularly in the UK context, was designed to accommodate employers' needs, flexibility in delivery of training, the acknowledgement of prior knowledge and onthe-job utilisation of skills through the use of assessors. This, it has been noted, has led to poor training quality based on loosely defined standards; as a consequence, VET training has a lower status among workers, and lower levels of uptake. Dieckhoff, in a comparative study of the UK, German and Danish VET systems, has also concluded that the free market competency based model has led to poorer labour market outcomes in the UK both in terms of income level and risk of unemployment (Dieckhoff, 2008). Research in various Asian countries, such as Taiwan, Singapore and South Korea has also brought into question the argument of the paucity of state led VET systems, supporting the premise that state intervention is sometimes required to foster rapid economic development (Ashton et al, 2002; F. Green et al, 1999). There is a counter argument to this however. While the model has come in for a great deal of criticism, as Wolf has pointed out, it should follow that these economies experience persistently poor economic performance; however the converse has been the case, and both the USA and UK (as examples of free market models) have experienced growth in spite of the perceived inferiority of VET performance in the respective countries (Wolf, 2002, p. 43). The findings reveal that the relationship between skills and economic performance is complex, and not adequately explained by the prevailing programme theory.

Another criticism levelled at the competency based model specifically, is whether such a model can deliver competitive advantage to firms and countries. It has been argued that the competency based model has at its heart the notion of making knowledge explicit and therefore transferable. As it is transferable, it is rational then to assume that it can also be transferred or copied by competitor firms and countries (Strathdee, 2005). The model also assumes that all skills and knowledge and indeed all industries' training are amenable to standardisation or that it is desirous for all industries to use such a model, and this is not necessarily the case (Smelt, 1995).

In terms of evaluation of VET, the competency model has been criticised for its assumption that qualifications are in fact an adequate proxy for skills, a point to which 
I will return in a later section (Bassanini et al., 2005). It has been argued that rather than being a proxy for skills, the attainment of unit standards simply leads to more credentialing (Wolf et al, 2006). Also, given the emphasis on flexibility the very thing that the unit standards were to signal - quality of training - has been undermined, as employers and workers alike have come to question the usefulness of these VET qualifications (Wolf, 2002).

In between the state-led and free market models, there are a number of models which vary according to the level of state and market intervention - the corporatist model (found in Germany and Denmark), local firms network model (example Italy) and institutional companies (example Japan) (See Table 2.1) (Briggs \& Katay, 2000; Crouch et al., 1999). All three of these models have as their hallmarks some degree of cooperation among the critical stakeholders. In the case of the corporatist model (or the German dual system), the system of apprenticeship is based on an institutional framework of cooperation among industry groups, government and firms, that is bounded by regulation and law. In the case of local firms network model, skill development is fostered through cooperation and sharing among firms, while in the institutional companies' model, skill development is fostered in the context of an employment relations climate of high trust and lifelong employment contract between employers and workers. Although these models are not without their challenges, there appears to be a high level of consensus among commentators on their efficacy in delivering higher levels of productivity and competitive advantage for the respective countries (Ashton et al., 2002; Culpepper, 1999; Dieckhoff, 2008; F. Green et al, 1999; M. Porter, 1998).

There is considerable debate then on how best to design skills policies. One dimension of this debate is whether the intended foci and outcomes of skills policies complement or compete against each other. For example, in competency based models, the programme logic has been to develop certified training across all industries. There is research however which suggests that focus should be on early education, cognitive skills and mathematical ability, and not so much on vocational education and training (Hanushek and Wobmann 2007, Ingram and Neumann 2006, Wolf, 2002; Acemoglu 2003). It can also be argued that not all industries require 
government or any other type of organised intervention as industries differ in size and importance to any economy (Smelt, 1995).

Irrespective of the VET model adopted, as noted earlier, VET policies have tended to be designed to achieve a multiplicity of outcomes (Hayward \& James, 2004; Lloyd, 2003). However, it can be argued that these outcomes, while all important, do not necessarily lead down the same pathway. Take the outcome of national economic development and productivity. The jury is still out as to how education/training contributes to this. As will be argued in greater detail later, other factors are important, for example capital investment, management style, the state of the particular industry/economy etc. to bring about this outcome. This makes attribution and evaluation difficult. This also poses a structural problem as well. If national economic development and productivity is one of the critical outcomes, who is best positioned to lead such a policy, is it employers, government? It has been noted that government and school-led strategies run the risk of being irrelevant. Employer-led strategies run the risk of ignoring individual and national and industry wide concerns (Billett \& Hayes, 2000).

If one of the aims of VET policy is to accomplish active labour market policy goals to which can be married social justice and inclusion goals, such as addressing youth unemployment and delinquency, reducing unemployment, and promoting full employment - the focus is primarily on decreasing unemployment and budgetary control by reducing the number of citizens on unemployment benefits. It is also about ensuring that unrepresented groups are active members of the labour market, such as minorities, women and youth. Many of these kinds of government training initiatives tend to be second chance education and training programmes, in other words, targeted at persons who have been unsuccessful in the formal education system. There might also be a difference in content of such training; emphasis for example might be on foundation skills. The success of such programmes tends to be evaluated differently, for example, the number of beneficiaries who have completed training and who are in long term employment, and, to a lesser extent, income levels after training.

The question is does success on these measures also contribute to other types of economic measures such as increased productivity? The data seem to indicate yes, but 
only to a certain extent; such persons do not necessarily increase their income levels and may still lack the level of literacy and numeracy skills to function in higher quality jobs (D. Green \& Riddell, 2003). Again, the question is what skills are the target population being equipped with, are these skills which are in demand and highly rewarded in the labour market? So while politicians have a tendency to postulate that education and training initiatives will contribute to both these goals, in reality, they may in fact be distinctly different goals, requiring different types of interventions. There is also the issue of access; who accesses these opportunities? Are they members of the target population? This raises the structural issue of how best to design policy to achieve the requisite outcomes. We come back to the question of who leads, and the differing models. Employer-led systems do not necessarily lead to increased access vis-a-vis government-led systems, as employers have no obligation to provide training, unless their buy-in is obtained.

What is clear is that there is no one model that is suitable to all contexts, and that each model is mediated by its unique national and organisational cultures and institutional arrangements. The different VET arrangements assume varied roles for key stakeholders in the provision of VET and the creation of VET outcomes. The more state-led models emphasise the role of training institutions in the provision of VET; however, this model is criticised for minimising the role of employers in influencing VET quality and relevance, which also decreases the benefit to trainees. The competency based model also has its challenges in that it assumes equal valuing of VET qualifications, which is often not the case, particularly because the funding model often creates perverse incentives for training providers to increase VET provision without a corresponding increase in VET quality (Wolf, 2011). The research on the corporatist, local firm and institutional companies' models all point to the role that labour market arrangements and workplace and sector contexts play in the use of and delivery of VET, and its outcomes, particularly, the role of employers in valuing and using VET initiatives.

\section{Human Resource Development (HRD) Theories}

The rhetoric of the centrality of skills to competitiveness has also filtered down to the micro-level in firms, as demonstrated by the evolution of HRD theory. It is somewhat 
strange to entitle this section human resource development theories, as much of the literature on HRD theory has decried the lack of theoretical underpinnings and consensus on the definition for the field of HRD (Elliot \& Turnbull, 2005; McGoldrick et al., 2001, p. 348); McLean et al., 2003). With reference to the work of Walton (1999), McGoldrick et al noted his criticism of the field of human resource development as being "jargon-ridden" and "meaning-hidden" (McGoldrick et al., 2001, p. 348). Bryson has noted that broad variation in the definition of HRD found in the literature results from the myriad perspectives of scholars in the field, such as the human resource management (HRM), professional association, academic, American or European perspectives (Bryson, 2007). As a result, definitions and the focus of HRD vary from those which incorporate both training and development (inclusive of career and management development), to those which view training as separate from development, to those who include training and development along with organisational performance issues (Bryson, 2007). Then there are those, such as McGoldrick et al (2001), who resist the notion of having any one definition for HRD by offering their own theory of the use of holographic metaphor. They purport that this philosophical standpoint can provide a contextual basis for the field, both in terms of research and practice, as it takes into account the multiplicity of lenses through which HRD can be seen. While this concept carries an all-embracing allure, it does not resolve the issue of definition, which is important to the practical considerations of HRD research, which by necessity must start with defining the boundaries of the phenomenon being researched.

I posit however that the field of HRD is not without theory. If one holds to the definition of a theory as being a concept of how the world works, then HRD literature and practice is underpinned by a number of theories, although they may not always be clearly articulated as such (Frey et al, 1991). Additionally, HRD is an applied field, and as such, tends to be concerned with application and practice, and not as much with developing empirically tested theories. The work of Fleetwood and Hesketh (2007) on the under-theorisation of the Human Resource Management-Performance (HRM-P) link is insightful to this notation. Although their focus is on HRM, their discussion implies a definition of HRM that is inclusive of HRD. They point to the proliferation of theories in the field, highlighting the fact that the field is not without theory; a total of forty-nine were cited (Fleetwood \& Hesketh, 2006, 2007). Despite 
this multiplicity, two broad categories of theories in the field can be identified, simply termed 'hard' and 'soft' HRM (Guest, 1999). The 'hard' theories tend to view workers as resources to be maximised; examples of these are resource based view of firm and Strategic HRM. The 'soft' perspective broadly speaking tends to focus on socio-psychological factors at play within the workplace, and are usually geared at fostering employee commitment and motivation (Beer et al., 1985; Guest, 1999). Examples of these kinds of theories are high performance workplace practices, social exchange theory and stakeholder perspective theory. The underlying commonality among them all however is that they all seek to explain or at least provide a prescription or model for understanding the link between HRM and organisational performance/competitive advantage.

Perhaps this link is best exemplified in what is dubbed the Harvard HRM Territory map (Beer et al., 1985). The model proposes that the analysis of stakeholder interests, including shareholders, employees, the state and wider community, along with situational factors such as workforce characteristics, labour market and business conditions, the legal and technological environment, ought to translate into HR policy choices. These policy choices should then centre on employee influences, such as their skills and motivation, the organisation of human resources, reward and work systems. These policy choices, when strategically executed will lead to a number of beneficial outcomes, such as commitment, competence and cost effectiveness, which result in the long term to individual and societal well-being and organisational effectiveness (Beer et al., 1985).

This mirrors the programme theory on skills espoused by policymakers on two counts. First, the assumption about skills in the business literature is similar: they both claim that investment in training (the focus being mainly on formal training) and other HR practices translates into competitive advantage gains for firms. Second, this theory tends to be espoused by particular commentators and academics, usually from a North American, large firm perspective. Thirdly, this theory has to a very large extent been unequivocally accepted. This is evidenced by the unprecedented expansion in HRD activities, both within firms, and as an academic discipline in the last three decades. For example, Velada et al note that in the USA, more than $\$ 50$ billion is spent annually on formal training, and that training investment by firms have 
increased worldwide (Velada et al., 2007). But it is a more complex interplay of factors that is often not acknowledged adequately in the VET policy literature.

\section{Critical HRD Theory}

Over the last ten years, a strand of HRD literature has emerged out of Critical management studies called Critical HRD theory, which posits that there is a need to challenge the assumptions of HRD (Fenwick, 2004). It is argued that the view of skills within HRD (and in VET policy for that matter) has largely been an economic view. Armstrong points out that there are two competing perspectives that underpin HR practices and theory - the unitarist and the pluralist perspectives (Armstrong, 2008, p. 7). In the unitarist perspective, human resources are viewed as any other business asset to be developed and deployed for the benefit of the organisation. The unitarist perspective is economic in its outlook, and the use of quantitative data such as HR costs is the preferred data used to evaluate HR contribution. The pluralist perspective on the other hand views employees as valued assets and as progressive beings, who can add value through their commitment, quality and adaptability. The preferred evaluation mechanisms from this perspective may also be quantitative in nature, but seeks to measure non-financial or 'softer' indicators such as employee engagement and development opportunities for workers (Armstrong, 2007, p. 8). Commentators like Stasz (2001) and others propose taking a socio-cultural perspective on skills, and challenging the unitarist assumption that what is good for the firm is good for the employee (Rainbird \& Munro, 2003; Stasz, 2001). The individual employees' perspective is for the most part overlooked in the research, as there is an overwhelming emphasis on organisational development and meeting organisational goals, which does not account for individual workers' needs, making the notion of HRD largely capitalist in nature (Antonacopoulou, 1999; Edgar \& Geare, 2005). Guest, for example in his discussion of the distinction between hard and soft HRM, looks at the view that HRM is a tool to trick employees into being willingly exploited. He notes the contradiction in the literature between the complaint that there is not enough HRM and those who fear its successful implementation (Guest, 1999; p. 487). This contradiction points to one of central tenets of Critical HRD which views workplaces as contested terrain rather than homogenous entities 
where the needs of all stakeholders are harmoniously aligned towards one profitable end (Fenwick, 2004, 2005; Garavan et al., 2000).

One of the assumptions that Critical HRD seeks to challenge is the performance perspective of HRD that sees HRD as a major vehicle of the new economy (O'Donnell et al, 2006). Underpinned by human capital and management theories, as human resources (aka human capital) are resources at the disposal of firms that ought to be developed and maximised for profit. Indeed a much banded about catch phrase is that the human resources of a firm is its most important resource; it is the new source of competitive advantage (Noe et al, 2000). For this to happen, human resources needs to be developed and deployed strategically; this then is the ambit of HRD professionals and practice. The empirical evidence often used is that top companies' investment in $\mathrm{HRD}$, whether it is in training, education or high performance work systems, leads to increased profitability and productivity (Pfeffer, 1998). Another underlying theory of HRD is the importance of evaluating HRD performance. As the argument goes, HRD, like every other part of an organisation, must prove its value, its contribution to the organisation. Indeed, from Kirkpatrick to Phillips, Kaplan and Norton, and Brinkerhoff, many have devised various methods of evaluating HRD (Brinkerhoff, 2003, 2006; Dockery, 2001; R. Kaplan \& Norton, 1996, 2001; Kirkpatrick, 1998a, 1998b; J. Phillips \& Stone, 2002; P. Phillips \& Phillips, 2007; Swanson, 1998). This quest to prove the value of HRD investment has been a difficult one, however, as it has been fraught with the same challenges faced by the measurement of human capital investment at the macro level as discussed earlier. It is difficult to determine causality for HRD impact, or to separate the impact of HRD interventions from other organisational and other factors; the measures often used are quantitative and often fail to provide any real information on impact, and the challenges go on. However, my purpose here is not to assess these methods, but to put forward what I see as some common issues that are of relevance to my research.

First, there is a heavy emphasis on marketing of HRD; the theory is that unless HRD professionals can prove the valuable contribution of HRD to the firm, HRD runs the risk of budget cuts and HRD practitioners risk job loss. An example of this is the number of publications produced by the Australian National Training Authority geared at promoting the use of HRD measurement among employers (Dockery, 2001; 
A. Smith, 2001). Indeed, one could take the cynical perspective that evaluation of HRD at the firm level could possibly be about the perception of value, as opposed to analysing any real value. This then is the distinction between policymakers and firms; whereas policymakers appear to agree on the necessity to invest in human capital as the path to economic growth, employers appear to need convincing; for employers this is not a given. This has implications therefore for both the implementation and evaluation of VET. As VET policy is implemented within firms, it cannot be taken as a given that employers and managers will have the same vested interest as policymakers. Nor can it be assumed that the value derived by employers from HRD investment is similar to the value perceived by policymakers.

Another underlying implication of this marketing emphasis of HRD is that employers and business owners are the main clients of HRD activities (Brinkerhoff, 2006; Kirkpatrick, 1998a; J. Phillips \& Stone, 2002). This has implications for the role of power in HRD practice. Whereas employers are interested in HRD mainly for the value or profit that they will derive from their investment, policymakers (at least in democratic societies) have an interest in balancing power between employers and workers, and have to walk the tight rope of balancing national needs, sector wide needs, employers' needs and the needs of the workforce. To give an example, one of the success indicators that is used in some empirical studies on the benefits of VET is labour mobility - whether the acquisition of VET increases workers chances for getting higher wages and better jobs (World class skills: implementing the Leitch review of skills in England, 2007). Employers on the other hand have almost completely opposite interests; they are interested in maximising their training investment. Indeed, to grant wage increases upon the acquisition of skills is to in fact diminish their investment. Also, a much cited reason for employers under-investing in VET is the fear of poaching; in other words, losing their investment (Abbot 1993).

This issue of power can also be extended to examining workplace learning. Although it has been argued that most learning takes place on the job, and that this is the most effective place for workers to learn, workplace learning is possibly even more subject to the above mentioned power struggles, which impact on its quality or existence. As Hager and others have rightly pointed out, the quality of the work context (for example management culture, work organisation) affects the extent to which workers 
learn. Indeed, it can be argued that the employment relationship is not a relationship of equals; therefore employers and managers can exert a great deal of control over how workers learn, and who accesses learning (Hager, 2004; Hager \& Beckett, 1999; O'Donnell et al., 2006). This is further compounded in the free market VET model, which is usually accompanied by increasing casualisation and job insecurity, which create environments that emphasize short term profitability over HRD investment (R. Hall et al., 2000).

Another way in which the debate has been termed is the learning versus the performance perspectives of HRD (McGoldrick et al., 2001). According to Elliot and Turnbull, this debate represents "the greatest tension in HRD," that is "the struggle to reconcile the needs of the individual with the needs of the employing organisation, the tension between autonomy and community" (Elliot \& Turnbull, 2005, p. 2). Tight has described HRD as a capitalist concept, reducing people to disposable assets (Tight, 2002, pp. 81-84). This has implications for the type of indicators researchers employ in their investigations on the impact of HRD activities, especially from a policy perspective. Indeed, one of the premises underlying human capital theory is that for employing firms to benefit from training, the financial benefit to the employee has to be lessened. The question as to who benefits from HRD activities has implications for any evaluation of government VET initiatives. Initial information seems to indicate that the notion of the customer of these programmes has evolved over time, from focusing on employers and the need to get their buy-in at the outset, to a shift of focus to providing training support to workers through apprenticeships, individual training plans etc (Harris, 2007). Who the customer is defined as, shapes policy design and implementation, and ultimately the outcomes and likely impact. The challenge for policymakers in particular is that national VET policies, especially those geared at increasing skills and productivity levels, are implemented at the level of firms. Particularly within the context of market-led VET policies, policymakers have little, if any control, over organisational environment in which work and learning gets applied (or not applied for that matter). Given the contextual nature of learning at work, the challenge for policymakers is how to influence employers to adopt workplace practices, and cultivate the kind of working environments that foster learning and worker empowerment (Eraut et al., 2000; Fenwick, 2006). However, that is assuming that there is agreement among firms, that cultivating and deploying new and higher 
skill levels are in fact the answer to creating a more productive society. The evidence however shows that this is not the case, as many firms can choose - and often do - to compete on the basis of low skills inputs; the high performance workplace system still remains a novelty rather than a norm in organisational practice (Keep \& Mayhew, 1999).

The issue of whose interests are served by HRD and VET policy is largely underresearched, as both have been assumed to serve the interests of all parties involved. The research that is available on employers' and employees' interests is very limited but insightful, and points to differences in interests and motives both between them, and among them and the interests of stakeholders such as policy makers. For employers, the internal (work organisation and culture) as well as external (technology, sector, market position, legislation) operational context affects the extent to which they engage in workplace learning; the more internal and external pressure experienced, the more likely they are to strategically manage workplace learning (C. Dunn, 2007; Francis et al, 2003; Kock et al., 2008). Also, employers in low skill sectors such as retail, food processing and hotels, are more likely not to view skills as being critical to their profitability (C. Dunn, 2007, Wilson \& Hogarth, 2003). Additionally, employers, particularly smaller employers, have a preference for specific, technical training, in-house training (Kitching \& Blackburn, 2002). The research on nationally recognised workplace training is even more limited. There is some insightful research out of Australia however that found that employers were motivated to engage in formal training for compliance purposes, such as health and safety; otherwise, qualifications are not as valued except for recruitment purposes for higher skilled staff (Ridoutt, Dutneall, Hummel \& Smith, 2002; Ridoutt, Hummel, Dutneal \& Smith, 2005; Ridoutt, Smith, Hummel \& Cheang, 2005).

Even less research has been done on why employees choose to engage in training and what value they derive from it. The research on employees' perspectives tends to be dominated by the issue of learning transfer, and the factors that facilitate or hinder the application of learning in the workplace, and cite the importance of factors such as supportive work environments and supervisors, quality and relevance of training and employee commitment (Martin et al., 2001; Rainbird \& Munroe, 2003; Santos \& Stuart, 2003; Velada et al., 2007). From the few studies I was able to review, the 
consensus is that workers engage in training for economic as well as non-economic reasons (C. Dunn, 2007; Learner Perspectives of Industry Training, 2007). For example, in a study of retail industry trainees in New Zealand, some of the greatest values derived from engagement in industry training were increased confidence both as an individual and as worker, and skill recognition; this study also indicated that economic gains from industry qualifications by way of promotion or increased pay was not a given; nonetheless, workers still found it valuable (C. Dunn, 2007). Another study by Edgar and Geare, also in the New Zealand context, revealed that employees were interested in training to increase their employability, supporting findings from elsewhere that employees have a preference for generic and visible skills and training that can be used outside of their current work organisation (Edgar \& Geare, 2005; Katz \& Ziderman, 1990; W. Smits, 2007). What this brief research overview highlights is that there are significant differences in how different stakeholders value HRD and VET, and this in my view, creates a challenge not only for evaluating its impact, but also the extent to which such policies can be successful and how policy success is defined.

The challenges outlined above are best summarised, in my view, by Bolton and Houlihan in the form of some interesting questions posed by them, pertaining to the analysis of humanistic HRM practices (Bolton \& Houlihan, 2007b). I think that they are also of relevance to policymakers and in the evaluation of the impact of government VET policies, and which I will adapt for the purposes of my discussion. The first is what needs do VET policies seek to meet, and who should define these needs? Depending on where one sits, (employers, unions/workers, policymaker), one will get different answers. The second is who gets to avail of them? Here the question was posed in terms of which employees, and points to the issue of equity of access, and who determines access to learning. However from a policy perspective there are additional access issues to contemplate, such as access by minority groups. Another related issue is which industries should access government funded VET resources. In the market-led competency model, the thrust has been to establish VET coverage for all or most industries; it could be argued however that scarce resources are put to better use by focusing on certain key industries, where the most potential benefits could accrue to the largest possible client groups. However this can also be viewed as another form of inequity. 
The third question is who prevails when it comes to competing interests? This is where policymakers find themselves performing a balancing act among stakeholders. This also has implications for impact evaluation and research methodology, a major challenge being to develop indicators that are equally valued and useful across stakeholder groups. According to Critical HRD theorists, there is a need to ask whose interests get served in HRD practice and in HR research, what knowledge counts (Fenwick, 2004, p. 198; O'Donnell et al., 2006; Valentin, 2006). Even if there was consensus among stakeholders on the value of HRD investment and the value in evaluating the impact of such investment, there would still be the practical issue of the development of appropriate metrics to be used, and the infrastructure to collect and analyse such data to produce usable information.

\section{Pedagogical Issues}

Much of the evaluative work on skills and training however, places heavy emphasis on formal training. There is however a growing appreciation in the literature, and in the policy dialogue on the role of informal or non-formal learning. Workplace learning in particular has gained a great deal of prominence, although research in the area is still somewhat limited (Nordman et al., 2006). Workplace learning theory, which has its roots in agency and social learning theories among others, takes issue with the traditional pedagogy of learning, which views formal training and classrooms as authentic sites of learning (Kitching, 2008b; Rainbird et al., 2004, p. 118). Instead, these theorists argue that the workplace is the central site where most learning in relation to work takes place, and that most of this learning cannot be captured by qualifications (K. Evans \& Rainbird, 2002). Workplace learning theory also recognises the value of tacit knowledge, and the fact that most of this type of knowledge and its acquisition is unnoticed (Nonaka, 1991; Strathdee, 2005). Hager however takes issue with the elusiveness of the concept of tacit knowledge however, as he argues that its vagueness suggests it cannot be developed in an intentional manner (Hager, 2000, 2004; Hager \& Beckett, 1999). This view has led to the development of strategies to foster guided learning within workplaces (Billett, 2000; Vaughan et al., 2011). Workplace learning also sees learning as socially constructed within groups and community, as opposed to residing within individuals (Chappell et 
al., 2002; R. Edwards \& Boreham, 2003; Fuller et al., 2003; Stasz, 2001). The extent to which the workplace - including job design, employment relations, individual motivations, organisational climate - facilitates learning has great significance for the use of skills and their impact on organisational performance (Ashton, 2004; Bryson et al, 2006; Rainbird et al., 2004). Given this contextualisation, the idea of learning being transferable is also challenged by these commentators (Eraut et al., 2000; Eraut \& Hirsh, 2007; Stasz, 2001). This is of particular interest when this is juxtaposed against the competency based national vocational qualifications systems, which have portability of skills as one of its central hallmarks, such as the models used in the UK and New Zealand. This contextualised understanding of workplace learning also has implications of the study of workplace learning practices within small and medium sized enterprises (Kitching, 2007). Given the large number and significance of SMEs, much of the research on training within VET has concluded that SMEs under-invest in training; however this is usually based on data looking at formal training courses and other quantitative indicators of training (Hoque \& Bacon, 2006). From the perspective of workplace learning, new research has pointed to the fact much more learning takes place within SMEs than previously reported (Kitching, 2008b). In fact, the concept of workplace learning embraces a multiplicity of learning strategies, and sees the distinction between formal and informal learning as blurred (Eraut et al., 2000).

If the tenets of workplace learning theories are to be accepted, this has implications for the evaluation and design of VET policy. At the level of policy design, the challenge for policymakers is how to design interventions to influence workplace learning (Eraut \& Hirsh, 2007). It also means that for evaluation and research on skills, the workplace is possibly a more meaningful unit of analysis (Holtom, 2006). This also implies a reconfiguration of the individual as the unit of analysis for research on skills. Instead of the emphasis on individual attainment of skills and qualifications, it is perhaps more meaningful to focus on how different individuals in the skills arena interact with each other, and their contexts to create or inhibit different outcomes. This brings to fore the importance of motivations, expectations and power struggles in implementation of skill policies. This also has implications for research methodology. Given that workplace learning is not readily discerned, qualitative research methods, such as the ethnographic approach, have been recommended to 
understand the complexities of workplace learning (Eraut \& Hirsh, 2007; Kitching, 2008b).

\section{How these outcomes are evaluated}

\section{Policy Evaluation Theories}

It is also critical to examine the body of work known as policy evaluation, as a foundation for my research for the following reasons. First, the focus of this research is public VET policy; secondly it will help to inform the research methodology to be employed in my research (which will be discussed later). Additionally, it is my view that the evolution and challenges in policy evaluation theories mirrors those related to human capital development and human resource development, and therefore offers further insight on gaps in the evaluation of the Industry Training Strategy.

Policy evaluation has its genesis in social science research methodology, and is considered an applied social science (Fischer, 2007). The application focus of policy evaluation is perhaps its most distinctive feature, which has influenced theoretical developments in the field. Its application focus however has led to one of the major criticisms of the field, which is that it suffers from the underdevelopment of theoretical underpinnings (Alkin, 2004). This is a criticism that policy evaluation has in common with HRD theory, though perhaps not to the same extent. According to King, the field of policy evaluation lacks validated theories of evaluation, as there is no conceptual consensus. Additionally, being a field of practical focus, the emphasis has been on practice and on programme theory, as opposed to developing empirically based evaluation theories (King, 2003). Criticism aside, the application focus of policy evaluation points to its primary interest, which is the determination of effects of public policy on society as a whole, and the provision of policy solutions (Behn, 1981).

Policy evaluation has a history similar to that of the social sciences. The first similarity is the domination of the positivist approach to methodology used in policy evaluation with an emphasis on quantitative data and the experimental and quasiexperimental methods. Alkin (2004) provides a useful overview and framework for 
understanding the evolution of policy evaluation theories. This framework, called the evaluation theory tree, identifies three major branches along which policy evaluation theories have developed - the methods branch, the values branch and the use branch. The evolution of theories along each of the three branches, has been driven by the increasing complexity of policy problems and the continuous need for accountability brought on by public sector reform initiatives in developed countries. In terms of methods, as with the rest of social sciences, there has been growing awareness of the limitations of the positivist paradigms. Given the complexities of the post-modern era, it was increasingly recognised that positivist methods with its emphasis on quantitative data was not able to provide suitable answers for policy problems. This kind of data tends to provide a useful baseline, but tends to gives indication of the average situation. Whereas policymakers usually are concerned with policy matters that fall outside of the norm or average, baseline data cannot answer the 'how' questions that so desperately need to be answered in order improve public service delivery, particularly for social programmes (Nolan \& Wong, 2004). Public Sector reform or the new public management system of governance that has more or less been adopted across developed countries has brought an increased emphasis on accountability for outputs and outcomes. This has given rise to greater emphasis and interest in policy evaluation, as a part of the accountability mechanism of governments.

Driven by the changing demands, the methods used in policy evaluation have evolved to embrace interpretive methods of enquiry, so much so that today, policy evaluation is considered a field typified by mixed methods of enquiry, which are contingent on the context and politics surrounding the research subject (Christie, 2003; W. Dunn; 2004; Fischer, 2007). The values branch refers to the role of the evaluator in assigning value to evaluation findings. This again has its roots in the dissatisfaction with positivist methods of enquiry, and its underlying assumptions of objective, value-free truth that can be unearthed through scientific, experimental research methods. This change in paradigm has been influenced by feminist and post-modern literature, as well as by social justice debates. However, policy evaluation theories in the values branch differ on perspectives of the role that the evaluator plays in assigning value to evaluation findings. Theories range from a unitary perspective, which relies heavily on the evaluator's skills and knowledge to assign value to 
research findings, and provide policy answers (as advocated by Scriven) to pluralist perspective, where the evaluator to varying degrees share the task of valuing with limited or a wide range of stakeholders (Scriven, 1967). At the other end of the spectrum, the evaluator's role is more akin to that of a consultant and facilitator, whose task is to help stakeholders to assign value for themselves, and to build their own policy evaluation capacity and improve their operations through learning. The understanding of evaluator as facilitator/consultant has been heavily influenced by theories of organisational learning and development.

The 'values' branch of the evaluation tree recognises the influence of the political process on policy analysis in general, and on policy evaluation in particular. These theories also recognise that evaluation is not a value-free process, and that evaluators do in fact place their own values on evaluation findings. Many of these theories have been influenced by social justice and constructivist paradigm, which advocate for the inclusion of stakeholders' perspectives, either to empower them or to recognise that stakeholders' experience of public policy is socially constructed, and that these experiences should be integral to the evaluation process (Alkin, 2004; Lennie, 2006). Included among these theorists are Guba and Lincoln's Fourth Generation Evaluation, Stake's Responsive Evaluation theories and Sabatier's Advocacy Coalition Framework (Alkin, 2004; Sabatier, 2007).

The development of the 'use' branch of policy evaluation theories has been subjected to similar influences as the values branch, particularly by theories relating to social justice and democratization, as well as organisational learning and development theories. These policy evaluation theories are also referred to as decision-oriented theories, and focus on using policy evaluation to assist stakeholders in decisionmaking. The development of these theories was also driven by pragmatic concerns about increasing the use of evaluation findings to inform policy decisions; although policy evaluation has gained popularity over the past thirty years, in reality, its findings have not always been popularly received, or valued by key decision makers (W. Dunn, 2004; Fischer, 2004). Theories in this group vary in terms of the range of stakeholders who are involved in, and are the focus of the evaluation. At one end, there are theorists such as Wholey and Cousins, who focus on programme personnel and the challenges they face in implementing and evaluating policy. At the other is 
Fetterman's empowerment evaluation theory where the focus is on policy programme recipients, and empowering them to conduct their own evaluations. Common to all the theories on the use branch is the involvement, participation and some degree of empowerment of policy programme stakeholders, and the names given to these various theories are proof of this: empowerment evaluation, collaborative evaluation, participatory evaluation, utilisation-focused evaluation, democratic evaluation, deliberative democratic evaluation, responsive evaluation, developmental evaluation, inclusive evaluation, and so on.

But what can be gleaned that is of relevance to this research? One, while there may be considerable debate on who should assign value to evaluation findings, what is clear from the literature is that all stakeholders impacted by public policies can and do assign value. This is done whether or not it is recognised in a formal evaluation process. This has important implications for effectiveness of policy evaluation and its capacity to lead to policy learning. Two, while there is a debate as to who should be the target of policy evaluation, the important lesson is that it can be targeted at different stakeholders, and depending on who is targeted, evaluation can yield different results. This goes back to the capacity of stakeholders to assign value to public policy for themselves, values which may not be similar to those espoused in the stated policy rhetoric.

This has implications for the evaluation of skills policies in particular. It makes the case for an inclusive approach to skills policy evaluation. By its very nature, skills policies involve many stakeholders at different levels, who negotiate such policies within their peculiar organisational and socio-psychological contexts, to create value as they perceive it. This is also a case for the greater use of qualitative research methodology in skills policy evaluation, as quantitative, positivist methods do not have the capacity to unravel these issues, especially where such policies intersect with individuals and their contexts.

It is also important to note in the policy evaluation literature, the link between performance management, auditing and policy evaluation. This has to be understood in the context of the new public management (NPM) system, and the wider public sector reform agenda of many developed and developing countries, with its emphasis 
on increased levels of accountability and public sector performance, where evaluation came to be seen as being part of the accountability mechanism. They are however not one and the same, but can be seen as complementary (Nielson \& Ejler, 2008; Wong, 2004). Some of the major distinctions among them are as follows:

- Performance management concentrates on collecting performance information against measurable targets, whereas policy evaluation is usually broader in scope and purpose, and seeks to examine intended as well as unintended results, and ideally is willing to question the validity and appropriateness of a policy (Blalock, 1999; Davies, 1999).

- Auditing is usually concentrated on assessing the level of compliance within a legislative context, more often than not, focusing on fiscal responsibility, whereas evaluation does not tend to be constrained by such legal boundaries (Chelimsky, 1996; Leeuw, 1996).

Auditing, performance management and evaluation have gained increasing significance under the NPM systems in many countries, as it became necessary to develop such systems to manage accountability for results in a context of decentralisation and devolution of authority. Auditing in this context has become an expanded field, extended to examining whether citizens have received value for money in public services. Increasingly in the public management literature and policy rhetoric, the distinctions among them have been blurring, the danger being the watering down of evaluation rigour, and the hijacking of evaluation for political purposes. NPM introduced a heavy emphasis on outputs, or the direct products or services delivered for all spheres of government, with the expectation that these would facilitate the achievement of outcomes or change in behaviour, function or status in the target recipients of outputs (Logic Model Development Guide, 2001). In a bid to develop accountability mechanisms, it then became easier and politically expedient to focus on what was measurable, and the development of quantitative indicators of output as proxies for desired outcomes, including for the education sector. A preference for econometric measures to evaluate policy developed; this is particularly evident in the emphasis on the use of quantitative data in assessing performance in the vocational education and training sector, typically judged by the 
number of trainees. According to Velada et al (2007) the expansion of training investment has led to increasing pressure to account for training outcomes.

Much of what is reported under the guise of evaluation within VET is really performance information dressed up, which provides information to support government interventions, without any real understanding of how VET investment creates value (if it does), thus the hard questions go unanswered. Other major pitfalls of this approach, particularly in the context of competency based VET policy, have been already highlighted under the human capital theory section. An analysis done by Fleetwood and Hesketh (2006) on the under-theorisation of the HRM-Performance link sheds additional light on the limitations of positivist methods of evaluation of VET policy. They point out that quantitative methods of evaluation of HR practices sees these practices, including learning as observed events that can be quantified and as such event regularities can be determined, and predictions made. They further argue that the weakness of HR theory lies in its reliance on these methods to develop theory, which makes these theories empirically weak, as HRM occurs within complex systems; as such they propose that a more useful approach would be to examine complex causality, which they define as "the wider conflux of interacting causal phenomena" (Fleetwood \& Hesketh, 2006, p. 1982, 2007). Their analysis is instructive, and I believe points the way to improve evaluative practices for VET. Another pitfall to note here is that quantitative measures often emphasize the average: the average income, years of schooling, and so on; however, from a policy perspective, what is often problematic are the extremities, in particular what factors create and change them and how, questions not easily, if ever, answered solely through econometric analyses (Nolan \& Wong, 2004).

Notwithstanding the criticism of over dependence on quantitative analyses in policy evaluation, it is important to recognise that the field of policy evaluation has been affected by a number of externalities, not least of which is the political context in which it is located, and the level of prestige it holds with power brokers (Fischer, 2007). The field is also impacted by capability issues. Policy evaluation is reliant on access to quality data. For example, ideal longitudinal panel data to analyse long effect of policy is very difficult and expensive to collect; it is simply easier to collect accessible quantitative data (like number of trainees), particularly if it suits the short 
term political needs of the time. Also, quality policy evaluations are contingent on the employment of quality policy evaluators, who are not always available, particularly in smaller labour markets (Lunt, 2003).

But what has been the New Zealand policy evaluation experience? Similar to the USA and the UK, interest in social research grew during the Second World War, with an emphasis on such topics as employee morale and war production. Prior to this, any semblance of evaluation activities were limited to the conduct of Royal Commissions and the collection of routine statistics (Lunt, 2003). In the late 1960's and 1970's, interest in social science research was again renewed in New Zealand, as was the case in the USA and UK, post-war period of economic prosperity came to an end, and difficult social problems requiring solution re-surfed, problems such as increased youth delinquency, rise in dependence on social benefits and public assistance, and poorer social and economic outcomes for Maori New Zealanders (Lunt \& Davidson, 2003). In keeping with trends elsewhere in the broader field of social science research, the methodological approach to evaluation during this time was mainly positivist.

With the launch of sweeping public sector reforms in the New Zealand public sector in the 1980's and 1990's (discussed elsewhere) came, at least in theory, an increased emphasis in evaluation as a means of meeting the obligations under the State Sector Act 1988, Public Finance Act 1989 and the Fiscal Responsibility Act 1994. There was an increasing demand for evidence to support government's decision-making as well as to meet needs for accountability and value for money for public services (SavilleSmith, 2003). However, according to many commentators, this demand for evidencebased policies was not put into practice in many instances. Firstly the changes served to undermine the evaluation capacity within the public sector, and much of reform activities went ahead without the use of evaluation evidence (Jesson, 1999; Lunt \& Davidson, 2003; Trotman, 2003). Additionally - perhaps due to capacity limitations there has been a tendency to rely on meta-analyses of research done in other countries, and to extrapolate similarities and differences to the New Zealand context; this however runs the risk of the findings having limited relevance to New Zealand, given that much of the research relates to countries with vastly different socioeconomic conditions (Pawson, 2002; Turner \& Washington, 2002). 
Since the late 1990's and beyond, there has been renewed emphasis on policy evaluation in New Zealand, brought about in part by the receptivity towards evaluation by the Labour-led government elected in 1999. The debate since has changed focus, and there is an increased emphasis on building evaluation capacity (as evidenced by the establishment of the Social Policy Evaluation and Research Committee, and reviews conducted by the State Services Commission), focusing research on impact evaluation and the achievement of outcomes, and best practices and methods for policy evaluation, including appropriate methods to take into account Maori values (Lunt \& Davidson, 2003).

\section{Evaluation Commentary}

Many commentators offer a variety of assessment of the programme theory of 'skills/VET $=$ economic performance + high wages'. Commentators point to the fact that the promises of VET policy have not been fulfilled. These are as follows:

- Growth of low wage jobs - While high skill jobs have increased as a proportion of jobs in the developed world, this has been overshadowed by the increase in low wage, low skill jobs characterised by routine, repetitive tasks (Chappel et al., 2002; Rainbird \& Munro, 2003). This has been coupled with significant growth in income inequality over the last twenty years in many developed countries including New Zealand, and the United States (Acemoglu, 2003; Baxendine et al., 2005; Pool et al., 2005a, 2005b, 2006). The source of this inequality has been blamed on the rising skill premia, where persons with higher skills levels have been able to command increasingly higher wages vis-à-vis the rest of the workforce (Acemoglu, 2003). Further, there is an increasingly popular view and some evidence that high skill jobs are also under threat from developing countries. Contrary to the accepted belief, developing countries are now also seeking to compete in the global marketplace on the basis of quality, innovation as well as price (Brown et al., 2008; Richardson \& Miller-Lewis, 2002). 
- Importance of demand - Several commentators have bemoaned the fact that VET policy suffers from an illogical programme logic, in that it assumes that increasing the supply of skills translates automatically into the accomplishment of the higher levels of productivity and performance. These commentators argue that demand-led strategies are necessary if VET policies are to succeed (Keep, 2007; Keep \& Mayhew, 2004; Nordman et al., 2006). There is increasing evidence of over-supply and under-utilisation of skills, particularly in the Canadian and UK contexts, and increasing credential inflation where employers are requiring more qualifications than needed for many jobs (Livingstone, 2005; Rainbird \& Munro, 2003; Tight, 2002). Several researchers and commentators in the UK also argue that without adequate incentives, firms could choose, and do choose, quite rationally to pursue lowcost, low skills strategies, as this is a viable option, particularly in many service industries, such as the hotel and food manufacturing sectors ( $\mathrm{P}$. Edwards et al., 2007; K. Evans \& Rainbird, 2002; Finegold, 1999; Finegold \& Soskice, 1988; Grugulis, 2003; Korczynski, 2005).

- The inadequacies of the unitarist perspective - It is argued that the approach to VET policy, in particular market/industry-led competency models, such as exist in the UK, Australia and New Zealand, takes a unitarist, employerfocused perspective, thereby ignoring both workers' interests, and the need for other structural and institutional arrangements necessary to foster skill development. This limited vision and approach has led to the observed shortcomings in VET policy outcomes. Much of the rhetoric that gave rise to the focus on skills and its role in the new economy was expounded by policymakers, and representatives of certain interests and paradigms. For example, Robert Reich, the champion of the "new economy" mentioned earlier, was a former Secretary of Labour in the USA and therefore represented a particular set of political and economic interests. Most of the literature supporting and advocating this rhetoric was devoid of evidence involving union/workers' perspective. Moreover, the rhetoric has presented learning as an individualised activity, thereby increasing emphasis on individual responsibility for their skill development, to the neglect of other deeper structural issues that may impact this skill development. One of these 
issues is the change in employment relations, and the rise of the employability theory. It is argued that the growth in casual work and sub-contracting, increasing corporate focus on short term profits and cost reduction, and widespread labour market deregulation together act as a disincentive for skill development, which requires factors such as employee loyalty and commitment (Chappell et al., 2002; Hall et al, 2000; Richardson \& Liu, 2008). In comparing the UK NVQ system and German dual system, Grugulis noted that NVQ system is unitarist, whereas German system is pluralist in nature, taking account of stakeholders' interests, which fostered buy-in and increased the perceived value of skills (Grugulis, 2003). The importance of the strength of regulatory and institutional frameworks, stakeholders' interest as well as business strategies are being more recognised as critical to not only skill development but to increasing productivity of firms and nations. This has been, for example, the basis for the skill eco-systems project in the Australian context (Buchanan et al., 2001; Hall \& Lansbury, 2006; Payne, 2007; M. Porter, 1998).

What these perspectives highlight is that the need to examine the importance of sector and workplace characteristics in creating beneficial outcomes for VET stakeholders. Of particular importance is the recognition of the differences in power relations in workplaces, which places great reliance on employer characteristics in creating VET outcomes. These perspectives however also define and limit the value of VET to employees as access to high wage jobs, and assume a polarisation between employer and employees' goals and motivation.

\section{Literature Synthesis}

A synthesis of the literature discussed in the preceding sections of this chapter reveals four broad paradigms, and each paradigm carries with it a particular logic and epistemological and ontological perspective (refer Table 2.2). 


\begin{tabular}{|l|l|}
\hline \multicolumn{2}{|c|}{ Table 2.2 - Emerging Paradigms from the Literature } \\
\hline Human Capital/VET Policy Logic & Stakeholder Theory Logic \\
\hline Strategic HRD Logic & Critical HRD Logic \\
\hline
\end{tabular}

The first is what will be referred to as human capital/VET policy paradigm. Its prevailing logic is depicted in Table 2.3:

\begin{tabular}{|l|l|}
\hline \multicolumn{1}{|c|}{ Table 2.3: Human Capital/VET Policy Logic } \\
\\
$\begin{array}{l}\text { Leads to increased productivity/social and } \\
\text { economic mobility/wages }\end{array}$ \\
\hline Participation in VET by employers and employees \\
\hline $\begin{array}{l}\text { In Recognisable skills according to National } \\
\text { Standards }\end{array}$ \\
\hline $\begin{array}{l}\text { Government invests in workplace skills } \\
\text { development }\end{array}$ \\
\hline
\end{tabular}

This is a paradigm largely expressed in VET policy documents, which is heavily influenced by economics, and speaks to a logic of how skills policy ought to work at a macro-level, particularly in competency-based VET models. Here there is a heavy leaning towards seeing skills, and the benefits of skills policies as facts that can be mainly observed and quantified almost separately from individual actors. So skills become observable and reported through qualifications and the meeting of national standards. The value of skills can also be observed through wages, unemployment rates, progression and so on. Even the social benefits of skills are also determined through observable, and/or quantifiable indicators such as increases in numbers of minorities completing qualifications or wage effects of qualifications. In this paradigm, the roles of stakeholders are assumed, in that stakeholders are seen as willing participants in the equation as the benefits of participation are mutually valuable. Employers will have more profitable businesses; employees will have more recognisable skills that are marketable and command higher wages in the labour market, and policymakers would have engendered social and economic progress.

The second paradigm that emerges from the literature is what will be referred to as the Strategic HRD Logic in Table 2.4: 


\begin{tabular}{|c|c|c|}
\hline \multicolumn{3}{|c|}{ Table 2.4: Strategic HRD Logic } \\
\hline \multicolumn{3}{|c|}{ More profits/Productivity } \\
\hline \multicolumn{3}{|c|}{ More productive, happier employees } \\
\hline \multicolumn{3}{|c|}{ ALIGNMENT } \\
\hline Business Strategy & HRD practices & $\begin{array}{l}\text { Other HR practices - } \\
\text { recruitment/compensation/work } \\
\text { systems }\end{array}$ \\
\hline
\end{tabular}

This is the paradigm often reflected in the HRD literature, and has among its chief advocates numerous HR consultants of great renown. The logic expressed here focuses mainly at the micro-level of work organisations: if there is alignment among a firm's business strategy, and all of its HR related activities including its HRD activities, then this will result in happier, more productive employees and greater levels of organisational productivity and profitability. It varies from the human capital/VET policy perspective, in that it purports a more complex combination of factors that have to be aligned in order for the desired outcomes to be achieved. However, the two paradigms are quite similar in two respects. The roles of the stakeholders are again assumed and the outcomes of HRD investment are deemed to be equally beneficial to all involved. Also in the Strategic HRD alignment perspective, the value of HRD investment (when it is evaluated) is defined in terms of what can be observed or quantified. So measures such as return on investment, retention rate, surveys using Likert-type scales and variety of quantitative indicators are often advocated in the literature.

I propose that due to the similarities between the two paradigms, they can be merged into one paradigm, which will be called the Strategic HRD/VET Policy logic (see Figure 2.1): 
Figure 2.1 - The Strategic HRD/VET Policy Logic

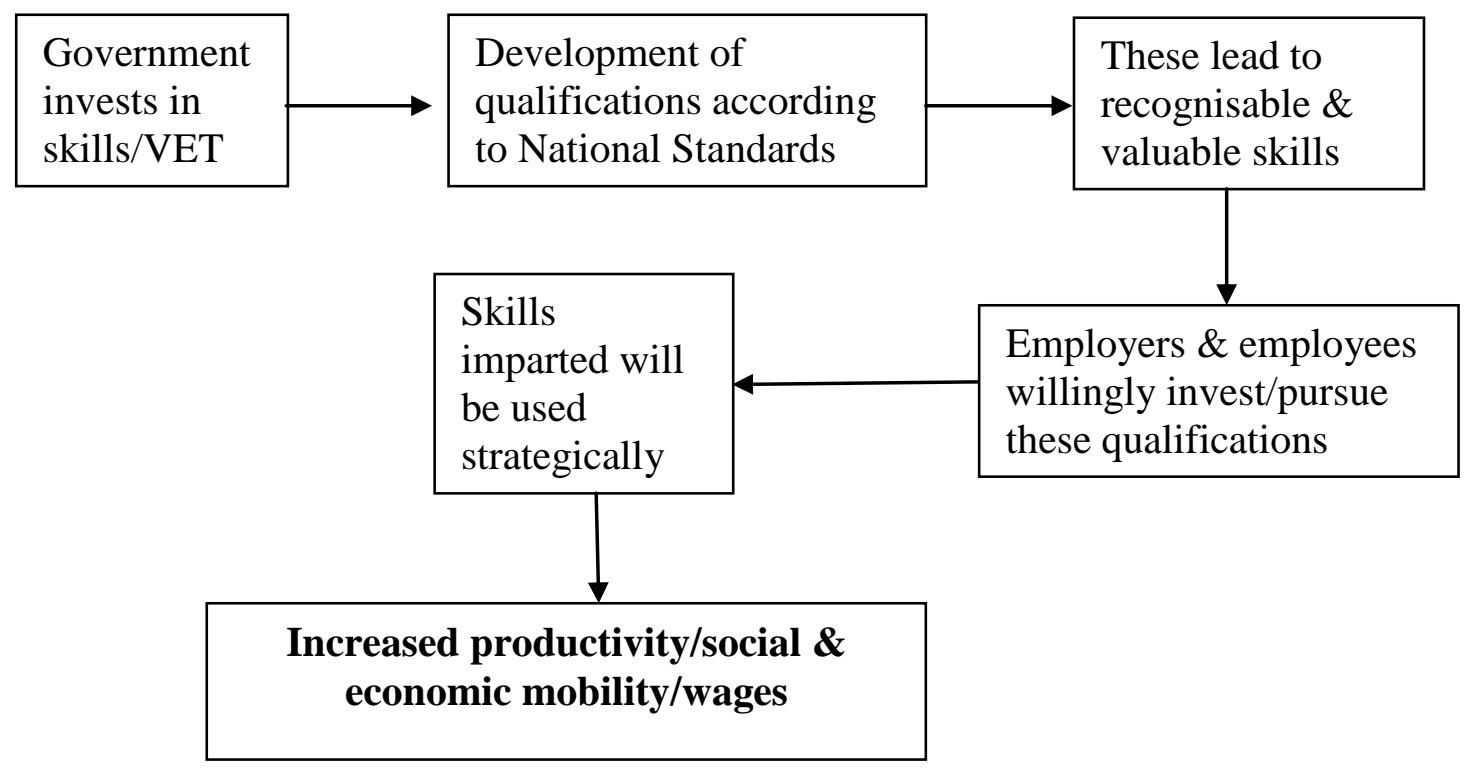

In this programme logic, government investment in workplace skills leads to the development of qualifications that meet the needs of both employers and employees, who then are able to implement the relevant Strategic HRD practices, included VET, to maximise skill utilisation and lead to organisational harmony, profitability and productivity. The accumulative effect of sufficient numbers of firms so engaged in VET and Strategic HRD and management practices will then produce beneficial outcomes at the societal level. There is a harmonisation of macro-level policy action, with micro-level/organisational strategy that produces the mutually beneficial outcomes of increased productivity, profitability, socio-economic progress and wage effects.

From the policy literature, particularly from the policy evaluation theorists, and practitioners who advocate for the involvement of stakeholders in policy evaluation to varying degrees, emerges another paradigm. This will be referred to as the Stakeholder Theory logic, depicted in Figure 2.2: 


\section{Stakeholder A \& their environment}

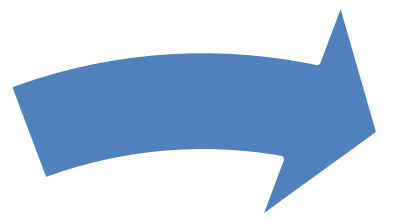

\section{Stakeholder B \& their environment}

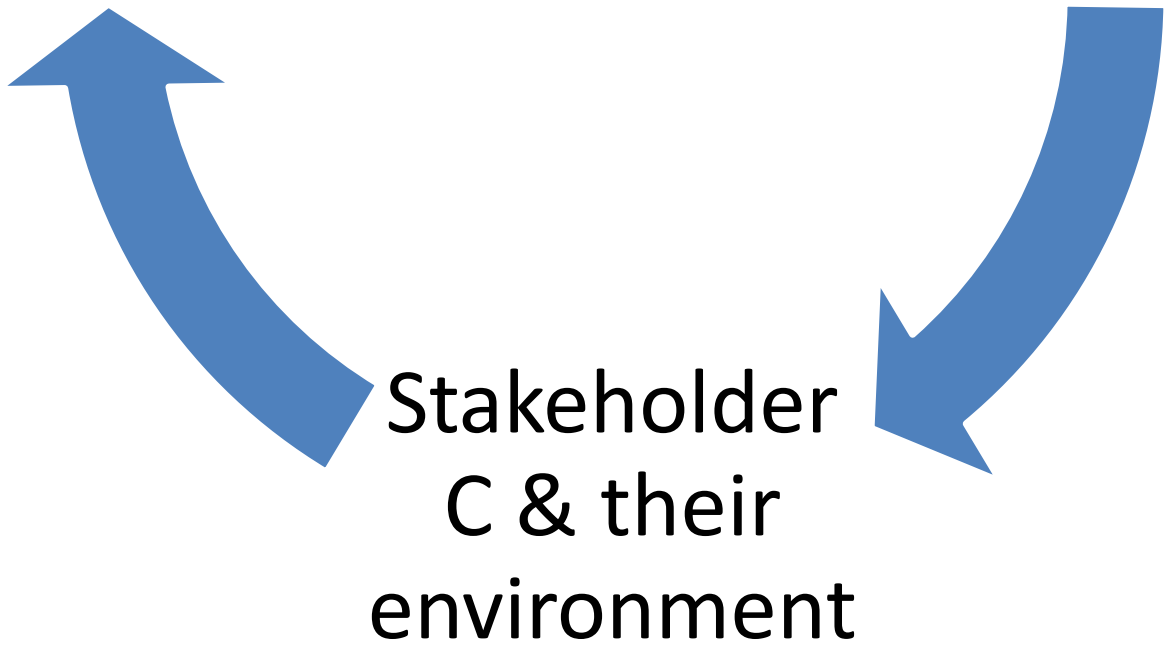

It is depicted as a cycle rather than as a linear process, as production of outcomes is seen as an iterative process. The logic here is that stakeholders' involvement is important to have more desired policy implementation and outcomes. If applied to the context of VET policy, by this logic, the value of VET policy is not assumed but flows out of an iterative process of interaction and dialogue among stakeholders. The value of VET policy could be seen as observable facts such as numbers of trainees, but there is room to consider that its value may not be observable and is bound up in the stakeholders themselves, and not necessarily separate from them. This perspective also recognises the potential for conflicting values. As a result, there would be a reliance on qualitative and interpretive enquiry and the use of its attendant research tools in order to gain understanding of outcomes. 
The fourth paradigm that emerges will be referred to as the Critical HRD logic. As the name suggests, it is very much influenced by the small but growing Critical HRD theorists from critical management studies perspective. However, one could also add industrial/employment relations writers in this category, as well as challengers of the logic of skills = productivity perspective (Keep, 2009; Lamm \& Rasmussen, 2008). What they all share in common is an appreciation of the role of power and conflict in determining the benefits of skills initiatives, whether at the micro or macro levels. At the micro level, it is understood that the employers and employees do not share equal power, and this impacts how training is used, and accessed, and whether training is always beneficial to employees. Like the Stakeholder Theory logic, this then leads to a leaning towards qualitative and interpretive research methods in order to examine the outcomes of skills investment from varied political perspectives. At a macro level, the outcomes of skills investment are seen largely as observable facts, similar to the human capital/VET policy logic. However these writers rely mainly on quantitative data to disprove the skills = productivity/prosperity paradigm, as they point to such data as the emergence of job insecurity, low productivity performance vis-à-vis increased skill investment, the role of labour market dynamics and growth of low wage jobs, as proof of their position. Unlike the other three paradigms it is difficult to diagrammatically represent it, as the other three paradigms are prescriptive, and are underpinned by a need to achieve some sort of end result. The Critical HRD logic can be seen as more critical and descriptive of why certain end results are not met, a perverse logic, as seen in Table 2.5:

\begin{tabular}{l} 
This diminishes national productivity and creates social inequity \\
\hline These workers are mostly doomed to a low wage, low skill existence \\
\hline $\begin{array}{l}\text { These workers in these low paying jobs also have no incentive to invest in skills } \\
\text { themselves, either because they cannot afford it or see limited scope for increased } \\
\text { earnings from the investment }\end{array}$ \\
\hline $\begin{array}{l}\text { As these organisations are still profitable, they have no incentive to invest in skills } \\
\text { This creates a large number of low skill, low paying jobs within profitable } \\
\text { organisations }\end{array}$ \\
\hline Changes in the global economy has led to growth in the service sector \\
\hline
\end{tabular}

\section{Table 2.5: Critical HRD Logic}

This diminishes national productivity and creates social inequity

These workers are mostly doomed to a low wage, low skill existence

These workers in these low paying jobs also have no incentive to invest in skills themselves, either because they cannot afford it or see limited scope for increased earnings from the investment

This creates a large number of low skill, low paying jobs within profitable

Changes in the global economy has led to growth in the service sector 
It can be argued that the Stakeholder theory logic and the Critical HRD logic share some common characteristics. One similarity is the recognition of the role of conflict and power differentials among stakeholders, which impacts on how decisions are made and the distribution of beneficial outcomes. In both programme theories then, outcomes are not viewed as necessarily being mutually beneficial or value-free. Both also advocate the empowerment of stakeholders, particularly those who within the normal power relationships often have limited control and agency. This involvement of stakeholders also extends to the approach to evaluation, which is a preference for qualitative enquiry to give voice to stakeholders' perspectives. Also quantitative methods and data are not ignored, but they are viewed as value-laden and political.

Given these similarities, I also propose that these two can be merged, into what is being termed the Critical HRD/Stakeholder Logic on VET outcomes as depicted in Figure 2.3:

Figure 2.3 - Critical HRD/Stakeholder Logic

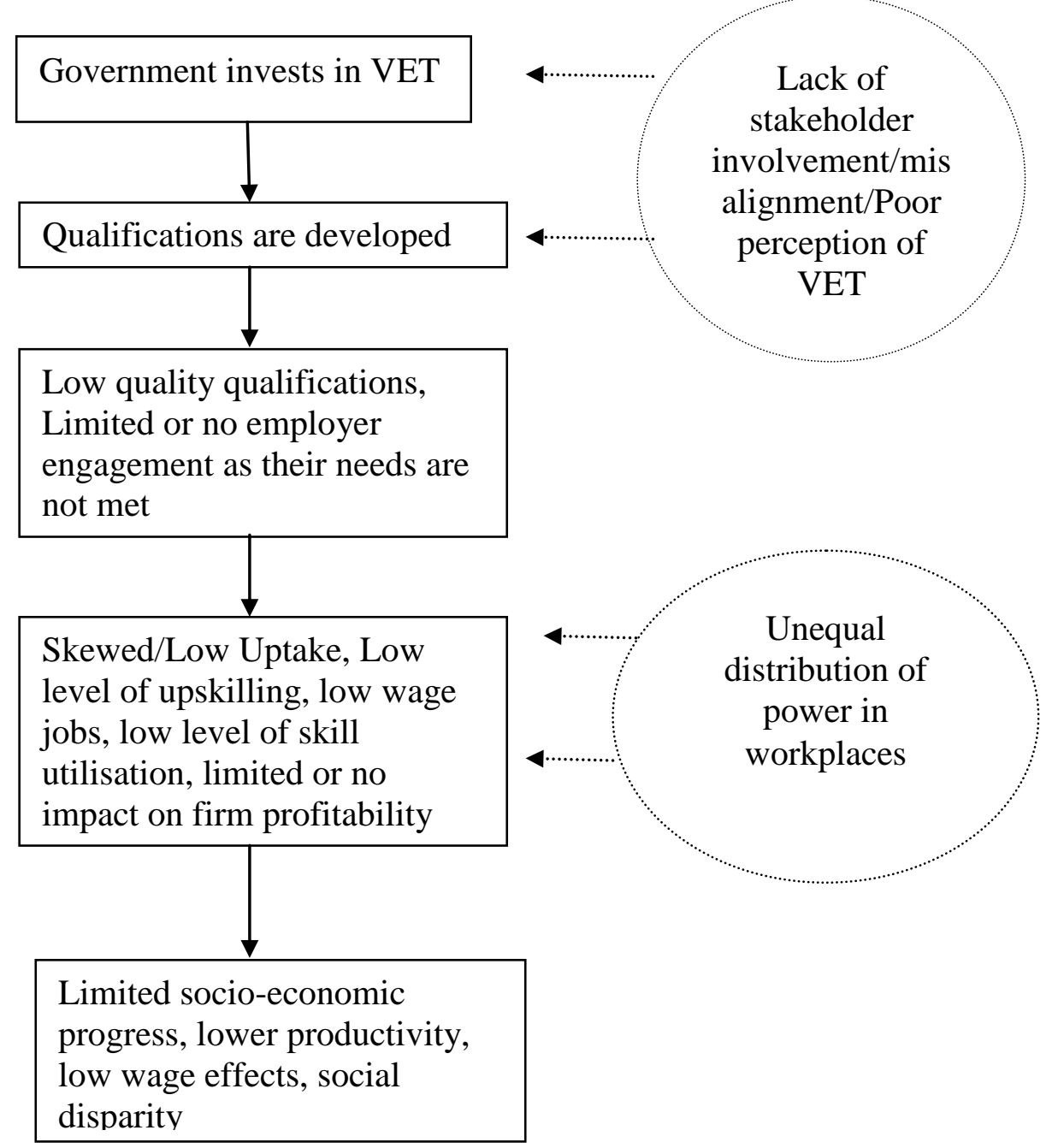


This logic model echoes the low skills road thesis (Buchanan et al 2000; Finegold and Soskice, 1999). It is also seen as a descriptive logic of the theory in use as far as VET outcomes are concerned, and acts as a countervailing argument to the Strategic HRD/VET logic which some argue is the theory espoused by policymakers and HRD consultants. The critical HRD/Stakeholder logic argues that despite increasing levels of VET investment on the part of governments, particularly in English-speaking countries, the commensurate improvements in productivity, skills levels, wage effects, and socio-economic mobility have not been realised, and at the root of this is the differences among stakeholders in terms of involvement and their values. At the macro-level, government funding sometimes creates perverse incentives for qualifications providers to focus on easy to develop qualifications to meet numerical targets. This is often with limited reference to what employers and employees actually need or value. The result is low level qualifications or qualifications that meet a limited number of employers' and employees' needs. At the organisational level, even when there is uptake of qualifications, the power relationships within workplaces often means that employees have limited decision-making power on what VET to pursue or on the extent to which any learning from VET engagement can be applied to work. Additionally, it is argued that there are some sectors and firms that operate profitably using a 'low wage/low skill' model, and as such, have no incentive to engage in VET. This all then leads to the poor outcomes, such as wage and social disparity, low skill levels etc.

In summary, this chapter has explored the main debates in the policy and academic literature pertaining to skills and VET. It has highlighted gaps in the evaluation of VET policy, in particular the limited understanding of how VET creates values for multiple stakeholders. Importantly, it has synthesized the literature to arrive at two paradigms of VET value creation, which provide a frame of reference by which the research data can be analysed, a point that shall be further discussed in the methodology chapter.

The following chapter provides a historical overview and analysis of the implementation and evaluation of Industry Training Strategy in New Zealand to date, in light of this broader literature. 


\section{CHAPTER 3 - NEW ZEALAND CONTEXT - INDUSTRY TRAINING}

This chapter is a review of the literature on the New Zealand Industry Training Strategy and system. It outlines the key characteristics of the system, analyses the background and historical context, including the factors leading to its inception, and an analysis of its implementation through to the present. The chapter concludes with an examination of how the strategy has been evaluated to date.

The Industry Training system can be aptly described as New Zealand's largest workplace learning programme, and is considered to be part of the tertiary education sector, with over 200,000 registered trainees annually (High Performance in ITOs, 2009). The qualifications received are nationally recognised on New Zealand's National Qualifications Framework (NZQF), which is developed and maintained by the New Zealand Qualifications Authority (NZQA). Industry Training is funded jointly by the New Zealand government, mainly through the Industry Training Fund, and through employers' contributions.

Currently there are 39 ITOs covering most sectors in the economy, but excluding most of the health and education sectors. Industry Training is a competency-based VET model, which uses a common platform, the NZQF for certifying and recognising different levels of qualifications from the secondary to the post-graduate level. Industry Training covers a wide range of formal training offerings aligned to Levels 2 to 5 on the NZQF, which are certificate and diploma programmes; the majority of Industry Training is focused at Levels 2 and 3. Programmes are divided into unit standards which are assigned a certain number of credits. Programmes vary widely in terms of the number of credits required for completion. At one end of the spectrum, there are limited credit programmes (LCP), which offer 40 credit training offerings, and are usually used as introductory training programmes, or to cover more targeted and specific training needs. At the other end are programmes which require as much as over 300 credits for completion, and have a duration period of 2 or more years. The Industry Training System also plays an additional role of being the recognition of prior learning (RPL) system recognising and accrediting existing skills levels of workers (Dyson \& Keating, 2005). 
There are a number of key players within the Industry Training System. Figure 3.1 highlights these, as well as their inter-relationships:

Figure 3.1 - Key Players in the Industry Training System

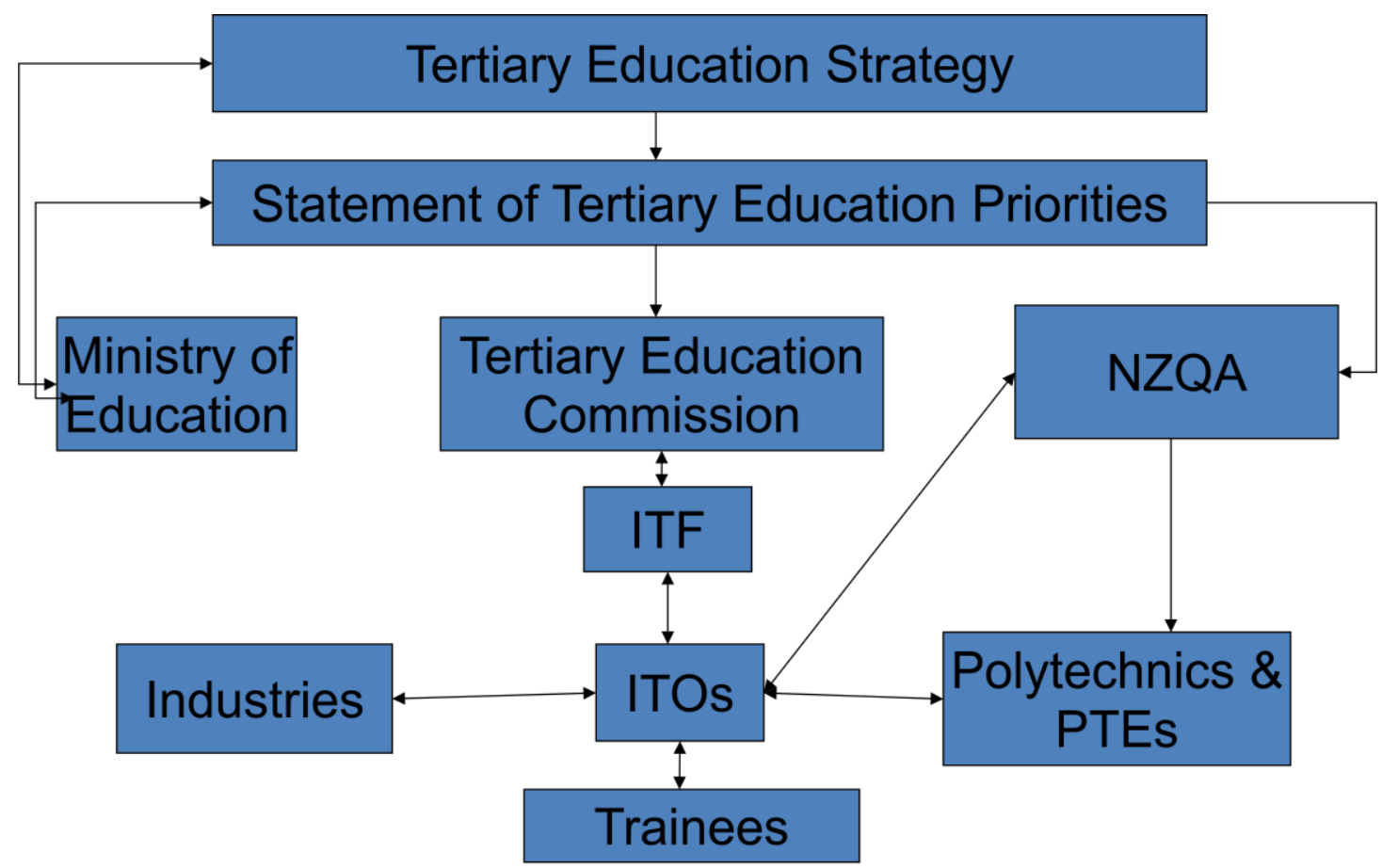

Being a part of the tertiary education sector, its parameters and strategic direction is outlined in the New Zealand Tertiary Education Strategy (Tertiary Education Strategy 2007-2012 incorporating Statement of Tertiary Education Outcomes 2008-2010, 2007). The Tertiary Education Commission (TEC) is the body currently charged with setting the policy framework, establishing and implementing the funding arrangements for the sector, and setting performance standards and monitoring the performance of the sector against these standards.

Another important player is the Industry Training Federation (ITF), and the industry training organisations (ITOs). The ITF is the umbrella body representing ITOs, and its main functions are policy advocacy on behalf of ITOs, and in partnership with a variety of stakeholders, to conduct research and promulgate best practices among ITOs. ITOs' main responsibilities are to develop and arrange training for workplaces within their designated sector. They also play the role of providing strategic leadership to their sectors in training and development needs. Additionally, they have 
delegated authority from the NZQA for the accreditation and the quality assurance of training.

The NZQA is the body responsible for the development of the quality assurance standards and the NZQF, to which Industry Training qualifications (among other tertiary qualifications) are aligned.

While the ITOs have responsibility for training design, they do not deliver the training themselves. Industry Training delivery is carried out either on the job, or within private training establishments (PTEs) or polytechnic institutions.

The training implementation is governed by a training agreement among the trainees, their employers and the relevant ITO.

It is important to examine the assumptions that underpin the design of the Industry Training Strategy, particularly the roles differing stakeholders would play in creating the required outcomes, and how those outcomes are assessed. The role of the state in the Industry Training Strategy is to set the policy framework and provide the necessary funding incentives and policy infrastructure, such as the NZQF to stimulate Industry Training. This represents a shift in the role of the state, away from being a direct provider of training, or apprenticeships, both in terms of design and delivery. The state's approach appears to fluctuate between being unitarist and pluralist, in that, the design favours employers' needs as being the superior driver to design and even deliver training. On the other hand, being the state, its approach has a pluralist focus on broader outcomes such as: increased equity for disadvantaged groups (example women, Maori and Pasifika peoples), improved labour market outcomes (example decreased unemployment), and socio-economic development for New Zealand. Its funding incentives are also evidence of this pluralist outlook, in that there is recognition that employers are likely to under-invest in Industry Training, and as such, their participation in its provision needed to be incentivised.

The development of the NZQF is the other major contribution of the state in the provision of Industry Training and the production of its outcomes. The main premise of the framework is that the skills can be defined as discrete unit standards that come 
together into qualifications which can then be transferrable across the wider labour market. The other major premise of the framework is that the assessment of skills can be done in a wider range of environments, not only in training institutions but also preferably within workplaces. The state then uses the attainment of unit standards and qualifications as the evidence to determine whether their desired outcomes are achieved. This aligns with the emphasis in public sector management, on the greater use of performance indicators to manage performance and increase accountability for public service delivery, in this case, the delivery of educational outcomes in the form of Industry Training.

Another major stakeholder is ITOs. These entities are intended to represent their sector's training interests, by designing training in keeping with sectoral needs. To a certain extent then, ITOs can be said to be unitarist in their outlook, in that the training needs are largely employer-driven. On the other hand, trainee support has over time, particularly since 2000's, has been another major focus of ITOs. This is evidenced in their efforts to address pedagogical concerns of trainees, particularly those with literacy and numeracy challenges. The assessment of unit standards is a function that is delegated from the NZQA to ITOs. The training of assessors, particularly to assess training delivered on the job, is a critical function of ITOs. Additionally, quality assurance is also another critical function of ITOs, which is done mainly through a process called moderation, which involves auditing pre-determined samples of assessments against quality standards. The logic of the Industry Training system then, is that assessors have the necessary competence to assess unit standards with a level of consistency that would then be accepted by the wider labour market as an indicator of skill level.

Employers, and by extension workplaces and managers/supervisors play a central role in the design, delivery and assessment of Industry Training. Employers under the Industry Training Strategy are expected to identify and communicate training needs to ITOs in order to shape the design of qualifications. They are also expected to engage in Industry Training, albeit through the motivation of access to funding, to subsidise their training costs. They are also expected to play a critical role in the delivery of training, through provision of opportunities to practice job skills, and in the assessment of these job skills. Additionally, in the design of the Industry Training 
system, workplaces may also provide assessment services, and requisite administration services attached, whether they undertake these themselves or engage the services of PTEs or polytechnics. There is then an implied investment on the part of employers in terms of providing workplaces that allow for the application, assessment and administration of Industry Training. There is also the underlying assumption that employers are driven by the need to have profitable businesses, therefore they will only engage in Industry Training if they are deriving this value from skills investment. Therefore employer engagement in Industry Training is seen as a proxy for skills use, and socio-economic investment, as business profitability increases.

The stance of trainees and their unions in the Industry Training system is then assumed to be one of willingness to engage in Industry Training. Trainees are assumed to be willing to participate in and complete Industry Training qualifications. In relation to their employers, they are expected to use skills learnt to improve organisational performance. From the perspective of the state as policymaker, they are expected to improve their earning power and employment opportunities, expectations that would be shared by the trainees themselves and their representatives. The mutually reinforcing benefits of Industry Training are encapsulated in the training agreement that is signed upon initial engagement in training, which is between the ITO, the employer and the trainee/employee.

\section{Background}

New Zealand, like many other countries, bought into the ideology of high wage, high skill economy, and adopted a market-led, competency-based industry training strategy. It is important to examine the contextual factors that led to the implementation of its Industry Training Strategy. The Industry Training Strategy must be viewed and understood in the context of the wider public sector reform agenda which commenced in 1984, with the election of the Labour Government. The post World War II era represented a period of economic boom in New Zealand (Avery et al., 1999; Brosnan \& Rea, 1992; Elkin, 1998; New Zealand Economic Growth: an analysis of performance and policy, 2004). It was an economy based on primary production, and founded on the principles of the welfare state and principles of 
universal rights to income, education, health care and security of employment, among others. These principles were considered sound at the time, as it translated into economic prosperity - in 1953, "New Zealand was one of the three or four wealthiest countries as measured by per capita GDP, reflecting a national ethos that considered the country as 'God's own."'(McLean et al., 2003, p. 50).

However several major shifts and shocks in the international economy starting in the 1960s brought about major crises in the New Zealand economy. Chief among these were the loss of preferential trading arrangements with the United Kingdom (UK), when the UK joined the European Common Market. As an economy characterised by dependence on primary production and the stability that preferential trading arrangements provided, this resulted in increased levels of competition (Crocombe et al., 1991). Other major shocks affecting the economy included the collapse in the price of wool on the world market following the Korean War, the introduction of synthetics (as a cheaper alternative to wool), and the oil crises of 1973 and 1979 (New Zealand Economic Growth: an analysis of performance and policy, 2004). All these shocks together resulted in a fall in GDP per capita growth vis-à-vis other OECD countries, increasing levels of national debt and unemployment; the welfare state was now required levels of government expenditure that the economy could no longer afford. Another major contributor to New Zealand's economic woes was the inappropriate institutional arrangements which were viewed as "highly centralised and promoted widespread regulation, protection and indexation..." and unworkable fiscal policies, centralised wage bargaining, protection of the trading sector and a highly centralised and regulated public sector (New Zealand Economic Growth: an analysis of performance and policy, 2004. P. 40).

This gave way in 1984 to sweeping public sector reforms, which were underpinned by the philosophy of deregulation, decentralisation and market economics, and which covered almost all areas of the economy from fiscal policy, to energy, transport, industrial regulation, business law, environment, taxation, government expenditure, social services, education and the labour market (Elkin, 1998).

But what was happening specifically on the education front, and specifically in regard to industry training? It is important to note what became termed as industry training 
was mainly called apprenticeship prior to 1984, but also included adult education and continuing education initiatives as well (Boshier, 1980; Murray, 2004). During the 1980 's the government commissioned numerous evaluations of the entire education sector, and the consensus among them all was the performance of New Zealand's education sector was dismal (Taskforce on Skills Development, 1990; Hawke, 1988). The Picot Report of 1988 summarised the inadequacies of the wider education system - it was marked by over-centralisation, complexity, lack of information and choice, ineffective management practices, and feelings of powerlessness (Hawke, 1988, p. 4). Hawke further argued that with minor adjustment, these characteristics also described the post-compulsory education system of the time (Hawke, 1988, p. 4). The report of the Taskforce on Skill Development succinctly outlines the state of crisis as seen by the policymakers of the day:

- New Zealand had low rates of participation in post-compulsory education, ranking $17^{\text {th }}$ out of 18 OECD countries; only $40 \%$ of school leavers go on to education beyond the compulsory secondary level.

- In 1989, almost half of New Zealand school leavers had no qualifications; $46 \%$ of the workforce had no qualifications.

- There was a decline in apprenticeships, brought on the restructuring of the economy in the 1980s and the subsequent retrenchments in both the public and private sector and reduction in training capacity (Taskforce on Skills Development, 1990, pp. 10-11).

The apprenticeship system at the time was also seen to be providing inequitable access to skill development, particularly for Maori, Pasifika peoples, women and other disadvantaged groups who also experienced higher levels of unemployment, and was also limited in coverage to a few trades. As mentioned earlier, the time served characteristic of the apprenticeship system was seen as not meeting the need of the modern economy, and it was felt that there was a need to move towards a competency-based model of skill development, that could assure the quality of trainees (N. Green et al., 2003; Hawke, 1988; Hawke et al., 1986; Reform and Change in Industry Training Conference, 1992). Additionally, by 1991, unemployment levels had reached record highs, with over 200,000 registered unemployed; of this number approximately $42 \%$ had no qualifications Reform and Change in Industry Training Conference, 1992). The common consensus noted in policy documents and 
evaluations of the education sector during this period, was that having a highly skilled workforce was critical in gaining competitive advantage:

"An effective response to the skills crisis cannot be delayed until the country can better afford it. Failure to act now is going to result in drastic reductions to standard of living. Investment in a skills base will make a substantial contribution to the recovery of the New Zealand economy..."(Taskforce on Skills Development, 1990, p. 5).

This should be seen within the context of the prevailing ideology at the time in New Zealand and elsewhere, irrespective of political affiliation (and which is still very dominant today) of the relevance and significance of higher education and training in creating "high skill high wage knowledge economies." The essence of this school of thought is that with the advent of Asian tigers (for example Japan) and low cost producers such as China and India, developed countries need to remain competitive through innovation and the development of higher quality goods and services for niche markets where people are prepared to pay premium prices. Therefore the labour force must have an adequate supply of skilled life-long learning knowledge workers, who can generate these new products and services, work with ever changing technologies, flexible work arrangements in jobs that utilise higher skills and therefore attract higher wages. This then is the formula for socio-economic advancement (Skills for productivity, employment growth and development, 2008). The rhetoric surrounding Industry Training at the time was highly idealistic. It appeared to be a one stop VET shop addressing upgrade training needs of current workers, retraining needs for those needing to change careers based on changing job markets, and remedial training for those with limited or no prior success in formal education (Grubb \& Ryan, 1999).

\section{Implementation}

It is important to note that labour market and skills training reform came about in the early 1990s, about eight years after the start of the reform programme, and substantial deregulation of other aspects of the economy. Labour market reform, launched by the introduction of the Employment Contracts Act (ECA) in 1991, brought about the reinstatement of voluntary unionism, freedom of association, freedom of contractual 
forms, minimisation of worker protection and enterprise bargaining (Elkin, 1998). The Industry Training Act of 1992 could be seen in part as compensation for loss of worker power brought about by the ECA; increasing access to training would help to restore equality in the balance of power between workers and employers, as more skilled workers could use their skills as a bargaining device, at least theoretically (McLaughlin, 2006).

The stated objective of the strategy was as follows:

Securing a high standard of living for all New Zealanders depends on New Zealand being internationally competitive for which a key requirement is a highly skilled and adaptable workforce, which can be achieved through effective industry skills training (Reform and Change in Industry Training Conference 1992).

The key features of the strategy were that it was industry-led, with government assuming the role of training facilitator, the training was linked to a National Qualifications Framework, and that it provided increased access to formal for disadvantaged groups and sectors with minimal training provision.

1) Industry-Led - Government saw its role as setting the foundation for all industries to take control of industry training design, and delivery in keeping with industry needs. This would largely be accomplished through industries forming Industry Training Organisations (ITOs). Under the Industry Training Act 1992, the roles of ITOs are:

- "Setting of national industry standards

- Purchasing training; and

- Quality assurance of training providers and workplace learning (N. Green et al., 2003; "Industry Training Act," 1992).

2) NZQF - Central to the Industry Training strategy (and indeed New Zealand's wider education reforms) is the creation of the NZQF aimed at providing "individuals with nationally-recognized and portable credentials, that reflect attainment of knowledge and skills" (Johnson cited by McLean et al, 2003, p. 54). This again is in keeping with 
similar initiatives in other countries, for example Great Britain, to create national standards for education. Hence a major feature of the strategy is that all training should lead to credits towards nationally recognized qualifications. The administration of the NZQF was and still is the role of the NZQA which is funded by the Government.

Government also sought to carry out its role as facilitator of the strategy through its funding arrangements initially through three streams:

- Assist in the establishment of ITOs and development of industry qualifications standards,

- Support administrative costs associated with training

- Subsidise the costs of block courses and off the job training (N. Green et al., 2003).

Oversight of the system was the responsibility of the Education and Training Support Agency (ETSA), which later became Skill New Zealand.

The Industry Training Federation was subsequently formed in 1996, as an advocate body for ITOs to government and other agencies and sector groups (Industry Training and Modern Apprenticeships statistics as at 30 September 2006, 2006; Industry Training Skills Leadership: the role of Industry Training Organisations in shaping skills in the New Zealand economy, 2006).

3) Increased Access to Training - One of the central aims of the strategy was increased coverage of more industries and improved access to Industry Training especially for disadvantaged groups such as women, Maori and Pasifika workers.

It is important to note that other complementary workplace learning strategies were continued and/or instituted by the government during this period, namely the Youth Traineeship programme (training places purchased by Government from industry to facilitate young people gaining systematic industry qualifications and work experience) and the Training Opportunities Programme (targeted at young people 
with few or no qualifications and disadvantaged members of the labour force) (Reform and Change in Industry Training Conference, 1992).

During the 1990's, the strategy experienced a number of teething pains, as could be expected with any new government policy. Smelt was contracted by the government to undertake a review of ITOs, and this review unearthed a number of administrative as well as policy challenges (Smelt, 1995). One of the administrative issues noted was the challenges faced by ITOs in carrying out the very detailed administrative work involved in developing national standards for their respective industries. Another issue was the uneven capacity among ITOs, a challenge which persisted until the Industry Training Strategy review in 2001. As could be expected, industries that already had a history of cooperation among industry players, and more organised training cultures were able to better organise and more quickly form ITOs and national training standards, for example the diary industry. This also impacted the ability of ITOs to attract funding for their activities, as there was sometimes fierce competition among ITOs to attract government funding, especially since the expectation that industry would largely fund industry training has never been realised. Certainly in the early years of the strategy, the bulk of the funding came from the government's contribution.

The funding of industry training went through several metamorphoses during the history of the strategy, but especially during the 1990's. Green et al provides a comprehensive review of the history of the funding arrangements, and the challenges experienced along the way (N. Green et al., 2003). The major challenge was to design an allocative mechanism for distributing the funds in a manner that was equitable and efficient, in keeping with the needs of each ITO. This was exacerbated by the fact that many ITOs experience tremendous financial challenges, and did not easily gain industry buy-in or industry financial support (Smelt 1995). Therefore in the early days of implementation, those ITOs which were more organised, were better able to secure bigger portions of the funding pie, which also had implications of equity in the development and access to training across industries. This lead to the development of a new funding arrangement, based on the price per Standard Trainee Measure (which was equivalent to 120 credits in the NQF). This price would vary with each industry due to differences in input costs. Another review was undertaken in 1999 and 
officials felt the funding arrangements encouraged a focus on inputs rather than outputs, and a preference for off-job training (which attracted more funding). The funding and reporting arrangements were subsequently redesigned to allow for reporting of only cash contributions of industry. In 2000, STM prices were frozen at 1999 levels; subsequently ITOs with lower STM prices received a top up to average price STM (Green et al 2003). Since 2000, both government and industry contribution for industry funding has been significantly increased from $\$ 65 \mathrm{~m}$ in 2000 to $\$ 106 \mathrm{~m}$ in 2004 on the part of government. For the same period, industry contribution increased from $\$ 27 \mathrm{~m}$ to $\$ 46 \mathrm{~m}$ (N. Green, et al., 2003). It is noteworthy that the original intention of industry being the major funding source for industry training has yet to be realised. The funding arrangements for Industry Training remains differentiated from the rest of the tertiary education system, and this continues to be a sore point (Baker, 2007; D. Hall, 2004; Seven pillars of growth: a New Zealand perspective, 2007).

Another implementation challenge was the competition for turf that developed among some ITOs. This was in part brought on by the difficulty experienced in defining the boundaries of organisations, as the definition of industry was very loosely defined in the Act (Smelt 1995, "The Industry Training Act," 1992). The fact that some occupational categories and certain skill sets were not unique to any particular industry also led to confusion, some duplication, and turf wars among ITOs; one of the classic examples cited in the literature is the power struggles between the Electrotechnology ITO and the Engineering ITO (Knowledge at work, 2001; Smelt, 1995). These challenges of industry definition and competition, in my view, possibly led to a multiplicity of ITOs during the 1990s; by 1995, there were 53 ITOs and others waiting to be formed (Smelt 1995). By 1997, the number of ITOs had stabilised at 51 (Elkin, 1998). The large number of ITOs particularly vis-à-vis other countries such as Australia, which is larger with far fewer industry training organisations, has been viewed as creating layers of bureaucracy for firms, as well as leading to duplication of effort and dilution of capacity among ITOs. On the other side of the spectrum, competition within certain industries mitigated against the formation of industry training for certain industries, one example being Telecom, which was not willing to share customer service training, which it viewed as being critical to their competitive position (Smelt, 1995, p. 28). 
Initially, industry training could only be purchased from polytechnics. This was subsequently changed following complaints about the lack of relevance of some of the training offered by the polytechnics. This has led to the increased involvement of private training establishments in industry training (N. Green et al., 2003). Smelt also argued that, in addition to the administrative challenges experienced during the implementation of the strategy, there were fundamental issues related to the premises upon which the strategy was predicated. This in his view stemmed from the lack of analysis on the part of government and other key stakeholders in determining the exact nature of the market failure that the policy was supposed to address (Smelt, 1995, p. 15). This issue will be examined later, as it has implications for expected outcomes and the challenges experienced in the evaluation of the strategy.

Notwithstanding the challenges as outlined, by 1999/2000, the Industry Training Strategy was deemed by government as well as some academics as being largely successful (Elkin, 1998; Knowledge at work, 2001; McLean et al., 2003; Skills for the knowledge economy: a review of Industry Training in New Zealand, 2001). The major gains cited were increased training coverage, increased access to training and increased numbers of trainees (Elkin, 1998). However, as a part of wider tertiary education review, a number of reviews were conducted of the industry training strategy between 1999 and 2001, which unearthed a number of weaknesses with the system. These could be categorised between administrative issues and more strategic issues. Among the administrative issues cited were the costs incurred by firms, especially smaller firms that had to do business with multiple ITOs, the lack of clarity on the linkages between industry training and other parts of the tertiary sector, and the persistent funding issues (adequacy of funding and differences in funding arrangements between industry training and other parts of the tertiary education system) (Knowledge at work, 2001; Skills in the knowledge economy: a review of Industry Training in New Zealand, 2001).

However there were other strategic problems that emerged from the reviews. Perhaps among the most critical was the reported skills shortages that emerged in the economy at the beginning of the $21^{\text {st }}$ century, particularly in the traditional trades areas which were prior to 1992 covered by the apprenticeship system. This was largely blamed on what was perceived as the destruction of the apprenticeship system which led to 
under-investment in trades training (Whiteford, 2006). The skills shortages could also be linked to the recovery of the New Zealand economy, which has been growing at an average rate of $3.9 \%$ annually since 1999 , which has led to the expansion of the labour force. Another issue facing the system was the uneven coverage and inequitable access experienced across industries, and for certain groups such as women, youth, Maori and Pacifika peoples. These strategic issues led to a number of key changes in the industry training system. First is the introduction of the Modern Apprenticeship scheme, designed to encourage youth participation in industry training and to address the problem of uneven unemployment rates among the youth population. Secondly, the first Tertiary Education Strategy was launched covering the period 2002-2007, which was spearheaded by a new central body - the Tertiary Education Commission - which replaced Skill New Zealand and which emerged out of the Tertiary Education Advisory Commission, which was set up to lead the tertiary education review. One of the features of this review was the increased emphasis on the strategic leadership role to be played by ITOs in providing leadership for their industries, in identifying skill needs, and forming strategic alliances among themselves to improve the quality of service delivery. Crucial to this change of emphasis was the removal of the restrictions on firms so that they were not limited to the services of their industry ITO. This has led to a number of mergers among ITOs and a marked reduction in numbers - today the number of ITOs stand at 39 .

The increased strategic focus of industry training deserves further contextualisation, and should be viewed in the light of developments in the political and policy arenas in New Zealand. With the election of the Labour Alliance government in 1999, and the economic recovery of New Zealand, came a shift towards improving policy information and consequently formulation and implementation. This was evidenced in the creation and reorientation of new departments of government. Along with the establishment of the Tertiary Education Commission, the Department of Work and Income (now Ministry of Social Development) was also formed, which resulted in welfare/work benefits administration shifting away from the Department of Labour, which assumed greater responsibility for labour market research and analysis of labour markets trends and economic outlook (Dalziel, 2007). Critical to this shift is the recognition that the complexity of policy issues required improved policy information and better designed policy solutions, which required the input of multiple 
stakeholders, otherwise dubbed as the 'whole of government' approach to policy implementation, to include not only inputs across government departments and agencies, but also other stakeholders from community including industry and other community groupings. This had led to a shift in the policy dialogue, away from seeing skills as the answer to skills being seen as a part of a policy mix of solutions required (Developing the second tertiary education strategy: Industry Training Federation submission to the Ministry of Education, 2006). This 'whole of government' approach was also accompanied by a shift in economic strategy which since 2000/2001 has focused on stimulating innovation and regional development, through the launch of the Growth and Innovation Framework (now the Economic Transformation Agenda), and the Regional Partnerships programme (Dalziel, 2007; Dalziel \& Saunders, 2003). In addition to ITOs assuming leadership for industry skills gap identification, polytechnics have given the role of co-ordinating the identification of regional skill development needs since 2006.

Also since 1999, these policy debates have been enriched by the increase in research (commissioned by government departments as well as undertaken by academia), examining issues such as innovation and regional development in New Zealand. In keeping with much of the debate and criticism of the human capital approach to education and training elsewhere, the research has unveiled a number of weaknesses impacting socio-economic development issues in New Zealand. This can be seen in part as a search for answers to explain New Zealand's economic recovery but continued underperformance in labour productivity vis-à-vis its competitors. These weaknesses include the need to build on entrepreneurial capacity to inform the performance of firms, and ultimately the economy, the need to increase capital investment, private sector funding of research and development and technology adoption, as well as insufficient strategic alignment between training in firms and firm performance in New Zealand (Davis, 2006; Durbin, 2004; Fabling \& Grimes, 2006, 2007; Knucket et al., 2002; Lamm et al., 2006; Mason \& Osbourne, 2007; Ryan, 2007; Workplace productivity challenge: report of the Workplace Productivity Working Group, 2004). Another dimension that has been added to the skills debate in New Zealand is the issue of workplace literacy and numeracy skills. This stems from the publication of IALS findings both for 1996 and 2006, which indicated that approximately $43 \%$ of adults aged $16-65$ have literacy skills below the level needed 
to function effectively in a knowledge economy, and $51 \%$ have inadequate numeracy skills (Literacy, language and numeracy action plan 2008 - 2012, 2008, p. 4). Since these findings have come to light, a plethora of workplace literacy initiatives have been developed through ITOs, the Department of Labour, the New Zealand Council of Trade Unions Learning Representatives Programmes, as well as other organisations (Gray, 2006; Key steps forward for workforce literacy, 2008). All these varied initiatives point to the recognition of the multi-dimensional characteristic of skills policy challenges, as well as the multiplicity of interventions addressing the various dimensions.

In 2008, the Skills New Zealand Tripartite group, consisting of membership from government, unions, Business NZ and the ITF launched the New Zealand Skills Strategy (New Zealand Skills Strategy Action Plan, 2008). This represents a crossroads in the discussion on skills in New Zealand, and is seeking to examine skills within a more holistic context of low productivity, uncompetitive wages, lower levels of capital investment, workplace practices and an aging workforce population (Harvey \& Harris, 2008; Ryan, 2007; Working smarter: driving productivity growth through skills, 2008). The challenge faced however is that such a strategy, like the 1999-2001 reviews, is reliant on consultation meetings, which while important and worthwhile, can lead to two potential dangers: first, the strategy gets hijacked by interest groups that actually choose or get the opportunity to participate in the process, thereby ignoring the needs of critical stakeholders; second, the strategy fails to benefit from in-depth research looking holistically at how skills interact with other organisational and environmental factors to deliver productivity and other benefits.

\section{Evaluation of Industry Training Strategy}

It is important to note that to date there has been no comprehensive assessment of the impact of the Industry Training Strategy. What exists are performance reports from government departments (Ministry of Education, Tertiary Education Commission and its antecedents), as well as the Industry Training Federation, and a few doctoral theses that have indirectly examined its impact (McLaughlin, 2006; Murray, 2004). Additionally, there are a number of research papers and articles from policymakers 
and academia, which includes either commentary on the strategy or from which one could form certain conclusions about the impact of the strategy.

Performance reports from government departments as well as the Industry Training Federation tend to evaluate impact utilising a number of quantitative indicators, most common being the number of trainees. Using this indicator, industry training can be seen and is seen as a roaring success. In 1992, there was a total of 15,805 participating in what was then termed "apprenticeship training or trades training" (N. Green et al., 2003). By 2010, the number of trainees grew to approximately 190,000 , covering $78 \%$ of the workforce (Delivering value: the contribution of ITOs to New Zealand vocational education and training, 2010). These numbers are further disaggregated by sex, industry and ethnicity to allow for further analysis. Even using quantitative indicators however reveal certain weaknesses. One of the goals of the strategy was improved equity of access to industry training by women, Maori and Pasifika peoples and other disadvantaged groups. Women still remain underrepresented in industry training although this position has improved over time, and can be partly explained by the preponderance of women in other sectors not covered by industry training (Bryson, 2007; Industry Training and Modern Apprenticeships statistics as as 30 September, 2006, 2006). For Maori and Pasifika peoples, they are now adequately represented in industry; however further analysis reveals that their training numbers are concentrated in specific industries such as forestry and seafood (Industry Training and Modern Apprenticeships statistics as as 30 September, 2006, 2006). Another quantitative indicator used to measure impact and specifically access is the number of ITOs that have been formed for industries that previously had no history of organised training. This should be seen as a plus, but by no means automatically translated into increased access and equity. A better quantitative indicator of improved equity for disadvantaged groups is the analysis of the numbers of persons accessing industry training who had no previous qualification; the numbers here are significant. In 2003, for example, $26 \%$ of all trainees had no previous qualifications; for Maori participants, 34\% had no previous qualifications, and for Pasifika peoples, 37\% had no previous qualifications (Industry Training 2003, 2004). However, these numbers will only tell us about who accessed training, not about who did not, and this makes it a somewhat spurious success indicator to use. 
The counter argument to this however is the use of data related to income, educational attainment and unemployment levels as well as the growth of knowledge-intensive occupations to justify investments in education and industry training. Data within New Zealand and elsewhere consistently reveal that the more highly educated enjoy higher levels on income and lower levels of unemployment. In New Zealand in 2005, "the median weekly income was...\$560 for those with an 'other tertiary' qualification," which would include qualifications gained from Industry Training. This compared with a median weekly income of $\$ 301$ for those with school qualifications and \$293 for those with no qualifications" (Smart, 2006). In terms of unemployment levels, in 2005, the unemployment rates for degree holders and holders of 'other tertiary' qualification were at $2.2 \%$ and $2.5 \%$ respectively. This compares with unemployment rates of $4.2 \%$ and $6.4 \%$ for those with school qualifications and no qualifications respectively (Smart, 2006).

There are many challenges with the use of these types of quantitative indicators. Firstly, as the literature has revealed, it is generally agreed that measuring the impact of education and training, particularly on firm profitability and socio-economic development is very challenging, as it is difficult to determine the direction of causality and to differentiate the contribution on various aspects of education and training as well as to differentiate the impact of education and training from other factors, such as structure of the economy, industry, and other firm characteristics. Additionally, industry training is but one segment of the broader education policy of government, and it is difficult to disaggregate its impact and contribution from other parts of the tertiary education sector and other government training initiatives, of which there are many. Therefore, it is perfectly understandable that policy makers should use easy to comprehend statistics, and easy statistics make for useful arguments to be used on political platforms. However, it is critical that quantitative data be carefully examined using more rigorous analytical methods, and qualitative methods to unearth the complexities of policy impacts of industry training. More rigorous quantitative analyses reveal inequities behind these high-level statistics. A major contributor to this debate is the findings of a number of studies examining regional inequalities in New Zealand carried out by the University of Waikato. These studies revealed that between 1986 and 2001, there was increased income inequality in New Zealand, which could be explained by differences in the development of 
regions (Baxendine et al., 2005; Pool et al., 2005a, 2005b). The major findings are summarised below.

- Auckland and Wellington have experienced the greatest change in occupational structures, with an increase in more knowledge-intensive occupations, as opposed to more rural areas, such as Northland, South Waikato, Eastern Bay of Plenty, which over the period had lower growth in knowledge-intensive occupations. Two factors noted were that these rural regions tended to be dominated by declining industries and higher level of Maori within their population and lower levels of educational attainment (Baxendine et al., 2005).

- National incomes in real terms were lower in 2001 than they were in 1986. However, real incomes increased in the Auckland and Wellington regions during this period. The gap between median incomes for Pakeha and Maori also widened during this period, with the top Pakeha earners earning twothirds more than top Maori earners (Pool et al., 2005a).

- Persons of Maori ethnicity had higher participation rates in occupations requiring fewer or no qualifications than persons of Pakeha ethnicity (Pool et al., 2006).

These findings reveal a number of issues. While the well educated are obviously better off, labour market outcomes are also affected by one's location and ethnicity, as well as what industry one is a part of and what type of related education and training one pursues. This at least partially explains some of the 'disconnects' observed in the economic performance literature for New Zealand. If one goes back to the premise that increasing the supply of skill would lead to improved economic performance and competitive advantage. Improved economic performance has been realised which has been attributed mainly to increased labour utilisation (and low levels of unemployment). However, in terms of labour productivity, New Zealand's performance has been far below the OECD average; in fact it has even been argued that with labour market deregulation, it was possibly easier for firms to increase employment rather than improving productivity through capital investment and innovation. In other words, while employment has increased, and there are increased levels of educational attainment at the tertiary level, this did not translate to any marked improvement in the competitive position of the economy. 
This aligns to the findings of critics of human capital/VET approach to economic development. In reality, the expected outcomes of such policies - high-skill, highwage economy - were too high and short-sighted, as it focussed on supply side of skills, and not demand (Buchanan et al., 2001; Chappell et al., 2002; Dillingham, 2002; Finegold \& Soskice, 1988; Lloyd, 2003, 2005; Payne, 2004).

According to Smelt, one of the underlying assumptions of the industry training strategy was that international competitiveness in New Zealand would be enhanced by the development of nationally recognised, portable industry training qualifications (Smelt, 1995, p. 8). However, there was little evidence to support this premise. Indeed, some commentators have pointed out that portable qualifications do not lead to increased competitiveness, as these are easily duplicated, and that it is tacit knowledge and skills that promote competitive advantage (Brown et al., 2008; Strathdee, 2005). It is also further argued that the real acquisition of skills and the use of skills to improve productivity come from workplace learning coupled with the development of learning cultures within organisations, which has been discussed elsewhere (Billett, 2000, 2004b; Hales, 2004). Also high-skill industries have not proven to be the largest source of employment growth; the biggest growth in employment have been in low-skill jobs, both in New Zealand and other OECD countries; hence it is argued that while education and training are important, from a policy perspective, it is critical to look at a more integrated policy approach to skills, and to be more strategic in policy interventions and government spending in the education sector (Buchanan et al, 2001, 2006; Wolf, 2002).

More importantly, the focus of evaluation on quantitative data provides no analysis of how skills impact on the desired outcome - productivity. It also represents a policymakers' perspective, or at least, it fulfils the need of policymakers to report on outputs achieved. This type of data provides no understanding on how Industry Training impacts the various stakeholders, and does not take their perspectives into account; it assumes that this data meets the needs of all stakeholders involved, something which a single performance management system is not likely to accomplish (Wholey, 2001). The renewed emphasis on evidence-based policy in New 
Zealand since 1999, has led to some changes in the evaluation of skills initiatives. Some of these changes are:

- The increase in the use of case studies. Initiatives such as the Workplace Productivity Agenda and the Competitive Manufacturing Initiative have sought to utilise the case study method to evaluate and report findings (Case studies: workplace productivity in practice, 2004). Although much of this work is geared at marketing the benefits of such initiatives, it is still an attempt to examine the relationship between skills and other interventions in the creation of outcomes such as increased productivity. Also it represents a departure from using macro-level statistical data in evaluating the impact of skills initiatives, to using the firm as the unit of analysis.

- Increased use of sectoral approaches. A number of analytical reports have been prepared for specific sectors, examining their environmental challenges and opportunities and skills' issues (Bryant, 2007; Liaise report: a forecast of skill needs and training priorities for the New Zealand Hospitality Industry to 2010, 2007; Smart food, cool beverage: New Zealand's future in the food and beverage sector, 2006; Tourism and Hospitality workforce strategy, 2006). While these have not all been evaluative in nature, they also are an indication of the change towards looking at complex interaction between skills and their sectoral context, rather than simply looking at quantitative data such as number of trainees per sector.

- ITO's profiles and investment plans. Since 2007, ITOs are required to develop profiles and investment plans, outlining the specific outcomes they are intending to contribute towards, and funding arrangements are to be linked to their accomplishment (Investing in a plan, 2007). While this work is still at the development stage, it represents an attempt to more comprehensively evaluate the work done by ITOs beyond number of trainees.

- Skills Action Plan. The 2008 Skills Action Plan itself leaves much to be desired in terms of its evaluative component, which is to be determined in future years (New Zealand skills strategy action plan, 2008, p. 32). However, one of its appendix plans, the Literacy, Language and Numeracy Action Plan 2008-2012, does attempt to develop an evaluative component, with a mix of qualitative and quantitative indicators. What is also interesting is the recognition of different outcomes for different stakeholder groups (Literacy, 
language and numeracy action plan 2008-2012, 2008, p. 18). This represents a more inclusive approach to evaluation, in that the differing value of the action plan to different stakeholders is recognised. However, further action on this plan did not materalise as the election of the National-led government led to changes in the Tertiary Education Strategy.

Since the election of the National-led government in 2008, two major studies have been published by the Department of Labour and the Ministry of Education on Industry Training (Crichton, 2009; Mahoney, 2010). The Department of Labour study examined the effect of Industry Training on earnings, taking into account the variables of sex, ethnicity, age and level of qualification completed. One of the major findings of this study is that young white males were more likely to complete qualifications at Level 4 and to experience an increase in wages upon completion. Another major finding was that lower level qualifications offered very little wage premium. The Ministry of Education study examined completion rates by level of qualification, sex and ethnicity. What was interesting about this study was that it used existing data, but looked at completions rather than participation. What was revealed was that completion rates were overall quite low for Industry Training, and varied widely across different sectors of the economy. It also showed that women and other ethnic minorities experienced lower completion rates than white males.

These studies also point to the fact that, although Industry Training was meant to increase social mobility for women and ethnic minorities, these inequities still persist. The Ministry of Education study in particular also highlights the risk of data manipulation in evaluation, and that quantitative data is not value-free.

No examination of the evaluation of Industry Training evaluation would be complete without a brief look at the use of stories in evaluation. These are often referred to as case studies or cases, and started to emerge in the 2001 evaluation of Industry Training. Since then, they appear often as parts of various ITO annual reports or on various websites promoting the successful use of Industry Training, such as the Department of Labour's Workplace Productivity website. The use of cases in evaluation gained even more prominence with the completion of a comprehensive evaluation of the work of the Agriculture ITO using Brinkerhoff's success case 
methodology (Agriculture ITO annual report - partners in productivity, 2008; Brinkerhoff, 2005). At a glance, it may appear that this represents a trend towards the use of qualitative, inclusive methods in conjunction with quantitative indicators in Industry Training evaluation. However, it can be argued that this is not the case. The use of the term 'case' or 'case studies' is suggestive that it has the same methodological rigour as academic case studies or success case methodology, but further reading of these cases does not reveal this. In fact, these have more in common with vignettes rather than with cases. Additionally, of all the 'cases' examined, only one case portrayed a negative outcome; all the other portray Industry Training in a favourable light. This is not to say the 'cases' are false, but it could be argued that if the cases are all successes, then there could be extreme selectivity in the choice of cases in order to market the benefits of Industry Training, and that these cases are not truly evaluative in nature.

Finally, the evaluation of the Industry Training strategy appears to fit the human capital/VET policy logic to a large extent, particularly in the earlier years through to around 2007. Increasing participation rates for both employers and trainees, including women and ethnic minorities were viewed as indicators that the strategy was valuable to stakeholders, perhaps based on a rational choice ideology. The latest studies by Ministry of Education and Department of Labour could possibly represent the critical HRD paradigm, which seeks to re-examine data available to determine whether the expected outcomes are actually being realised (Crichton, 2009; Mahoney, 2010). However both perspectives view the value of Industry Training as observable facts that can more or less be quantified, whether in terms of numbers of trainees and participating employers, or wages, or completion rates or sex or ethnicity or progression to higher levels of qualifications. All these are important data; however they are limited, in that they do not explain how these outcomes come about. Also they do not examine the role and perspectives of the various stakeholders in the creation of these outcomes. 


\section{CHAPTER 4 - METHODOLOGY}

This chapter outlines the methodology utilised for this research. The previous chapters identified that VET evaluative research currently has two major gaps. First, VET policy has suffered from a lack of empirical research to gain better understanding on the determinants for VET engagement for its varied stakeholders, the value these stakeholders derive, the processes that create or hinder value creation, and how this value is assessed. Second, the paradigms underpinning VET evaluative research (as identified in the Literature Review) have not been made explicit and have not been subject to empirical research, to test their validity and applicability to an understanding of research in the field. The methodology seeks to address these gaps, both in terms of the research questions driving the research, as well as in the methodological approach. The discussion commences with the research questions and the rationale for the research is discussed, followed by the description of the research design and analytical framework, and the limitations and boundaries of the research.

\section{Research Questions and Rationale}

The main research question is as follows:

Using New Zealand's Industry Training Strategy as the research focus, how do different stakeholders evaluate the impact of a VET policy?

Additionally the research also aims to answer the following subsidiary research questions:

- What value do stakeholders derive from VET engagement and how is that value determined by them?

- How is value created for different stakeholders from engagement in VET?

For the purposes of this research, VET policy was defined as upgrade training. Grubb and Norton's definition of upgrade training is utilised, where VET policy is geared at the provision of additional training to employed individuals, either to foster their career advancement or to provide support in the face of technological and organisational changes, which impacts their jobs (Grubb \& Ryan, 1999, p. 10). This 
choice of definition was driven by two concerns. Firstly, the Industry Training Strategy can largely be defined as a VET policy focused on upgrade training for persons in employment. Secondly, as noted in the literature review, it is critical to define the various types of VET policies, as this has implications for the approaches to policy evaluation.

A qualitative approach guides the research design, mainly owing to the fact that it was more suited to answering the research questions which are exploratory in nature, examining not only the 'what' of Industry Training, but the 'how'. To an extent, the research philosophy is informed by Hanberger's (2001) characterisation of postpositivist research (and specifically post-positivist policy evaluation). This view rejects rational positivist assumptions, that there is one truth that can be arrived at using scientific methodology (Hanberger, 2001, p. 14). Post-positivists instead adopt a relativistic epistemological paradigm that asserts that there are multiple ways of understanding the world depending on one's perspective, and that there is no one valid form of knowledge (Denzin \& Lincoln, 2005; Hanberger, 2001).

The Industry Training Strategy as a government training initiative and public policy gets implemented and is experienced differently by its various stakeholders. The strategy therefore has multiple realities, and there are multiple perspectives on how the strategy creates, or does not create value for its stakeholders. As a result, multiple understandings exist among stakeholders on how that value gets created. In other words, to use the policy evaluation jargon, there are, in reality, different logic models and programme theories at work. The present disquiet in the New Zealand context with its skills strategy is, in part a recognition that something is amiss with the current skills development strategies, as the desired outcomes of higher productivity, and higher wages have by and large eluded the nation (Harvey \& Harris, 2008; New Zealand Skills Strategy Discussion Paper, 2008; Working smarter: driving productivity through skills, 2008). I posit that, at the heart of this disconnect is a faulty programme logic and a lack of understanding and consensus on what outcomes are desired (in others words, what is value) and how those are to be achieved. This is critical as within the public policy context, what is perceived as being of value, gets evaluated, and what gets evaluated gets incentivized. Using the example of Industry Training, if what is seen as valuable is increasing the number of trainees and unit 
standards completed, then that is what is assessed, as is evidenced in numerous performance reports covering Industry Training (Industry Training 2005, 2005; Industry Training and Modern Apprenticeships statistics as at 30 September 2006, 2007). As a consequence, Industry Training funding is directly linked to the number of trainees and completion rates. Drawing on workplace learning and Critical HRD theories (which have already been discussed), I argue that the value of Industry Training can be better understood through the perspectives of its stakeholders, and that it cannot be assumed that all stakeholders get the same value from the strategy. Also the process of value creation for different stakeholders can only be understood within their unique context, and is not fully explained by quantitative methods.

However, this research, while accepting the possibility of differing viewpoints among stakeholders, leans towards an interpretive constructionist position that is "...concerned with the lens through which people view events, the common expectations and meanings through which people interpret what they see and what happens to them." (Rubin \& Rubin, 2005, p. 28) These, if passed on from one generation to another, then form a culture. The research design proposes that groups of like stakeholders of Industry Training can be viewed as operating within a particular cultural arena, such as workplace, an ITO or the policy sphere. Additionally, the space in the Industry Training sector occupied by the particular stakeholder group can be seen as a unique cultural space, with its own shared meanings and understandings of Industry Training, and its unique value. Additionally, the notion of truth differing from individual to individual becomes problematic when conducting research aimed at better policy solutions. Further this research design posits there is an assumption of shared meaning in one paradigm of VET, and another assumption of opposing meaning. However no research has explored these meanings to determine the extent to which they differ, or are shared or how these meanings become created. (Rubin \& Rubin, 2005).

This research also takes a hypothetico-deductivist approach, as defined by Wengraf (2001) whereby the body of prior theory on VET and its related fields is used to generate a particular hypothesis that is to be tested through the collection, and analysis of relevant facts. In the case of this research, this body of prior theory has been 
encapsulated into two paradigms of VET logic, which then provide the lens through which the data collected is analysed.

\section{Research Design}

The research design is best described as a multiple stakeholder investigation through the use of in-depth interviews and secondary data sources, and a comparative programme logic/paradigm analytical framework developed from the literature. It is designed to critically compare the perspectives of different stakeholders on the evaluation of the Industry Training strategy. Being exploratory in nature, there is a preference for gaining an in-depth understanding of the perspectives of the selected research subjects, rather than seeking to gather data to make broad generalisations (Gerring, 2007). In keeping with the central tenets of qualitative research, my research gives preference to multiple data sources - respondents representing different stakeholders and supportive secondary data/documentary evidence that they can provide, which may be either qualitative or quantitative in nature (Denzin \& Lincoln, 2005, p. 3).

In line with the overarching research questions, the research is designed to collect and analyse the perspectives of different stakeholders of the Industry Training Strategy. Stakeholders are defined as groups that directly affect, or are affected by Industry Training through their engagement with it. From the literature related to Industry Training, three categories of stakeholders are identified: i) policy makers and industry interest groups; ii) employers/managers from selected organisations; and iii) trainees from selected organisations. In each of these categories, the stakeholders targeted by this research are discussed below.

\section{Policy Makers and Industry Interest Groups -}

These groups either have direct responsibility, or have significant influence and stakes in Industry Training, either at a national or sectoral level, or represent significant interests. They are as follows: 
Tertiary Education Commission - overall responsibility for leading the implementation of New Zealand's Tertiary Education Strategy, of which Industry Training is a subset.

Department of Labour - among its responsibilities are the implementation of active labour market policies and the conduct of research on skills shortages and needs in order to inform policy action.

New Zealand Qualifications Authority - responsibility for establishing and maintaining the qualifications framework underpinning Industry Training qualifications, as well as for quality assurance.

Industry Training Federation - the umbrella organisation representing industry training organisations, which has a vested interest in evaluation of the impact of industry training, and which seeks to influence government policy as it relates to industry training

Industry Training Organisations - responsibility for organising, developing, assessing and quality assuring Industry Training for the industries they represent. For the purposes of my research, focus was placed on industry training organisations that represented the sectors to be covered by the research - tourism and state sectors.

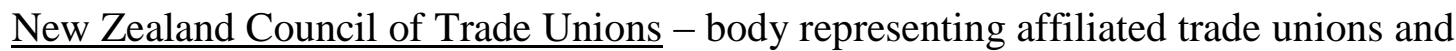
the workers they represent, and member of the Skill New Zealand group with lead responsibility for the conceptualisation of the Skills Strategy, and which has an interest in the skill development of its members.

Business New Zealand - body representing their affiliated employers' associations, and a key partner in the Skills Strategy.

Tourism Industry Association of New Zealand - body representing tourism organisations, and key stakeholder in the development and implementation of the tourism skills strategy and tourism policy generally. 


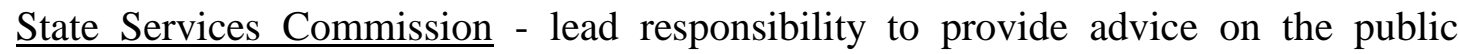
management system, including human resource policies.

Ministry of Tourism - responsibility for policy for the tourism sector.

Traditionally, policymakers and industry interest groups have been highly influential in shaping the Industry Training Strategy. How they think about and evaluate skills has a great deal on influence on other stakeholders and Strategy's implementation (Salaman et al, 2005, p. 5).

\section{Case Studies of selected organisations}

For analytical purposes, two categories of stakeholders were identified as representing end users of Industry Training with work organisations - employers/managers and trainees.

Four case study sites were identified - two state sector organisations and two tourism organisations. Information regarding employers/managers and trainees were collected at these sites. The case study methodology was considered ideal for the collection and analysis of information regarding these stakeholder groups, as the workplace (as was stated earlier) is regarded in this research as a unique cultural site within which Industry Training takes place. These case studies allow for in-depth exploration of the inter-relationships between stakeholders, and their work setting in the VET engagement process, as well as allow for corroboration of findings (Yin, 2003).

The organisations examined were drawn from the state and tourism sectors which engage in Industry Training. These sectors are of interest to me as, the public sector is where I have worked, and will work upon my return to Jamaica. The tourism sector is a very important and large sector both in New Zealand and in Jamaica. Additionally, I believe the sectors would possibly offer an interesting contrast of the Industry training experience, with the state sector representing a larger, more formal work organisation structure, as opposed to firms within the tourism sector, which have a tendency to be smaller, more flexibly organised, and privately owned. These sectors were also chosen as they are a part of the wider service sector. There is a concentration in the 
literature on skills in the manufacturing sector. However, the service sector is the largest segment of the New Zealand and the world economy, and is deserving of additional research. While this is not intended to make the sample organisations representative of the population of tourism and state sector organisations, variation in organisational size was critical in order to observe any variations in Industry Training implementation.

\section{Employers/Managers}

Employers and managers, including Human Resource managers were identified as a stakeholder group that is an end user of Industry Training, and also has decision making responsibility in relation to the engagement in and facilitation of Industry Training. This stakeholder group represents managerial perspectives on Industry Training.

\section{Trainees -}

Trainees from the organisations identified represent the other critical end-user of Industry Training, as they agree to, pursue and utilise Industry Training qualifications.

\section{Data Collection}

The data collection process commenced with the literature review from which the stakeholder groups were identified. It then proceeded with the collection of data from policy makers and industry interest groups, which was then consolidated and analysed. This analysis guided the collection of data from employers/managers and trainees in the selected organisations. The data collection process was approved by the Human Ethics Committee of the Victoria University of Wellington.

In-depth, face to face, one on one interviews were conducted with each interviewee using a core set of key questions covering their rationale for Industry Training engagement, the value derived from this engagement and how this was evaluated by them. These interviews are best described as being both topical and responsive, in that the research issue - in this case Industry Training, is highly visible, therefore 
interviews were conducted with respondents who were most likely to answer the questions; the goal from these interviews and research design was to gain depth of understanding, rather than quantifying data results (Rubin \& Rubin, 2005). A research question map was carefully designed to ensure that question guides were prepared for each stakeholder group respondent, and that the questions aligned directly to responding to the main research questions. These question guides were then consistently used for each interview and the data captured under each question/heading. This process greatly assisted in the codification on the data, which will be discussed under the Data Analysis heading. Appendix A provides additional details on the questions used. Additionally, probing questions were also used during the conduct of interviews in order to seek clarification and additional data. The research design and data sources were expected to provide respondent triangulation, as well as ensuring the representation of multiple stakeholders. This is important especially for the multiple stakeholder approach in VET policy research, in order to understand their views and experiences, and how these shape their engagement with and valuing of Industry Training (Salaman et al., 2005).

Interviews with policymakers and industry interest groups were conducted first. This assisted in setting the context for undertaking the interviews within the selected organisations, and increased the chances of coverage of all the pertinent research issues. Interview participants were identified using two methods - internet searches for relevant contact persons within the organisations listed above, and snowballing technique, where participants were able to recommend other possible interview candidates. The latter was used more extensively at the user organisational level, as participants had to be accessed through a main contact person within the organisation.

Table 4.1 below outlines the research framework that guided the data collection, as well as the number and types of interviewees. 


\begin{tabular}{|l|l|}
\hline \multicolumn{2}{|c|}{ Table 4.1 - Numbers of Interviewees and Stakeholder Groups Represented } \\
\hline STAKEHOLDER GROUP & NUMBER OF INTERVIEWEES \\
\hline $\begin{array}{l}\text { Policy makers/Industry Interest } \\
\text { Groups }\end{array}$ & $\mathbf{1 6}$ \\
\hline - Tertiary Education Commission & 1 \\
\hline - Department of Labour & 3 \\
\hline - New Zealand Qualifications Authority & 1 \\
\hline - Industry Training Federation & 2 \\
\hline - Business New Zealand & 1 \\
\hline - Hospitality Standards Institute & 2 \\
\hline - Aviation, Travel, Tourism ITO & 1 \\
\hline Learning State (Public Sector ITO) & 1 \\
\hline - New Zealand Council of Trade Unions & 1 \\
\hline - Tourism Industry Association of New & 1 \\
\hline Zealand & 1 \\
\hline - State Services Commission & 1 \\
\hline - Ministry of Tourism & $\mathbf{1 6}$ \\
\hline Employer/Managers (including \\
managers)
\end{tabular}

In the case of policymakers and industry interest groups, while a list of these participating organisations is included, opinions were not attributed to individuals nor specific organisations. Instead the analysis makes attributions to specific stakeholder groups, for example, policymakers, industry training organisations.

In line with ethical requirements, for organisations from the tourism and state sectors, information provided by participants was not disclosed to others. Additionally, opinions are only attributed to classes of participants, for example, trainees, managers/employers, and not to individuals or individual organisations. Also, 
organisational anonymity is maintained to protect the organisations. For this reason, copies of secondary data when provided is only referenced, but not included in the findings. Some sections of quotations used in the analysis chapters were deleted in order to maintain interviewee anonymity.

\section{Secondary Data}

Where available, secondary data such as evaluation reports, business reports, documents associated with Industry Training administration (description of courses, training agreements, training assessments) were examined. The aim was to establish chains of evidence to support information provided in interviews at the case study sites, and to ensure construct validity through multiple sources of evidence.

\section{Data Security}

All interviews were transcribed, and transcription notes and summaries of interview results stored in a secured locker in my office for the period stipulated under the University's ethical guidelines.

\section{Data Analysis}

A comparative approach was used to analyse the data collected. There were two layers of comparative analysis - comparison among the three stakeholder groups identified and comparison of stakeholders' perspectives against the two paradigms identified in the analytical framework.

The first layer was to compare stakeholders' views. The aim was to identify similarities and differences among stakeholders' perspectives, and to address one of the gaps identified in the literature where VET evaluation is lacking in its consideration of a multiple stakeholder approach.

The second layer was to compare stakeholders' views through the lens of the analytical frameworks identified and developed from the literature. As discussed previously, within the literature there are two broad and seemingly competing and 
opposing programme theories on the creation of value from public investments in VET. For the purposes of this study, the first I have referred to as the Strategic HRD/VET logic. The logic here is that the state invests in skills/VET, which then leads to the development of nationally recognised qualifications. These lead to recognisable and valuable skills. Employers and employees then willingly participate in VET, and having participated and acquired skills, these are then used strategically within the work organisation, and this leads to a range of outcomes - increased productivity, wages effects, social mobility etc.

The assumptions that underpin this logic are that VET outcomes are mutually beneficial to all involved, they are value-free and are largely observable facts that can be determined by quantitative methods and data.

The second programme theory I have referred to as the Critical HRD/Stakeholder logic. Here, there is a critique of the taken for granted assumptions of the Strategic HRD/VET logic, and it tends to focus not so much on how things work, but on why things are not working as they should. The common thought here that can be applied to VET policy evaluation is that outcomes are value-laden and context-specific, and are only mutually beneficial to all stakeholders through struggle and negotiation. It is however a theoretical perspective that has not been empirically tested.

This framework then became a point of reference for analysing interviewees' responses. The underlying question here was to what extent did responses reflect either of the programme theories within the framework, or did a different logic emerge from the data. The analytical framework is depicted below in Table 4.2. 


\begin{tabular}{|c|c|c|}
\hline \multicolumn{3}{|c|}{ TABLE 4.2 - COMPARATIVE ANALYTICAL FRAMEWORK } \\
\hline Factors & Strategic HRD/VET logic & $\begin{array}{l}\text { Critical HRD/ } \\
\text { Stakeholder logic }\end{array}$ \\
\hline Orientation & $\begin{array}{l}\text { Performance/Instrumental } \\
\text { orientation; purports to be } \\
\text { pluralist in outlook }\end{array}$ & $\begin{array}{l}\text { Developmental } \\
\text { orientation; criticises VET } \\
\text { policy as being unitarist in } \\
\text { outlook }\end{array}$ \\
\hline $\begin{array}{l}\text { Attention to Pedagogical } \\
\text { Issues }\end{array}$ & $\begin{array}{l}\text { Lack of explicit attention; } \\
\text { assumption of learner } \\
\text { needs being met }\end{array}$ & $\begin{array}{l}\text { Attention to learners' } \\
\text { needs critical to learning } \\
\text { and application }\end{array}$ \\
\hline Roles of Stakeholders & $\begin{array}{l}\text { Assumes stakeholders' } \\
\text { role definitions are clear, } \\
\text { performed consistently, } \\
\text { and are complementary, } \\
\text { leading to shared outcomes } \\
\text { for all. Employers' } \\
\text { engagement is seen as a } \\
\text { signal for the provision of } \\
\text { workplace support for } \\
\text { VET, including assessment } \\
\text { services etc. }\end{array}$ & $\begin{array}{l}\text { Questions whether } \\
\text { stakeholders' role } \\
\text { definitions are always } \\
\text { complementary, and } \\
\text { carried out consistently. } \\
\text { These roles may even be } \\
\text { competing, to the } \\
\text { detriment of some } \\
\text { stakeholders, especially } \\
\text { trainees. }\end{array}$ \\
\hline Funding & $\begin{array}{l}\text { Assumes that funding } \\
\text { incentivises stakeholder } \\
\text { engagement in ways that } \\
\text { produces mutually } \\
\text { beneficial outcomes }\end{array}$ & $\begin{array}{l}\text { Questions whether funding } \\
\text { incentivises perverse } \\
\text { behaviour to the detriment } \\
\text { of beneficial outcomes }\end{array}$ \\
\hline Evaluation & $\begin{array}{l}\text { Preference for quantitative } \\
\text { performance indicators to } \\
\text { evaluate. Typical } \\
\text { indicators are completion } \\
\text { rates, number of trainees } \\
\text { by age, sex and race }\end{array}$ & $\begin{array}{l}\text { Preference for qualitative } \\
\text { data to evaluate }\end{array}$ \\
\hline Outcomes & $\begin{array}{l}\text { Assumes outcomes are } \\
\text { mutually beneficial for all } \\
\text { stakeholders. Typical } \\
\text { shared outcomes are skills, } \\
\text { portability of skills, higher } \\
\text { wages and productivity, } \\
\text { increased socio-economic } \\
\text { equity for disadvantaged } \\
\text { groups }\end{array}$ & $\begin{array}{l}\text { Challenges the } \\
\text { assumptions of mutually } \\
\text { beneficial outcomes for all } \\
\text { stakeholders. }\end{array}$ \\
\hline
\end{tabular}

The research design utilised the programme logic model as a key data analysis tool. Programme theory is defined as the underlying assumptions about how a programme will work to accomplish the outcomes intended (Bickman, 2000; Owen, 1998). A 
logic model is a diagrammatic representation of a programme theory (Cooksky et al., 2001; Julian et al., 1995; Kaplan \& Garrett, 2005). Programme theory or logic was developed by Suchman in late 1960's, and further developed by Joseph Wholey, Michael Patton, and more recently Funnell in the Australasian context and the Kellogg foundation in the USA, among others (Funnell, 2000; Patton, 2002b; Suchman, 1967; Wholey, 1987). It was developed as a way of outlining the events or interventions within a public policy programme that would "produce a certain outcome or sequence of outcomes" (Alkin, 2004; Baehler, 2003; Logic Model development guide, 2004; Yin, 2003, p. 127). It has also been utilised for evaluation purposes, where programme theory serves a more descriptive function, which is to uncover how the programme actually works in reality (Rogers, 2000). Programme theory and logic models have gained increasing popularity among public service managers in New Zealand and elsewhere and within the NGO sector as a way of meeting the demand for increased levels of accountability and performance (Logic model for the evaluation of the 10-year strategic plan for Early Childhood Education: pathways to the future, 2003).

The use of programme theory, and theory-driven evaluations were developed in part as an alternative to the weaknesses of quantitative, positivist policy evaluations (House, 2001). According to House, the utilisation of grand social theories as a basis for evaluations failed, as "there were no social theories that seemed to have the explanatory power or credibility of physical theories" (House, 2001, p. 311). The alternative - to construct a model or programme theory on which to base evaluative studies - provides the advantage of setting the parameters for data search, of testing rival explanation and clearer appreciation of social causation (House, 2001).

Other advantages of programme theory/logic models are that as policy development approach, it can facilitate collaboration among stakeholders, strengthen the policy process by brining assumptions to the fore for explication and critique, and it allows for ease of communication about what a policy is about. As a policy evaluation tool, it has the advantage of defining the policy outcomes, and impacts against which the policy can then be evaluated. 
Some of these very advantages can pose a challenge for this particular research design. Firstly, logic models can be criticised as taking a positivist approach to policy evaluation, in that it is a statement of causal effect, although depending on the complexity of the model used, complex causality can be captured. Secondly, in its attempt to achieve ease of communication, a logic model can run the risk of oversimplification of a policy (Gregory, 2004). Thirdly, while its development is potentially inclusive, there is a tendency for programme theory/logic model to overlook equity issues, which may seem to run counter to the inclusive approach that it hoped for in this research design (Baehler, 2002).

For this research, it is argued that different stakeholders of the Industry Training Strategy may engage in Industry Training operating with differing programme theories, and assumptions, and that could in part explain the disconnect between the grand policy aims of a high skill, high wage, highly productive society and the reality. The aim of the research then would be unearth these theories and assumptions using logic models, and to critically compare the differences and similarities among stakeholder groups. The policy process is constantly intersected by the often competing value systems of its stakeholders, and this has to be borne in mind, particularly as it relates to the evaluation process. The analogy used by Fischer of policy as a well crafted argument is useful, in that good policy has to take account of contending positions, contentious issues and most importantly the fact that assumptions, and evidence of policy have both strengths and limitations (Fischer, 2007). The question then arises, if policy is a crafted argument, whose voice is it; is it possible for the policy process to be hijacked by some stakeholders wielding more political power, to the detriment and exclusion of others? A well crafted policy argument, including policy evaluation, then has to take into account the different voices (and by extension values and concerns) of its stakeholders, for the purposes of fostering democracy as well as greater levels of policy understanding. One of the strengths of this data analysis methodology is that it provides a useful construct to interrogate the data collected, and to communicate the research findings. It also provides a systematic way for delineating "who is saying what and in what context" (Barbour, 2008, p. 216). The final analysis then, represents a syntheses of understandings that come about by combining different individuals' and stakeholders' detailed reports of their experiences with Industry Training (Rubin \& Rubin, 2005). 
There are two potential drawbacks with this methodology. The first is that the analysis runs the risk of being inundated by a multiplicity of logic models, which makes data analysis intractable (Donaldson \& Gooler, 2003; Torvatn, 1999). To minimise this risk, thematic analysis was used as a complementary data analysis tool. This involves identifying themes or patterns within the data. Drawing on the guidance provided by Barbour (2008), this entails "identifying patterning in (the) data..." and doing some counting while stopping short of "making statistical inferences" (Barbour, 2008, p. 217).

The second potential drawback is concerned with the unearthing of the assumptions that underpin the programme theory of the different stakeholders, the risk being how to limit researcher bias, and not to presume participants' assumptions. The challenge however, is that research participants may not always be aware of the assumptions that underpin their perspective, and may not be able to articulate these with clarity. In order to minimise researcher bias, it is critical to ask a lot of probing questions, to adequately capture participants' perspectives, while ensuring that questions are not asked in such a way as to cast a judgement on respondent's actions or motives (Patton, 2002a). Transcripts or summaries of the interviews were also provided to participants, to give them the opportunity to state whether their views were sufficiently captured.

As the question guides were used consistently for all interviews, these provided natural categories for codification of the interview and secondary data. From the analysis under the different codes, themes emerged and then developed, both through the lens of stakeholder group responses, and the comparative paradigms. These data were then synthesised into global themes or the revised logic that emerged from the data (Attride-Stirling, 2001).

\section{Limitations}

A number of access challenges led to possible limitations in the research, including: the small number of cases studied; participant numbers; and variation in the availability of secondary data. 
The original research design was to examine seven case studies sites representing different types of state sector and tourism organisations. In the case of the state sector, the Wilson matrix for state sector organisations was used as a typology of state organisations, the four categories being production, procedural, craft and coping organisations (Gregory, 1995). In the case of tourism organisations, the typology of tourism businesses used in the Tourism and Hospitality Workforce Strategy was adopted, that is accommodation, attractions and activities (Tourism and Hospitality workforce strategy, 2006). The intention was to provide a point of comparative analysis among different types of state sector and tourism organisations. Only four case studies sites were eventually explored in this research. The main reason for this was the tremendous challenges faced in locating organisations which were both willing to participate in the research, and who utilised Industry Training across all or a wide range of their employees.

Another research challenge was accessing the targeted number of research participants at the case studies sites, particularly managers/supervisors and trainees. This was again partially due to the reduction in case sites, as well as difficulty getting respondent cooperation. A total of fifty interviews with trainees and managers/supervisors were targeted; in the end a total of thirty-five interviews were conducted with these respondent groups.

The third limitation was the lack of secondary data for two of the case study sites. Originally, the aim was to examine secondary data for all case study sites, as a source of corroboration for data from interviews. However, due to time constraints and difficulties in accessing participant organisation, a decision had to be taken to use these organisations. This limitation was not considered detrimental to the data collection and analysis process on two counts. First, interviews conducted at the level of policymakers and industry groups revealed that there were variations among workplaces in terms of their level of sophistication in VET engagement, with related training practices being managed with different degrees of formalisation. Therefore, the absence of secondary data is seen as a reflection of that reality. Secondly, the use of different interview sources provided adequate levels of data corroboration. 


\section{Research Outcomes}

This research contributes to both practical as well as academic knowledge. In terms of academic contribution, it adds to the field of Critical HRD by expanding its application to the public policy arena, as it relates to skills initiatives. The research also contributes to the policy evaluation literature. Specifically it explores the expanded use of programme theory through the inclusion of multiple stakeholders' perspectives and theories, and the exploration of the interplay among stakeholders in the evaluation of the Industry Training Strategy. The final product is a critical analysis of the connections between programme theory and outcomes within and among stakeholder groups. A theory of how skills policies create value and are evaluated from a multiple stakeholder perspective is a final outcome that can then be tested through future empirical research. This fills in part the gap in evaluative research on skills, which largely ignores stakeholders' perspectives, especially at the organisational level, and within the New Zealand context. This makes this research unique as previous investigations of comparative stakeholder perspectives have been confined to employers and employees. This research also helps fill the gap in evaluative research on nationally recognised workplace training. The recommendations inform future direction on a more effective evaluation framework for the Industry Training Strategy, and skills policies generally. 


\section{CHAPTER 5 - DATA ANALYSIS - FINDINGS FROM POLICYMAKERS AND INDUSTRY INTEREST GROUPS}

In this chapter, the findings from the interviews with respondents representing policymakers and industry interest groups (as outlined earlier in Table 4.1) will be discussed and analysed. The interviews for this group of respondents totalled 16 and are numbered respondent 1 to 16 for confidentiality purposes.

The findings are categorised under the various research questions starting with the subsidiary questions and ending with main research question. Additionally, the analysis exposed a number of recurring themes emerging from the data, which are discussed against the background of the comparative analytical framework, along with the programme theories revealed by the data.

What value do employers and trainees derive from this engagement and how is that value determined by them?

\section{Value for whom?}

For these respondents, their definitions of the value of Industry Training were shaped by their keen awareness of its impact on a range of stakeholders. While all the interview participants generally identified the same set of stakeholders - trainees, employers, industry, government, society, there were marked differences in how these recipients were perceived. In some instances, it was clear that there was a hierarchy of clients, which was defined by the power the recipient was perceived to have. On one hand, employers were identified as being the principal recipients of Industry Training, as exemplified in the following comments:

\section{Respondent 15}

"It has to be the employers; they are our key. Without them, it doesn't matter. There could be all the learners stacked up in the world but without the employers buying into Industry Training, those opportunities aren't there for learners."

Respondent 14

"And what happened was ITOs were set up as employer organisations. The old concept which had been embedded in vocational education for at least 100 
years, of unions being full, formal participants in the vocational education system, that went overnight."

\section{Respondent 11}

"The organisation. So even if an individual approaches us, we ask them to work through the organisation..."

This is reflective of a unitarist viewpoint, as well as the practical and pragmatic concerns of implementing Industry Training, particularly from the perspective of an ITO (Lamm \& Rasmussen, 2008). Although Industry Training only takes place when there is a signed agreement among an ITO, the trainee and the employer, the employer is the only party that is required to make a financial contribution to the cost of the training. Some respondents further pointed out that especially for SMEs, that cost can be quite substantial. Therefore, how employers value Industry Training can become more relevant than the benefits to other stakeholders, particularly from the perspective of an ITO which depend to a large extent on the cooperation of employers for their existence.

Other respondents however had a more pluralist view, and tended to shy away from identifying any one principal client for Industry Training, as exemplified in the following quotations:

\section{Respondent 6}

"I think the employers are, with the trainees a close second. Because the training agreement is signed between the employer and the trainee, and it becomes a part of the employment agreement. So without the employer nothing happens, but without the employee nothing happens either."

\section{Respondent 10}

"I don't think that we would pick a winner between the two of them. I mean the whole process should be student-centred... That said, we want equally to meet the needs of industry...."

Respondent 9

"I think the client is industry, which is both employers, and firms and employees." 


\section{Respondent 1}

"Another huge shift I think has been prompted by the shift in tertiary education in New Zealand from demand-led which went right through the 80 's, to now one that is supposed to be based on stakeholders' needs. On needs of the industry, needs of the learner and of the community."

There was a definitive pattern in the type of stakeholders who tended to have a unitarist versus a pluralistic client perspective. Interview participants who were closer to the policy centre all expressed a pluralistic client perspective, while the further from the policy centre the participant was, the greater the tendency to lean towards a more unitarist perspective. This is not unexpected as persons at the policy level, being closer to the seat of government would be expected to reflect the concerns of the wider electorate. It has been argued though that in the first decade of Industry Training, despite the calls for greater equity of access to training for minorities and under-represented workers in sectors with little or no training, that employers were considered by government as the principal client. Some commentators argued that it was an even more narrow definition of employers, as large companies represented in the Business Round Table group who were the main drivers and influence on Industry Training and on government policies at the time (Crocombe et al., 1991; Elkin, 1998; Smelt, 1995). So the change to a more pluralistic client view expressed by some interviewees mirrors the view reflected in the policy literature, with the change to a Labour-led government in 1999, and an adoption of more pro-worker policies, for example the repeal of the Employment Contracts Act and the passing of the Employment Relations Act, and the introduction of what has been termed 'Third Way' policies, and a shying away from strictly market-led government philosophy (L. Evans et al., 1996; Lunt et al, 2003).

This change over time in government philosophy, it appears, has led to the word 'industry' having multiple meanings among stakeholders. From the interviews, there was a tendency for those taking the more unitarist view to define it as employers, while those with a more pluralistic client perspective tended to have a broader definition. But even then, there was no consistent definition, an inconsistency that appears in the policy literature although not specifically acknowledged. So on one end, industry is defined as employers. At the other end of the spectrum, after analysing the various interview comments as well as the policy literature, I believe 
industry is a specific value chain bounded by the production of a common set of goods and services which includes customers, employers, managers, taxpayers, government etc but whose boundaries are quite permeable.

The variations in definitions of who is considered the principal client, and who or what is industry have implications for the evaluation of Industry Training. These variations reveal that definition of value is potentially both political and subjective, as it is shaped by who is seen as having the decision-making power at the particular points of engagement. What is clear also is that the tension in the literature as exemplified in the comparative analytical framework reflects tensions in reality in the VET implementation process among these stakeholders. That tension is expressed through the varying orientations of Industry Training, whether it is unitarist or pluralist in outlook. If in reality, Industry Training is fundamentally unitarist, given the power that employers exercise over the engagement process, this may translate into Industry Training being more instrumental in nature to the neglect of more developmental concerns, such as employability and development of trainees, and a focus on their pedagogical needs, a concern that thinkers of the Critical HRD persuasion argue. The role of employers and how they execute that role can therefore impede the VET engagement process for other stakeholders, for example employer insistence on certain types of training, which may not result in trainees being adequately skilled to compete in the wider labour market, and ITO acquiescing to these demands against better judgements. On the other hand, there is a competing view among some of these stakeholders to strive towards making Industry Training pluralist in its outlook, and to provide balance to all stakeholders' needs. What then emerges here is not a clear cut preference for one paradigm over another. The data presents a reality that is fraught with tensions between pluralist and unitarist concerns, and which is shaped by the power bases of the different stakeholders.

The values that were identified by respondents were a) a variety of quantitative outcomes, b) skills/ skill utilisation, c) career progression/skill recognition/portability, and d) increased access/equity/learners' self worth. 


\section{a) Quantitative Outcomes}

Not surprisingly, numerical performance indicators (PIs) were one of the most commonly identified value among interviewees. However, quite often, unlike the policy literature, interviewees varied in their perspective on the use of PIs. On one hand, there were those respondents who viewed their numbers as an indicator of success, as exemplified in the following statements:

\section{Respondent 13}

"We are looking at KPIs around assisting some emerging demographic groups - Maori, Pacific Island, women - and we look at how their population within their trainee populations compares with the population that we have from the census for the industries within their coverage... So our figures really speak for themselves; we're sitting at the moment at about 10,000 trainees - way over budget in terms of the STMs that we are funded on. You understand how we are funded? We over-achieve significantly; I think we are one of the largest over-achievers."

\section{Respondent 9}

"But our numbers are still pretty high, so we must be doing something right, and because of the requirement for the cash contribution, so employers always have to put some money in, so again there has to be a sense of valuing going on."

\section{Respondent 15}

"We are cheap compared to polytechs and PTEs. We are cheap return on investment; so you've got 10,000 trainees just in hospitality, and how many does the local polytechnic have?"

\section{Respondent 11}

"We want to actually increase our trainees' numbers because it looks good for, for TEC, and also for the industry."

This is not surprising and is reflective of the requirements of the funding arrangements and performance reporting mechanisms that are currently in place for the monitoring of the Industry Training system (TEC, 2005). The performance reporting system utilises a variety of quantitative indicators as proxies for the desired outcomes of the system. These indicators are hinged on participation, completion and progression rates. The argument presented was that increasing levels of participation by trainees and employers, as well as completion were proxies for valuing on the part 
of trainees and employers. Increasing participation by disadvantaged groups, such as Maori and women, as well as increasing learning progression along the National Qualifications Framework was viewed as proxies for socio-economic progress. This is based on the assumption that increased learning and participation should result in increase wages, reduced unemployment and employment mobility. This is an example of a bounded rationality evaluation model, where perfect information is not deemed possible, so HR metrics are developed as "...they are believed to approximate some valued output or outcome...." (Holton \& Naquin, 2005, p. 265). The performance reporting system is reflective of the Strategic HRD/VET policy logic in that these quantitative indicators are meant to indicate the collective, pluralist value of Industry Training to a wide range of stakeholders - minorities, trainees, employers (Lamm \& Rasmussen, 2008). This again is not surprising as these indicators are set at the policy level, where the political concerns would be to seek out collective interests as far as is possible, or at least be seen to be doing so. But the quotations also indicate the possibility of specific interest groups' or unitarist's agenda, that are encapsulated in these numerical indicators. There appears to be a value of credibility for various stakeholders that is gained from increasing performance along these quantitative indicators - “...because it looks good...." This value of credibility that is gained from the numbers is then translated into a political bargaining chip used to advocate for and justify government's Industry Training spend, whether it is to increase it, to accommodate "over-achieving" ITOs or to gain increased parity in funding between the ITO and polytechnics sectors. This then supports the Critical/stakeholder programme logic that evaluation is not a value-free process, and that it is political process.

The value-laden nature of quantitative evaluative data is perhaps more exemplified by the responses that expressed caution and even hostile cynicism to the use, or perhaps more appropriately, the misuse of quantitative data. The following quotations are an indication of this perspective:

Respondent 3

"I think the way the funding works is that there is a very heavy emphasis on signing up trainees, and getting qualifications and credit completions. And the question I would ask is: is that resulting in good quality." 
"How do you evaluate this? How do you measure performance when you are trying to drive behaviours and practices and productivity, and things that are somewhat more intangible, and more difficult to measure than the number of people enrolled or qualified, and both of those are important measures that we have to keep measuring. But we have to find other ways of measuring performance, and looking at a more rounded picture of the performance."

\section{Respondent 1}

"When we did a large survey of what was available in the training space, and there were literally hundreds and hundreds and hundreds of qualifications on the books and God knows how many of them were actually functional and running. But there was an absolute plethora of courses that were potentially available, and $90 \%$ of them, nobody had any idea if they were effective, useful or targeted or whatever. Just driven by EFTS funding and bums on seats. It paid a private provider to pop up with another course, you know. In terms of effectiveness and evaluation and was this actually achieving anything for the productivity of the industry - nobody had any idea."

Respondent 2

“

ITO was probably concentrating on things like and and

that sort of thing because that was a steady flow of apprentices who were going through the levels and had good completion rates. where is the money in that? So they had no knowledge, no effort, no interest."

\section{Respondent 4}

"I know of several cases where an ITO or provider will just call up their HR friends and say 'We're running a course.' 'How many trainees do you need? Ok.' Then they would just round up the trainees like cattle; no concern about who needs it or anything. All that was important was meeting the target to get the funding."

There are a number of issues that can be raised from these quotations. First is the ongoing challenge which is also reflected in the policy literature on the best way to design funding incentives to drive behaviour, and how to avoid perverse incentive and subsequently perverse outcomes. The term "bums on seats" was used repeatedly by several of these respondents as a way is disparaging the over-emphasis on quantitative indicators. The main argument of respondents here is that numerical indicators was too limited in assessing performance of the Industry training system, and that the attachment of funding to achievement of quantitative outcomes has led to the Industry 
Training system producing valuable outcomes for those who are responsible for getting the trainee numbers and qualifications development increased, but not quality outcomes, a point that is reflected in the literature (Smelt, 1995; Wolf, 2002; Wolf et al., 2006).

Second, the quotations emphasise the quantity versus quality debate that was raised by many of the respondents, the essential argument being that the value of quantitative outcomes seem to run counter to respondents' notions of quality outcomes. This notion of quality tied to the next value that was identified by respondents - skill utilisation.

b) Skills and Skills Utilisation

Skill utilisation was the outcome that was identified by all respondents as a major outcome of the Industry Training system, and appeared to be the indication of the quality and health of the system, as these quotations highlight:

Respondent 3

"You've got the qualifications, and the ITO goes along to you as a business and says: "I've got this qualification that would suit you." And you say: "Yep, that's good. I'll get all my trainees signed up, and I can tick off yes I'm training." But that's based on the notion that the skills developed will be used in the business and will add value."

\section{Respondent 1}

"But the guts of it is, what Brinkerhoff said has made quite a shift to saying instead of just developing the skills in isolation, you ought to involve management at the beginning, relate it to a business plan, and then at the end have good training - we usually do that quite well, and then remove barriers to the implementation of those skills that have been learnt into the business."

Respondent 6

"There is absolute connection between the development of a high skill, high wage, high productivity economy."

\section{Respondent 7}

"So it's about productivity, bottom-line, retention, and those are probably the key things; that's what's important to them." 
This aligns with the Strategic HRD/VET policy logic, and echoes the argument within the VET policy and Industry Training literature on the link between skills and productivity at the individual, firm and national levels (Grubb \& Ryan, 1999; Harvey \& Harris, 2008). Despite the agreement on skill utilisation as an important value to be derived from Industry Training, there were major differences among respondents on the extent to which skill utilisation as a quality outcome was and should be achieved. This is rooted in the differences between the unitarist and pluralist perspectives in relation to Industry Training, and what emerges from the data are differences in pedagogical perspectives and logic among interviewees about Industry Training's purposes, what causes it to be effective, and how funding arrangements therefore ought to be designed or not designed in keeping with logic argument. Three different pedagogical arguments have been identified in the data, and are outlined in Table 5.1, and the perspectives expressed centre around four key issues - VET outcomes in the form of the kind of qualifications the system ought to produce, the nature of assessment attached to qualifications, whether qualifications should be suited to meeting long, medium or short term needs, and the critique of whether the funding arrangements impede or facilitate the particular viewpoints. 


\begin{tabular}{|c|c|c|c|}
\hline \multicolumn{4}{|c|}{$\begin{array}{c}\text { TABLE 5.1 - Industry Interest Groups and Policymakers' Perspectives of } \\
\text { Pedagogical Issues Affecting Industry Training }\end{array}$} \\
\hline & $\begin{array}{l}\text { Pluralist - multi- } \\
\text { client focus }\end{array}$ & $\begin{array}{l}\text { Pluralist - Trainee- } \\
\text { Focus }\end{array}$ & $\begin{array}{c}\text { Unitarist - } \\
\text { Employer-Focus }\end{array}$ \\
\hline Outcomes & $\begin{array}{l}\text { Pedagogically } \\
\text { sound Industry } \\
\text { Training } \\
\text { qualifications are a } \\
\text { certain breadth and } \\
\text { length but not too } \\
\text { lengthy }\end{array}$ & $\begin{array}{l}\text { Pedagogically sound } \\
\text { Industry Training } \\
\text { qualifications have a } \\
\text { strong theoretical } \\
\text { component which is } \\
\text { not best delivered on } \\
\text { the job }\end{array}$ & $\begin{array}{l}\text { Fit for purpose } \\
\text { Industry Training } \\
\text { qualifications is } \\
\text { defined by the } \\
\text { needs of the } \\
\text { industry, } \\
\text { should not be } \\
\text { defined by length } \\
\text { or credits }\end{array}$ \\
\hline Assessment & $\begin{array}{l}\text { Pedagogically } \\
\text { sound } \\
\text { qualifications } \\
\text { should meet the } \\
\text { needs } \\
\text { kinaesthetic } \\
\text { learners who most } \\
\text { likely have had } \\
\text { poor success in the } \\
\text { primary and } \\
\text { secondary education systems. } \\
\text { Preference for on } \\
\text { the job, evidence } \\
\text { based assessment }\end{array}$ & $\begin{array}{l}\text { Pedagogically } \\
\text { Industry sound } \\
\text { qualifications } r \text { Training } \\
\text { not be only evidence- } \\
\text { based and should } \\
\text { include off job } \\
\text { assessment within } \\
\text { more traditional } \\
\text { educational institutions } \\
\text { such as polytechnics }\end{array}$ & $\begin{array}{l}\text { Fit for purpose } \\
\text { Industry Training } \\
\text { qualifications } \\
\text { should } \\
\text { evidence-based, } \\
\text { and this is the best } \\
\text { way to know that } \\
\text { the learner can do } \\
\text { the job. Suitability } \\
\text { of assessment } \\
\text { methods have to } \\
\text { be determined by } \\
\text { cost-effectiveness } \\
\text { and ease of use }\end{array}$ \\
\hline Perspective & $\begin{array}{l}\text { Pedagogically } \\
\text { sound Industry } \\
\text { Training } \\
\text { qualifications } \\
\text { provide learners } \\
\text { and the wider } \\
\text { labour market with } \\
\text { skills for the } \\
\text { medium to long } \\
\text { term, and not just } \\
\text { the short term }\end{array}$ & $\begin{array}{l}\text { Pedagogically sound } \\
\text { Industry Training } \\
\text { qualifications with a } \\
\text { strong theoretical } \\
\text { component provide } \\
\text { learners and the wider } \\
\text { labour market with } \\
\text { skills for the medium } \\
\text { to long term, and not } \\
\text { just the short term }\end{array}$ & $\begin{array}{l}\text { Fit for purpose } \\
\text { Industry Training } \\
\text { qualifications will } \\
\text { meet the needs } \\
\text { identified by } \\
\text { employers, whether } \\
\text { short term or } \\
\text { otherwise }\end{array}$ \\
\hline Funding & $\begin{array}{l}\text { Funding is } \\
\text { designed to ensure } \\
\text { that Industry } \\
\text { Training } \\
\text { qualification meet } \\
\text { these minimum } \\
\text { criteria for } \\
\text { pedagogical } \\
\text { soundness but are } \\
\text { shortened to enable } \\
\text { easier completion }\end{array}$ & $\begin{array}{l}\text { The funding and the } \\
\text { wider system is driven } \\
\text { by numbers and } \\
\text { employers' short term } \\
\text { interests, that turns out } \\
\text { learners who are not } \\
\text { necessarily competent. }\end{array}$ & $\begin{array}{l}\text { Funding formula is } \\
\text { not designed to } \\
\text { meet these needs } \\
\text { and ways and } \\
\text { means have to be } \\
\text { devised to get } \\
\text { around them }\end{array}$ \\
\hline
\end{tabular}


At one end of the spectrum, there is the unitarist perspective, which characterises Industry Training's effectiveness as it being 'fit for purpose', the specific purpose being meeting the 'needs of industry,' industry being defined in this world view as employers. Here, an Industry Training qualification's purpose is to equip with the specific skills required at the time. The quotation below exemplifies this perspective.

\section{Respondent 15}

"What is a qualification? Is a qualification 3 years at university, or is the qualification a particular skill? When we talk to people about unit standards and quals, we talk about a unit standard representing a skill as a qualification in its own right. It is a record and evidence that someone can do a particular skill - I have the qualification in handling and maintaining knives, so I am competent to use a knife now. People need to shift their idea about what a qualification is. It doesn't need to be a 40 credit certificate with all these unit standards that don't apply to the person in the workplace, and that they have had to sit through and do, but they don't actually do in their job."

The evidence-based assessment model associated with Industry Training is seen as ideal, and assessment methodology should be determined by ease of use and cost, thus making on the job assessment preferential. Being 'fit for purpose' means meeting employers' needs, whether short, medium or long term, and as such, persons holding this view take exception to funding only being linked to qualifications meeting a minimum number of credits. This is also an argument posited for not relying only on completion rates as a key performance indicator, as part of a qualification may still be useful in terms of meeting skills needs. What is deemed pertinent is the acquisition and use of the skills needed, and not the acquisition of qualifications, as defined by educationalists whose preference is for traditional, institution-based learning solutions. This is certainly reflective of the human capital theory perspective, which argues that employers are more likely to value training that is specific to their needs (Becker, 1962).

The second perspective expressed is trainee centred, which questions whether Industry Training has been as beneficial as it is purported to be. This is a proemployee, social justice concern, but this perspective is also rooted in the pedagogical debate which appears to surround Industry Training. Some of the arguments here are that Industry Training, by being so evidenced-based, has lost a great deal of the 
theoretical component that was formerly included under the old Apprenticeship system, where theoretical components were delivered off-job. Proponents of this perspective argue that with more and more Industry Training being done entirely on the job, trainees were being trained in a 'Stand by Nellie' approach, and being assessed in a 'checklist' manner. The following quotations express these quality concerns regarding Industry Training:

\section{Respondent 14}

"Immediately we started to see vocational education as being enterprisespecific... So theory went; educational elements of your training went, and many employers were able to set up training packages, which were designed to meet the companies' short term needs. The long term planning and the concept of training actually being vocational education disappeared with very serious consequences."

\section{Respondent 4}

"So yes, I turned the machine off properly; I isolated this switch, you know. Understanding some of the important details of the theory of electrical motors as to why it goes around in circles when you turn the switch; that's not there... And the discussions I've had about quality of training, and people getting qualifications and they clearly can't do it, and had all the answers in the back of the book anyway."

They further argue that this has resulted in workers not really being sufficiently skilled, and this has been a major factor leading to New Zealand's poor labour productivity performance. Here, industry is also defined as being employers, and this is considered to be undesirable and an uneven distribution of power. The funding arrangements, from this perspective, are seen as faulty, in that they encourage the meeting of employers' short term needs, such as Occupational Health and Safety training, to the neglect of a broader educational grounding, to the detriment of the trainees, and ultimately the wider economy. This reflects squarely the Critical HRD/Stakeholder paradigm on several counts. It argues for a developmental approach to VET, with a focus on ensuring the quality of learning and teaching. This viewpoint however is underpinned by an understanding of the roles workplaces ought to play in the use of skills, as it is the use of adequate skills in appropriate ways that will lead to better economic performance. However, it is argued here, in keeping with the Critical HRD/Stakeholder perspective that in reality, the roles of employers and managers in 
Industry Training is often not carried out in keeping with appropriate quality standards; further, given the power imbalance in the workplace, there is no compulsion to adhere to such standards. This then results in inadequate attention to pedagogical issues, and limited learning and application. Finally, in keeping with the Critical HRD/Stakeholder paradigm, these respondents argue that the funding system and the types of quantitative indicators utilised serve to perpetuate these systemic weaknesses, whereby beneficial outcomes of Industry Training are only experienced by a few stakeholders, but not the majority - the trainees and the economy, making the Industry Training system a unitarist one.

The third perspective is the pluralist one, which attempts to balance the needs of trainees, employers and the wider labour market. The pedagogical perspective here is that Industry Training must meet certain criteria in terms of number of unit standards, in order to be considered educationally sound. However, they must also not be so cumbersome as to not meet the needs of employers and of kinaesthetic learners, for whom Industry Training is a second chance at success in formal education. The following quotations reveal this perspective:

\section{Respondent 1}

"So we wound up with very large qualifications, national qualifications. And the people that were going into the workplace and learning in this area aren't academic; they are kinaesthetic learners; they are people who learn by doing, have had poor success rates in formal education. And these large national certificates were a real barrier to them."

Respondent 2

"We've got smaller, more focused qualifications. They in turn are able to be broken down into limited credit programmes at the front end, and supplementary credit programmes at the back end to give a group of qualifications that are flexible...."

When this balance is achieved, Industry Training will meet the needs not only of learners, but of the labour market in the medium to long term, and not just the short term needs. Funding therefore has to be designed to encourage this balance, and this is the logic underpinning some of the performance indicators currently used, such as completion of qualifications within a designated timeframe. This reflects the Strategic HRD/VET logic in its attempt to accommodate and balance pluralist concerns. It 
varies somewhat from this paradigm however in two respects. One is that mutually beneficial outcomes for all stakeholders are not assumed to be natural outcomes of Industry Training; instead mutuality has to be achieved through the crafting of funding incentives to accommodate learner needs, and equity outcomes for disadvantaged workers, for example. The second point of departure is the attention to pedagogical concerns, which is assumed to exist under the paradigm. Instead, attempts to address particular learner needs are made systemically through the incentive structure to size qualifications into more manageable chunks. However, the logic expressed here also contains the same pitfalls of the Strategic HRD/VET paradigm. There is for example an absence of how shorted, more attainable qualifications will translate into the broader socio-economic outcomes for VET. Also, the role of employers and managers in accommodating and quality assuring VET delivery and assessment is treated as a given in the value creation process for Industry Training.

It is important to point out that although three different logic perspectives have been discussed here, that in reality, these analytical categories do not appear as clear-cut as the table may suggest, and in fact, some interviewees expressed over lapping perspectives. One common concern across all perspectives is with the multiplicity of Industry Training qualifications that now exist. All interviewees expressed the view that this has led to a great deal of confusion within the system for all stakeholders, who commonly appear to be at a loss as to how to make sense of them all, a confusion summed up by the following statement:

\section{Respondent 8}

"Something along the lines of the rationalisation of the qualifications within the tourism sector, some of the research indicating that there is 600 odd qualifications out there, and just confusion and lack of understanding as to what they all mean."

It appears then that the benefits from having national qualifications as signals of skills have been severely undermined in reality by the proliferation of qualifications, a systemic behaviour encouraged by the funding arrangements. The differing perspectives outlined here is a continuation of the debate on the use of numerical indicators for the evaluation of national HRD policies, and a number of questions can 
be raised, which have also been raised in the literature. Do qualifications equal skill, especially when there is a vast proliferation of qualifications with almost any range of flexible unit standards? (Antonacopoulou, 1999; Cox, 2007; Grugulis, 2003) . Given the ease of use of numerical data, (making it something that will always be used for policy evaluation purposes) what type of numerical data would better indicate the quality desired, and minimise the risk of quantity over quality? But perhaps more pertinent to the research issue is which policy prescription is correct, because each model proposes different formulae for Industry training success. Furthermore, each model carries a different definition of success, making evaluation challenging, as different stakeholders use different evaluative criteria.

Ultimately, the differing arguments presented here highlight again that there is a challenge between the espoused value of skill utilisation = productivity argument of the Strategic HRD/VET policy literature, and the counter arguments of the Critical HRD/Stakeholder logic. In the Strategic HRD/VET logic, the quality of skills that are developed is assumed. It is also assumed that there is a commonly held definition of quality skills, and that stakeholders involved will utilise the skills, and that barriers to skills usage are not addressed in this logic. However, as seen, in reality, many stakeholders from their varied political positions, do challenge these assumptions. Skills and skills utilisation appear to be terms that are subjectively defined and produced.

\section{c) Career Progression/Recognition/Portability}

The next values identified by these stakeholders were the values of career progression, recognition and portability, as portrayed in the following quotations:

\section{Respondent 14}

"...there is a demand from the staff; that's the other area where there could be demand from seeing a benefit in qualifications, and from the unions, that this is something they want; it's part of their career development, development on the job."

\section{Respondent 15}

“...workplace training is about recognition for your skills. Obviously you are in this job and you are doing it well; let's credentialise you for it. It is a big driver." 


\section{Respondent 12}

"So quite often it's saying, you've been at this job for 2 years now, it would be quite easy for you to have some evidence or workplace documentation and that will help you gain a qualification. Definitely that is a driver for people, that they want to do that."

"but I can apply it to my job, and it's going to make me more employable to my employer, and the outcome of that is that I am going to have better prospects that will benefit my family, me and family."

Respondent 13

"You've got individual coming through workplaces, through businesses; they're looking for some sort of career pathway for promotion;

\section{Respondent 11}

"...it is not just about them gaining the qualification; it is about them being on a pathway of learning; about gaining skills to be self-directed learners, and to see learning in progression, as a continuous part of working."

These have been grouped together as in the data, they appear as intertwining concepts. Career progression was viewed as increased employment mobility, associated with upskilling and therefore acquiring higher wages. Recognition of skills was seen as both systemic and personal; that individuals could gain national qualifications and therefore have their skills accredited, but also have the personal satisfaction of being recognised as a skilled worker. Portability was seen as the labour market benefit to be derived from acquiring recognised qualifications. The linking argument then is that having one's skills recognised through national qualifications would lead to portable skills, that result in career progression. This reflects the Strategic HRD/VET logic in terms of the mutually beneficial nature of VET outcomes that the logic is supposed to produce. Qualifications here are indicators of skills, an indicator that is recognised by trainees, their current and prospective employers, and the wider labour market. These qualifications produce these specific outcomes for trainees, but they are equally valuable to employers to the extent that they will willingly provide career progression affordances to trainees and higher wages. 
d) Access/Equity/Self-worth

The following quotations reveal that improved access to training for minorities and under-represented groups such as Maori, women and persons who were unsuccessfully in the traditional educational system remains an enduring value expected of the Industry Training system.

\section{Respondent 13}

"But there is also a lot of people within the travel industry who have no qualification, who have learnt on the job, and one of the value-adds for the travel industry is that we can say we can help credentialise your staff, in terms of rewarding them for what they do on an everyday basis, and they can get some recognition there."

\section{Respondent 6}

"New industry coverage, people doing training who didn't get training before, particularly Maori, was very important."

Respondent 14

"...there is a lot of pride in achieving these qualifications on the job..."

"But doing a good job, it is part of your self worth, your self value."

This is reflective of the Strategic HRD/VET logic that results in these mutually beneficial social outcomes, and the belief that access to learning opportunities is a basic human right in order to unlock human potential and foster self actualisation. This further reflects the logic's assumption that the acquisition of qualifications, irrespective of the kind and quality of these qualifications, is an appropriate proxy for skills, and that their acquisition automatically lead to socio-economic progress.

\section{Value to these stakeholders}

Before moving on to the next research question, it is important to discuss not only how these stakeholders view value in relation to employers and trainees, but also what is the value to them as players in the Industry Training System (Smelt, 1995). The following quotations reveal some of the political considerations that are at play which impacts the valuing of Industry Training. 


\section{Respondent 5}

"In 1992, the Minister of State Services, Bill Birch ... asked the State Services Commission to develop a public sector response to the government's 1992 Industry Training Strategy...Ministers of State Services, particularly Mr Birch when he was Minister, but recently Trevor Mallard, have been quite outspoken in their support for Industry Training and its importance, and have wanted SSC to give that message to the departments, that this is important, and we expect you to participate."

\section{Respondent 3}

"There was a tendency with the Ministers who were there that they wanted to know about success, so Modern Apprenticeships was one of the flagships of the Clark government. They wanted to be able to stand up at election time and say Look what we've done, new apprenticeships blah, blah, blah. So Helen Clark would just make up the number she wanted to add to her election promise on her way to give a speech. And our people would be at the speech and say oh so that's what we are going to be doing. So it was very political and very much success story."

The quotations speak to the influence of formal political power's impact on Industry Training, but there are also other forms of political power among these stakeholders that have influence on the valuing process. As indicated, at the Ministerial level, numbers are used as a persuasive tool to either win votes or influence support for certain policy decisions. Unions, having lost most of their influence with the passing of the Employment Contracts Act, want to maintain or regain waning relevance through training/concern for wages and progression. ITOs need funding to survive and thrive, and as indicated earlier, are incentivised to increase the quantity of their training arrangements, which can be at the expense of quality considerations. Industry bodies' concerns in relation to Industry Training appear to vary based on the sector in question. For the tourism sector, there are concerns about skills shortages, retention, and so Industry Training's value is seen in relation to those concerns. For the State Sector, as the quotations above suggest, the valuing of Industry Training can be influenced by Ministerial concerns about Industry Training. This mirrors the concerns of the Critical HRD/Stakeholder perspective, which argues that the Strategic HR/VET logic of alignment of roles of VET stakeholders is faulty; these roles can be competing and defined by vested interests, particularly at the level of institutions that are originally designed to facilitate VET implementation. In other words, the Strategic HRD/VET logic takes for granted the facilitatory nature of these institutions, such as 
ITOs, and VET policy evaluation can be enriched through a better understanding of how these institutions impact the creation of VET outcomes.

All the respondents to some extent have a vested interest in the positions that they take in relation to the valuing of Industry Training. Additionally, all the respondents, by training and experience, are what one could consider HR experts. They all had extensive experience in the field, and therefore views expressed reflect an allegiance to the training field and its benefits. This then translates into a constant need to persuade and to sell training benefits, and to even use their HR knowledge as a leveraging point in persuasive arguments with other stakeholders. The following story recounted by a respondent encapsulates this type of persuasive argument:

\section{Respondent 13}

"I had a meeting with some highly educated, more doctorates in the room than you could shake a stick at. And I asked them the question about whether or not we should be investing in numeracy and literacy initiatives in the sector. And of course the immediate response from people who are

running these major was "Oh no, we are a better type of person. There are a lot of highly qualified people here." So I said, "Well humour me please. I would just like to ask you two questions. Can I have a show of hands around the room whether or not you could demonstrate a high level competency in reading a balance sheet?" And there is a sort of nervous shuffle around the room. "You've been tasked with putting forward the business case for the investment in ICT in your sector. Can I please have a show of hands around the room about your capability to do that?" And so there is another nervous shuffle...."

So they are more likely to support the view that Industry Training is beneficial to organisations, and to view persons who do not share that perspective as being uninformed. If this viewpoint is credible, then this presents a challenge for VET policy implementation, as a HR practitioners' mindset and training appears to be critical to successful VET engagement. This is an issue that is explored further in this chapter when the role of HR champions in the VET engagement is examined.

\section{How is value from Industry Training determined by its stakeholders?}

This research question seeks to unearth the evaluative practices of these stakeholders. The question aims to understand how these respondents determine the extent to which 
their anticipated impacts from Industry Training were realised. The analysis of the responses revealed a tension among these stakeholders between the use of official and often quantitative evaluative data and the use of their experience as practitioners in the field. This is reflective of the tensions between the two paradigms in the analytical framework. On one hand, those who advocated the views of the Strategic HRD/VET policy logic tended to also cite the use of quantitative evaluative data as their means of determining the value of Industry Training. On the other hand, those who expressed views which were more critical of the Industry Training system tended to use their experience or stories as their means of evaluation.

In the case of quantitative outcomes, primarily numbers of trainees, numerical indicators were often the means of evaluation. So numbers are simultaneously an outcome and an evaluative device. This, as already indicated, is predicated on the performance reporting system utilises to monitor the Industry Training system, as the following statement shows:

\section{Respondent 1}

“...TEC in 2007, where the move went from funding rules, regulations and profiles and charters, to investment plans, outcome-focused or results-focused education, which are based on key performance indicators that are proxies for what we think the industry needs. Things like completions of national qualifications, completion of national qualifications within a duration that has been set by the ITO, those sorts of things."

Skills, career progression, access, equity and recognition were also assessed by stakeholders aligned to the Strategic HRD/VET policy logic using quantitative indicators. This is not surprising as the competency movement in training out of which Industry Training was born, is based on the premise that skills through a national qualifications framework could be made visible, objective and quantifiable. Career progression is deemed to be made visible, objective and quantifiable via completion and movement up the qualifications framework, in the case of Industry Training, through the various levels. The same principle is also applied when evaluating access and equity outcomes in relation to minority groups. Recognition is also then easily determined by the system, as trainees gained a record of achievement. 
Respondents who expressed criticism of the use of quantitative indicators did so, on the basis that their experience as practitioners leads them to an assessment and judgement that often runs counter to the Strategic HRD/VET doctrine. The following quotations are some examples:

\section{Respondent 14}

"I heard of this company that I was told invested heavily in training. And they did, but all of it was Occupational Health and Safety. Nothing else. And to make matters worse, most of the staff were Maori. So these poor fellows had no opportunity to improve themselves, to really engage."

Respondent 5

"I have serious questions about the assessment process involved. For example, I had to work with a Personal Assistant who didn't have a clue about how to do her job. Yet she had an Industry Training qualification in her area. I just don't know."

All of the these quotations raise a number of questions - questions about whether equity and access can be measured by participation rate only, whether qualification = skill, whether in reality qualifications lead to career progression, particularly as measured by wage effects. But the common basis of these conclusions was the respondents' experience when interfacing with the Industry Training system. This is not to say that the conclusion drawn by these respondents are necessarily incorrect. For example, since the interviews were conducted, new research conducted in 2009 by Department of Labour/Statistics New Zealand on the links between Industry Training and improved earnings showed that Industry Training only resulted in significant improvements in earnings when trainees complete at Levels 4 and above, and that white, young males benefited from greater wage effects than other categories of trainees (Crichton, 2009). This then is an indicator that those who argue that Industry Training has little effect on trainees' wages and career progress may not be off the mark. This also is in keeping with other research conducted on VET elsewhere where it is argued that the education gospel has been exaggerated, and that while education does lead to greater mobility, it does not do so equally (Wolf, 2002).

However the fact that stakeholders rely on their experience as a major means of evaluation is significant, as while one can argue (as outlined earlier) that the use of 
quantitative indicators can prove problematic, the reliance on experience is also equally problematic, as it is also tends to be highly subjective and political. What the data also highlighted was the tendency among stakeholders to use their experiences, and that of their colleagues, as the basis of their evaluations, irrespective of which paradigm their views seemed to align with. These then tend to become stories, that are then used as persuasive devices in the bid to gain political traction. The following statements exemplify this:

\section{Respondent 10}

"Only anecdotal, and it has improved...I mean, these stories I've had from numerous employers...."

\section{Respondent 2}

"And I guess some of the evidence we see, which is anecdotal, there is a lot of pride in achieving these qualifications on the job...."

\section{Respondent 3}

“...but they will tell you stories about what it means to individual firms...You will get all these stories about how it helps their training systems... So there is the public good, and the private good."

\section{Respondent 9}

"But in terms of proving the case for more funding, and it having some effect, so what we did we relied on stories. So we got stories about individual companies and how it was having an effect, and these are quite powerful with politicians."

What then may be occurring is that as stakeholders interface and share their experiences, these become stories that are repeated and become artefacts of the system or examples of a particular viewpoint. The following story for example, was repeated by three different respondents:

\section{Respondent 10}

“...___ was at the ITO and her predecessor will tell the same story. Industry basically old knarly bastards who knew what they wanted and demanded it now. Hilarious stories. But what they did was created a training environments by helping those organisations meet the accident and compensation requirements, health and safety requirements. So they'd give them small chunks of training to help them reduce their liability to the 
government. And then what they found was that some companies would come back and say that was good, what can you do next? And I used to keep hearing those stories. You give them something, you show them it works, and then what else can you do for me? What else have you got? Well, I'm glad you asked. I just love that story about how you get into a hard-nosed non-training environment with training, and then you get into other areas."

This is similar to what one finds in the Industry Training policy literature. The Brinkerhoff-led study on returns of Industry Training in the Agriculture sector has been influential in the use of success cases (Hardy, 2008). Consequently, there has been an increase in the use of 'cases' as a means of determining and selling how Industry Training leads to increased skill utilisation, and other organisational benefits. For example, numerous stories, commonly called cases are cited on the use of Industry Training to improve workplace productivity. The challenge is however that it is unclear how these success 'cases' are selected. It can possibly be argued that the use of the word 'case' to describe these stories gives it credibility and an air of empirical authenticity. But it however should not be equated with academically defined case studies, as all these 'cases' are examples of success in Industry Training, and never highlights any failures. The same can be said of how some respondents referred to 'research', that the reference to the term 'research' provides validation for a certain viewpoint, and then becomes a selling device for Industry Training advocates.

\section{Respondent 13}

"...we go back to that research project that we are doing in order to better sell that, to have research that says invest and you will see a return."

\section{Respondent 15}

"We know that research has been done around the productivity output of supervisors. If you train and assess a first line manager or supervisor, the amount of productivity that you gain from their confidence, from their needing less supervision, from them being able to problem-solve, and be smarter in the way they work, we know that there is a key area of productivity that comes from the value of that qualification.

The challenge is that the selection of the stories tend to be the successful ones, or at least the story that supports the opinion of the person in question. 
It should also be pointed out that the reliance on experience and practitioner wisdom as a means of evaluation is also a response to the limited empirical research and research funding available. Almost all respondents noted that lack of emphasis on research, as exemplified by this comment from one respondent:

\section{Respondent 6}

"Evaluation has not been done at either the individual level, firm level or a country level. There are big gaps in what we know about why, whether it is good or not."

Most bemoaned the need for more research to be done, an issue that was being addressed as more ITOs develop internal research capability. However, these findings highlight the evaluation process as subjective and value-laden. Evaluative data, whether it is quantitative or experiential, needs to be questioned in terms of the motives and value positions of its users. This highlights the gaps in both paradigms in the analytical framework. The Strategic HRD/VET logic's preference for the use of certain quantitative indicators as proxies for broader VET outcomes has its shortcomings. The link between how qualification attainment fosters career progression and increased productivity is unclear, not understood, and potentially may not even exist. The Critical HRD/Stakeholder logic offers this kind of critique, but this critique appears more often than not to be based on personal experiences and hunches. The absence of the use of robust research to underpin these arguments, weakens the logic, and also run the risk of being used for political purposes, thereby not representing an improvement in the Strategic HRD/VET logic's approach to VET evaluation.

On a final note on how value is determined, none of the respondents were able to indicate how they determined the value of portability of Industry Training, neither by way of their experience or the use of any form of evaluative research. Portability then appears to be an enduring outcome that is expected from Industry Training, but one that has not been subjected to either formal or informal evaluation. This reflects one of the biggest gaps in the Strategic HRD/VET logic, as portability of qualifications is espoused as one of the mutually beneficial outcomes for both trainees and employers, and by extension the wider economy. In the face of increased job insecurity caused for labour market and economic deregulation, portability of workers' skills was to be 
their new bargaining chip in the labour market. The lack of mechanism to measure this outcome represents a major flaw and collapse in the logic.

\section{How is value created for different stakeholders from engagement in the}

\section{Industry Training Strategy?}

This research also wanted to unearth the processes and factors that led to the creation of value for these stakeholders. By extension, these also explain the factors that lead to engagement or lack of engagement on the part of stakeholders. The interview data revealed six major factors that lead to the creation of value for these stakeholders (See Figure 5.1).

Figure 5.1 - Factors leading to Value Creation from Industry Training: policymakers and industry interest group perspectives

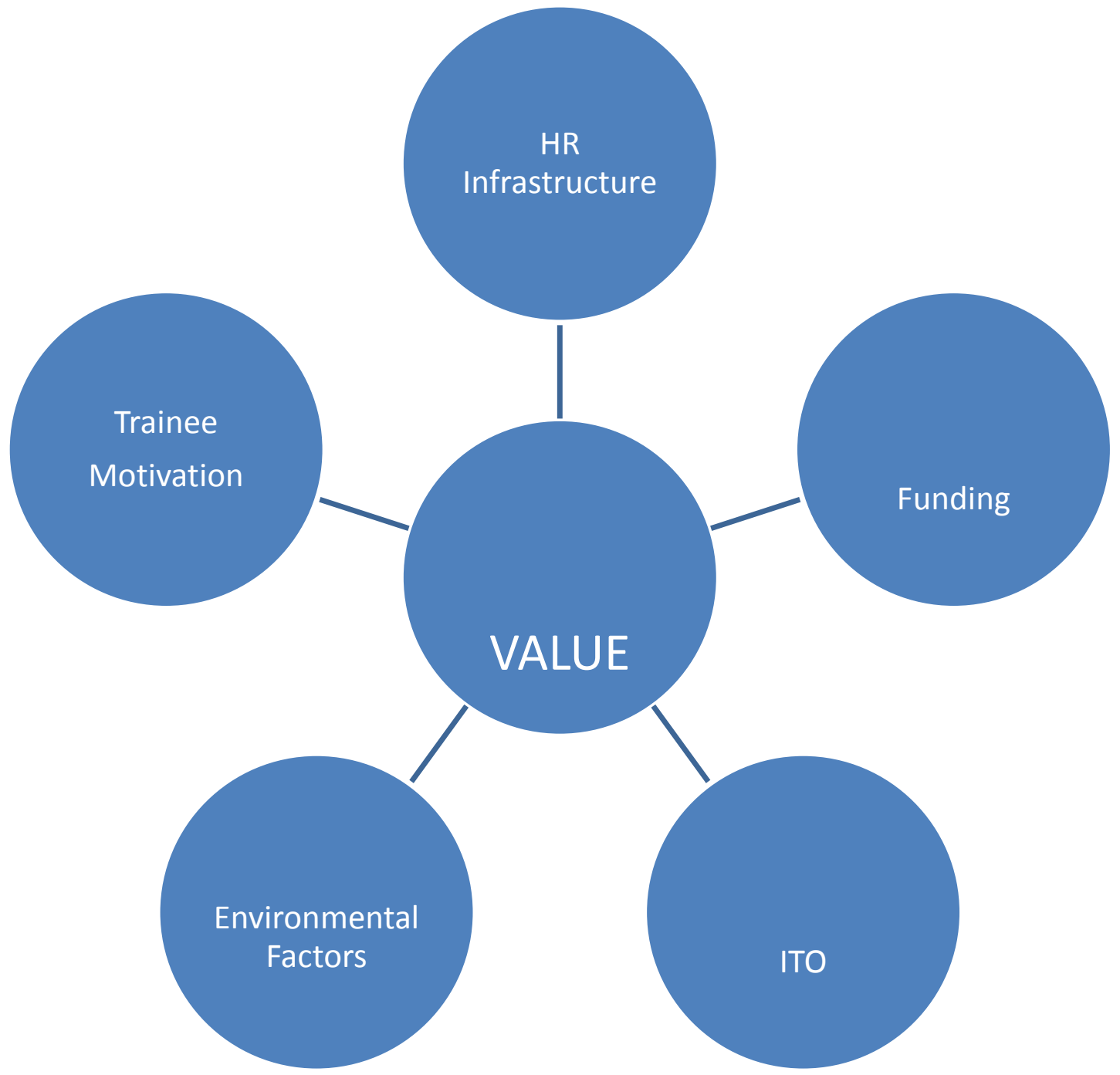




\section{a) HR Infrastructure}

The existence of an HR infrastructure was identified by most interviewees as essential for creating value from Industry Training, both at the organizational level and the sectoral level. One of the characteristics of the HR Infrastructure identified by respondents were the presence of champions, persons within the organization or the sector who believed in the potential of Industry Training and were prepared to undertake its implementation, as the following quote shows:

\section{Respondent 8}

"And so what happened was they were slower in getting into training, because they had to have an industry group of enthusiasts that set the industry training organisation up, made the relationships with NZQA, learned about unit standards and how it all worked..."

Another characteristic of the HR infrastructure identified was a history and culture of training investment whether in the sector or in the organization. Hence not surprisingly, respondents noted that sectors that had an established history of Apprenticeships prior to 1992 when the Industry Training Act was passed, and organisations that already had quite structured training programmes more easily engaged in and gained benefit from Industry Training. The following quotations highlight some of these points:

\section{Respondent 12}

"Now same scenario is a medium sized company, larger NZ employer. We are probably talking around 1000 employees (they are still tiny little businesses on a global scale). But they have got an HR and Training capability inside which actually supports (and a HRM and HRD system) them keeping people employed and developing them in quite a structured way that a SME doesn't have. These people can't engage, they've got Mom and Pops businesses; they are struggling to survive; they don't have that capability in HRD...."

\section{Respondent 16}

"It could be that they've got a structured training programme and they have been able to align the qualifications to the training programme that they have. So it hasn't been that much extra work from them; they were going to be doing the training anyway, and actually there is a value-add for the trainee as they get a qualification." 
The above quotations also highlight the third characteristic of the HR Infrastructure which is HR capability. HR capability appears to be defined by respondents as the knowledge of how skills can be utilised to create value such as increased productivity for example. It is also defined as linked to a wider management capability in terms of understanding one's sector, and how skills combine with technology, and quality management practices to add value, as the following quotations exemplify:

\section{Respondent 4}

"An informed industry is an industry that understands, particularly those that have got lots of SMEs, that understands the strategic value to their industry from education and training. And not just training for their employees, but their own professional development. The education investment, in research and development, in technology transfer, the whole 9 yards. That's the industry that feeds into a strategic training plan."

\section{Respondent 6}

"And the only way to drive productivity is a good combination of skills, technology and management capability - business strategy can be folded into management capability if you like."

\section{Respondent 14}

"...there is almost no point in a workplace unless you have a management system that is capable of utilising the skills that have been developed."

\section{Respondent 5}

“...NZ's management competency profile in terms of the OECD is not that great. There is not a lot of good basic management skills even in some quite senior positions."

The data aligns with research findings elsewhere, which shows a direct correlation between firm size, presence of HRD capability and culture and greater investment in training, including VET (Ashton, 2002, 2004; Becton \& Graetz, 2001). The data also shows that HRD and management capability is both the answer and the problem as far as skills deployment is concerned; its presence is a necessary input to the creation of value from skills it appears, and its absence is the reason for under-investment in skills and poor utilisation. These findings also raise issues for the access and equity goals for VET investment. Large organisations and sectors with strong training traditions have greater capacity to align their training programmes to the Industry Training system. This does not significantly improve accessibility to VET for 
disadvantaged groups, as these firms and sectors already provided access to VET (Tight, 2002). This supports workplace learning research as well as the Critical HRD/Stakeholder perspective that the benefit of VET to learners is dependent on workplace affordances (Vaughan et al, 2011).

\section{b) Government Funding}

All participants, barring none, expressed the view that without government funding, Industry Training would not have happened, and that there would be far less investment in employee training and development in New Zealand. Therefore it incentivised training investment. However, given that the lack of HR infrastructure can create a disadvantage to Industry Training engagement, the structure of the funding arrangements then becomes even more important incentivising the kind of outcomes desired from the system. And the performance reporting system has assisted in this regard, for example, increasing the numbers of Maori and Pacific Islanders participating in Industry Training, in keeping with equity and access values. However, the history of Industry Training funding also reveals that with demand-led philosophy underpinning the structure of funding, some sectors with longer histories of training have ended up receiving more funding over time (N. Green et al., 2003).

Also like HR infrastructure, government funding, was viewed as both saviour and the devil. As pointed out, respondents view it as driving training investment, but also, in combination with the performance reporting system, creating perverse incentives, such as the proliferation of qualifications, and particularly low level qualifications (World Class skills: implementing the Leitch review of skills in England, 2007). The Strategic HRD/VET logic views government VET investment as a means to the desired end results, and makes no allowances for potential perversion. Through the Critical HRD/Stakeholder lens, it can be argued that funding at least in some instances, is not only the means to achieve outcomes but can be an end in itself - for example receipt of maximum levels of funding to maintain financial viability of an ITO. This paradigm can take into account how different values among stakeholders can alter behaviour in response to system incentives. 


\section{c) ITOs}

The quality of the operations of ITOs was also identified as being critical to the creation of value from Industry Training. What was revealed that the role of ITOs particularly since 2002 with the increased emphasis on their strategic leadership function has increased in complexity, something which is reflected in the increase is staff size and operations of the ITOs interviewed (Industry Training skills leadership: the role of industry training organisations in shaping skills in the New Zealand economy, 2006). In order to carry out their official stated role, ITOs appear to have to be adept at the following:

- Building trust and authority within their sectors:

○ Respondent 12 - "From an ITO's perspective, it was building that trust to get the industry to see the value of developing qualifications for their industry and how it was going to improve the skills of their staff and inevitably their bottom-line.... Once the qualifications were developed - which is an on-going thing for us as an ITO - making and getting them to see how it can be valuable and useful for them, in terms of upskilling their staff, and actually putting some money towards a training budget that will support Industry Training."

- Marketing their role and services:

○ Respondent 15 - "We do a lot of cold calling. We get in contact with workplaces to see if they are interested in training for their staff. While they might meet with you, it can be quite difficult to convert them into all these things that we're saying."

- Providing support at the sector, organisational and individual trainee levels through collaboration:

- Respondent 13 - "If you look at the nexus role that ITOs hold between these range of stakeholders, and industry, government and other tertiaries and then the businesses themselves, the customer - it's an incredibly complex range of stakeholders."

○ Respondent 9 - "...they are boundary organisations; they live on the boundary of education and training, the labour market and skills, of employers and employees, of industry and government. They are network, connecting organisations; it is just part of what they do; they have to try and balance those competing interests to the best of their ability." 
Most respondents pointed out that carrying out these roles is very challenging for ITOs, as one, there are a number of varied stakeholders to appease, as this quote highlights:

\section{Respondent 3}

"The long term goal for industry training must be for the ITOs to meet the skill need of their industry. So they have to respond to their employers. What ITOs have to do is keep the employers reasonably happy, one, and keep the TEC reasonably happy, and often there is a government ministry or department that they are responsible to, such as ITO for historical reasons need to keep the Ministry of happy; regulatory ministries and their goals will be different and the ITOs must balance those off. And we have seen ITOs in trouble when they haven't got the balance right."

Two, as highlighted earlier, the performance indicators by which they are assessed and receive funding can create certain behaviours which can run counter to these roles. So for example, it is easier to collaborate with some organisations, for instance those with a greater proportion of large employers, and a strong training culture, and not others, which may in fact have greater need of Industry Training. Increasing trainee numbers may not always lead down the same path as increased equity or even increased productivity. This again highlights that stakeholders' values and perspectives differ, thus making the evaluative process political and value-laden, a process that is fraught with conflict that has to be resolved.

\section{d) Environmental Factors}

The wider environment was also identified as impacting the valuing of Industry Training by stakeholders. Two environmental factors were highlighted by interviewees:

- The labour market. The level of unemployment was identified as having an impact on the perceived value of Industry Training. When unemployment is low, trainees have little incentive to engage in Industry Training or education generally, as they may be able to gain well paid employment without these qualifications. This view is captured by the following quote from a respondent: 


\section{Respondent 4}

"The situation that we hit a couple of years ago were the jobs; people were just waiting to give people jobs and better jobs; people were getting jobs that they weren't even really skilled for. But they had done some training and it wasn't worth them finishing because they had a job. In times like that, that is a response from individuals, whether it is in their interest in the long term or not."

Another factor, which seemed to be the case with the tourism sector, is perception of the industry. Tourism suffers from seasonal, often low-paid employment which acts as a disincentive to training investment. What appears to be the converse to this for the tourism sector however is the occurrence of big tourism drawing cards, the most significant one now being World Cup Rugby, to create the need for an influx of trained workers, which then becomes a major incentive to invest in Industry Training.

- The regulatory environment. Health and Safety and other types of certification requirements for various jobs were identified as being instrumental in creating value from Industry Training. This was seen as beneficial, as it became the window of opportunity to increase training in some sectors. Conversely, some respondents noted that it also meant that valuing of Industry Training in some organisations became confined only to this type of training, therefore distorting numbers and limiting access and equity at a qualitative level. This is similar to findings from other research, particularly on employer motivation to invest in VET, which showed a propensity to limit VET investment to training linked to legal requirements for employee certification (C. Smith \& Ridoutt, 2007).

These may not by any means be the only environmental factors that create or inhibit value creation from Industry Training. What is important to note however is that the impact of environmental factors is not taken into account in the Strategic HRD/VET logic. Taking the Critical HRD/Stakeholder perspective then appears that environmental factors impinge on stakeholders' values and perceptions, and ultimately the value they believe they derive from Industry Training investment. 


\section{e) Trainee Motivation}

Respondents from ITOs noted that motivation level of trainees themselves was also a key factor in the extent to which trainee derive value and are able to complete Industry Training qualifications, as the following quote suggests:

\section{Respondent 11}

"The trainee needs to be quite motivated, and if they are not motivated, they need to have somebody within the workplace who will support them and motivate them. And those are the sort of places where we get the best feedback because they can see the result."

There are two factors highlighted from the interviews concerning trainee motivation. The first is the trainee's own assessment of the labour market, and the extent to which it is worth investing in any kind of education and training, including Industry Training. The other factor is the extent to which the trainee is either personally motivated, and values training for whatever reasons, or the extent to which within the workplace there is motivating support provided, in whatever form. At the organisational level then, the level of agency of the trainees as a stakeholder in the process, as well as their interaction with other organisational stakeholders, such as supervisors, are deemed critical to the creation of value. However, in the Strategic HRD/VET logic, this is largely ignored.

\section{Synthesis}

Table 5.2 summarises the major findings from interviewees representing policymakers and industry interest groups. In response to the main research question, how do these stakeholders evaluate the impact of Industry Training, as an example of a VET policy - they do so subjectively in the main. They struggle among the availability of empirical data often juxtaposed against their subjective and contextualised experiences, formal policy positions, their own agendas/values and that of other stakeholders. 


\begin{tabular}{|c|c|c|}
\hline \multicolumn{3}{|c|}{$\begin{array}{c}\text { TABLE 5.2 - Summary of Findings - Policymakers and Industry Interest } \\
\text { Groups }\end{array}$} \\
\hline Value Identified & How determined & How created \\
\hline Quantitative Outcomes & Quantitative Indicators & $\begin{array}{l}\text { Funding } \\
\text { arrangements/Performance } \\
\text { reporting system }\end{array}$ \\
\hline Skills/Skills Utilisation & $\begin{array}{ll}\text { - } & \text { Limited formal } \\
& \text { research } \\
\text { - } & \text { Experience } \\
\text { - } & \text { Cases } \\
\text { - } & \text { Stories }\end{array}$ & HR Infrastructure \\
\hline Career Progression/Wages & Quantitative Indicators & $\begin{array}{lr}\text { Funding } & \text { arrangements/ } \\
\text { Performance } & \text { reporting } \\
\text { system } & \end{array}$ \\
\hline Recognition & $\begin{array}{l}\text { - Qualifications } \\
\text { Framework } \\
\text { - Unsure } \\
\text { recognition in the } \\
\text { labour market }\end{array}$ & Qualifications Framework \\
\hline Portability & $\begin{array}{l}\text { Unsure of portability in } \\
\text { wider labour market }\end{array}$ & Qualifications Framework \\
\hline Access/Equity & $\begin{array}{ll}\text { Quantitative } \\
\text { Indicators } \\
\text { - Experience }\end{array}$ & $\begin{array}{lr}\text { Funding } & \text { Arrangements/ } \\
\text { Performance } & \text { reporting } \\
\text { system } & \end{array}$ \\
\hline Self-worth & Experience & HR Infrastructure \\
\hline
\end{tabular}

What then emerges is that there is a more complex logic at work in the Industry Training that creates both what stakeholders view as positive as well as negative outcomes. This is depicted in the logic model in Figure 5. 2 
Figure 5.2 - Programme Logic for Value Creation from Industry Training Perspectives of Policymakers and Industry Interest Groups

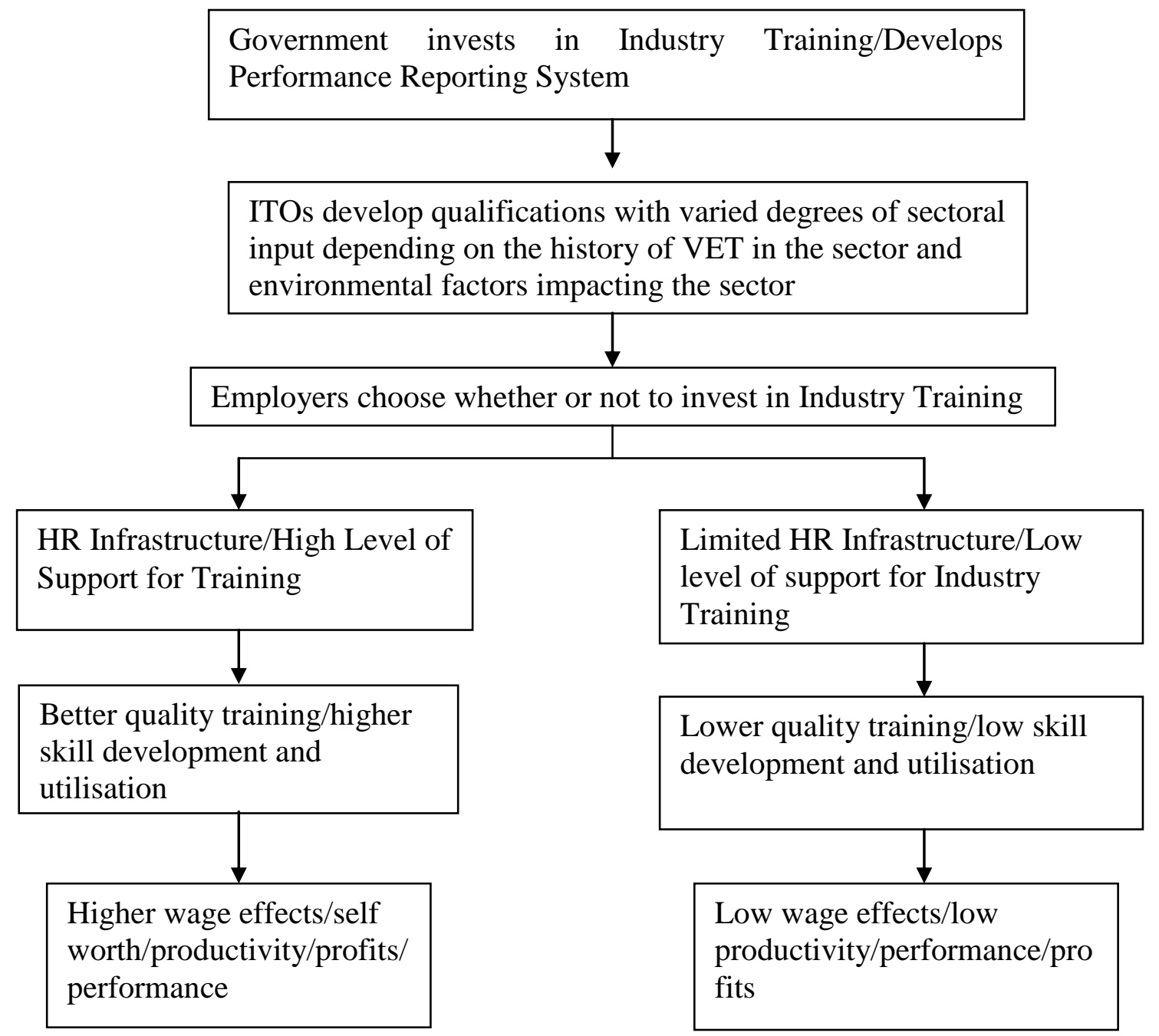

This logic then supports to an extent the Critical HRD/Stakeholder logic in that different stakeholders have different values which drive how they engage in Industry Training. Some of the main drivers are the level of HR infrastructure, and Industry Training support at the sectoral and organisational levels, as well as how stakeholders respond to the funding incentives. This then affects the quality and accessibility of Industry Training, as well as the extent to which Industry Training translates into skill utilisation and other beneficial outcomes. This does not however debunk the Strategic HRD/VET logic; rather, the new logic that emerged from this data set is an expanded, more complex inter-relationship among different factors, that can either hinder or create value creation in VET engagement. 


\section{CHAPTER 6 - DATA ANALYSIS - FINDINGS FROM TOURISM ORGANISATIONS}

\section{Background to the Tourism Sector's Engagement in Industry Training}

The tourism sector in New Zealand encompasses Maori tourism, adventure tourism, local attractions, information centres and tours operations (Career maps and pathways, report, 2008). It is also widely accepted that the sector has overlaps with other sectors, particularly the hospitality, retail, travel, transportation and personal services sector (such as spa services). The tourism and hospitality sectors combined are a major industry in the New Zealand economy. It is estimated that $10 \%$ of the labour force is employed in these sectors. Also, domestic and international tourists combined contribute NZ\$18.6 billion dollars to the economy annually (Career maps and pathways, report, 2008).

It is estimated that around 104,000 persons are employed in tourism organisations. The sector faces a number of human resource challenges. First, the tourism product offering is still largely seasonal, which leads to seasonality in employment in the sector, and which diminished the profile of the sector as one providing favourable career opportunities. The sector also has a large number of SMEs, and a high percentage of the tourism workforce is comprised of migrant workers (Tourism and hospitality workforce strategy, 2006).

The tourism sector generally did not have a history of high levels of investment in training and development, and was one of the sectors that saw an increase in the provision of workplace training with the introduction of the Industry Training Act and Fund, and the establishment of the ATTTO. The level of penetration of Industry Training in the tourism sector, while it has improved, remains low relative to the size of the sector, with an average of just under 2000 tourism Industry Training trainees a year. Much of the Industry Training provided is at the lower levels of the qualifications framework, with a preference for LCPs, and most of the training concentrated at Levels 2 and 3 on the NQF (ATTTO annual report: setting the standard for training in aviation, tourism, travel and museums, 2007). 


\section{Background to the Tourism Organisations}

Background to Company A

Company A was a small and successful Maori business involved in nature tourism, offering a variety of guided tours as well as accommodation and food and beverage services to a more limited extent. The staff complement consisted of 1 full-time manager, 3 full-time guides and 1 part-time guides. The employer/owner was not involved in the daily operations, but is the one who established the business, its business plan, recruited the staff, initiated Industry Training engagement and assisted in facilitating the training.

The business at the time of the research was 8 years old, and according to the owner, had undertaken informal training of its staff from the outset. Typically in this sector, these jobs are considered low skill jobs, in which on the job training was the only available staff development opportunity available. Two years prior to the research, the owner made the decision to improve the quality of training by offering the staff formal training in Customer Service and Guiding at the NVQ Level 3. This was at the time of the research a one-off engagement in Industry Training. The owner worked closely with the Industry Training organisation which provided a trainer/assessor, who tailored the qualification to suit the needs of the Company. The trainer along with the owner facilitated the training over 3 weekend seminars conducted at 3 month intervals in a manner typical with Maori learning style. Additionally, trainees were expected to complete assignments for assessment on their own, although all reported that they depended on peer support to complete these. Interviews were conducted with the business owner, the full-time manager who was also a trainee and female and 3 trainees -2 female and 1 male. All the females interviewed were full-time staff, who had been employed to the organisation at the outset, and who possessed no other tertiary qualifications prior to undertaking the Industry Training qualification. The male trainee was a part-time guide who had other tertiary qualifications, and a fulltime career in a different field. As noted in Appendix A, the four respondents from this company are numbered respondent 17 to 20 for confidentiality purposes. 
Company B

Company B was a successful tourism attraction company that offers food and beverage services, has been in operation for over 40 years at the time of the research, and is a part of a group of companies.

Company B can be described as an extensive user of Industry Training, having been on the organisations to pioneer its implementation in the 1990s. All of its employees have or were currently engaged in Industry Training. Below is Table which outlines how Industry Training is used in the Company.

\begin{tabular}{|l|l|l|}
\hline \multicolumn{3}{|c|}{ TABLE 6.1 - Industry Training Qualifications pursued in Company B } \\
\hline Type of Respondent & Industry Qualification & Target Employees \\
\hline All employees & $\begin{array}{l}\text { Limited Credit Orientation } \\
\text { Programme (focuses on } \\
\text { Customer Service) }\end{array}$ & $\begin{array}{l}\text { All employees (must } \\
\text { successfully complete as } \\
\text { part of probationary } \\
\text { period) }\end{array}$ \\
\hline Junior Staff & $\begin{array}{l}\text { Hospitality Training NVQ } \\
\text { Levels 2 - 4 }\end{array}$ & Food and Beverage Staff \\
\cline { 2 - 3 } & $\begin{array}{l}\text { Engineering NVQ Levels } \\
2-4\end{array}$ & Technical Staff \\
\cline { 2 - 4 } & $\begin{array}{l}\text { Occupational Health and } \\
\text { Safety NVQ Levels 2 - 3 }\end{array}$ & $\begin{array}{l}\text { Technical Staff (staff who } \\
\text { manage the attractions) }\end{array}$ \\
\hline potential) & $\begin{array}{l}\text { First Line Management } \\
\text { and Leadership } \\
\text { Development NVQ Level } \\
4\end{array}$ & $\begin{array}{l}\text { Managers and emerging } \\
\text { managers }\end{array}$ \\
\hline
\end{tabular}

The Industry training qualifications pursued in the areas of Hospitality Training, Engineering and Occupational Health and Safety are typical for these occupational groups in the tourism sector, and in the engineering field. However, the Limited Credit orientation programme is atypical of the sector. Additionally, according to data gathered from the Industry Training organisation, most managers within the tourism 
sector are not formally trained in management, given that most tourism organisations are manager operated, family-owned small businesses. So the provision of management training in Company B is also not typical of the tourism sector.

The training programmes are directly aligned to the organisational structure and the career paths within the organisation, with entry level orientation programmes in Customer Service for all employees irrespective of previous qualifications and training, technical training for the engineering, food and beverage and other technical staff, and managerial training for its managers.

The organisation had the internal capacity to undertake much of its own course development, training facilitation and assessment, with these persons, a total of 25 across the group of companies, carrying out these roles in addition to their full time duties. The training has a small classroom based component, but the majority is carried out on the job and/or through individual work assignments. These are typically demonstrated on the job and validated by managers and assessors. The exception is the First Line Management and Leadership Development programmes, which involved written project assignments being submitted by trainees for assessment.

As it relates to the findings, no notable differences in perspectives were observed between the organisations in terms of how they responded to the questions, in spite of the differences in size and implementation.

Findings from data collected from employers, managers, supervisors and Training managers are analysed separately from the data collected from trainees, in order to compare managerial perspectives with trainees' perspectives. As outlined in Appendix A, these interviewees (totalling 6) are listed as respondents 21 to 26 for confidentiality purposes. 


\section{MANAGERIAL PERSPECTIVES}

\section{What value do managers/employers derive from engagement in Industry}

\section{Training?}

In both organisations, managers and employers identified a) skills and skills utilisation, b) employee retention/employer reputation, c) creation of a learning culture and increased access to learning, d) equity and employee self confidence, as the values they derived from engagement in Industry Training.

a) Skills and skill utilisation

Trainees' acquisition of skills was, not surprisingly, viewed as one of the main values to be derived from engagement in Industry Training, as the following quotations reveal:

Company A:

Respondent 17

"But we believe we can improve profitability by increasing the value in the product that we offer. That involves improving the quality of everything we do, including the delivery of the guides and the staff, just increasing their professionalism, increasing their knowledge. As they are able to offer and provide more to our clients, we are able to charge more; clients are getting a better product, are getting more, and they are prepared to pay for more. And there is a direct correlation in my opinion between the two."

Respondent 18

"It is important for our guides to have training. I mean, it is a benefit for them as well as for us. They had to have training of some sort."

\section{Company B:}

Respondent 21

"To develop, to grow our own middle management."

Respondent 22

"And it is quite good, as these guys can get upskilled quite easily in what we do, and how we do things." 


\section{Respondent 23}

"Once you know that everyone who is coming through the door is getting trained at the same level, consistent training."

From the managerial perspective, a major purpose of Industry Training was to ensure the maintenance of performance standards. Industry Training played a vital role in orienting trainees to the performance culture of the organisation - "...how we do things" - and in particular, to each organisation's customer service standards. In both organisations, managers expressed the view that the delivery of consistent quality customer service was key to maintaining their reputation and profitability. The maintenance of consistency was then seen as the unique value of Industry Training as opposed to other forms of in-house training. Respondents cited that the structure provided by the Industry Training qualification meant that training was consistently delivered to a particular standard, which in turn enhanced their service quality and client satisfaction levels. Skills, for these respondents, was defined quite broadly, covering technical aptitude, as well as general knowledge and 'know-how' in relation to the performance of specific jobs. Being tourism organisations, customer service skills featured significantly as being critical to client satisfaction.

For Company B, the secondary data examined corroborated the interview findings, in that the job descriptions developed for jobs within the organisation, as well as the performance standards used in their employee evaluation system aligned directly with the competency standards attached to the Industry Training qualifications. This level of alignment can be attributed to the fact that the organisation designed its own qualifications within the framework provided by the ITOs. Company A did not have that level of formalisation of its HR practices, which is typical for an SME. However, the client satisfaction survey employed by the company was examined, as the employer indicated that these were reviewed collectively at the weekly staff meetings, and that the level of client satisfaction was an indicator of skill utilisation.

This is reflective of the Strategic HRD/VET logic, and the economic and performance perspective of training (Combs et al., 2006). For these managers, the Industry Training used provided the organisation with skills that they recognise as being valuable. Also they gain value from these skills gained from Industry Training, by 
being able to utilise them within their unique organisational context. The strategic utilisation of skills within the logic relates to the provision of organisation-specific skills, and their ability to align Industry Training provision with their specific operational standards and functions of the organisation. Industry Training then has not only a performative function but also a socialisation function. This is interesting in light of debates in the VET literature on the extent to which VET training does or should provide generic or specific skills (Keep, 2007). What is portrayed in these perspectives is that value is inextricably linked to the ability of Industry Training to meet the specific skills needs of these organisations.

\section{b) Retention/Good Employer Reputation}

Staff retention was cited as another important value of Industry Training, not only for their individual organisation, but also for the wider tourism sector. This was of greater importance to Company B, as they experienced more challenges with staff turnover given the characteristics of their local labour market, which has a large number of internationally mobile workers. The following quotations exemplify these views:

\section{Company A}

\section{Respondent 17}

"And if it is good for the industry, then it is good for everyone."

\section{Company B:}

Respondent 21

"And we have certainly benefited from our reputation as an employer... Why did we do it? We did it because our industry is traditionally seen as a low-pay, low-skill, job to do for a short time, while waiting to do something else. But what happens is a lot of people come into the industry, not with a high level of education, and they actually stay; they actually stay for life... and we found that by investing time and resources into developing staff, and offering something they couldn't get elsewhere, it really has made the organisation more attractive."

Respondent 22

"And the guys can walk away in 6 months time and go and work on the , but remember that we gave them those qualifications." 


\section{Respondent 23}

"There is benefit to us in them going away knowing that we gave them something."

"To me, that is why I want to give them that broad base of knowledge. That's why I want them to be $100 \%$ ready for whatever is out there, because they are not only carrying themselves; they are actually carrying name...."

This echoes concerns expressed in the New Zealand Tourism Strategy that the tourism sector was constrained by high employee turnover, which negatively impacted the national tourism product (Tourism and Hospitality workforce strategy, 2006). Industry Training then was viewed by these managers as being important in developing and retaining sector skills, as well as assisting in marketing the tourism sector as a viable one in which to pursue a career. This also runs counter to the view that employers would have no incentive to invest in Industry Training as they ran the risk of their staff poached by other employers (R. Hall \& Lansbury, 2006 Modernising vocational education and training: $4^{\text {th }}$ report on vocational education and training research in Europe, 2009). Industry Training provision, particularly for Company B, was seen as adding to their reputation as good employer, and that this would assist in staff retention in a sector where high turnover was a norm. However they also accepted staff turnover as an inevitability, but still viewed their investment in Industry Training as a contribution to the wider tourism skill base, as captured in the following statement:

\section{Respondent 21}

"But we are all out for the same thing. We want New Zealand .....to be a destination of choice. So if we can get everybody's standard higher, then that's the best thing."

At the organisational level, managers in both organisations noted that Industry Training assisted with staff retention and the maintenance of staffing and skill levels. In the case of Company $\mathrm{A}$, the employer and manager noted that due to the fluctuations in the number of visitors, they used part-time staff for peak seasons, who were also trained using the Industry Training qualification. In this way, they were able to achieve employment flexibility and maintain service quality, as part-time staff was equipped with the skills to perform to organisational standards. In the case of Company B, they utilised the Apprenticeship system to ensure that they were always able to fill critical positions when needed. In this way, their operations were not as 
heavily impacted by staff turnover. The finding here runs counter to arguments that employment flexibility, particularly the increased use of part-time workers, leads to lower levels of employer investment in training (Richardson \& Liu, 2008).

The secondary data provided by Company B again corroborated these interview findings. They undertook annual employee engagement surveys, which measured employees' perspectives on the Industry Training provided, among other factors. Additionally, Company B also had a documented retention strategy, which included targeting Industry Training to meet critical skill needs likely to be impacted by turnover, such as in its restaurant. It is noted however that the focus was more on numerical flexibility as opposed to multi-skilling. Company A did not have this kind of documentation.

The perspectives expressed here mirror the doctrine of the new psychological work contract, where the provision of training has become the currency of exchange between employers and workers (Benson, 2006). It is reflective of a pluralistic attitude towards VET, where Industry Training provides the basis of a social exchange among stakeholders in the tourism labour market. According to these respondents, qualifications provide value that is mutually beneficial to trainees, employees and the wider tourism sector. In this sense, the Strategic HRD/VET logic is reflected here in that Industry Training is viewed as providing mutually beneficial outcomes to all stakeholders. However, from a Critical HRD perspective, it could also be argued that although the data indicates that Industry Training produces mutually beneficial outcomes, this is an end result that is assumed in the literature. Here, mutually beneficially outcomes are deliberately pursued as a preferred choice, and a solution to gain employee buy-in in exchange for their labour. It is also important to note that many of these respondents also indicated their involvement in various tourism sector bodies; therefore these pluralist views voiced by them could be a mirroring of the pluralist, official positions often projected by such bodies.

c) Creation of a learning culture

All the managers and employers noted that one of the key values from engagement in Industry Training is the creation of a learning culture in their organisation. Learning 
culture was defined here as employees constantly and actively showing that they were learning and were seeking learning opportunities, as the following quotations reveal:

\section{Company A:}

Respondent 18

"Now they just can't stop learning."

\section{Company B:}

Respondent 22

"Employees now constantly ask what other learning opportunities there are. Sometimes we can't keep up."

In the case of Company $\mathrm{B}$, this is not a surprising result, as the organisation provided access to a wide variety of Industry Training opportunities at various levels of the organisation ladder. Company A, as earlier noted, had only accessed one Industry Training offering. However, the employer in particular, believed that the training provided a platform for the trainees where they could further develop their own knowledge and skills on the job.

The documented career pathway used by Company B provided corroborating evidence of the learning culture developed, as each job and job level had Industry Training requirements attached. Company A again did not have any documented strategy of job enrichment or training; however, it was observed that after the training, the organisation increased the numbers and diversity of its tours, as viewed on its website. This dovetailed with the interview findings that this was evidence of the continuous learning among its trainees, in that additional learning facilitated product diversification for the organisation.

The developmental view of training is expressed here, and for these managers, there appears to be no tension between the developmental and performance purposes of Industry Training (McGoldrick et al., 2001). Industry Training provided a culture of learning that fostered both individual development as well as improved organisational performance. In this sense, the outlook is pluralistic, and there is no tension between the performance and developmental orientation of VET, which is suggested in the 
comparative analytical framework. However, learning boundaries are defined by managerial concerns - the skills needs of the organisation, which gives credence to the criticisms levelled by the Critical HRD/Stakeholder perspective in that VET serves unitarist concerns. However, the point of departure revealed in this data set is that this is not necessarily detrimental to employees' concerns; nonetheless the limitations on learning due to unitarist concerns exist.

d) Access/Equity/Self Confidence

Another value from Industry Training identified by managers was the increased access to learning opportunities it provided to persons who had little or no previous qualifications, as the following quotations highlight:

\section{Company A:}

\section{Respondent 17}

"We couldn't expect our part-time staff to pay for their own training. For example, one of them is a single Mom; there is no way she could afford it herself."

\section{Company B:}

\section{Respondent 21}

"So there is definitely benefit. Some people come to us with no qualification whatsoever or very limited qualifications. And if we can put them through getting nationally recognised qualifications, as they are with NZQA, then they are not even realising that they are getting qualifications in the long term. They are just working, and we are just assessing them as they work. So there is definitely value to it."

\section{Respondent 22}

"We have a guy who left school at the earliest he could; I think it's 14 or 15 . And he worked on a dairy farm in the North Island. He came down here to work, and we put him on the . We put him through the very basics of the Limited Credit Programme. And then we identified that he would make a good Modern Apprentice. ... and he is just amazing. He has just done so well, and we have now identified him as a Management Trainee. So we are putting him through Level 4 and Level 5 qualifications, our First Line Management. And then he is going to be travelling around the country as a Management Trainee. To get that position, we have to interview him for it. And it did come out that 
he is just so overwhelmed by the fact that we're giving all this time and effort, It's not an effort; it's really not. The programme is there, and the programme is about identifying the right people for the programme. And he is actually really articulate. He always thought that he was academically challenged. But he really, really isn't. It's just that school wasn't for him."

It appears then that these managers placed value on both the 'hard' HR values such as skill utilisation and performance, and the 'soft' HR values, which focus on development, not only as a tool to be used by the organisation, but as creating opportunities for staff to develop their potential as individuals. This aligns with the definition of human capability as freedom to achieve things in life that people value (Bryson \& O'Neil, 2008). This is also reflective of a pluralistic perspective on the value of Industry Training, which is surprising as much of the literature would suggest that employers' tendency is to be unitarist in their outlook, and in relation to VET, view its benefits only from a performance perspective (Bolton \& Houlihan, 2007a). This then gives credence, at least from these managers' perspectives, to the Strategic HRD/VET logic in that Industry Training is mutually beneficial to all stakeholders.

However, it is important to recognise that this value can be viewed as a positive, unintended consequence of Industry Training engagement. While the respondents' pride in observing the development of trainees' confidence and their increased learning was undeniable, the primary purpose of the organisations' decision to engage in Industry Training is to acquire the necessary skills to facilitate organisational operations and growth. This can be seen by the fact that trainees with other tertiary qualifications were also required by the organisations to undergo the training in order to be equipped with job-specific skills and knowledge. Also, using the Critical HRD/Stakeholder lens, it can also be argued that the trainees' freedom to develop through access to Industry Training, was confined by organisational prerogatives and managerial choices, rather than trainees' choices.

\section{How is the value of Industry Training determined by managers/employers?}

Table 6. 1 outlines how managers/employers in these organisations determined the value of Industry Training engagement. 


\begin{tabular}{|l|l|}
\hline \multicolumn{2}{|c|}{ TABLE 6.2 - How value is determined by managers/employers - Tourism } \\
Organisations
\end{tabular}

Interestingly, both organisations utilised formal evaluation and performance management systems as a part of their business operations. For both companies, the assessment of Industry Training provided a means of evaluating whether learning had taken place. For Company B, their formal employee evaluation process was used to determine whether employees were employing the skills used, as the standards were aligned to the competency standards attached to the qualifications. Company A had no formal system of employee evaluation, but used its client satisfaction surveys as a means of indirectly measuring skills use and overall job performance. However, neither used formal evaluation systems to measure the discrete value or impact of Industry Training. Instead, they focused on measuring the outcomes that were of importance to the organisation. In the case of Company A, they placed a very heavy emphasis on customer service evaluation, and utilised the feedback to re-examine their performance, and to make customer service improvements. Company $\mathrm{B}$, in addition to staff performance management system, also utilised an annual climate survey among employees: 
"It is a climate survey. It covers such topics as training and development, all those sort of things, the extent to which they would recommend the employer as a place to work, their levels of satisfaction with their job. And that's certainly an indicator. We think that investing back certainly adds value to employees' perception of the company."

It is possible to conclude that in keeping with some of the observations in the literature, these companies do not evaluate Industry Training (Grubb \& Ryan, 1999). However, taking a decision-making perspective advocated by Holton and Naquin, another conclusion is that the more traditional methods in the literature of evaluating training, such as ROI, was not relevant to the Industry Training outcomes that are valued by these stakeholders (Holton \& Naquin, 2005). So, in the case of Company B, as employees' perception of the company as a good employer was important to them, this is what they sought to measure through their climate survey. For Company A, high quality customer satisfaction is a main value of Industry Training, so customer service quality is what they focused their evaluation on. Industry Training in their scenarios is an important input in the equation to get the value they wanted. They do not utilise the normative evaluation methods advocated in the mainstream HRD literature (Kirkpatrick, 1998a; J. Phillips \& Stone, 2002). However, their evaluation methods can be deemed as rational methods of assessing the outcomes that they value, in order to assist them in their decision making processes.

The assessment component of Industry Training was also a means by which the value of skills was determined by these stakeholders, as exemplified by the following statement by a manager in Company B:

\section{Respondent 21}

"With unit standard-based training, there is actually the assessment attached to the end of it. And because of that, the trainees actually have to apply. There is more thinking going on; there is more evidence required from them of their learning. It is actually more difficult for them; they can't just sit there in attendance only. They've actually got to show that they have learnt something at the end of it. So there are 2 things. First, that adds value to the organisation; we know that they are actually getting it."

The achievement of unit standards was seen as equivalent to trainees possessing the skills in question, and at the desired level. Assessment then renders learning into a 
visible concept that can be known with a level of certainty. This aligns with the underpinning concepts of the competency movement in VET.

Managers and employers also used their experience, observation and informal feedback from other employees as a means of determining the value of Industry Training. This was more obvious in how they determine the values of access/equity/self worth. It could be argued that neither set of managers in these organisations implemented any formal means of evaluating the values of access/equity and self worth, and that this could be an indicator of these having a lower level of importance that other values such as skills and their utilisation. It would also seem that these are values that these organisations did not necessarily deliberately set out to achieve, but were unintended and positive outcomes. Another perspective however could be that these impacts could not necessarily be measured usefully in any other way, except tacitly. Even if these were the unintended values derived from Industry Training, it was obvious from the interviews that these were highly valued by these managers. All these respondents spoke about these values in terms of its impact on changing trainees' lives, particularly their confidence levels, and the pride they themselves took in observing and facilitating those changes. The following statements capture these sentiments:

\section{Company A:}

Respondent 18

"Definitely the staff feeling good about themselves and their role and their place has been an obvious thing to me. It's value to us."

\section{Company B:}

\section{Respondent 22}

"So I think to see the feedback from people like that is so rewarding as a HR Manager. It is like identifying people; it makes it all worthwhile."

In examining how value is determined by managers using the analytical framework, it can be argued that the methods of determining value are largely value-laden. Although both sets of managers identified the same values from Industry Training engagement, there were variations in the formal evaluation mechanisms that are used. This suggests that preferences for one form of evaluation over another may be based on practical concerns as well as on what is deemed necessary to formally evaluate. 
This then constitutes a value judgment. There is also a heavy reliance on determining value through experience and observation; a tacit and intuitive understanding of value, which is more in keeping with a more pragmatic approach to evaluation, rather than an adherence to normative HRD evaluation methods, particularly for SMEs (Yang, 2003). In the case of these managers, there was an inclusive stance that is taken in determining value, in that the experiences of the trainees themselves are taken into account in assessing value, whether through their feedback or climate surveys. Rather than assume that Industry Training was mutually beneficial, there was an effort to determine benefits for the trainees as well as for the business.

To an extent, the Strategic HRD/VET logic is mirrored here as Industry Training from the data is seen as addressing pluralist concerns. However, there is a reliance on more qualitative type data in evaluating whether pluralist needs have been met, such as employee engagement, client satisfaction and informal feedback generally. Additionally, more traditional methods of evaluation expounded by the Strategic HRD/VET logic are also employed, such as completion rates and qualification assessments. The dichotomy then between the two paradigms of the analytical framework is not as wide as has been indicated in the literature.

\section{How is value created for managers/employers from engagement in Industry} Training?

For managers in both tourism organisations, value from Industry Training engagement was created through a) their HR infrastructure, as well as through b) the provision of training subsidies provided from the government via their ITOs.

\section{a) HR Infrastructure}

The presence of a robust HR infrastructure was essential for the creation of value from Industry Training engagement. This was sometimes identified directly by these interviewees but also inferred through some of the statements made by them. Given the differences between the two organisations in terms of size and level of Industry Training usage, the HR infrastructure was markedly different; however this factor was evident in both organisations. 
In the case of Company B, the presence and prominence of an Industry Training champion was noted as being critical to the level of Industry Training usage, and the benefits derived from it, as the following statements reveal:

\section{Respondent 21}

"The high compliance that you really need to have a strong culture of understanding the importance of it. And it needs to be championed by somebody who has seniority, which is where I came in. It wasn't a choice. I told the company they had to do it."

Respondent 23

"If you know -------- is in charge of this complex, and --- is also HR. So a lot of our thing is very training influenced. It does have a major influence."

In the case of Company A, it was the employer who had extensive experience in the tourism and travel industry, who played the role of Industry Training champion, as the following quotations from the employer reveal:

\section{Respondent 17}

"Right at the outset we developed our own training, and our own training was based on our staff, our Maori staff had many of the prerequisites in terms of hospitality, because they were involved in a lesser or greater degree in providing traditional Maori hospitality on the marae for example. They would have been either working in the kitchen, or at the front welcoming guests. They would have been doing something that was associated with hospitality. They may not have realised that but that's what it was. So it wasn't such a big step really for many of them. But some of the things where they were deficient; deficient is not the right word, but some of the areas they weren't so familiar with were some of the wider tourism aspects, some of the geographical issues, or international geographical issues, different cultural issues, all the things that broaden their understanding are the things we had to develop training around."

\section{Respondent 18}

"It (Industry Training) is a legitimate cost for the business, so it wasn't really an issue."

The employer then had the capability to assess skills gaps of the staff, and to determine what kind of training needed to be developed. It is also important to note that in the case of both organisations, the Industry Training champions were also 
involved in the wider tourism industry in various capacities. This was not a deliberate choice in terms of organisational selection. However, it means that the perspectives represented here would be shaped by the influence and presence of these Industry Training champions within these organisations. Additionally, the strong HRD and management background of these champions also meant that they started their engagement in Industry Training from a position of valuing training. In other words, they approached Industry Training from the standpoint that it would provide them with the value they were seeking. The question then is whether the belief in the value of Industry Training assists in creating value from engagement. This would then support other findings which noted the positive impact managers can have on increased training investment, especially within SMEs (Kithcing, 2008b; Kithcing \& Blackburn, 2002). This implies that the seeming underinvestment by many SMEs in training and VET in particular, may be linked not only to financial constraints, but also managerial capacity and values as it relates to training.

In addition to having a strong Industry Training champion, having a supportive organisational culture was also seen as creating value from Industry Training. As stated earlier, top management support for Industry Training created internal value for Industry Training for both organisations. However, there were other factors that assisted in creating a supportive organisational culture. For Company B, the presence of a career structure that was aligned to an Industry Training learning pathway created an incentive for engagement in Industry Training. Within Company A, the view was expressed that the organisational environment fostered learning, a factor that Industry Training assisted in fostering, as these statements suggest:

\section{Respondent 17}

"Some of the training they are doing enables them, I think, to learn more and absorb more, simply because of the learning they have obtained through the training programme, and understanding what people want. And they quickly understand that they have a very fruitful learning environment."

Respondent 18

"You are learning all the time. There is always something you can learn every time... whether it is about the visitors and the people...there's lots. There is always something to learn. And we do expect them to do self-directed learning ..." 
In both cases, the organisational environment created opportunities for growth and development through Industry Training and learning generally. However, in the case of Company B, that growth was via traditional career ladders, which the organisational size allows for. For Company A, the organisation structure was small and flat, thereby providing limited scope for upward mobility/promotions. However, this was not viewed as problematic, as growth is via job enrichment, as they postulated that the work environment was a rich ground for continuous learning. Also most of the staff are part-time, and so for some of them, this job was not the only source of income, and so career growth in these jobs was not an expectation for them.

Another aspect of the HR infrastructure was the knowledge of the technical operations associated with implementing Industry Training. As expected, Company B, being larger and a more extensive user of Industry Training, possessed a much more extensive technical infrastructure, including thirty internal assessors. These managers emphasised the need for this internal capacity to cope with the technical demands, as the following highlight:

\section{Respondent 22}

"So I think the surprise has been the volume of work involved in keeping it going, the time involved in assessments and reporting, in moderation, in maintaining the completion rates that you need. That's very, very time consuming.

Respondent 21

"I am actually able to train assessors myself, so we are kind of self sufficient. We don't have to outsource that, which is very expensive."

The secondary data provided by Company B corroborated these interview findings as assessment records, training plans and training programme design and materials all attested to the extensive HR infrastructure developed by the organisation.

For Company A, the technical capacity was provided through the ITO, including the provision of an assessor: 


\section{Respondent 17}

"The ITO has been involved with us at the outset. The training they provided focused on what we wanted our staff to learn."

They expressed a high level of satisfaction with the services provided by the ITO, and unlike Company B, viewed the process of engagement in Industry Training as being relatively easy and pain-free. The reason for this perspective was that the technical aspects of the implementation such as assessment and delivery were carried out by the ITO.

What is reflected here is an expansion of the Strategic HRD/VET paradigm in that the HR infrastructure provided in support of Industry Training is a critical factor in the creation on VET outcomes as determined by these stakeholders. This infrastructure in a competency based model such as Industry Training is extensive, requiring additional expertise in assessment and management of the attendant bureaucracy, which is provided either internally or externally. What is noted here is that this factor is heavily dependent on the role, and stance employers and managers choose to take in determining how much will be invested in this infrastructure which comes at a cost to them in terms of time and expertise. In this regard, the concerns served here are unitarist; any employee centred concerns are strictly at the discretion of the employer/managers.

b) Training Subsidies

Company B cited training subsidies as being a major factor that drove their engagement in Industry Training. Managers here noted that the organisation would have engaged in Industry Training without the receipt of training subsidies, but not to the extent that it did. Therefore training subsidies increase the quantity of Industry Training undertaken, as the following statements reveal:

\section{Respondent 22}

"We approach more in terms of an internal training and assessment. And we use the subsidies that we get from the ITOs to support that training and development internally. If we then can't source the money from the ITO to assist us with the funding of the training, and we are having to buy materials, it doesn't work for us. It works for a SME but not for us. So we in all 
likelihood will be pulling out of that, which is a real shame. So the future is a little uncertain...

I think we would have done it without the subsidies in the first instance, but we wouldn't have done as much. We would probably have just stuck to say Hospitality Level 2, and that was about it, sort of easy stuff, easy stuff. You see, we've also got (a polytechnic) here, who has free fees."

\section{Respondent 21}

"The funding to us is actually very important as a company. The cost in doing this is massive, and because we are doing it all ourselves; we're not using providers, clearly if we do get a subsidy from the ITO, it goes straight back into re-developing resources, helping to pay for the staff development. So not getting a subsidy makes a huge difference..."Tragically, it has been reviewed and we have to re-write it, and it'll cost us a fortune. You talk about surprises. Well, it is not a surprise because you know it is going to be reviewed, but what is always a surprise is how much they are changing, and what does that mean for our qualification, and how much is that going to cost. It cost about $\$ 20,000$ to get the material written, and it is probably going to cost about $\$ 10,000$ to get them reviewed and re-written. I simply don't have the time, and it is not my core business. We've got to get a writer to do it, and it has to be premoderated again, and it is going to be 5 modules instead of 4 , so it takes longer. But that's life, isn't it? It sucks. But if you want something, you have to accept that the rules will change from time to time."

What the above statements revealed also was that Industry Training costs were very heavily weighed in making the decision whether or not to engage and the extent of engagement. Costs were a filter through which the value of Industry Training is assessed, and the costs to the organisation were significant. Costs also are evaluative criteria that are constantly used to decide whether to engage in Industry Training, and the level of engagement. For example, Company B made the decision to discontinue engagement in a particular Industry Training programme, due to the increased costs in delivering the programme, brought about by changes made by the ITO. Additionally, these statements also highlight some of the debate in the literature about generic versus specific skills, and whether employers are motivated to invest in generic skills and the role of government in funding VET to compensate for shortfalls in employers' skills investment (Benson, 2006; Keep, 2007; Sheldon \& Thornwaite, 2005). Here we see that this firm in developing their own training materials was providing organisation-specific skills. The flexibility afforded by the qualifications framework allows for these organisation-specific qualifications to be aligned to the national framework and as such, the organisation becomes eligible for receipt of training 
subsidies to underwrite their training costs. This raises a debate - on one hand, the question arises as to whether public funding should be utilised to underwrite the costs of what effectively is firm-specific training. On the other hand, it could be argued that such use of government funding was justified, given that it was contributing to the national skills base, as well as developing the national tourism product in this instance. Additionally, it can also be argued from a human capital theoretical perspective that without government funding, there would be under-investment in skills that would negatively affect the wider society (Acemoglu, 1997). This was the argument put forward by the employer in Company A:

\section{Respondent 17}

"...it is government funded because it is providing an improvement in the national capacity; small but nonetheless, it is not just benefiting our business. It is benefiting the national tourism product."

Interestingly, the employer in Company A expressed pleasant surprise on learning of and receiving training subsidies, as seen in this quotation:

\section{Respondent 17}

"The ITO reimbursed us I thought for quite a significant part of our cost. It was great, and I was quite surprised by that."

This indicates that the decision by this organisation to engage in Industry Training was not motivated by training subsidies. The training subsidies were discovered after the fact of engagement. This is not to say that the organisation did not weigh the costs associated with Industry Training, as when asked if they would undertake Industry Training in the future, hesitation was expressed and costs and the wider economic climate were cited as reasons for caution against investing further in Industry Training, at least in the near future.

The findings here fill in missing gaps in the Strategic HRD/VET logic. The logic emphasises government subsidy as a focal input. The data here shows that the quality of the HR infrastructure available to organisations is also a necessary input for deriving value from Industry Training, and to correct market underinvestment in training. There is a clear divide here between the HRD literature and the VET policy literature. Whereas the HRD literature acknowledges the adequacy of the HR infrastructure to support learning and learning transfer, this is not an input that is 
acknowledged explicitly or is perhaps assumed in the VET policy literature (Brinkerhoof, 1989; Holton, 2005).

As it relates to the role of funding in the Strategic HRD/VET policy literature, these perspectives show that it does increase the quantity and quality of investment in skills development. However these employers were already investing, and would continue to invest in training, whether or not there was access to training subsidies. Training subsidies then served to increase the level of investment where there was already some degree of investment (Tight, 2002). This corroborates with other research findings which show that those who access training tend to continue to access further training. This is not to say that the increased access to Industry training was not achieved through the provision of training subsidies in these organisations. However, this highlights a broader policy discussion about the most effective use of training subsidies, particularly in light of the organisational specificity of the training which may limit the extent to which the skills gained are in fact portable in the wider labour market.

\section{TRAINEES' PERSPECTIVES}

\section{What value do Trainees derive from engagement in Industry Training?}

In both organisations, trainees identified a) skills and its utilisation, b) improved career prospects and c) self confidence as the benefits they derived from their engagement in Industry Training.

a) Skills and skills utilisation

The acquisition of new skills and knowledge and ability to transfer these to their jobs was identified by all the trainees interviewed as being of value to them, as the following statements reveal: 


\section{Company A:}

Respondent 19

"It gave me an insight in terms of what I needed to know. And I suppose, I had never worked in that sort of industry before."

\section{Respondent 18}

"The knowledge pertaining to different cultures and what they expect and what their needs are. So that was really helpful because we deal with a lot of different nationalities. I found that really helpful. That was it really, apart from some of the admin stuff which I learnt, which was on the computer, there are some tips there that I got out of that which were helpful, help me do my work a bit faster."

\section{Company B:}

Respondent 24

"Just that upskilling eh."

This echoes the performance orientation towards VET. This runs counter to the Critical HRD perspective, which tends to view the performance orientation towards skills as being distinctly managerial and potentially exploitatively (Antonacopoulou, 1999; O’Donnell et al., 2006; Sambrook, 2009).

\section{b) Career Prospects}

Trainees in Company B cited the opportunity for career development as a benefit derived from their engagement in Industry Training, as noted in these quotations:

\section{Respondent 25}

"So it wasn't just to upskill a half decent person. It was something that you could push towards and may be build on later on."

\section{Respondent 26}

"It sort of opened the door of opportunity really...people will see working at as a career for them. It's not just a job until they go to another country.

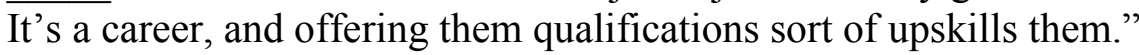




\section{Respondent 24}

"I would say one of the unexpected benefits was actually getting this job." (comments from a trainee who moved from the Apprenticeship programme to the management trainee programme and who now held a managerial position)

In Company $\mathrm{B}$, the secondary data corroborated these interview findings, as the organisation had a document career pathway strategy aligned to its Industry Training provision.

Improved career prospects were not a benefit cited by trainees from Company A. As was earlier noted, this is not surprising given the difference in organisational size, structure, and terms of employment. Company B was larger and had structured career development linked to Industry Training qualifications that trainees have the opportunity to pursue. Company A, on the other hand, was small, with mainly parttime employees, so traditional, upward career mobility would not be offered and as such would not be an expectation that trainees would have. Instead, these trainees noted how Industry Training assisted in their capacity to learn and to do their job confidently. In this organisation also, the growth in learning of the trainees over time allowed the organisation to offer additional and differentiated guided tours. It can be argued then that for these employees, career prospects were viewed in terms of job enrichment and horizontal career growth. This is a perspective that aligns with the career literature, and how the concept of career has changed in light of the rise in the occurrence of flatter organisational structures, where upward mobility is limited (Benson, 2006; Inkson, 2006). There is a divergence then between the career literature and the Strategic HRD/VET logic, where in the latter, career mobility is viewed vertically as upward mobility and increased wages. Particularly in the New Zealand context, where there is a preponderance of small organisations, equating career development with upward mobility and wage increases might be a limiting indicator of VET system performance, and does not recognise the other ways in which trainees' careers are being developed.

What is indicated here is that the outcome of vertical career progression promulgated in the Strategic HRD/VET logic is reflective of a large organisation context, but is not an outcome of much relevance for VET use in SMEs. However, this outcome is more the result of the organisational and job design and culture that is deliberately created 
by the employers/managers, rather than an outcome of the completion of qualifications.

c) Self Worth/Confidence

Trainees also identified increased confidence, and self worth as values they derived from Industry Training. This value appeared closely related to the other values of skills utilisation and career prospects. They noted that they gained a great deal of confidence from having the skills and knowledge to do their jobs, for example, handling face to face interactions with customers. Additionally, the opportunity to grow in their careers and jobs also provided them with a sense of purpose and confidence. The following exemplify these perspectives:

\section{Company A:}

Respondent 20

"It gives them a bit more self importance."

\section{Company B:}

\section{Respondent 24}

"And then the company pushed me through all these courses and got me on to this management traineeship. It sort of gave me a little bit of guidance for where I wanted to be. So probably in terms of how it has benefited me is I probably would have still been a , or potentially on the benefit."

It can be concluded then for these trainees, that they derived value both from the ability to perform their jobs and the personal development gained. This shows a balance between the performance and developmental orientation towards training, rather than these being polar opposites (McGoldrick et al., 2001).

\section{How are these values determined by trainees?}

The values identified by the trainees interviewed were determined by their personal experiences of the benefits of Industry Training, as well as through their own observations of other trainees. This aligns with other observations in the policy evaluation that notes that at the individual level, persons rely on their personal 
experience of public policy as their means of evaluating its effectiveness (Thomas, 2006). Skills for example were evaluated by the extent to which they were able to use these skills on the job, and the extent to which they saw these skills/knowledge as being relevant to effective job performance. For example, trainees from Company A spoke at length about the training they received on how to greet visitors, and willingly demonstrated this during the interview without prompting. On the other hand, they also spoke about some of the training they received in office administration and voiced the view that it bore no relevance to the job of guiding. Career prospects, whether upward or lateral mobility were determined by the trainees' experiences of gaining promotions or having their jobs enriched, or by observing these in the working lives of their colleagues. The value of self-worth and confidence was also something that they spoke about experiencing at an emotional level. Also trainees were able to observe this in other trainees in the way they carried out their jobs, such as being able to speak to visitors and to look at them directly.

Again, not only is there no tension between the performance and developmental aspects of training, there is an almost symbiotic relationship between the two. As they perform their jobs, they gain and hone their skills, and this in turn provides the trainees with self-confidence and developmental opportunities in the way of job enrichment or promotions (McGoldrick et al., 2001). What is also seen here is that the narrow range of quantitative indicators used in VET evaluation under the Strategic HRD/VET model are not able to capture these perspectives and VET effects, giving credence to the use of other more qualitative type data suggested by the Critical HRD/Stakeholder model.

\section{How are these values created for trainees?}

Value for the trainees from both organisations was created both from a) the HR infrastructure provided, and from b) the fact that the training was nationally recognised. 
a) HR Infrastructure/Alignment between qualification and the job

Organisational support for Industry Training was identified by all trainees interviewed. This was seen as a major factor both in terms of providing the opportunity to access Industry Training, as well as the support received to complete the qualifications successfully. The following encapsulate this view:

\section{Company A:}

Respondent 20

"I think it is awesome eh, that they took all of us guides like family, and gave us the training. They didn't have to."

\section{Company B:}

\section{Respondent 26}

"And then the company pushed me through all these courses and got me on to this management traineeship."

Another factor that assisted in creating value for trainees is the fit between their jobs and the training received. While this was not directly identified by trainees, the fact that they all noted their increased ability to do their jobs and to use the acquired skills, points to this alignment, which would have made skill utilisation possible. Additionally, the presence of career ladders and/or the opportunity for job enrichment also assisted in creating value from Industry Training, as trainees noted their ability to move into different jobs, or to experience their jobs being changed and enriched. This was corroborated by the secondary data. For Company A, this was evidenced by the new and diversified tours that were implemented after Industry Training. In Company B, the documented career pathways and its alignment to Industry Training qualifications revealed the organisational support for staff development.

Training delivery methods utilised by the organisations in delivering Industry Training were also identified as creating value for trainees, in that the methods used allowed for ease of learning. The following are statements to this effect: 


\section{Company A:}

Respondent 19

"And that was really good because we did it as a group."

Respondent 20

"...it was well presented, so it made it easy for us to get through, and we worked as a group, we didn't just work as individuals, which made it helpful. We could help each other."

\section{Company B:}

Respondent 26

"A lot of it is on job training, so you are really getting qualifications in terms of what you already know. So it's just aligning the qualifications with what you are doing already."

\section{Respondent 24}

"We are sort of getting a little bit of both worlds - working, getting the money and getting the qualifications."

In the case of Company B, the fact that the training is work-based was seen as beneficial, as it was easy to apply learning, and it was about gaining recognition for skills already being learnt and used in their jobs. For Company A, the training was delivered through a series of weekend-long conferences, as well as through selfdirected work. However, the trainees here identified the group setting as being important to getting through the qualification. Organisational support then, was not only from the manager or employer, but from work colleagues. Also it would appear that while individual motivation was important in helping them to complete the qualifications, much of the motivation was externally provided through support found within the work organisation.

This supports the HRD literature, especially the training model of analysis/delivery/transfer (Kirkpatrick, 1998a; J. Phillips \& Stone, 2002). The findings here also support the high performance workplace literature, which supports the view that a sense of belonging also facilitates performance and self-confidence in trainees. In the VET literature, there is an argument that VET training tends to be more valuable in regulated industries, where VET training is necessary for entry, and 
it creates a license to practice occupational community (Keep, 2009; Ridoutt et al, 2005a, 2005b). Here the training is not by and large regulated in that sense, but communal nature of Industry Training creates that sense of community and organisational belonging. This in turn creates a context and culture where VET is highly valued. What is also seen here is a meeting of the two paradigms in the analytical framework, as VET can be both learner/development centred and performance oriented, as seen in the commonality of perspectives between employer/managers and trainees. However, employers/managers' decisions on how they will execute their role of providing workplace affordances such as learning support are critical in creating value for trainees.

b) National Qualification

Trainees also expressed that the fact that the training resulted in nationally recognised qualifications was of benefit to them, as seen in the following statements:

\section{Company A:}

Respondent 20

"So I suppose by sitting these courses, you know, you do need to sit them and to get qualifications and that, yeah."

\section{Company B:}

Respondent 25

"We are sort of getting a little bit of both worlds - working, getting the money and getting the qualifications."

"I got a qualification so actually I got New Zealand residency."

The fact that the qualifications are nationally recognised led to a number of benefits for trainees. According to them, these ranged from gaining qualifications without having to give up earnings or acquiring student loans, to gaining points in order to access New Zealand residency, to viewing the qualifications as a step in furthering their careers. This aligns with the Strategic HRD/VET logic which argues that the acquisition of nationally recognised qualifications is beneficial for employees (Hillage \& Pollard, 1998; Modernising vocational education and training: $4^{\text {th }}$ report on 
vocational education and training research in Europe: a synthesis report, 2009). However, within the logic, benefits to employees in having nationally recognised qualifications is defined as being able to signal one's employability in the wider labour market. Here, however, these trainees are not defining the benefits of nationally recognised qualifications in the same manner. First, they were still in the employ of the organisation that provided the Industry Training, and as such had no experience themselves of testing the wider marketability of their qualifications. Instead, the benefit of qualifications seemed to relate to either mobility within the same organisation, or other personal benefits derived from having qualifications, such as a sense of accomplishment or assisting in qualifying for residency.

\section{Synthesis}

In examining the data, there are striking similarities between managers' and trainees' perspectives. Both managers and trainees identified skills and skills utilisation, and self confidence as key values to be derived from engagement in Industry Training. Even values that differed could be viewed as being complementary to both trainees and managers. For example, managerial values of employee retention, good employer reputation and increased access to education directly complement trainees' values of career development opportunities. The question then arises whether the experiences of Industry Training mirrors the Strategic HRD/VET logic or the Critical HRD/stakeholder logic. At one level, the mutually beneficial nature of Industry Training identified here appears to align with the Strategic HRD/VET logic. However, taking a multiple stakeholder approach to gathering data, and having found mutual benefits to these stakeholders, does not mean that the mutually beneficial outcomes of Industry Training can be assumed. Particularly given the small sample, this is a conclusion that can be drawn only in relation to these interviewees.

An in-depth examination however provides interesting insights as to how Industry Training was able to be mutually beneficial to these organisational stakeholders. In answering the 'how' question for the creation of mutual value, an adjusted logic emerges, depicted in Figure 6.1. 
Figure 6.1: Programme Logic for Value Creation - Tourism Organisations

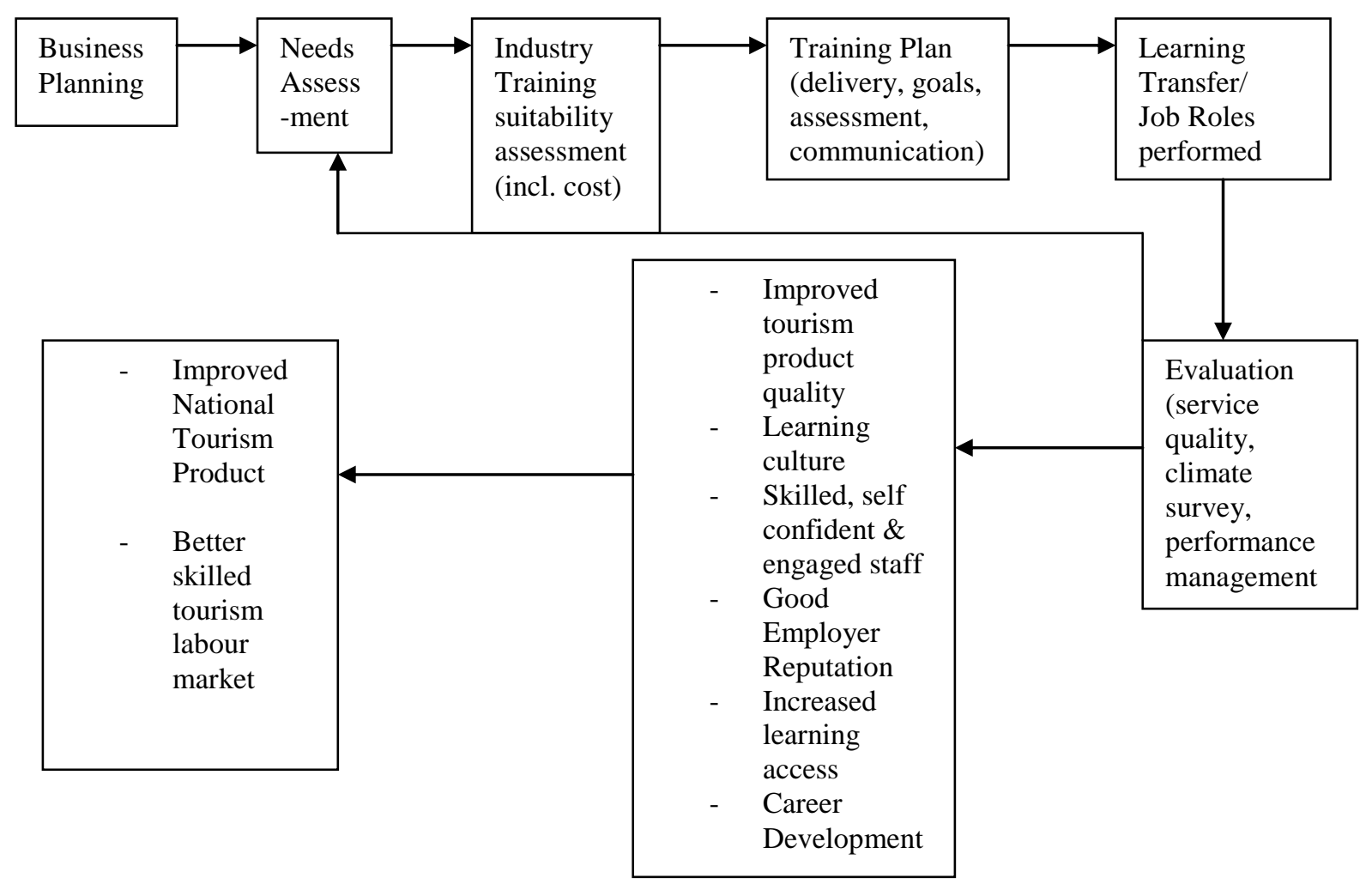

Firstly, there has to be a training champion with sufficient decision-making power within the organisation. This champion has to have a belief in the value of training to the employees and the wider organisation, and ensures that training is an integral part of how the organisation functions. They are also very concerned about the provision of quality service and the contribution of high quality training and trained staff to delivering quality service. This is then what attracts them to Industry Training; they are attracted to the training subsidies provided, but are more interested in the quality assured nature of Industry Training. Additionally, they make a determination that the training provided through Industry Training meets their specific organisational needs. They are therefore willing to invest in Industry Training - funds, infrastructure, needs identification and training delivery. The champions are extremely hands-on in the process of Industry Training engagement. In the case of Company A, the employer assisted in delivering part of the training, and attended the training along with the employees. In the case of Company B, the champion was also heavily involved in Industry Training delivery and assessment. 
Having an organisational culture and norms that are supportive of Industry Training is another important input in creating mutually beneficial outcomes for all organisational stakeholders. For example, in both organisations $100 \%$ of employees had engaged in Industry Training, and it was used to gain entry into these organisations. This therefore creates a community of practice, somewhat similar but not as rigid as license to practice training practices in regulated industries. There is also a pluralistic attitude towards Industry Training, particularly on the part of managers and the training champion. The characteristics of these champions are also important, as they have to possess expertise in training needs analysis, Industry Training design and assessment and learning support, or at least appreciate the value of these, and access the experise from elsewhere. This translates into viewing the benefits of Industry Training not only from an organisational/bottom-line perspective, but also from the standpoint of the benefits to the individual trainees and the wider tourism sector. This is influenced by the champions' involvement in the tourism industry at the sectoral level, and this influence is then channelled throughout the rest of the organisation. The on-going value of Industry Training to all the stakeholders is underpinned by strong internal communication of the importance of training, the strong alignment between the training undertaken and the actual jobs, and high levels of employee engagement. The decision-making power to engage in Industry Training resides with at the managerial level, but there appears to be a deliberate attempt to share its gains with other stakeholders. In this sense then, what is reflected here aligns with the Critical HRD/stakeholder logic, in that mutual benefits are derived through a process of consensus among the stakeholders.

How do these stakeholders evaluate Industry Training? They do so largely subjectively. There is a heavy reliance by both managers and trainees on their personal experiences and observations in determining the value of Industry Training. A tacit, intuitive understanding of value appears to be the way in which trainees and managers assess Industry Training benefits, and in this sense, evaluation is also highly contextualised, as value is viewed vis-à-vis the experience of value in the organisation. Where formal evaluation mechanisms are utilised, for example customer feedback, performance evaluation systems, or climate surveys, these do not evaluate Industry Training directly or exclusively. The evaluations used in fact do not reflect normative HRD evaluation practices such as return on investment analysis. Instead, 
the choice of formal evaluation is based on the kinds of decisions the organisation deems necessary to make, and the kind of data they are interested in. In that sense then, there is a prioritising of some data to the disregard of others, and that in itself must be based on a value-driven decision on what is important to know.

Not only is evaluation subjective, it is also inclusive and pluralist. Value is understood from a multiple-stakeholder perspective, value to the managers/employers, trainees and the tourism sector. This is done either through having an appreciation of how other stakeholders experience value, and also deliberate involvement of stakeholders in evaluation, for example, through a climate survey. Value is then something that is a shared experience and benefit. The use of quantitative data then is rather limited then, and appears largely confined to numbers of trainees and completion rate as part of the requirement placed on the organisation by the ITO to access training subsidies. However, there is a greater reliance on qualitative data as defined by the organisational information priorities, intuitive understanding and experiences to determine Industry Training's value. 


\section{CHAPTER 7 - DATA ANALYSIS - FINDINGS FROM STATE SECTOR ORGANISATIONS}

\section{Background to the State Sector engagement in Industry Training}

The state sector in New Zealand refers to the central government constituting 34 departments, but excludes the health and educational services and local government (Human resource capability survey of public service departments as at 30 June 2007, 2007). Prior to 1984, the New Zealand economy was heavily centralised, including the then Apprenticeship system. The state sector carried much of the responsibility for providing a large number of the apprentices for the trades and engineering sectors, as many were employed to provide a variety of centralised services, such as the railway and road works. With the move to liberalise the economy and reform the state sector through a series of decentralisation and devolution initiatives, the state essentially relinquished its role as main provider of Apprentices to the labour market (Murray, 2004). a

With the passing of the Industry Training Act in 1992, a decision was taken by the State Services Commission to establish an Industry Training organisation for the state sector, as was the case for most of the other sectors of the economy. However, as it was part of the state machinery, it was not eligible to receive funding from the Industry Training Fund, unlike other ITOs. As a result, the Public Sector ITO (PSITO) was relegated to being a desk within the State Services Commission. This meant that the state sector's involvement in Industry Training was extremely minimal. In 1999, with the election of the Labour-led government, there was a shift in thinking, and an increased concern about building state sector human capability. This came against the background of lower levels of unemployment, and the increased competition for skilled labour. This concern was evidenced by increased research on the human capability of the state sector, and the drive from the State Services Commission to promote the state sector as an employer of choice (Career progression and development survey: results for the New Zealand public service, 2005; Strategic plan for the employer of choice and excellent state servants development goals, 2006). Part of that strategy included promoting training and development opportunities for state sector employees, including Industry Training. As a result, the PSITO, later re- 
branded Learning State, began to receive Industry Training funding. Consequently, it grew in terms of staffing, research capacity, and training offerings.

At the time of the research, the state sector had between 3500 to 4000 trainees annually (Public Sector Industry Training Organisation Strategic business plan 2006$2009,2006)$. Its level of penetration in the state sector is low relative to the size of the state sector, which had approximately 44,000 employees, and approximately 320,000 in the entire public sector (Human resource capability survey of public service departments as at 30 June 2007, 2007). However, there are key ministries which utilise Industry Training in the development of large percentages of their staff. The state sector organisations included in this research fall in this category.

\section{Background to the State sector Organisations}

\section{Background to Department X}

Using the Wilson Matrix of categorisation of state agencies, Department $\mathrm{X}$ can largely be described as a production type state organisation, that is largely responsible for the delivery of observable outputs and services (Gregory, 1995). At the time of the research, the staff complement was approximately 400 employees.

The occupational profile of the organisation is typical of state organisations, which included a range of junior administrative/clerical positions, as well as line and support services managerial staff. Qualifications typically held by clerical and junior administrative/clerical employees are high school qualifications and Certificates and Diplomas from Institutes of Polytechnics, in addition to the completion of several inhouse training programmes offered by the Department. Managerial staff typically hold university qualifications at the bachelors and post graduate levels, although some possessed only high school qualifications and Certificates from Institute of Polytechnics and would have been promoted to the managerial ranks based on skill level and experience gained over time.

Department $X$ had been engaged in Industry Training for approximately $3 \frac{1}{2}$ years at the time of data collection, and the general consensus among respondents was that the 
management of Industry Training in the Department was dysfunctional. At that time, only documentation available on Industry Training in the Department was a broad plan indicating that they had embarked on implementing a blended learning strategy to foster skill development and staff retention. This meant that trainees were then involved in self-directed learning, where they were given the syllabus and assignments for each module being undertaken. Time off during work hours (typically a few hours each week) was provided to undertake these assignments. Managers were expected to ensure: that the time off was given; that trainees were provided with the opportunities to complete assignments as a part of their jobs; and to sign off on whether trainees had completed the requisite hours and displayed the skill levels as required by the particular module.

According to data gathered from interviews, the then Learning and Assessment Manager was given a great deal of latitude to sign up as many employees as possible for Industry Training programmes. That manager was also a trained assessor for Industry Training qualifications, having gained assessor training in previous employment outside of the Department. As a result, the manager was able to provide the necessary support to trainees in terms of guidance to find material to complete assignments and tests, as well as to either assess modules completed or source assessment services. This manager resigned after a year, and was replaced by another, who also was a trained assessor who was able to provide a similar level of support to trainees, in terms of guidance and assessment. This manager also had the latitude to sign on trainees for various Industry Training qualifications. During the first two years of engagement in Industry Training, it appeared that it was being adequately implemented, based on the criteria of module completions as well as provision of support for trainees.

However, the second Learning and Assessment Manager also resigned after a year, and the position was not filled for six months. Additionally, in the wider Training and Development Unit, over the course of $3 \frac{1}{2}$ years, there was a $100 \%$ staff turnover. At the time of the research, all the staff in the unit had under one year service in the Department; none of them were trained assessors and no other trained assessor was on staff in the Department. 
Documentation of the Industry Training process was extremely limited, with the only document available in the Department being a broad statement on the rationale for implementing a blended learning strategy (which was mentioned earlier). There were no formal evaluations done at any level on Industry Training, whether feedback from trainees or from assessors. In fact, at the time of the research, the Department had embarked on undertaking a review of its Industry Training engagement. At the commencement of data collection, the Department's records on the number of trainees and the qualifications being pursued were so incomplete, that they had to obtain this data from the relevant Industry Training organisations. This information was obtained eventually, and 100 trainees were reportedly enrolled in Industry Training programmes ranging from Client/Customer Services, Business Administration, First Line Management, Adult Education and Training and Occupational Health and Safety. According to the interviews with the managers, about $50 \%$ of the trainees were merely enrolled, and many had even forgotten which programmes they were enrolled in. Many of the others had commenced the modules but were having challenges in completing. One of the major challenges had to do with the inability of the Department to provide internal assessment services, and the difficulty of sourcing available external assessors. The other major challenge faced was that these Industry Training qualifications were designed on the premise that trainees would be engaged in work aligned to the qualifications, and as such, completion of assignments and exhibition of the necessary skill level would be a natural outflow of their work. In many cases, this alignment did not exist, and therefore, there were delays in trying to arrange for trainees to gain the necessary experience required, as well as to locate internal managers with the skill to sign off on these areas.

This state of affairs meant that there were challenges in gaining access to respondents; however, it also meant that those who participated freely shared their perspectives, and the challenges being experienced were openly acknowledged. In the end, a total of 10 interviews were conducted with one Learning and Assessment Manager, four managers/team leaders and five trainees. Interview participants - the exception of two - all had a relatively short service with the Department of less than two years. As outlined in Appendix A, these interviewees are identified as respondent 27 to 35 for confidentiality purposes. 


\begin{tabular}{|c|c|c|}
\hline \multicolumn{3}{|c|}{ Table 7.1 - Description of Trainee Respondents for Department X } \\
\hline $\begin{array}{l}\text { Trainee Occupational } \\
\text { Group }\end{array}$ & Sex and Years of Service & $\begin{array}{l}\text { Industry Training } \\
\text { qualification pursued }\end{array}$ \\
\hline $\begin{array}{l}\text { Trainee } 1 \text { - Junior } \\
\text { Administrative/Clerical }\end{array}$ & $\begin{array}{l}\text { Female (over } 20 \text { years } \\
\text { service) }\end{array}$ & $\begin{array}{l}\text { Occupational Health and } \\
\text { Safety (pursuing) }\end{array}$ \\
\hline $\begin{array}{l}\text { Trainee } 2 \text { - Junior } \\
\text { Administrative/Clerical }\end{array}$ & $\begin{array}{l}\text { Female (over } 20 \text { years } \\
\text { service) }\end{array}$ & $\begin{array}{l}\text { Client/Customer Services } \\
\text { (completed) }\end{array}$ \\
\hline $\begin{array}{l}\text { Trainee } 3 \text { - Junior } \\
\text { Administrative/Clerical }\end{array}$ & $\begin{array}{l}\text { Female (just under } 2 \text { years } \\
\text { service) }\end{array}$ & $\begin{array}{l}\text { Client/Customer Services } \\
\text { (completed) }\end{array}$ \\
\hline $\begin{array}{l}\text { Trainee } 4 \text { - Middle level } \\
\text { management }\end{array}$ & $\begin{array}{l}\text { Female (just under } 2 \text { years } \\
\text { service) }\end{array}$ & $\begin{array}{l}\text { Adult Education and } \\
\text { Training (completed) }\end{array}$ \\
\hline $\begin{array}{l}\text { Trainee } 5 \text { - Junior } \\
\text { Administrative/Clerical }\end{array}$ & $\begin{array}{l}\text { Male (just under } 2 \text { years } \\
\text { service) }\end{array}$ & $\begin{array}{l}\text { First Line Management } \\
\text { (pursuing) }\end{array}$ \\
\hline
\end{tabular}

\section{Background to Ministry Y}

According to the Wilson matrix classification of state sector organisations, Ministry Y is a coping organisation involved in both policy implementation and service delivery (Gregory, 1995). The Ministry began its engagement in Industry Training in 1999, in a very limited way, but became heavily engaged in 2003. At that time, the Ministry was faced with widespread criticism of the quality of its service delivery, the cause of which was linked to the low level of educational attainment among its junior administrative/clerical and middle management staff. While senior managerial positions were typically filled by university graduates, the holders of junior administrative/clerical and middle management positions typically possessed at the time no more than high school qualifications, and had a long tenure in the Ministry.

The decision to engage in Industry Training was part of a wider change management strategy within the Ministry, which included changes in organisational structure, business processes, job re-design and introduction of new information and communication systems. In 2003, a new HRD manager was hired with extensive experience in Industry Training implementation. The focus of Industry Training engagement was in the area of customer service within the service delivery arm of the Ministry. Given the constraints of the research, focus was placed on the NVQ Level 4 \& 5 Leadership and Management Development Programme. However in addition to this programme, the Ministry also implemented a Customer Service programme and the Emerging Leaders programme, both at the NVQ Level 3. Additionally there was a programme in place in partnership with the Victoria University of Wellington for Maori and Pasifika graduates of the leadership and management programmes to 
matriculate to pursue post graduate studies in Public Policy or Strategic Studies. This was a part of the larger state sector initiatives to improve higher level educational access for these disadvantaged groups in the labour market.

Based on the data gathered from the interviews, during the initial years of implementation, the Ministry experienced numerous challenges, all relating to capacity issues to support Industry Training. While the training materials and curriculum were provided by the Industry Training Organisation, the materials required rewriting to meet the needs of the Ministry's learners. In particular, care was taken to utilise language and examples that were typical to the Ministry. Initially, external consultants and assessors were engaged to re-write the materials as well as to conduct the assessments. At the outset, evaluations of the quality of materials and assessments were undertaken. This involved examination of the training materials to ensure alignment with the organisation's needs and culture, as well as examining the quality of the assessment process. Both were found wanting, which led to the organisation hiring full time staff both to develop, review and maintain training materials, to manage the Industry Training process, and to conduct the assessments. This is also in addition to the training of other assessors who carried out these functions along with their full-time jobs.

The Leadership and Management programme trainees were all middle managers within the Ministry, many of whom did not have any post high school qualifications, although some had bachelors degrees and post graduate qualifications. All the trainees had access to a wide range of internal training programmes prior to commencing this programme.

The programme was designed to both develop and to recognise management and leadership skills. Trainees could request to engage in the programme, but all had to be recommended to participate in it. Once selected, the trainee and his or her manager were notified via e-mail, with an explanation of the requirements by both parties. A meeting was then set up with a learning coach, in which the relevant documentation, (which included guidelines and assignments), was passed to the trainee, as well as clarification provided. The trainees were also provided with a peer coach, which was typically a colleague who had already completed the programme, who could be called 
upon for assistance. Trainees also met with their supervisors at the beginning, during and at the end of the training to discuss assistance required and how the training would be utilised.

The programme took the form of a number of self-directed assignments, usually around solving a variety of leadership and management challenges. At the end, the trainees were required to meet with the assessor, who then provided feedback, which could mean them passing or having to re-submit assignments.

Upon completion, formal evaluations were conducted with the trainees as well as their managers to assess the quality of training, as well as how the training was used, using a series of closed as well as open ended questions. Additionally, the assessment process was evaluated annually using a structured quality assurance system, aimed at maintaining consistent quality standards. This was also accompanied by an annual review of the training materials based on feedback from trainees as well as assessors.

Additionally a summative evaluation of the programme was done some months prior to the start of data collection, which used a questionnaire of open and closed questions to determine the quality and impact of the training programme, both at the personal and organisational level, targeting both trainees and managers. Overall, this evaluation report revealed a high level of satisfaction with the programme.

At the time of the research, the Ministry had 518 managers who had completed the Leadership and Management programme. A total of 15 interviews were conducted with 2 HRD managers, 3 managers/team leaders and 10 trainees. All these trainees, (five males and five females), were middle managers with service ranging from a minimum of $8 \frac{1}{2}$ years to 25 years with the Ministry. Most had no other tertiary qualifications prior to completing the programme, with the exception of 2 male trainees who had degrees. One female trainee, at the time of the research, had matriculated from the training programme to the post graduate programme in Public Policy. As outlined in Appendix A, these interviewees are identified as respondent 36 to 50 for confidentiality purposes. 
In both organisations, staff were spread over the entire country and even overseas. As a result, off the 25 interviews conducted, 10 were conducted by telephone with respondents from various geographical locations. Findings from data collected from managers including HRD Managers were analysed separately from the data collected from trainees, in order to compare managerial perspectives with trainees' perspectives.

\section{MANAGERIAL PERSPECTIVES}

\section{What value do managers derive from engagement in Industry Training?}

There were significant differences in the values identified across the two organisations among the managers interviewed. Managers from Ministry Y identified a) skills and skills utilisation, b) the creation of a learning culture, c) staff motivation and engagement, d) increased equity, access to learning and self confidence, as the values derived from Industry Training engagement. In contrast, most of the managers from Department X perceived e) no real value or limited value from engagement in Industry Training. The differences in the organisation's experience of Industry Training implementation account for this variation in perspectives.

a) Skills and skill utilisation

Within both organisations, the acquisition and utilisation of skills were identified as the most important value derived from engagement in Industry Training. However, this benefit was much more emphasised among respondents from Ministry $\mathrm{Y}$, and much less so in the other. This is not surprising, as the view expressed by most respondents from Department X was that Industry Training was "not working." In fact only one manager in that organisation identified skill utilisation as a benefit of Industry Training, whereas all the managers from Ministry $\mathrm{Y}$ identified this as a benefit. Below are examples of some of the statements to this effect: 


\section{Department X:}

Respondent 28

"One of my staff was doing a problem-solving work-based project as a part of a NZQA qual, and she made a recommendation to me about how we could improve the waiting time for call-in services by adding a phone line. It was brilliant. We implemented her recommendation and it improved our productivity tremendously. If I can get a couple of suggestions from staff like that, then I would say the training is worth the investment."

Ministry $Y$ :

Respondent 38

"After the training, it just brought home to her that she couldn't achieve everything by herself, but to involve the whole team.... And we had to say to her, 'Let some go. Put into place what you have learnt about how to involve other people.' It made a difference to the way in which mail was sorted and distributed."

\section{Respondent 40}

"From learning from that NZQA system, they might have come back and put into place something learned, which has improved the workflow, has given us good value for money. It saved us a lot of time and effort and money. So that could result in a pay rise."

\section{Respondent 41}

"We provide technical training as all organisations do to help them to do their job. So what we will do is we provide technical training that says this is what good customer service looks like. When you are dealing with a client, we do these sorts of things, and this is what good customer service looks like."

What is expressed here is reflective of a performance oriented view of training, with a heavy emphasis on the application of learning. This also aligns with HRD literature that advocates that the ability to transfer learning is where the emphasis should be placed in order to derive the performance benefits and value-add from training investment (Brinkerhoff, 1989; J. Phillips \& Stone, 2002). In Ministry X, respondents further noted that the specific value that Industry Training provides is its structure, which lends itself to a consistency not only in training delivery, but in quality, as the following statements exemplify: 
Ministry X:

Respondent 36

"And it also provides a platform of consistency."

Respondent 41

"What I've found generally is because they have found the training beneficial, they do apply it. So I haven't had to say why are you not doing this. They actually use it; they use the information, the added knowledge that they have gained. They apply it in their work generally, because I'm familiar with it, all the language that is used is what we do. Coaching is a term we use, and coaching means the same thing to us. So when I am talking about their style and that, we are speaking the same language. The follow-up with the managers have been relatively easy because they have found the training useful. They take it back and they do use it."

For Ministry Y managers, value was derived from the ability to tailor the Industry Training provided to their organisation-specific requirements. Industry Training played the role not only of equipping staff with specific skills, but in organisational acculturation. The secondary data also corroborated these interview findings. Specifically, Ministry Y's employee evaluation system and its accompanying competency profile mirrored the competency standards attached to the qualification, as it related to the trainee's supervisory functions. Additionally, there were comprehensive business and training plans which outlined the linkages between the Industry Training programmes and the performance expectations. In contrast, there was an absence of any kind of secondary data in Department X, which corroborates the interview findings that there were no clearly documented goals for Industry Training in the Department.

The findings here appear to support the Critical HRD/Stakeholder perspective in that VET is largely unitarist and performance oriented. However, in the context of the state sector, this can be seen as a public good, as the services provided by state organisations are expected to benefit the general population, as opposed to simply earning profits for a few shareholders. Also, given the definition of VET in this research as upgrade training, it is reasonable that such VET interventions be performance oriented in nature, as it is supposed to be designed to deliver workrelated skills in an organisational context. The findings also reveal that managers play a critical role in terms of providing learning support through feedback and coaching, 
among others. However, this role definition and execution is carefully and deliberately planned, managed and assessed in Ministry Y. This reflects the Harvard Business School model of HRM, where HR and organisational practices have to be designed to create alignment and value (Beer et al, 1985). This then supports the Critical HRD/Stakeholder perspective in that roles of stakeholders cannot be taken as a given, but must rather be deliberately negotiated and executed. As seen in Department X, the clear definition of supervisory roles in relation to Industry Training was not identified; neither were other HR and organisational practices supportive of this training. This also has implications for the use of certain quantitative indicators to measure VET success. For example, completion rates do not reflect this benefit of trainees. The experience of Department $X$ revealed that in many instances, qualifications can be acquired without utilisation in the workplace. Finally, the benefit of skill utilisation has strong links with the specificity of training, in that the greater the level of tailoring of the training to the organisational context, the greater the level of skill use. However, this raises questions in relation to the portability of these qualifications.

b) Creating a learning culture

The creation of a learning culture was a value identified by managers in Ministry $\mathrm{Y}$ only. The view was commonly expressed by these managers that, prior to implementation of Industry Training, it was challenging to get employees interested in pursuing learning opportunities; the situation was reported to have largely been reversed, with staff members now actively seeking learning opportunities, rather than having to be prodded. What also seemed to be vital to respondents was the benefit of recognising the skills of employees, and how this contributed to enhanced learning and job performance. As the leadership development programme was also heavily focused on recognising the skills the trainees used in carrying out their jobs, Industry Training then provided a platform for trainees to better understand the skills they had and how they could be better used. The following quotations provide some examples of this perspective: 
Ministry $Y$ :

Respondent 40

"So that's about goal setting, having plans, if you want to go somewhere, making sure you have a plan. That you are evaluating, you're checking things. And if things aren't going right, then you are looking at solutions to try to bring it on to track or it may even be that you shouldn't have been doing that, and so you have to completely re-think. Just part of that structure of having to learn, having to seek out information etc. For some people, they have never done that."

Respondent 39

"...it is more of an urgency around the work that they do, and the influence that they have on other people, other staff. What I mean by that is because they have a bit of a wider picture, they can then impart that knowledge to the other staff members. And they also encourage staff to look at their own development. So obviously if people are starting to do that, then usually proactivity starts to improve as well."

\section{Respondent 38}

"Also, like I was saying, it is that self awareness and understanding your job that you actually do. And a lot of people, you know, they know that they do the job. But when you get them to talk about all the different things that they do, it is quite eye opening and they feel like they have really achieved something."

For Ministry Y, the secondary data also supported the interview findings. This was evidenced in the learning and development plans that were implemented for all trainees, and specifically for how they would utilise the Industry Training in their jobs. The organisation's training plan and offerings found on the intranet also revealed that trainees were exposed to a variety of learning affordances on a continuous basis. Additionally, copies of speeches from the Ministry's Chief Executive found on the intranet also revealed repeated references in support of Industry Training and continuous learning.

This shows then that these managers' perspective towards Industry Training was not only performance oriented, but that they were also interested in the developmental benefits. The two perspectives here are not viewed as opposites, but as harmonious partners. This runs counter to some of the views expressed in the Critical HRD literature, which tends to see the performance expectations of training as being in opposition or neglectful of the developmental goals of training (McGoldrick et al., 
2001). Additionally, the Strategic VET logic appears to be reflected here, particularly as it relates to the capacity of VET to simultaneously meet multiple and mutually beneficial goals. However, the findings here expand the programme theory, and highlight some other important inputs. What is clear from above statements is the importance of the input of communication - imparting, talking, encouraging, influencing. This appears to be a necessary accompaniment to foster not only the learning environment of which they boast, but also the transfer of learning. This mirrors the findings from the literature on informal and tacit learning. These writers argue that the distinction between formal and informal learning is blurry, and in fact both work together to create value for individuals and organisations (Billett, 2004a; Kitching, 2008a). This then is not a new insight, but it is an insight that has not been fully brought into the VET policy literature, where the input foci tend to be on funding and other institutional and structural arrangements such as qualifications framework. These, while important, may not be sufficient to realise the expected gains from VET investment. This points to an expanded understanding of the role of managers in the value creation process. Not only do they facilitate the identification of skill, but they also have to play an active role in creating opportunities and structures to create the learning environment.

\section{c) Staff Engagement/Motivation}

For managers in Ministry Y, the creation of a learning culture was associated was the increased engagement and motivation of staff. It was postulated by these respondents that increased staff engagement was an outflow of increased self awareness on the part of trainees of their skills. Also Industry Training seemed to create a platform where staff was encouraged to engage in training application in solving operational problems or improving service delivery. This in turn led to the view that staff felt more valued for their contribution as well as for the opportunity to undertake the training. The following statements highlight these viewpoints: 
Ministry $Y$ :

Respondent 36

"It's about the outcomes we achieve for our clients, and I guess the key is that our staff are engaged in making the difference in that respect. The better engaged they are, the better results they are getting."

\section{Respondent 41}

"...it does also instill some sort of self confidence I guess. That you are confident in your role, and then confident to look around at other roles and then explore other opportunities, look at other developments."

Respondent 39

"I definitely saw that people did feel valued getting the opportunity to undertake the qualification."

There was secondary data which corroborated these interview findings; the annual employee engagement survey was used, along with the employee evaluation system to gauge levels of staff engagement and motivation. It should be noted these instruments were focused on evaluating a number of elements, of which training was only one factor.

In Department X, only one manager identified Industry Training as having the value of staff motivation, as the following statement reveals:

\section{Department $X$ :}

Respondent 29

"This is a very isolated unit, and there isn't that much scope for mobility, so by offering my staff training, it gives them a boost, and let's them feel valued."

Here then Industry Training was seen as assisting in increasing staff morale in the face of job isolation and limited job mobility.

The outlook expressed here by these managers is pluralistic in that the value is defined not just in terms of fostering employee engagement and organisational performance but also in terms of personal value to the trainees as well as clients. VET then assists in facilitating a social exchange among stakeholders. Strategic HRD/VET 
perspective would assume that this exchange is a given and mutually beneficial. However, taking a Critical HRD/stakeholder perspective, it can be argued that this is an assumption that may not always be reflected in reality. For example, as seen in the last quotation, Industry training can also be offered in exchange for lack of other opportunities for development such as career prospects, which could potentially lead to even further employee demoralisation (Wood \& Wall, 2007). Furthermore, it could also be argued that the focus on staff engagement is ultimately geared towards instrumental purposes - how to get higher levels of work output - and was not an end in itself.

\section{d) Access/Equity/Self-Confidence}

In Ministry Y, while it was not the main focus of Industry Training implementation, managers noted that the provision of the training created increased access to educational opportunities to a number of trainees who, prior to Industry Training, had only high school qualifications. What was of value to the respondents was the transformation that Industry Training engagement brought about in the trainees' lives, particularly their new levels of self-confidence, as the following statements reveal:

\section{Ministry $Y$ :}

\section{Respondent 36}

"I can tell you, this one Maori lady. She had been working here for years. Didn't have any qualifications, didn't do well in school. Thought she couldn't learn. She was a good worker, but she had no belief in herself. We encouraged her to do the training. After much prodding, she did. She not only completed, she matriculated into the Masters in Public Policy at Vic. Today she heads up a division in one of our sister agencies. Completely transformed. That is what this training can do."

\section{Respondent 38}

"One of my managers, before the training, she could hardly speak. She had no self-confidence. After the training, she was making presentation before the Chief Executive and other senior managers."

Respondents also noted however that the training was accessed by employees with varied educational qualifications, including those with degrees, and expressed the view that the training was also valuable to these trainees. They noted however that the 
impact on trainees who previously had no qualifications was greater, and the pride the managers took in observing this transformation was very evident from the interviews.

For both entities, as is the case with all organisations participating in Industry Training, it is a requirement to target disadvantaged groups such as Maori and Pasifika employees, and to report these statistics. However, for Ministry Y, this data was readily available and used in their internal training reporting. Additionally, the Ministry also had a documented strategy for staff development for Maori and Pasifika employees.

This represents a pluralistic perspective towards Industry Training, and is also reflective of equity initiatives within the state sector (Edgar \& Geare, 2007). From a managerial perspective in Ministry Y, it appears that Industry Training can achieve multiplicity of goals and address the needs of all stakeholders. The Strategic HRD/VET logic then reflects this organisation's reality, at least from the managers' viewpoint.

Interestingly, this was not a value identified by any of the managers from Department $X$ at all. Department $X$ in contrast only had a statement of broad intent in an organisational memorandum, speaking to the enhancement of learning opportunities for employees, and in particular Maori and Pasifika employees, which was issued at the commencement of Industry Training engagement. However, there was no other documented programme or strategy geared at these equity goals. This also suggests a distinction between espoused theories and theories in use as it relates to the use of Industry Training in this Department (Schein, 2004). This highlights that VET outcomes are not universally accepted and defined, even among a particular stakeholder group. This aligns with the Critical HRD/Stakeholder logic which argues that, potentially there are multiple programme theories at work in VET implementation, and homogeneity of goals and experiences among and within stakeholder groups cannot be assumed. 
e) No Value

In Department X, most of the managers interviewed expressed the view that Industry Training qualifications were of little or no value. Below are some of the specific views that were expressed:

\section{Department $X$ :}

\section{Respondent 31}

"...we are not prepared to do it just for the sake of it. We need to see if there is a value for the people doing it. There are some qualifications in the public sector which I question their value, like there is one around public service induction or something like that. Well, why do you need a qualification to say that you've been through an induction programme? That to me is nonsense. And I think, there is a lot of those out there. But people get funding for them, so it is a great thing to have. I'm quite sceptical about the number of qualifications, the number of unit standards that there are, and the level of some of those unit standards as well."

Respondent 30

"It's a bit of paper, great. No value."

\section{Respondent 29}

"The other thing about NZQA unit standards is that a lot of them have been dumbed down quite a bit; they are quite easy to achieve."

The perception of the lack of value appeared to emanate from varied sources and experiences, whether in the ease with which the qualifications could be achieved or the proliferation of state sector qualifications, without the attendant value being made explicit to the respondent. It should also be noted that some managers interviewed were unaware of the fact that their supervisees were pursuing Industry Training qualifications, until they were asked to participate in the research. This then would naturally increase their perception of the lack of value, given the poor communication surrounding Industry Training in the organisation.

The Strategic HRD/VET logic then does not apply to this organisation. Industry Training engagement here did not equate to valuing of Industry Training necessarily, 
and certainly not to other outcomes identified such as skills utilisation. This can be explained by the lack of goals at the outset of implementation, and lack of alignment and fit with the rest of the organisational operations. In the initial years of implementation, the organisation had an assessor, who was able to facilitate trainees as they undertook these qualifications, which led to higher levels of completion. As trainees were completing, Industry Training then was thought to be functioning properly. However it can be argued that the organisation could not have derived any value beyond completions. This aligns to what some writers refer to as the "training religion', in that all good and modern organisations provide training, so the provision of Industry Training fulfils the role of aligning the organisation to the image of good organisational practices. It can be therefore argued that this is too limited an expectation, which resulted in little value; a fact that became more glaring with the gap created from staff turnover in the Training Department.

It is also noteworthy that the managers in Department $\mathrm{X}$ were also unitarist in their determination of the lack of value of Industry Training, as they made no reference to other stakeholder needs, such as trainees, but related their views to strictly instrumental concerns, which were based on their personal opinions about Industry Training. Managers from Ministry Y, on the other hand, tended to view the value of Industry Training from a multiple stakeholders' perspectives - trainees, organisational performance, and clients.

\section{How is the value of Industry Training determined by managers?}

Ministry Y had a clearly defined system of evaluation, which could be described as providing both summative and formative evaluation of the Industry Training undertaken. This was corroborated by the secondary data available, specifically the development and implementation of a training communication plan, learning transfer plans and evaluations of assessors' performance in quality assuring the Industry Training offerings. The evaluation covered:

- Meetings between assessors and managers of trainees to determine whether the stated goals of the training were met, as indicated in the following quotations:

\section{Ministry $Y$ :}




\section{Respondent 37}

"They do it during the programme, but at the end of it, we did an evaluation with the facilitators, just where these people rated in the system."

\section{Respondent 36}

"Well at the end of it, we had to meet with the course facilitators and go through it to see just exactly how they had gone through the course."

- Meetings between managers and trainees to determine whether the stated goals were met and to develop and monitor learning transfer plans:

\section{Ministry $Y$ :}

\section{Respondent 38}

"Most of my managers that have done the leadership development programme, I get them together every couple of months and we do have a 2-day development programme. But they are usually ones that I have done myself or sourced out from various areas within the Ministry."

This was documented formally in Performance and Development Reviews.

- Meetings between assessors and trainees to determine whether the stated goals of the training were met, and how learning could be transferred

- Meetings between assessors and their managers. It should be noted that this organisation employed full-time assessors; therefore quality assurance is their full-time job. Formal performance evaluation for assessors is then part of the normal performance management system of the organisation. Additionally, the HRD manager noted that their performance evaluation was very heavily focused on the maintenance of the quality of training, and not on the number of completions. This was because it was felt that emphasis on quantitative targets such as completion rates, rather than on quality standards would undermine the value and perception of Industry Training within the organisation. Bi-annual reviews are conducted with assessors as well as the 
curriculum developers to review the actual training, and its materials as a part of a process of continuous improvement:

Ministry $Y$ :

Respondent 36

"Every year we are finding things that we can improve the way we are saying or asking for things."

- One-off survey of trainees and their managers - this consisted of a series of questions using Likert scale response, as well as the collection of written responses. A copy of the survey was provided, and the main focus was to determine the value of the Industry Training at the individual level, as described below:

\section{Ministry $Y$ :}

\section{Respondent 39}

"It was more about the actual value to you or value to you as a manager to actually having people... and are you actually seeing a difference from the ones that have gone through and completed the programme to those that haven't. Do you find that they are more focusdriven than perhaps those that chose not to. So trying to get that sort of differentiate to sort of determine.... And I think that was one of the key findings that we did find is that it does give them that energy to actually go out and may be do something else, try something else."

\section{Respondent 37}

"I think the other thing too is that we had a lot of free text within that survey."

It should also be noted that managers were very explicit about not attributing organisational outcomes to Industry Training only. Industry Training was viewed as being part of a wider equation to bring about organisational outcomes, key among them being improved client service delivery. This is illustrated in the following quotation from one of the managers interviewed:

\section{Ministry Y:}

\section{Respondent 36}

"The filtering effect is that we've got better developed managers who are managing better developed staff, who in turn are providing much better 
customer service to our client base. Much more professional, much more aware...We are getting a lot less complaints.... we are not getting the complaints we were getting. The types of complaints are not the same, always hating the way that they've been dealt with. Because at the front line our people are trained in Customer Service, and they've got appropriate processes in place to ensure that they minimise those sorts of complaints."

As noted earlier, the implementation of the leadership development programme for front line managers was a part of wider reform, which included customer service training, improved business processes and organisational restructuring. This is reflective of much of the HRD literature which notes the difficulty in attributing a causal relationship between training and organisational outcomes (Fleetwood \& Hesketh, 2006, 2007). However, from these managers' perspectives, this is not viewed as a difficulty per se, but as an accepted fact. Also from a decision-making perspective, managers appear satisfied that the Industry Training was playing its role in the wider organisational context which was to improve client service delivery among other goals. The evaluation mechanisms utilised therefore satisfies their data requirements (Holton \& Naquin, 2005).

Managers also used their experience and observations, as well as that of their colleagues to arrive at their assessments of the impact of Industry Training. The use of personal experience was certainly evident within Department $\mathrm{X}$, where no formal evaluation methods were used to evaluate Industry training there, whether directly or indirectly, as the following statement reveals:

Department X:

Respondent 27

"I haven't seen any surveys, documentation or anything that measures the success of using NZQA within ."

Whether or not there were formal evaluations, managers used their experience of interaction with their supervisees, as well as reflections from colleagues as a means of evaluation. Some managers were able for example, to recount examples of employees utilising the skills received or exhibiting self confidence or accessing promotions as well as other learning opportunities. Managers in Department $\mathrm{X}$ also depended on their experience to arrive at the view that Industry Training was of little or no value. In other words, most of them believed it to be of no value because they could not 
observe the value, whether in terms of the acquisition of usable skills, or changes in performance or other behaviours. Additionally, given the poor communication and the lack of clear expectations of Industry Training in the organisation, managers would naturally have been unclear on their own expectations.

Both organisations used quantitative indicators as a means of determining the value of Industry Training. Both utilised completion rates as a means of determining at least one element of training success. For Ministry Y, completion rates were important in that it was an indication of the extent to which the programme was being smoothly implemented, and that trainees were satisfied with programme quality. From a financial perspective also, completion was important as it was the basis on which training subsidies were granted. However, it was emphasised that quality of training delivery was more important than number of trainees, as the following statement revealed:

Ministry $Y$ :

Respondent 36

"But we had to manage that so that it wasn't all based around how many people you get through. It was more based around your performance as an assessor. So it was looking at how did your moderation stack up? Because if people are frequently getting through and moderation is saying that is not good enough, then we need to look at the issues that are being raised in that."

In Department X, the Training Department reported that of the 100 trainees signed on to an Industry Training agreement at the time of the research, only $1 / 2$ were actively pursuing the qualification. This was then viewed as the main indicator of the lack of success of Industry training within the organisation. Further, the signing on of the 100 trainees was viewed as the pursuit of numerical objectives, something which was viewed negatively, as it was not properly focussed or thought out. Below is one of the observations made in this regard:

Department $X$ :

Respondent 27

"However, the way that it has been run here up until now, in that anyone has been able to sign up. So that's even people who are part-time, people who are under-performing." 
There are clearly vastly different evaluative practices and evaluative perspectives within these two state sector organisations. For Ministry Y, evaluation practices are pluralistic and inclusive, in that they sought to involve the perspectives of the stakeholders - assessors, managers, trainees. Additionally, evaluation was designed to evaluate a variety of outcomes - performance outcomes, developmental outcomes as well as educational quality outcomes, again from the perspectives of the different internal stakeholders. While some of the evaluations undertaken were strictly related to measuring the impact of the particular Industry training programme, much of the evaluative practices were integrated into the wider HR practices and organisational operations, for example, the use of performance evaluations and developmental reviews.

This in many ways aligns with the Critical HRD/stakeholder perspective for two reasons. First, the fact that stakeholders' perspectives are sought out means that it is not assumed that the outcomes are automatically considered to be mutually beneficial to all stakeholders. Secondly, there is a preference for the use of both qualitative and quantitative data, with perhaps a greater leaning towards qualitative data, gathered both formally and informally. Evaluation is then value-laden, as it centered around what is valued - quality of assessment, skill use, impact on trainees. The value-laden nature of evaluation is also accepted by the organisation, and as such, evaluative practices sought to unearth what those differing values were from the different stakeholders' viewpoints.

For Department X managers, the limited formal evaluation seemed to be associated with their perception of the lack of value. This is not surprising, and it can be argued that given the lack of clear goals and the undervaluing of Industry Training in the organisation, it followed that no resources would be spent on developing any formal evaluation mechanisms for Industry Training, whether directly or indirectly. Their use of the completion rate as the only performance indicator for Industry Training aligns to their goal of having staff complete qualifications. 


\section{How is value created for managers from engagement in Industry Training?}

The HR infrastructure (a) and training subsidies (b) were identified by the managers interviewed in both organisations as the key factors that helped to create value from Industry Training engagement. However, there were stark differences between the organisations in terms of the quality of the HR infrastructure, attitudes to training subsidies and the resourcing of Industry Training.

a) HR Infrastructure

In both organisations, the HR infrastructure was identified as a key factor in creating value from Industry Training. In the case of Department $X$, the absence of this infrastructure was cited as the main factor inhibiting the organisation from realising the value from Industry Training.

The characteristics of the HR infrastructure that were identified by participants were top management support for the training, the technical capability to implement Industry Training (including training design, assessment, understanding of the qualifications framework), and wider organisational support for Industry Training (including managerial support). In the case of Ministry $\mathrm{Y}$, all the managers interviewed identified top management support for the leadership development programme as being one of the keys to realising the success the organisation had experienced. The CEO in particular was identified as being important in championing the programme, as the following statement exemplifies:

\section{Ministry $Y$ :}

\section{Respondent 39}

"The executive actually does talk about leadership versus management, and how important it is going forward, and he has done for some years around that. So I suppose if it is being messaged at the top, it starts coming down, then people will get behind it."

This top management commitment was also translated into the Industry Training technical capacity that was necessary for implementation. Interviewees, particularly those from the Training Department described at length the process and the 
mechanisms that the organisation put in place over time to ensure the successful implementation of the programme. These are outlined below:

- Hiring of a new Head of Training with extensive experience in Industry Training implementation;

- Undertaking a comprehensive needs analysis, which involved numerous meeting with employees and managers to determine what was the exact nature of the jobs involved;

- This then translated into the design of the training. This involved initially the employment of external consultants; however over time, this capacity was developed internally;

- Once the training was ready to be moderated, an extensive communications campaign was undertaken across the organisation, geared at informing employees about the programme, its intent, and what they could expect. It was also geared at getting buy-in;

- At the time of the research, the organisation employed a team dedicated to managing the programme components, inclusive of pre-moderation, moderation and assessment functions. They also customised the State Sector qualifications to align with their organisational needs, and this was subjected to constant review.

The HR infrastructure also included the support that managers provided to the trainees directly, as the following statements show:

Ministry $Y$ :

Respondent 38

"My role was to be a sponsor for them and to assist with any ideas or plans they wanted to put through for leadership or being in a team environment. I was just a general overall support for them. So if they struck a problem in their understanding of the course facilities or the programme, then I would suggest this is what you do, or go and see that person to get direction."

Respondent 39

"But this is something - every 3 or 4 months, we have coaching sessions with each service manager, right? And from that coaching session, we look at what their needs are, what they would like to see themselves doing, keep themselves 
updated. So they choose to do this NZQA leadership course as part of their development."

Respondent 40

"Depending on which programme it is, my role is around making sure that they get given the space to do what they need to do. Also if they need to have developmental opportunities, I need to try and slot those in for them. Part of my role is also in supporting the managers who are maybe looking after some of these staff. So it might be that I might mentor them up with another manager, a more experienced manager. If it is a staff member doing the Emerging Leaders programme, I will link them in with another manager just to provide them with some guidance and talk to them about what's happening at a higher level and stuff like that."

\section{Respondent 36}

"They go and do the training and on completion of the training, we talk about what it has meant to them, and how they are going to apply it in their role, and as part of on-going coaching, we just follow-up and make sure that they are actually applying the new training."

For Department X, the lack of HR infrastructure was identified by managers as a major factor in the failure of Industry Training within the organisation, as the following statements highlight:

Department $X$ :

Respondent 29

"And I think it is about getting that culture around the team leaders that a key part of their role is the development of others, and creating a space for people to take something that they have learnt on a course and transfer it back unto their jobs. For too often people come back from training, get work dumped on them, and go back into their old habits, because they are not actually given any space in which they can try out and develop the new skill."

\section{Respondent 27}

"So it's like getting team leaders to understand their role in the training process. It's what they do before the person goes on training, but also what they do when they come back. And that's about creating space for people to apply what they have learnt to the job, and accept that they will be slower; they won't do it as well as they might in 6 months time. It's just a higher understanding of the learning process that people go through."

Respondent 30

"I've been trying to establish what development there is. And I couldn't tell you to be honest. There seems to be very little in for the staff. We are 
doing performance agreements at present. One of the requirements is 'What are your career aspirations? What development plan do you have in place?' We are currently struggling to fill that, to try and find answers. And I am not alone as a Team Leader. It's that time of the year when we are trying to do that."

\section{Respondent 31}

“And we've got team leaders who don't even really understand what NZQA is, so they can't even have a discussion with their staff member around that."

From the statements, it appeared that there was not sufficient understanding of or management support for Industry Training. Additionally, it also appeared that the organisation did not have clear goals for Industry Training; there were never any needs analysis completed, or any understanding of how it aligned with the jobs and wider organisational functions. The training programmes were not communicated effectively across the organisation; neither was it adequately resourced. The following statements sum up this assessment:

\section{Department X:}

Respondent 30

“And we've got staff, as I've said, who have been signed up for qualifications that don't fit with their job. At present, for example, I had someone on my team who received a unit standard via e-mail with no resources."

Respondent 31

"But sometimes you have to manufacture or create opportunities for them to experience, or to do what they need."

\section{Respondent 29}

"One of them has started a Certificate which I wasn't aware of, some time ago. This has only recently come to my attention....The majority of people don't learn by having to fill out a test. And that's all that's offered at the moment."

Respondent 27

"A few years ago, implemented what they called a blended learning strategy. And when they put this strategy in place, they looked at all levels of learning offered by the learning and development team. And it was just used to obviously to benefit staff by providing them with qualifications 
that they can work through on the roll, which is something outside of planned training courses, and systems training that comes in. And the idea is or the belief is that we would have - this is what I have read, the reason why it was implemented - greater staff retention, happier staff because they feel valued, because they have been given an opportunity to do something that not everyone is given an opportunity for."

The last quotation in particular echoes statements emanating from the Public Sector ITO, and the promotion of Industry Training across the state sector, and the advocacy for the use of blended learning strategies in training delivery. However, the organisation did not appear to have had a clear understanding of how that would be best used in their context. As earlier indicated, it is unclear which employees would be targeted for Industry Training and why - for example whether it was a part of the compensation system to reward good performance. Also there were no plans or discussions as to how it would relate to the wider training and organisational environment.

b) Training Subsidies

Interviews with the Training departments in both organisations revealed that the training subsidies provided through the ITO were an incentive for engagement in Industry Training. However, the subsidies appeared to have driven different types in behaviours and attitudes towards Industry Training in these organisations. In Department X, training subsidies made Industry Training a "cheap" training option, which made it attractive to engage in, as the following quotation suggests:

\section{Department X:}

\section{Respondent 27}

"I suppose the thing is, up until now, it has been a relatively cheap way of what the business has perceived - training people. Because there has been one person who has done the internal assessment pretty much. And they have provided what little training there might have been. So someone would ask how do I answer this question or where do I find this information, and they have told them. And of course, we get the refunds once someone completes a unit standard; we get a small refund from Learning State. So that's a subsidy towards the salary of the person who has been doing it. So it's been perceived as a rather cheap way of doing it."

The subsidies then incentivised Industry Training engagement but not strategic engagement, where it was a means to a specific end goal. In other words, it can be an 
erroneous assumption that organisations which engage in Industry Training are managing their training functions in keeping with normative HRD principles such as conducting needs assessment, and promoting learning transfer and use (P. Phillips \& Phillips, 2007). Additionally, it also appears that the funding was a means by which to provide training with minimal organisational commitment of its own resources.

Ministry $\mathrm{Y}$ also noted the importance of the training subsidies, as the following statement reveals:

Ministry $Y$ :

Respondent 36

"There are a lot of changes going on with the ITOs and the TEC, because the way they have funded it has changed. And for people like us, what used to happen is we would get a subsidy for the credits, which was good for us, because we could then use that subsidy to maintain our infrastructure. Now they are moving away from that. We are now having to support that infrastructure internally. And when times get tough, those are the sort of things people look at and ask do we really need this. Although we've been really lucky. With our front line people, we have had a little bit of a tightening up. Rather than an expectation that people will complete the qualification, now there is an application that they have to go through to engage in the qualification. That's not a bad thing, because it means that the people who are doing it, really want to do it. They don't feel they have to."

Here, the training subsidies were also important in terms of minimising the cost of Industry Training engagement, and its removal did force a re-thinking of the extent to which this engagement would continue. In this case, it would likely result in somewhat fewer numbers for trainees. However, in contrast, this organisation had committed much of its own resources to fund and support its Industry Training infrastructure. This difference emanates from different values and attitudes towards Industry training at the outset. For Department $X$, their goals appeared to be to provide cheap national qualifications to staff, with minimal organisational investment, as all training is beneficial and in keeping with normal organisational expectations and practices. For Ministry Y, their goals appeared to be to close the organisational skills gap in terms of customer service and middle management capacity. In other words, there were specific problems they encountered, for which the Industry Training was designed to provide a specific solution. However, the point of difference 
between the organisations is the specificity of purpose. The challenge then is not the absence or presence of training subsidies, but the intent of use of these subsidies.

This finding reveals a limitation in the Strategic VET logic, as it does not address value creation at the organisational level. It also assumes that the input of funding and qualifications system and framework are sufficient to create value (P. Smith, 2007). Findings here counter the logic. Funding can both create and hinder value. What appears more vital is the managerial attitudes and perspectives towards Industry Training - their understanding, values and expectations. Also what is vital is the HR infrastructure to underpin the training. Values and attitudes towards Industry Training come first. From that flow the systemic requirements - understanding of what is involved, the resources commitment, and quality concerns.

\section{TRAINEES' PERSPECTIVES}

\section{What value do Trainees derive from engagement in Industry Training?}

All the trainees interviewed from both organisations expressed the view that they found value from engagement in Industry Training. These values were a) skills and skill utilisation, b) recognition and c) self confidence. This finding is interesting in relation to Department $\mathrm{X}$, where the trainees also expressed a number of concerns about quality of the training process, which will be discussed later. Notwithstanding those concerns, they still held the view that the training was valuable. This concurs with findings from other research that trainees do find training to be valuable (Guest, 1999). However, trainees from Ministry $\mathrm{Y}$ expressed greater levels of satisfaction with the quality of the training process, and the alignment of the training to their jobs.

a) Skills and skill utilisation

All trainees interviewed (with the exception of one) from both organisations identified skills acquisition and utilisation as benefits they derived from the Industry Training programmes they undertook. Below are some of their quotations on the value of skills acquired: 


\section{Department X:}

Respondent 33

"Dealing with difficult customers... There was a writing unit, so things like writing e-mails. That's been beneficial."

Respondent 34

"Well I did a difficult customer talk with the group on how to treat customers. Part of that was taken from the paper."

Respondent 35

"It really helped me to better deal with clients. For example, clients from the Pacific Islands, before the training, I couldn't understand why they wouldn't look me in the eye. After the training, I have a much better understanding of their culture, and I now know how to serve them."

\section{Ministry $Y$ :}

\section{Respondent 46}

"I think it will, because you get a lot of opportunity to practice what you've learnt at work. I'm finding it really useful."

\section{Respondent 43}

"So for me, the benefit was being able to put my head around what's working for management - when you become a manager, what do you do?.... I think it is very important to have that upgrading of skills while you are working... When you are talking about your staff, there are more complications when you are a manager, than just making sure that your staff are reporting to you. Appraisals are very important, to have that relationship. It is a bit more stressful when you try to work around your staff."

\section{Respondent 42}

"I think that it is useful for identifying skills that you have, and how you can further use them to improve your centre.

Respondent 49

"You know, my team is one of the best teams in the country at the moment. This team has been winning the best team award ..... So that helped me to develop and support my staff."

Trainees then had a performance orientation towards Industry Training, which runs counter to Critical HRD/Stakeholder perspective tendency to view performance 
orientation as being unitarist and managerial (Antonacopoulou, 1999; O'Donnell et al., 2006). For these employees, the ability to improve their job performance was a distinct benefit they derived from their engagement in Industry training.

\section{b) Recognition}

From the interview responses, two different definitions of skill recognition emerged. The first view of skill recognition had to do with trainees being able to identify the skills that they possessed and used in their jobs. This was the case among many of the trainees from Ministry $\mathrm{Y}$, which is not surprising as leadership skill recognition is a major component of the Industry Training programme here. Also linked to this view is the recognition on the part of the organisation of their skills and contribution to the organisation, as the following quotations reveal:

\section{Ministry Y:}

\section{Respondent 44}

"The main benefit for me at this stage, I guess for me, is the acknowledgement that the work that I do is at that level, that standard."

\section{Respondent 47}

"The Ministry invested that back into me so I have something to show for the skills and experience that I have gained along the way."

\section{Respondent 42}

"It gave me a greater awareness of my own skills. It wasn't that it developed new skills, but it was about recognising some that perhaps I hadn't recognised that I might have had."

The other view of recognition relates to the portability of the qualification, and its value in terms of career prospects. Some of the interviewees from Ministry Y, while finding the training valuable in terms of skills acquired and used, tended to view the training as being of little or no value in terms of provided career advancement. The following statements highlight this perspective:

\section{Ministry $Y$ :}

\section{Respondent 48}

"Hmm, to be quite honest, whether it puts you to the head of the class for promotion opportunities, no (with emphasis) I don't think so. I think your 
reputation and skills and capabilities will do that for more than actually what your formal qualifications are in the Ministry."

\section{Respondent 47}

"But it is totally unique to . I don't think you would be able to deliver some of it anywhere else. So I don't think it would be very valuable going out into the private sector."

\section{Respondent 45}

“... it hasn't affected the future prospects I have... there doesn't seem to be a rhyme or reason or a real understanding of what we can get out of doing this."

\section{Respondent 50}

"I would say, 'Well you're probably better off going to do something at uni or picking up some management papers.' Because at least it's more recognisable; at least it's more internationally recognisable too I suppose, than just sort of training programme that you get done through your work."

Respondent 44

"Whether or not that actually has any value externally to employers, I'm not sure. ...I don't know how much value that would have now that I am doing a Masters degree, I know that my little certificates look pathetic next to a Masters."

This is a perspective that was also shared by some of the trainees in Department X, which is exemplified in the following statement:

Department $X$ :

\section{Respondent 33}

"It was really just a thing to do for my own benefit I suppose, no great benefit in terms of advancement or anything."

Only two trainees who were interviewed, both of whom were employed by Department $X$, expressed the view that their qualification assisted them or they expected it would assist them in improving their career prospects. These were their comments:

Department $X$ :

Respondent 34

"I did the Customer Service course, and I think it did help me to get my current role which is a Customer Service one." 
Respondent 32

"And if I went to get a job elsewhere with that certificate, I would be more preferred than a person that didn't have it. And I think it is also recognised in Australia."

There are several issues raised here. First, that awareness of one's skill level is a legitimate benefit to trainees, and broadens the definition of upskilling that exists within the policy literature. Upskilling is normally seen as acquisition of new skills or higher levels of skills. Here what we see is that identification of skills in use is important, as it is linked with increased skill use, or better use, as well as increased sense of self worth and confidence. Second, increased specificity of training seems to increase utilisation, but leads to a decreased perception of its portability in the wider labour market, or its ability to improve career prospects. There are a number of possible reasons for this. Within the state sector, respondents noted that there is a preference for university qualifications, particularly for career progression above middle management levels. Also, the career structures and the rules for how employees progress within the state sector also shape how Industry Training qualifications are viewed. Employees are promoted based on a merit system, and positions are advertised; promotions are not automatic and pay increases on completion of Industry training qualifications are not an organisational norm. Also a variety of factors would be taken into account in making a decision to promote an employee, key among them being their performance record. The following quotation captures these factors:

Ministry $Y$ :

Respondent 46

"If you put in place what you have learned, and you improve your performance, you can then increase your chances for promotion or increase pay. But no, it is not automatic."

Also, due to the specificity of the training, the trainees interviewed tended to view it as workplace learning, and did not perceive its utility outside of the organisation. The trainees from Department X pursued qualifications that were more general, and were not tailored to their specific organisation. However, to link their perspective strictly to the general nature of their qualification could be faulty. One of the individuals had a specific experience of being promoted into a position that was aligned to the Industry 
Training qualification. The other was pursuing a qualification in the training field which is internationally recognised. What this could imply then is that portability is dependent on career structure, organisational characteristics, the field of study and the reputation of the qualification in the wider labour market. Also, they would be aware of the culture and processes for promotion within the state sector, so they would not have that expectation. Examining this issue from a Critical HRD/Stakeholder perspective, there is no equal valuing of Industry Training, as perspectives are value laden, and to some extent dependent on organisational characteristics. Also, based on this data set, the norm in the Strategic HRD/VET logic of viewing career progress as an indicator of VET success is faulty, as career progress is more complex, and not solely linked to VET completion (Skills for improved productivity, employment growth and development, 2008).

c) Self Confidence

Particularly for trainees who were mature learners, and who had not pursued any qualifications for a number of years, Industry Training helped to restore their confidence in their ability to learn, and provided them with a sense of accomplishment, as the following statements suggest:

\section{Department X:}

\section{Respondent 33}

"It felt really good to complete the courses. I didn't think that I would ever be able to study again at my age."

\section{Ministry $Y$ :}

\section{Respondent 47}

"Apart from the fact that it was nice for me to achieve it at personal level,..."

However, some trainees from both organisations who had other tertiary qualifications also identified increased self confidence as a benefit they derived from Industry Training. This was particularly true of trainees whose degrees did not include supervisory management education (in the case of those who completed the leadership development programme), or whose degrees were in a different field from the particular Industry Training qualification. For them, the training provided them 
with confidence to either manage other employees, or confidence from being competent in the specific field and developing other life skills, as the following statements reveal:

Department $X$ :

Respondent 32

"Basically to become a confident trainer that can realise the needs of the learners. And to teach them in the appropriate way, that would be responsive to their needs."

Ministry Y:

Respondent 43

"Sure I did a degree. But I didn't learn how to manage staff. I picked a few things over the years, but the training helped me to cement my knowledge on how to supervise. Now I know what I am doing, instead of just fudging around and hoping for the best."

Respondent 49

"But it helps you personally as well. I've got young kids, you know. My son is 22 and my daughter is 16,17 now. And when I did the course particularly on how to deal with difficult behaviour, that helped me to change my way of living. That helped me to support my kids in a better way. So it did help me personally ...."

These trainees then gained personal value, as the training equipped them not only with skills, but allowed them to gain the confidence to lead fuller lives. This is in keeping with findings from other training research, which concluded that the development of human capability should ultimately end in this outcome - increased capacity to lead a better life (Bryson \& O’Neil, 2008; O’Donoghue \& Maguire, 2005). This is reflective of the Strategic HRD/VET paradigm, which views VET as being targeted towards pluralistic goals, and having the capacity to meet both performance and developmental VET outputs.

\section{How are these values determined by State Sector trainees?}

Trainees in both organisations determined the value of Industry Training based on their personal experience. This reflects other observations made elsewhere in the policy evaluation literature that, at the individual level, persons rely on their experience of public policy as their means of evaluation (Thomas, 2006). Skills for 
example, were determined largely by the extent to which they were able to utilise the skills in their jobs. Recognition of skills was determined through the assessment process and feedback in Ministry Y. Recognition when defined as portability and career progress was determined either by personal experience of progression or by trainees understanding of the job market for the skills which seemed to be derived from perceptions and information for peers. Self confidence naturally was determined by their personal experience of increased self confidence.

Organisational context also seemed to play a key role in trainees' determination of the value of Industry Training. Many trainees, for example, were encouraged to undergo Industry Training because other work colleagues had done the training, giving a sense of it being valuable within the organisational context. The following quotations convey this role of the organisational context in determining value:

Department $X$ :

Respondent 32

"Because quite a lot of people in my team who are trainers have completed the training. So it seemed worthwhile for me to do it as well."

Ministry $Y$ :

Respondent 44

"And also I was a new manager, and I felt that all, pretty much all the rest of the managers who had been around for a long time had done something like that, something similar to it. And I did not want to be behind them. I wanted to have as much information and knowledge as they did."

\section{Respondent 47}

"A couple of the other managers had done them previously, and had said that they were quite good. So we said we would give it a go. So yes, previous people who had done the course had said it was worthwhile. So that was good; that's what pretty much made up my mind."

Organisational context then is a filter through which value was assigned to Industry Training. In the case of Ministry Y, due to the large numbers of managers who had done the programme over time, and the infrastructure and communication that had developed around it, the organisation was able to build up a community of practice. Therefore there is common valuing of Industry Training; as a result, employees then 
believed it to be valuable. For Department $X$, while they may have had a large number of trainees, they were pursuing different programmes largely in individual silos. In some cases, trainees commenced programmes without the knowledge of their managers. This, coupled with the lack of communication and infrastructural support, meant that no community of Industry Training practice developed. This then led to undervaluing and other challenges with Industry Training here.

These findings support the Critical HRD/Stakeholder perspective on evaluation, as the limited range of quantitative indicators preferred under the Strategic HRD/VET perspective, do not reflect the trainees' perspectives identified here. The use of qualitative data allows for a richer understanding of VET value through the eyes of trainees. Further, the value of Industry Training to trainees does not exist as external facts outside of their experience; rather outcomes - whether beneficial or not - are part of the employee experience. Another crucial finding here is that the critical role played by the workplace structure and culture to either enhance or minimise the value of VET for trainees, as the workplace community, including quality of management and work relationships with co-workers and mentors, all impact the quality of the learning experience, and directly shape trainees' perceptions.

\section{How are these values created for State Sector trainees?}

The quality of the HR Infrastructure provided by the organisation was the single definitive creator of value for State Sector trainees interviewed. This supports other views on the importance on workplace quality in fostering workers' development (Fenwick, 2006; Ryan, 2007). Specifically, trainees identified a) the level of organisational support, the alignment between the training and their jobs, and b) the quality of the training and assessment process as the specific factors that helped to make the training valuable to them, or conversely, to de-value the training. Trainees from Ministry Y expressed very high levels of satisfaction with the quality of the HR Infrastructure provided. On the other hand, trainees in Department X experienced a number of deficiencies in the HR Infrastructure, which posed numerous challenges for them. 
a) Level of Organisational /Alignment between training and job function

Being able to access support to complete the training was identified by trainees as a major factor in creating value from Industry Training engagement. In Ministry Y, trainees identified their managers, training mentors and their peers as the main sources of support, as exemplified in these quotations:

\section{Ministry $Y$ :}

\section{Respondent 50}

"I guess the support that we used was that we found amongst our own group. So there were another couple of managers that were going through and were doing it with me... And competition helped too. We're that competitive. We are all managers at the same level so it was easy to say, 'I've done this one and this one.' It would kind of motivate you a little bit to get yourself together.'

\section{Respondent 44}

"So if I'm home, I can ring up a support person, or one of the people who have been on it to just guide me as to where we should be going."

\section{Respondent 47}

"There was always somebody you were able to ring up if you had got into a situation where you weren't sure which direction to go in with a certain question or something like that."

\section{Respondent 46}

"Just supporting the time away from the office to be able to collate information and to undertake the assessment. Also contact with other managers within the region that had undertaken the qualification, and, you know, providing that sort of support as well."

The nature of trainees' job roles also assisted in creating value from Industry Training; these statements from trainees highlight this:

\section{Department $X$ :}

Respondent 33

"Well, I am the health and safety rep. And they offered if I wanted to do it, so I said yes." 
Respondent 34

"At the time, I was in a Customer Service role. So just to learn some new skills in that area."

The job role then creates value in terms of creating access to the training in the first place. In other words, trainees were able to get the opportunity to pursue the training as it was deemed to be related to their role. Additionally, the job role creates the opportunity to use the skills acquired. Conversely, trainees from Department X noted that they had challenges completing their on-the-job assessments as part of the qualifications, because they did not carry out those task requirements as a routine part of their normal job function. The following quotation from a trainee in this organisation highlights this point:

\section{Department $X$ :}

\section{Respondent 32}

"You have to be in the role to really be able to achieve it. Or you have to be in an organisation that can create the opportunities for you, as opposed to it being so that if I wanted to get into training, I would need to do these things. But you can't do that. You have to be virtually in it, in a training role, or have access to it to achieve the qualification."

A number of issues are raised here. First, the marketing of Industry Training as being convenient form of training because of its work-based nature is overstated (What do we mean by skills, 2007). There is still an organisational requirement to carefully select the appropriate Industry Training programme, and to ensure alignment with the organisation and job functions. Second, although much of the learning that takes place through these Industry Training programme was self-directed, for the full learning benefits to be realised, organisational support is vital. In Ministry Y, the support was provided through various sources - peers, managers, former trainees, mentors, assessors, facilitators. The support infrastructure then is an integral part of the community of Industry Training practice that had been created in this organisation. The presence of the infrastructure also creates value in another way. Its very presence communicates that the training is valuable to the organisation, as such an extensive infrastructure would not be attached to something that was not valuable. 
The findings here again support the Critical HRD/Stakeholder perspective, which argues that the support role played by stakeholders, particularly managers, cannot be assumed or taken for granted. Rather, it has to be understood, defined, agreed and actively pursued. Additionally, whether VET provides beneficial outcomes to trainees is highly dependent on the workplace culture and managerial decision making to foster and develop the required support mechanisms, and whether the extensive managerial expertise exists to develop these mechanisms, as VET, unlike other forms of training, require additional expertise and administrative processes, (such as assessment management), to facilitate its smooth execution.

b) Quality of Training and assessment process

Trainees in both organisations identified the nature of the training delivery and assessment as being important to them. This created value for them in that it either hindered or facilitated their learning. In Ministry Y, all the trainees expressed a high level of satisfaction with how the training was both delivered and assessed, and with the quality of training facilitation, as seen in the following statements:

Ministry $Y$ :

Respondent 44

"It's who the facilitators are, and the fact that they are very familiar with our business. They know what our managers have to deal with on a day to day basis, means the content is very relevant; it's not just book knowledge being taught. It's actually make it really practical and useful. They use the precoursework that they ask them to do. So it makes the whole process relevant."

Respondent 46

"The trainers are excellent. It is a small group always. When I did my first one, you know, the leadership development programme, mostly there were about 7 or 8 people, and the best thing is it is more about not about you know normally you get stuff which may not be relevant to a Ministry. Like you go to some professional development you may have courses that they may not be directly relevant to your own job. These courses had been relevant to our jobs."

Respondent 43

"For me personally, I value the level of communication, and I found it to be an excellent way to do an assessment. And I was relaxed and the assessor was excellent. So for I appreciated that that was the way that I could do it, rather than sitting by myself completing a number of different modules. Not knowing whether I was on the right track or not." 
In Department $X$, all the trainees identified several weaknesses in the assessment process, including delays in having assessments completed or lack of assessors, as well as with the quality of training materials provided. The following quotations capture these views:

\section{Department $X$ :}

Respondent 33

"Not yet. I've only done 3 whole papers so far, and only one of those have been marked, because there is no assessor, so I don't know if I am doing it right as yet."

\section{Respondent 35}

"I would never recommend that anyone do this training now. There are no assessors. I was just left on my own with no support, no guidance."

\section{Respondent 32}

"But you know, maybe because of my background. Maybe to someone else..I guess the whole course really is a bit laid back. Some of the materials, things that you find are just wrong or not described in the right way. And some times it is quite repetitive; they are asking you to do the same thing over and over again."

This respondent went on further to describe the challenges she experienced in having her assessments completed due to the time constraints facing the assessor:

"So she has to travel all over the country taking workshops and she is having to mark all of them, which takes a long time. So you are having to hand in your next assignment without knowing how well you did in the first one. So you don't know if you are on the right track."

The delays in assessment were viewed, not only as a lack of organisational support, but also seemed to affect their perception of whether learning was taking place. This is a reflection on the minimalistic approach to providing Industry Training support by the organisation. This then is likely to be a contributing factor to the low completion rate for Industry Training in the organisation. The use of completion rate can then be a reasonable proxy for quality of training and training support, at least to some degree. Success in Industry Training appears to be dependent on decision makers taking into account stakeholders' needs, in particular trainees - how they learn and what support they require. 
From a Critical HRD/stakeholder programme theory, attention to pedagogical needs of trainees is an important input, in order for trainees to derive value from VET. It is only through the acknowledgement and provision of that support that mutually beneficial gains can be realised from VET investment. Again, the data here reiterates the need for resources to be allocated and attention paid to the assessment process attached to Industry Training. This indicates a dependence of trainees on managerial know-how and willingness to make the necessary investment.

\section{Synthesis}

There were marked differences in the implementation of Industry Training in these two state sector organisations. From the data, there are some interesting trends worth noting. The first is that successful VET implementation appears largely dependent on following the normative training models of needs analysis, delivery and evaluation. To further elaborate, the inputs associated with success are the presence of an Industry Training champion to drive the implementation, detailed training needs analysis and design, communication and buy-in, learning/job alignment, systems for learning transfer, mechanisms for continuous evaluation, and stakeholders' involvement at all stages. These factors were present in Ministry Y. These inputs then resulted in outcomes that were mutually beneficially from the point of view of the managers and trainees interviewed - skills utilisation, learning culture, increased training access and equity, self confidence and staff engagement. The converse is also true. As seen in Department X, when these inputs are absent, the benefits from Industry Training are more limited, particularly for managers. This then does not reflect the Strategic HRD/VET logic, which sees VET engagement as being automatically beneficial to all stakeholders (Reform and Change in Industry Training Conference, 1992). Engagement or high levels of enrolment do not equate to realising the expected benefits. The Critical HRD/Stakeholder logic better reflects the implementation experiences in these organisations, in that a process of negotiation and understanding of stakeholders' needs and interests bring about mutually beneficial outcomes for stakeholders. Without that negotiation however, benefits are not realised, or are quite limited.

Below in Figure 7.1 is a logic model, based on the data: 
Figure 7.1 - Programme Logic for Value Creation from Industry Training: State Sector Perspective

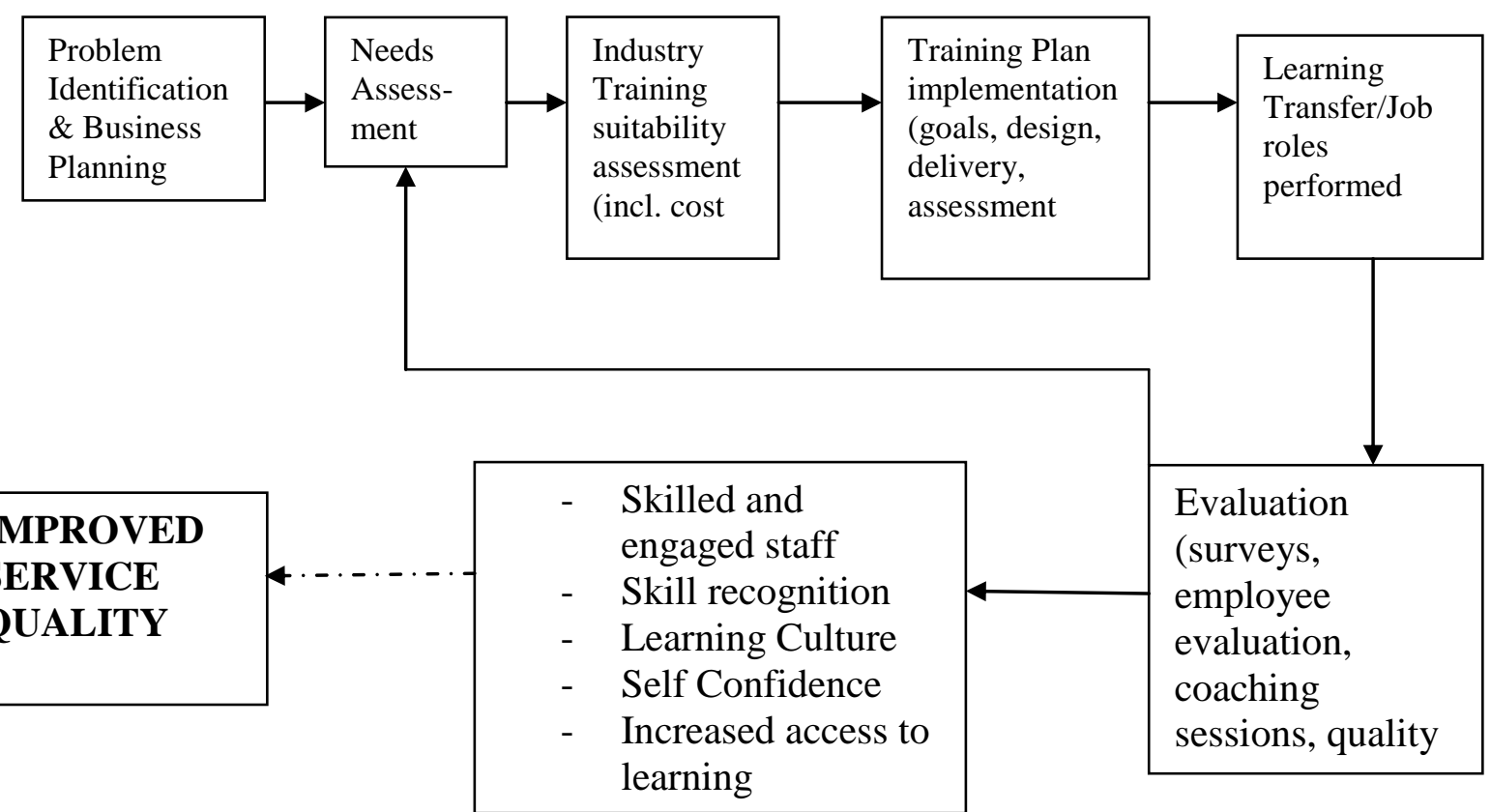

How did these state sector stakeholders evaluate the impact of Industry Training? They did so subjectively, and this was driven by the different value context within the respective organisations. Value context here means the dominant value that was attached to Industry Training within the organisation, which created a context for its implementation. These two organisations had very different value contexts, which resulted in differences in approaches to evaluation. For Ministry Y, Industry Training was more highly valued, and this was driven by the champions. This translated in the development of organisational capacity to implement Industry Training. Also, this led to implementation of evaluative practices, as organisations will not measure what they do not value highly. It can be postulated that due to the higher premium placed on Industry Training, there was a greater motivation to evaluate, leading to the greater emphasis placed on formal evaluation. Evaluation for this organisation was also pluralistic and inclusive, in that it sought to involve the needs and perspectives of all stakeholders. Both qualitative and quantitative data are utilised, but there was a greater reliance on qualitative data, which aligns with the stakeholder approach to evaluation. There was a reliance also on stakeholders' experience to evaluate training 
impact, particularly among trainees, but there was a concerted effort to integrate individuals' training experiences into the formal evaluation system. Department $\mathrm{X}$ had a contrasting experience with Industry Training engagement, which was largely mismanaged, and resulted in little benefit from both managerial and trainee perspectives. The flaws in their experience relate to the absence of the factors which facilitated Industry Training success for Ministry Y. These factors include the lack of analysis of Industry Training suitability, absence of clear goals for Industry Training, and the lack of consistent provision of workplace support, including systems to facilitate assessment and skills use. 


\section{CHAPTER 8 - DISCUSSION AND CONCLUSION}

In this chapter, a synthesis of the perspectives across all the stakeholder groups is presented. The discussion is essentially a synopsis of what the multi-level analytical approach taken in this research reveals about VET evaluation. The utility of the analytical framework developed for this research is also examined.

Overall, differences among stakeholders were based on their perceptions and experiences of success or failure in Industry Training engagement as well as organisational and sector characteristics.

As a reminder, the premises for doing this research and for the multi-level approach are highlighted:

- $\quad$ The VET policy rhetoric in the main fails to make the distinction among the various types of VET initiatives, which poses major challenges in its evaluation. This is addressed by focusing this research on one type of VET initiative - upgrade training.

- $\quad$ All stakeholders who are engaged in VET utilise some mechanism for evaluating their engagement.

- $\quad$ A better understanding of the evaluation of VET policy practice could be unearthed through a multi-level analysis involving a wider cross-section of VET stakeholders.

- The literature reveals two competing paradigms of how VET policies create value and ought to be evaluated, based on a number of assumptions and criticisms. However, these have remained under-researched, particularly as it relates to the roles and experiences of VET stakeholders in these processes of evaluation and outcome creation.

This research then sought to address these concerns about VET evaluation from a multiple stakeholder perspective.

What emerges from the data is a very complex picture. On one hand, there is clearly evidence of some degree of shared, collective understanding of VET evaluation. This 
is evidenced by the fact that most stakeholders identified common values they derived or expected to be gained from VET engagement. There were however differences among stakeholders in how these were defined and evaluated. These values - a) skills utilisation, b) quantitative outputs, c) career progression/wage effects, d) portability/recognition, e) equity/access goals - will each be examined.

\section{DISCUSSION OF COMMON VALUES IDENTIFIED}

\section{a) Skill Utilisation (Retention/Capacity Building)}

Skill utilisation was the only value identified by the majority of interviewees and all stakeholder groups. This represents a shared, collective understanding of one of the purposes of Industry Training. Also all stakeholders, to varying degrees, relied on their experience or the experience or observation of others to determine whether or not this was achieved.

For policymakers and industry interest groups, there was the tendency to either evaluate skills utilisation based on stories (commonly identified as success cases in official documents) and individual experiences. They also evaluated using numbers of trainees and employers engaged as a proxy for utilisation. For managers and employers, there is a marked difference between those who deemed themselves to be successful users of VET and those who did not. For successful users, skills utilisation was determined through the collation of qualitative performance information. The type of qualitative data varied from organisation to organisation, but commonly included the collection and use of performance information from a variety of organisational stakeholders. They also relied on their experiences and observation of skills use within the organisation or work unit to assess this outcome. For trainees, they relied on their individual experience of utilising the skills acquired to determine this value. Within the Strategic HRD/VET logic, skills utilisation is deemed to be adequately reflected by quantitative indicators such as number of employers engaged. Based on human capital theory, it is argued employers who are driven by the need to focus on bottom line issues would not be engaged, if they were not deriving instrumental benefits (Acemoglu, 2003; Becker, 1962). However, from the data, it can be concluded that such data can only reflect a partial reality. Evidence from 
Department $\mathrm{X}$ for example, (an organisation which described itself as an unsuccessful user) highlighted that it is possible for organisations to engage in Industry Training without having skills utilisation as an explicit end result. Also, from a multiple stakeholder view, the use of these kinds of quantitative data to evaluate skill utilisation does not reflect how most stakeholders actually evaluate. This is because skill utilisation is a value that is experienced, and most stakeholders define it within the parameters of their context, their experience or the experience of others. This also supports the findings from Grubb and Ryan (199) that the use of sophisticated methods to assess skills use and productivity are generally not employed by organisations, perhaps due to the complexity of these measures. This then leaves stakeholders to rely on other simpler, interpretive mechanisms in order to assess VET value.

This then poses an ontological question for researching skill utilisation, whether skills utilisation as a VET outcome can only be known through the interpretive experience of stakeholders. At the micro-level of organisations, a qualitative, inclusive approach appears to unearth more in-depth and richer data on the value of skills utilisation. Within the organisations, it is a shared understanding and experience, but this is obviously bounded by the organisational context. Therefore, it represents an organisational reality, not a macro-level reality. Also, at the organisational level, there are usually fewer stakeholders' interests to satisfy, and often higher levels of consensus on how performance is defined (Propper \& Wilson, 2003). For policy makers and industry interest groups, the stakes are different. As organisations only have a limited range of stakeholders' interests to satisfy, evaluation can be more utilitarian. As seen for successful user organisations, formal evaluations were shaped by the kind of data they valued for organisational decision-making, such as quality of customer service and job performance. For policymakers and industry interest groups, there is a wider range of stakeholders' interests to take into account. However, as seen in the data, not all stakeholders are viewed as having equal levels of influence, which aligns with the thinking of other policy evaluation commentators (Dixit, 2002; Wholey, 2001). In the VET policy literature and Critical HRD literature, the discussion has not focused on the vested interests of policy makers and especially industry interest groups, and how this impacts VET evaluation. Due to these vested interests, the use of both trainee numbers and interpretive experience were both 
subject to political filtering. So, for example, many stories-cum-case studies represent the political perspective of the stakeholder, such as cases of successful skills use. This political filtering is shaped by the need to justify VET spend, and to encourage greater investment. While there is some support for the use of stories in VET and wider policy evaluation, there is the need for caution against the biased selection of favourable stories of success, and the omission of others (Brinkerhoff, 2006; Thomas, 2006). This confirms concerns within the policy literature, which notes the politicisation of evaluation which can be harmful to evaluation quality and use (W. Dunn, 2004; Fischer, 2007).

Another major finding is that skills utilisation is not only valued by employers and managers, but also by workers/learners. This runs counter to the Critical HRD logic, which views the performance orientation towards skills as being the purview of managerial perspectives, and potentially exploitative of employees (Antonacpoulou, 1999; Bolton \& Houlihan, 2007a; Valentin, 2006). Trainees interviewed were as concerned about the use of skills as managers, so much so there was the tendency to view training that could not be used on their jobs as useless. One interpretation is that these workers had been brainwashed into this mode of thinking through the organisational culture. However, this assumes that workers possess no capacity for individual agency and thought (Heyes \& Stuart, 1996). Another conclusion then is that the polarisation of workers versus employers/managerial interests in the Critical HRD literature is too narrow and does not always reflect the reality (Fenwick, 2005).

There is also the challenge of data inconsistency, in that different stakeholders utilise different data sources to evaluate the same outcome. Skills utilisation is measured in so many varied ways across the organisations researched - from using performance evaluations, customer feedback, staff engagement surveys, to coaching and development reviews. This is further complicated by the fact that sometimes the evaluation of the training was only indirectly determined. This confirms one of Holton and Naquin's HRD evaluation models, where they argue for the possibility that organisations do not use the normative HRD evaluation methods, for example ROI (Holton \& Naquin, 2005). Instead organisations are guided by the decisions they need to make. In addition, from this data, not only are organisations' managers guided by what data they need to make decisions, they are also guided by their values. 
Decisions are driven by values. Those values can be rooted in rational economic choices, such as skills use, or service quality, but it is not necessarily limited to that. The other challenge is that all organisations involved in VET may not even make any deliberate attempt at any formal evaluation, as seen among some of the research respondents.

This is problematic at the policy level where macro-level evaluations are needed to guide policy choices. Therein lies the practical attraction of using quantitative performance indicators. However, most of the quantitative indicators typically used, such as trainee numbers, provide little insight on the extent to which VET is utilised. This is an on-going challenge for the field of policy evaluation, whether it can escape its positivist's roots and its bias for over-simplified quantification, and whether these limitations have to be accepted, given the fact that some aspects of policy performance defy measurement but perhaps have no other acceptable means of evaluation (Dixit, 2002; Gregory, 2004).

Hence, the case can be made for the use of different kinds of measurement, perhaps the development of a skill utilisation index. Research in this area is growing but is at present limited to broad-based perceptions on skills use and quantitative analyses attempting to assess information technology skills use (Downey \& Zeltman, 2009). Particularly for the service sector, the development of such an index would not be a simple task. Care would have to be taken as to which skills would be the focus, and some common definition of the skills sets in question would be needed in order to have comparability. Bearing in mind these challenges, surveys could be developed targeting managers and trainees, which examine: incidence, frequency of skill use, and factors that inhibit or encourage skill use, such as managerial support, alignment to job - all factors identified across stakeholders as pertinent to skill utilisation.

In summary, in examining the findings on skill utilisation against the analytical framework (see Table 4.2 for a summary of the framework), a number of conclusions emerge. First, the findings negate the performance/instrumental dichotomy, as VET (when defined as upgrade training) is not viewed as exploitative nor as failing to be learner-centred. Second is that for skill utilisation to be realised, it requires high levels of attention to pedagogical concerns, quality and administration of assessment 
mechanisms, and specificity of training content and design for the workplace environment. As a result, this places responsibility for VET success in the hands of employers/managers. This poses a serious policy challenge; if employers/managers have the greatest impact on VET success, the issue of how to influence employer/managerial behaviour becomes critical. Funding, in keeping with Critical HRD/Stakeholder logic, may create perverse incentives for some Industry interest groups, such as ITOs, to increase numerical participation, but it does not appear from the data to influence employer/manager behaviour in terms of their support for and skills in implementing Industry Training (Wolf, 2011). Additionally, this outcome is mutually beneficial across stakeholder groups, but the extent to which employers/managers play a supportive role determines the extent to which this value is realised by all stakeholders. Lastly, the reliance of skill utilisation on the workplace specificity of training material and its application, can run counter to other VET outcomes, such as portability of qualifications in the wider labour market. The fact that Industry Training is largely upgrade training however, means that the real focus of training is to upskill current employees, and not to increase portability. This however begs the question as to whether state investment in VET of this nature produces sufficient public good to justify the provision of training subsidies.

\section{b) Quantitative Outputs}

One of the most fascinating findings is that quantitative outputs as a value derived from VET is not shared across stakeholders. Approaches to quantitative outputs among stakeholders can be viewed as a continuum. Stakeholders who are closer to the policy action (such as policy makers and ITOs) appear to rely more heavily on quantitative outcomes as a major VET outcome. In fact, debates about quantitative outcomes appear to be 'policy-speak', a debate among policymakers and industry interest groups. Other Industry Interest groups that are key but not necessarily major policy decision makers are more inclined to be sceptical of quantitative outcomes, even hostile towards them. For employers/managers at the micro-level of organisations, these are not a central focus, particularly among successful users. Here the collection of quantitative data is to some degree an administrative function required by the VET system, rather than an end game in itself or a way of determining value. Employees do not use specific numbers of trainees to determine the value of 
Industry Training. However the participation of their peers in Industry Training seems to influence their determination of the value of training. The fact that several persons within an organisation or work unit had undergone the training created a sense of valuing. This however is more about the culture of the organisation, the shared experience, and the development of a community of practice around Industry Training created by having a certain number of trainees within the organisation, rather than a focus on quantitative outputs per se.

The Strategic HRD/VET Logic of focusing on quantitative outputs as proxies for numerous VET outcomes is not totally nullified, based on the research findings. For example, among successful users of Industry Training, the large percentage of trainees within the organisation (in two cases $100 \%$ of all employees) is associated with building organisational capacity to deliver higher quality client and customer service. Among successful users, there was also a clear link between provision for learning need/ learning support and higher rates of qualification completion. However, these quantitative indicators do not fully reflect a complete picture of the state of Industry Training. As the data also revealed, large numbers of trainees do not always indicate greater organisational capacity. Additional questions have to be asked of the data surrounding issues such as training quality and use. In other words, quantitative outcomes have to be critically examined, and one useful way is by gaining insights from the stakeholders themselves.

Another important observation from the data is that the values identified by stakeholders are in fact outputs rather than outcomes. This is in large part shaped by the fact that the Industry Training system is assessed using a performance management system rather than through evaluation as defined in the evaluation literature. According to Davies (1999), and other commentators, performance management systems within the policy sphere are about the definition of measurable results and the accounting for resources and resource allocation based in these results (Ball \& Halwachi, 1987; Davies, 1999; Ruppert, 1995; Thomas, 2006). He, along with other commentators, characterise performance management systems as being a continuous part of the management infrastructure, the purpose of which is to answer the question of what policy outputs are produced. Evaluation on the other hand normally occurs as a one off event, and is aimed at answering questions relating to 
policy impacts and how these are produced (Mohan et al., 2006). The prevalence of the use of quantitative indicators to assess the Industry Training system heavily influences how several of the stakeholder groups examine its value. This reflects assertions made by Barnetson and Cutright (2000), where they argue that performance indicators become normative assumptions that shape what issues stakeholders examine and how they examine them. This influence is seen in the identification of the same set of values from Industry Training engagement across almost all stakeholder groups.

Not only do most stakeholder groups define VET value in terms of outputs, there is also an underlying assumption of a causal, linear relationship between outputs and outcomes (Davies, 1999). This is particularly reflected in policymakers', industry interest groups' and some of the managerial perspectives. This is identified in the literature as one of the risks of the new public management performance systems adopted in New Zealand and elsewhere, where relationships between outputs and outcomes are over simplified. For example, when examining the skills and skills utilisation, they can either be considered outputs or inputs. If viewed as outputs, then they are an end result of VET engagement. However, if the VET system is expected to contribute to wider outcomes, then these are then inputs to be used along with others to create outcomes such as higher levels of labour productivity for example. The latter - the delivery of outcomes - then presents much more complex understanding of outcome creation, in this case how skill and its use interact with other inputs to deliver outcomes. It is this that policymakers and other stakeholders need to aim to understand, rather than erroneously assuming VET outputs automatically lead to desired outcomes, or aiming to delineate the impact of VET in isolation of its context, which is next to impossible.

Overall, these findings support the Critical HRD/Stakeholder's critique on the limitations of the Strategic HRD/VET logic. The use of these quantitative indicators cannot determine whether performance/instrumental or developmental concerns are being met, with the exception of assessing ITO performance and providing justification for state funding, which is potentially a perverse effect of state funding. Notwithstanding, the data provides some indication that completion rates can be linked to attention to pedagogical needs of learners, as well as provision of general 
support for learning. Funding impact on encouraging VET participation appears to be limited, as successful VET users in the research engaged in training, outside of Industry Training; however, the provision of subsidies served to increase the scope of training provision. This presents a major policy question of whether state funding should be targeted at organisations that are already investing in training, and whether this sufficiently addresses equity and access outcomes to warrant such funding.

\section{c) Career Progression/Wage Effects}

Career progression is another value that was commonly identified across all stakeholder groups. However, there were differences in its definition and evaluation. For policymakers and industry interest groups, it is defined as both learning progression and wage effects. At the organisational level, the size of the organisation appeared to determine how career progression was evaluated. In larger organisations with well-defined career paths and career development planning, career progression was viewed as upward mobility. For the small organisation, it was defined as job enrichment, rather than as upward mobility. This is an important fact to note, as within the Strategic HRD/VET logic, career progression and attendant wage effects are viewed as one of the major outcomes expected of VET policies (Ingram \& Neumann, 2006; W. Smits, 2008; Stasz et al., 2004). However, such a view can be problematic. Wage effects do not operate in isolation, but are dependent on the organisational context. From this data, trainees are likely to experience greater wage effects when they are employed in larger organisations that have and encourage clear career paths, as seen in Company B and Ministry Y. Therefore, the wage effects are not only the result of VET engagement, but a result of the organisational context. The other observation is that perhaps viewing career progression as wage effects and upward mobility does not reflect the experiences of career mobility in the SME context. In SMEs, scope for upward mobility, by virtue of the small size of their organisational structure, would be limited, as evidenced in Company A. Also SMEs are likely to have to contend with smaller profit margins, which would impact their ability to pay higher wages. This is important for the New Zealand context, as well as economies characterised by large numbers of SMEs. The use of upward mobility and wage progression as the only indicators of success of VET, would result in a failing grade for VET engagement in SMEs. However, by also focusing on job enrichment or 
enlargement, this may provide a more holistic view of career progression. Additionally, from the data, trainees in larger organisations are more likely to progress to higher levels of learning, and then only when this is actively facilitated by the organisation. In small organisations, it is possibly less likely to trainees to progress to higher levels of learning, either because the costs are prohibitive, or the organisation itself does not require it. This however does not signify that the training is not useful, simply because it did not lead to higher levels of learning. This provides additional insight on the peculiarities of training and VET in particular in the SME setting, which is often neglected in the literature, where normative training models and practices are those within the large organisational context (Kitching, 2008a; Kitching \& Blackburn, 2002). These differences then can only be unearthed through the use of the multi-level analysis, bearing in mind the differences in stakeholders' characteristics and context.

When these values are examined against the analytical framework, it is observed again that the two paradigms are not always competing, and that both developmental and performance/instrumental needs can be served through VET engagement. However, the data also points to the context that would provide for these needs to be realised, which is largely shaped by the role played by employers/managers, organisational and job design, provision of learning support, and organisational size. Funding has no influence directly on these characteristics, although it can assist in offsetting employers' costs. The use of career progression and wage effects can be used as measure of VET success to some extent, but its absence should not be translated to mean that VET is unsuccessful or not unbeneficial, as other value such as improved job performance, is an equally valued benefit for all stakeholders. Also, career progression and wage effects from the data are not a direct result of VET completion, but emanate from the career structures within organisations.

d) Portability/Recognition

Within the Strategic HRD/VET logic, portability and skill recognition is inextricably linked with the outcomes of career progression. From the research findings, for some stakeholders, this linkage is crucial. However, given the variations among stakeholders in defining these concepts, they are discussed here separately. 
From the data, it appears that there was some confusion among respondents surrounding the outcomes of portability and recognition, both in terms of definition and evaluation. At one end of the spectrum, policy makers and ITOs adhere to the belief that the achievement of qualifications and unit standards equate with the acquisition of skills. In other words, qualifications signal and certify skills, and make them portable in the labour market. This reflects the Strategic HRD/VET paradigm, where qualifications render skills both visible and capable of being evaluated in quantifiable terms (Hillage \& Pollard, 1998; Qualifications and lifelong learning: OECD policy brief, 2007).

For other industry interest groups, they share a similar definition of portability as career mobility but scepticism abounds as to whether qualifications signal skills. These criticisms centre on the confused signals to employers caused by the proliferation of Industry Training qualifications, and the poor quality of assessments and training which does not lead to trainees actually acquiring skills in some cases. Or in other cases, the criticism was that Industry Training was sometimes so organisational-specific that its portability to the wider market place was limited. These assessments were however arrived at based on interviewees' experience or the experience of other colleagues. There is then a tension between official quantitative VET performance data and practitioners' knowledge and experience. This also reflects the tension between the Strategic HRD/VET paradigm and the Critical HRD/Stakeholder logic. For these industry interest groups representatives, issues relating to organisational politics and power were seen to impact training delivery, for example, whether care would be taken to adequately train and adhere to quality assurance standards, or to ensure that learners received adequate theoretical as well as practical knowledge. These arguments echo debates in the VET literature on the distinction between education and training, and the arguments about whether training should equip learners to both know how to perform tasks as well as why they should be performed in a particular way (Hager, 2000, 2004.). From a multiple stakeholder perspective, there are differing views on the definition of quality VET provision, and how quality of VET provision can be assured. This significantly impacts the extent to which the value of portability and recognition of nationally recognised qualifications is perceived among across stakeholders in the labour market (Heise, 1998; Kis, 2005). 
At the organisational level, there are two types of portability that emerge from the data - internal labour market and external labour market portability. Among the larger successful user organisations, career pathways aligned to qualifications facilitated the portability of training in the internal labour market. Managers from successful user organisations also expressed the belief that the qualifications gained within their organisations were portable to the wider sector, whether the tourism or state sector. However, there was no indication they used Industry Training qualifications gained in other organisations as a signal for skills of potential workers; some even expressed scepticism as to whether the quality of qualifications gained elsewhere could be guaranteed. There is an underlying tension revealed here. On one hand, managers from successful user organisation exhibit pluralist concerns, this time in relation to the labour needs of the wider sector of which their organisation is a part. On the other hand, the fact that they only appear to place their faith in the quality of their own assessments and qualifications speaks to both the specific nature of the training provided, as well as the quality assurance concerns raised by some industry interest groups.

Among trainees, there was no consistency with regard to the value of portability and recognition. Some expressed the belief that the qualifications will or had been portable, some using their own career progression as a means of arriving at this evaluative judgement. Others viewed the certification of their skills as valuable in and of itself. In these cases, it is the qualifications that served as the indicator of recognition. Others highlighted the specificity of training as being useful in terms of equipping them to perform their jobs better, but of limited value in terms of external portability. This however was an opinion expressed, rather than a limitation that they had personally experienced. These learners had worked with the same organisation for several years, and expressed no plans to leave the organisation.

There are several underlying issues and questions that emerge in relation to the recognition and portability outcome. These are important to address, as the portability of qualifications and the establishment of a national system of skills recognition was one of the main reasons for the Industry Training policy, and other competency-based qualifications frameworks in the first place (Field, 1991; Reform and Change in 
Industry Training Conference, 1992). The first issue is that quality of assessment is critical, as trust in the quality of assessment is important in establishing validity in the minds of stakeholders. Second, there is a tension as to whether the degree of specificity of Industry Training affects qualifications' portability. This is not an easy question to answer. On one hand, from the data, successful user organisations ensure that the qualifications meet their specific needs, and are aligned to their jobs and services offered. Learners from these organisations also value the specificity of training, as it facilitates ease of learning and transfer to jobs. If training is specific, does this mean that it is therefore not transferable in the wider labour market? This it seems would depend on the qualifications in question. In these organisations, the qualifications, while having organisation-specific components, also had a number of generic components, for example, the First Line Supervisory Management programmes in both Ministry Y and Company B.

More importantly, in terms of evaluation, very little is actually known about the extent to which the outcome of portability has been achieved, even though this is a much touted benefit of Industry Training, and competency-based qualifications systems as a whole. Moreover, should portability be measured in terms of career progression of trainees, as earlier noted, this could be problematic, as career progression is both lateral and vertical, and is dependent on a number of factors, of which qualifications is a single factor.

A multi-level analysis therefore reveals that there are variations in definitions of portability. To some extent, this variation is context specific, based on the varied characteristics of the organisation or sector or occupational group to which the qualification is linked. For example, in larger organisations, internal portability may be of greater significance to stakeholders; the converse may also be true for smaller organisations, where external portability may be more valued, given the limited scope within the organisation. Portability may also be more aligned with career progression, where qualifications lead to greater access to other jobs or more expanded job roles. Additionally, it may also be defined as learning progression, where the achievement of qualifications lead to access to higher levels of learning. Finally, portability and skill recognition may not always be viewed as one and the same thing, and may for some stakeholders provide a distinctly different benefit. 
This is not to suggest that one definition should be preferred over another. However, the use of the term portability in the VET policy literature ought to be more specifically defined, and its attendant complexities should be noted. Without this acknowledgement, faulty and inadequate analyses on the value of portability will continue to be made, especially in respect of how it is actually assessed by varying stakeholders.

A discussion about portability and recognition would not be complete without an examination of employability, and what light this research sheds on this issue. The concept of employability is inextricably linked to portability, and the perceived need for society to ensure that citizens can find sustainable employment in volatile labour markets by being equipped through VET and other educational provision. One of the limits of this research is that it is solely focused on work-based VET provision, whereas much of the employability literature either does not make the distinction between different types and purposes of VET provision, or is focused on the welfareto-work link or on the mutual recognition of qualifications trans-nationally (Peck \& Theodore, 2000; Ward, 2008). By focussing on work-based VET provision, this research provides additional insight on the concept of employability in relation to this specific type of VET provision vis-à-vis other kinds. This is a distinct point of the analysis that needs more attention in the VET evaluation literature.

One of the important issues for VET policies geared at increasing employability is whether such qualifications actually make its holders more attractive to employers (Keep \& Mayhew, 2004; Peck \& Theodore, 2000; Sheldon \& Thornwaite, 2005) . In much of the literature, it is argued that VET provision does not have this effect, and that employers will restrict VET provision to those areas where the acquisition of certification is required by law or regulation, a view that was shared by some industry interest group respondents (Ridoutt et al., 2005). The findings from this research do not fully confirm these views, as employers were willing to invest in Industry Training, and in areas outside of those with a regulatory requirement to train. However, what is observed here is that the attractiveness of Industry Training tended to be limited to VET that was internally provided. If the attraction of VET provision is limited to that which is internally provided, and therefore more organisationally 
specific, this has implications for the extent to which VET policy can impact employability in the wider labour market.

Another issue is whether workers value VET provision as a tool to increase their employability. The findings here confirm other research that employees do place value on VET provision and its ability to increase their employability in the labour market (Edgar \& Geare, 2005). The data however provides greater light on trainees' perceptions of employability, as this valuing was not consistent among trainees. Perceptions of employability were shaped by organisational context, occupational group, field of training and sector characteristics. This supports the notion of employability as a social construct, that is not solely defined by employee characteristics and employment rates, but is affected by a series of demand trends, as well as by the experiences and values of the stakeholders themselves (McQuid \& Lindsay, 2005; Moore, 2009).

The research also provides for a useful critique of the indicators of employability commonly used, particularly within the Strategic HRD/VET logic. One such indicator is the employment rate of VET graduates, and in the Industry Training context, statistical analyses do reveal correlation between Industry Training qualifications and higher rates of employment (Crichton, 2009). However, one of the challenges of using this as an indicator of employability in the context of work-based training is that trainees access this training by virtue of their status as members of the organisation providing the training, therefore it follows that their employers are more likely to retain their services in order to re-coup their training investment (Heise, 1998). Based on the research findings, a more useful indicator of employability in relation to workbased training is to examine rate of retention, and in the case of larger organisations, rate of career progression, a finding also confirmed in the literature as being associated with work-based training (Hansson, 2008). Another indicator of employability used in the literature is the extent to which VET qualifications facilitate career change and movement in the wider labour market (Chappell et al., 2002). Again, this research was not able to, nor designed to specifically examine the extent to which trainees experienced this benefit in depth. However, there is some indication that some trainees perceived this as being a benefit of VET engagement. However, this is a problematic indicator for two reasons. As stated earlier, this perception varied 
according to context; therefore employability and portability has to be analysed within sectors and within occupational groups (Heise, 1998). The second reason is that, from the data, it was observed that most of the Industry Training provision was designed to equip trainees to perform their current job roles. While this could equip trainees for other jobs within the labour market, it is not necessarily designed to do this, making this indicator of limited utility.

e) Equity/Access/Second Chance Education/Self Confidence

These values have been placed together as they all relate to equity goals expected from VET investment, which is to provide increased access to minority groups and persons who had no previous success or limited success in the formal education system (Industry Training 2005, 2005; Tertiary Education Strategy 2002-2007, 2002). Although this was valued across all stakeholder groups, there were significant differences in how it was evaluated, and to some extent how it was defined.

For policy makers and some industry interest group stakeholders, it was measured using quantitative indicators, such as numbers of women, Maori and Pacific Island trainees, and numbers of trainees without previous qualifications. For stakeholders at the organisational levels and some industry interest groups, it was measured qualitatively. For them, it was more about how these categories of trainees were transformed by the training, particularly in the area of their self confidence. It is important to note that at the managerial level, only managers and employers from successful user organisations identified this as valuable to them. Also these organisations do collect the statistics on how many trainees fall in the various minority groups, as they are required to submit this information to their respective ITO as part of their application for training subsidies. However, managers in assessing the impact of Industry Training in minorities would refer to the transformational impact on their behaviour and performance, rather than the organisational statistics collated.

This reveals again that the strict characterisation of managerial perspectives as unitarist is a broad generalisation that may not be true in all cases (Fenwick, 2005). Managers and employers may willingly embrace both developmental as well as 
performance orientation towards HRD. In fact, from data, it is the organisations with managers that embrace both, and are more pluralist in how they value Industry Training, that define themselves as being successful training users. For successful users, this balance in orientation is also evidenced in the fact that the selection of potential trainees was based on job function, and not on level of qualifications. In all of the case study organisations, for example, several of the trainees interviewed had other tertiary qualifications including degrees. This reveals that the training aimed at equipping learners to perform their jobs, a definitive instrumental perspective. This also speaks to the specificity of the training offered as well, as it is obviously not assumed that persons could have developed the skills in question from prior qualifications. However, from the interviews, these managers were also concerned about offering access to training to persons from these minority and disadvantaged groups. This is evidenced by the level of encouragement trainees spoke of receiving, as well as the level of pride exhibited by managers when they spoke of the progress of these trainees.

Equity and access goals have been defined by several stakeholders, especially at the policy and industry interest group levels as a correlated output-outcome pair, in that increased access to VET is strongly correlated to increased equity, for example in employment outcomes. This assumption, when examining the research data, is not totally without merit, as several examples were cited by respondents of trainees from disadvantaged groups in the labour marker improving their employment prospects through Industry Training engagement. However, the data also revealed that there are several other factors involved in creating these improved employment prospects, including organisational size, culture, quality of training implementation and the development of career pathways. Therefore the access equals equity logic is in fact over-simplistic, and ignores a wide range of factors that contribute to social equity outcomes.

In summary, from the examination of these outcomes in the context of the analytical framework, it is seen again that VET engagement can produce mutually beneficial outcomes, and can be simultaneously instrumental and developmental in orientation. However, the role that employers/managers, HR champions and workplace affordances play in bringing about equity outcomes is highlighted by the data. 


\section{EXAMINING THE USE OF THE ANALYTICAL FRAMEWORK}

The analytical framework utilised in this research hinges on two competing logic for understanding VET policy implementation, and this section addresses the utility of this framework in analysing the data. The paradigms vary based on the competing characteristics outlined in Table 8.1: 


\begin{tabular}{|c|c|c|}
\hline \multicolumn{3}{|c|}{ TABLE 8.1 - COMPARATIVE ANALYTICAL FRAMEWORK } \\
\hline Factors & $\begin{array}{l}\text { Strategic HRD/VET } \\
\text { paradigm/logic }\end{array}$ & $\begin{array}{l}\text { Critical HRD/ } \\
\text { Stakeholder } \\
\text { paradigm/logic }\end{array}$ \\
\hline Orientation & $\begin{array}{l}\text { Performance/Instrumental } \\
\text { orientation; purports to be } \\
\text { pluralist in outlook }\end{array}$ & $\begin{array}{l}\text { Developmental } \\
\text { orientation; criticises VET } \\
\text { policy as being unitarist in } \\
\text { outlook }\end{array}$ \\
\hline $\begin{array}{l}\text { Attention to Pedagogical } \\
\text { Issues }\end{array}$ & $\begin{array}{l}\text { Lack of explicit attention; } \\
\text { assumption of learner } \\
\text { needs being met }\end{array}$ & $\begin{array}{l}\text { Attention to learners' } \\
\text { needs critical to learning } \\
\text { and application }\end{array}$ \\
\hline Roles of Stakeholders & $\begin{array}{l}\text { Assumes stakeholders' } \\
\text { role definitions are clear, } \\
\text { performed consistently } \\
\text { and are complementary, } \\
\text { leading to shared outcomes } \\
\text { for all. Employers' } \\
\text { engagement is seen as a } \\
\text { signal for the provision of } \\
\text { workplace support for } \\
\text { VET, including assessment } \\
\text { services etc. }\end{array}$ & $\begin{array}{l}\text { Questions whether } \\
\text { stakeholders' role } \\
\text { definitions are always } \\
\text { complementary, and } \\
\text { carried out consistently. } \\
\text { These roles may even be } \\
\text { competing, to the } \\
\text { detriment of some } \\
\text { stakeholders, especially } \\
\text { trainees. }\end{array}$ \\
\hline Funding & $\begin{array}{l}\text { Assumes that funding } \\
\text { incentivises stakeholder } \\
\text { engagement in ways that } \\
\text { produces mutually } \\
\text { beneficial outcomes }\end{array}$ & $\begin{array}{l}\text { Questions whether funding } \\
\text { incentivises perverse } \\
\text { behaviour to the detriment } \\
\text { of beneficial outcomes }\end{array}$ \\
\hline Evaluation & $\begin{array}{l}\text { Preference for quantitative } \\
\text { performance indicators to } \\
\text { evaluate. Typical } \\
\text { indicators are completion } \\
\text { rates, number of trainees } \\
\text { by age, sex and race }\end{array}$ & $\begin{array}{l}\text { Preference for qualitative } \\
\text { data to evaluate }\end{array}$ \\
\hline Outcomes & $\begin{array}{l}\text { Assumes Outcomes are } \\
\text { mutually beneficial for all } \\
\text { stakeholders. Typical } \\
\text { shared outcomes are skills, } \\
\text { portability of skills, higher } \\
\text { wages and productivity, } \\
\text { increased socio-economic } \\
\text { equity for disadvantaged } \\
\text { groups }\end{array}$ & $\begin{array}{l}\text { Challenges the } \\
\text { assumptions of mutually } \\
\text { beneficial outcomes for all } \\
\text { stakeholders. }\end{array}$ \\
\hline
\end{tabular}

It is fair to say that the analytical framework has proved to be a useful lens through which to analyse the data gathered. However, by using this lens to examine the data, it 
has also unearthed that stakeholders' perspectives on VET outcomes, and how they evaluate those outcomes, do not necessarily fall neatly into either paradigm. This highlights some of the gaps in the literature. The strategic HRD literature largely focuses on performance/instrumental and unitarist purposes of training generally, with almost no specific focus on VET (Boxall, 2003; Brinkerhoff, 2003; Velada et al., 2007). The VET policy literature mainly reflects policymakers' concerns. While the focus is on pluralist concerns - in the achievement of outcomes for multiple stakeholders' needs, this body of literature tends to focus on a narrower range of stakeholders - country, firms/employers and learners. Here, there is often the assumption that stakeholders' interests are adequately represented by quantitative indicators such as wage effects, numbers of employers engaged and so forth (R. Hall \& Jones, 1999; Hanushek \& Wobmann, 2007). Furthermore, there is limited attempt at multi-level analyses, and when these occur, there is usually an omission of industry interest groups as key stakeholders in the VET policy process. The Critical HRD literature has its own assumptions about the power imbalance between workers and managers, and the neglect of workers' developmental needs and workplace rights (Sambrook, 2009; Valentin, 2006). In addition, most of this literature focuses on theoretical arguments, with limited empirical research supporting them. The stakeholder theory literature certainly zeroes in on the involvement of multiple stakeholders' and their interests to improve policy implementation and evaluation (Buchholz \& Rosenthal, 2004; Walters et al., 2000). However, this body of research focuses on smaller programmes, with limited application to the evaluation of VET, and in particular workplace training (Beierle, 2002; Pahl-Wostl, 2002).

This research then assists in filling the gap in the literature, where there is a need for better understanding of where VET policy, HRD practice and stakeholders' concerns intersect. The research confirms policymakers' interests as reflected in the VET literature. They attempt to balance pluralist concerns. However, these are not simply employers' versus learners' needs, but there is also the concern for sector development needs. Policymakers do rely on quantitative data as proxies for desired outcomes, also confirming what was seen in the VET policy literature.

Among industry interest groups, the struggle between competing interests and paradigms are very evident. Again these interests are not confined to the balancing of 
workers and managerial interests, but there are also their individual and sector interests as well. These interests vary from:

○ The survival interests of ITOs, and the effect of funding incentives on behaviour, which some view as sometimes leading to perversity such as the proliferation of qualifications;

- Differences between the developmental versus performance/instrumental view of VET, and how that leads to variations in definition of VET quality, such as work based versus institution based, and balancing shorter term employers' needs versus longer term sector and learner development needs.

Again this reiterates the challenge of the politicisation of evaluation. The lesson here is that different VET stakeholders, because of the interests they represent, can have very different definitions of what constitutes VET success. This aligns with the policy literature on the impact of incentives in influencing client behaviour. As it relates to VET, it is not only the impact of incentives that has to be taken into account. Industry interest groups tend to lean towards either supporting performance/instrumental or developmental goals of VET, and this affects their own evaluation of VET outcomes. Added to this, most industry interest groups rely on their own experiences and that of their peers to assess whether the outcomes they value are being met.

At the organisational level, performance/instrumental VET outcomes are valued by both managers/employers and trainees, which runs counter to the Critical HRD/Stakeholder logic. In fact, from the data, the neglect of instrumental concerns appears to lead to limited value being derived both for managers and trainees. There are several reasons for this result. Firstly, Industry Training is specifically designed to meet instrumental needs, particularly work based training. Where it is successfully implemented, it is designed to be aligned to job performance. Training assessment is designed to naturally and easily occur while trainees are carrying out their jobs. It is primarily viewed as workplace learning. It may assist these stakeholders in other ways, but it is firstly instrumental. Instrumental concerns on the part of successful user organisations were also exemplified in their careful needs analysis, concerns for service quality, and how they conduct formal evaluations. It can also be seen in their cost benefit analysis, where training subsidies are carefully calculated in order to determine the organisation's level of engagement in Industry Training. 
This focus on instrumentality is not necessarily detrimental to workers, as employees value being able to do their jobs well. This desire to perform is not a factor that is taken into account in the Critical HRD literature (Antonacopoulou, 1999). This also supports other findings in the HRD literature that workers perceive training and other HR functions as being beneficial to them (Guest, 1999). Furthermore, there is a need for a more expansive definition of shareholder value of organisations beyond profitability. For example, for the state sector, where profits are not a concern, the delivery of quality public service is of benefit to clients, and the country at large.

The data also revealed that both managers/employers and learners have a concern for developmental outcomes. To some extent, this is a by-product of instrumental concerns. Among successful users, managerial instrumental concerns were tempered by developmental concerns. This was seen in concerns for learner needs, tailoring delivery to suit learning styles, provision of learning support, and career pathways in some cases. But it could be viewed as a means to an end, where the meeting of developmental needs were an exchange for their commitment to job performance.

This however does not explain decisions to invest in training of workers who have no prior educational success. It would be perfectly rational not to invest in training such persons, as there might be limited or no return on investment, and such trainees would require more organisational support to assist them in their learning. However, among all users, there was evidence of managers making the choice to encourage such learners, and to believe in their potential to succeed at gaining Industry Training qualifications. This certainly would not describe every case, indeed perhaps not most, but it does show that managers can prioritise developmental concerns over performance concerns. Notwithstanding, instrumentality supersedes developmental concerns. The meeting of developmental needs always occurs within the context of organisational priorities; for example, there are limits to what kinds of Industry Training learners can access through their workplaces.

There is also a definite link between instrumentality and training specificity, and VET success in this research. Successful users have higher degrees of tailoring to meet their specific performance needs. This tension between development and performance 
orientation of VET is also reflected in the on-going debates as to use of training subsidies. Should government be funding be used to support organisational instrumental needs or workers' developmental needs? Does the meeting of organisational instrumental needs also lead to workers' development needs and wider labour market skills needs? There are no simple answers to these questions, but what the data points to is that, in order to gain mutually beneficial outcomes from work based VET, there has to be an instrumental focus. From an implementation perspective, instrumentality makes skill assessment easier. It also appears to set the platform to manage the meeting of the mutual needs of both learners' and organisational development needs (Boxall, 1996).

\section{HOW DO STAKEHOLDERS EVALUATE IMPACT OF VET POLICY?}

Table 8.2 below summarises the response to the main research question: how do stakeholders evaluate the impact of VET policies?

\begin{tabular}{|c|c|}
\hline \multicolumn{2}{|c|}{ TABLE 8.2 - Evaluation Methods Employed by Multiple Stakeholders of VE' } \\
\hline Policymakers & $\begin{array}{l}\text { - Quantitative Performance } \\
\text { Indicators } \\
\text { - Experience }\end{array}$ \\
\hline Industry Interest Groups & $\begin{array}{ll}- & \text { Experience } \\
- & \text { Stories } \\
\text { - } & \text { Quantitative Performance } \\
& \text { Indicators }\end{array}$ \\
\hline Managers/Employers & $\begin{array}{l}\text { - Management Information of } \\
\text { choice } \\
\text { - Experience }\end{array}$ \\
\hline Trainees & - Experience \\
\hline
\end{tabular}

The multi-level analysis used in this research reveals that, although stakeholders may share an interest in similar outcomes to a large degree, there are differences in how they evaluate the extent to which these have been met. Policymakers rely more 
heavily on quantitative performance indicators as the main means of evaluation. This reflects positivist influences, where value is viewed as observable facts that can be understood in quantitative terms. Another argument that could be posed however is, given the challenges in determining VET outcomes, particularly data challenges, these indicators are proxies representing such outcomes. The indicators used by policymakers also seek to reflect pluralist interests, as they measure impacts in relation to both managerial (such as number of employers engaged) and workers' interests, particularly those from vulnerable groups. This is expected as governments have vested interests in serving and in being seen as serving the multiple interests of its citizens.

For industry interest groups, the use of quantitative performance indicators is shaped by the demands of the performance monitoring framework developed at the policy level. Additionally, both quantitative indicators and success stories are persuasive devices to market the benefits of VET, and to justify VET spend. Managers/employers from successful user organisations utilise varied performance information to evaluate the impact of VET investment, either directly or indirectly. Trainees, along with all other stakeholders, rely on their experience as an evaluative mechanism.

Whether experience or quantitative performance indicators or management information is used by stakeholders, what is clear is that VET evaluation is a subjective, value-laden process. This highlights that, the impacts of VET policy are to a great extent experienced. Thus VET outcomes are highly contextualised, as experiences are delimited by organisational boundaries, vested interests and philosophical perspectives in relation to VET purposes.

\section{NEW LOGIC}

Finally, the data gathered from these multiple perspectives reveals that there is a common programme logic of how valuable outcomes can be created for stakeholders. This emerges from the fact that all successful user organisations had similar characteristics that contributed to their achievement of outcomes both for managers and trainees. Furthermore, the absence of these characteristics also seemed to 
contribute to the limited success experienced by the unsuccessful user organisation. In addition, many of these characteristics are also identified by the other stakeholder groups interviewed. It is important to draw attention to the fact that the data reveals that value from VET investment could be created for service sector organisations whose jobs are not traditionally covered comprehensively by VET provision. Figure 8.1 outlines the logic. 
FIGURE 8.1 - REVISED PROGRAMME LOGIC FOR VET POLICY IMPLEMENTATION

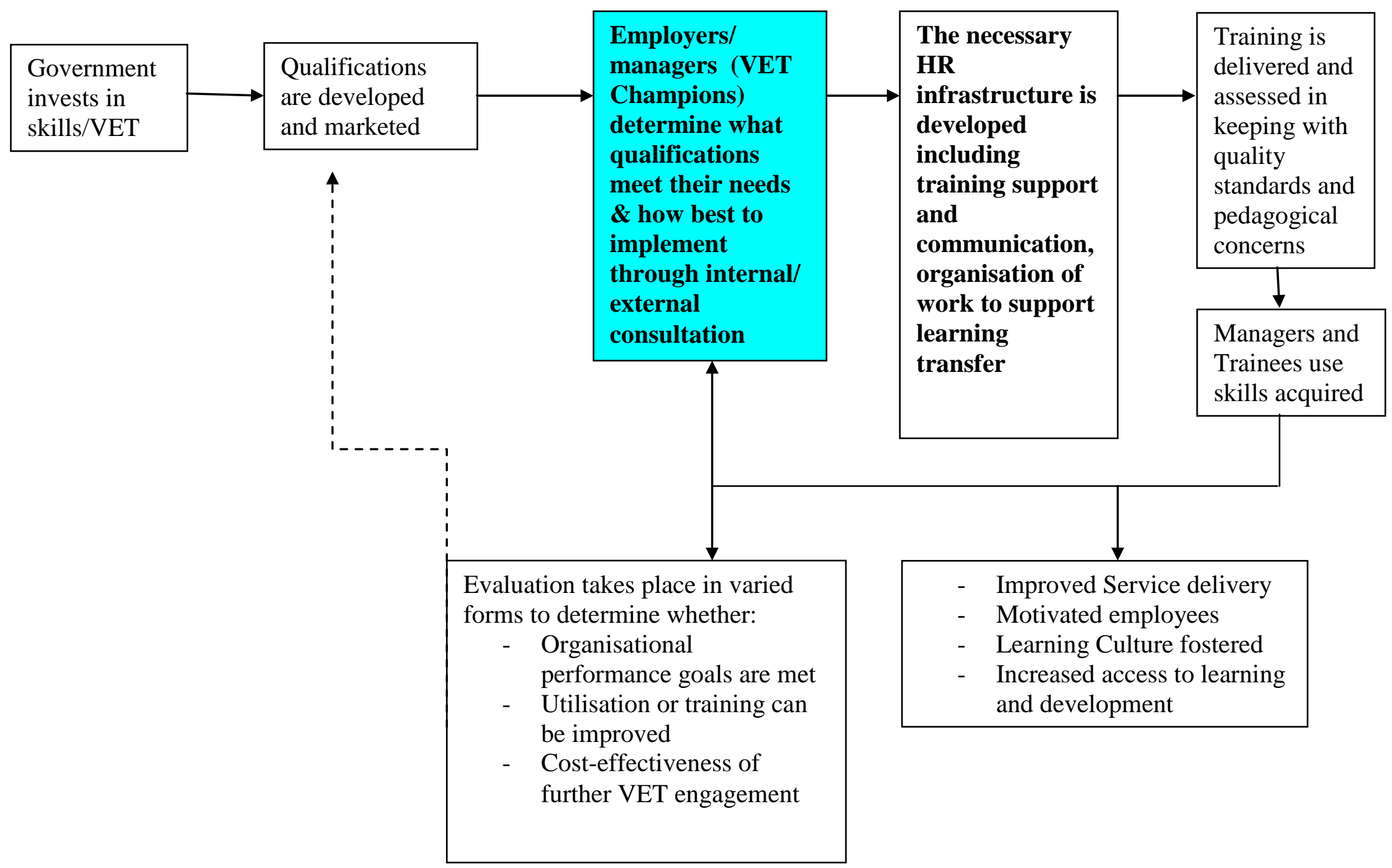


Perhaps the most vital input required to create favourable outcomes is the presence of VET champions. At the sectoral level, this is dependent on the drive and capacity of the ITO and other key industry participants who believe in the potential of VET investment. At the organisational level, such champions are critical. They always operate at a senior level within the organisation and have the capacity and authority to influence behaviour within the organisation. Champions also possess a high level of technical knowledge in VET implementation, or they are prepared to acquire that knowledge through their ITO and/or consultants. The retention of the champion is critical. In all cases, champions are a part of the organisation from the outset of VET implementation. Finally, champions at the outset have a strong belief in HRD investment, and this investment always precedes VET investment.

Funding is also another important input. The availability of training subsidies drives VET investment, and is heavily weighed in assessing the associated costs and benefits. However a major distinction between successful user organisation and unsuccessful users is the willingness to invest additional organisational resources in VET implementation. Training needs analysis, whether formal or informally conducted, is also a critical activity carried out by successful users. The analysis is driven by instrumental concerns, such as service quality and consistency in training standards. It also covers developmental concerns such as suitability of delivery and assessment methods to trainees' needs. Importantly, analysis also determines whether Industry Training as provided will adequately meet the organisations' needs, and what work may have to be done to ensure this alignment.

Adequacy of the HR infrastructure is also another key input. Successful VET implementation requires support for VET implementation. This involves quality communication to all organisational stakeholders, the establishment of the technical infrastructure to manage the VET process. A high level of alignment between job functions and training is also critical, as this facilitates seamlessness between job performance and training assessment. Support also comes in the form of the social relations among trainees and between trainees and managers. Individualistic approaches to VET delivery yield limited impact. Greater levels of success are associated with trainees pursuing training in groups, with clear support networks. Although much of the training examined in the research would fall in the non- 
traditional spheres of VET investment, what is clear is that service sector organisations can over time develop communities of VET practice. Additional value can be gained from VET engagement where the completion of VET qualifications can be used to gain entry into the organisational group, or where it becomes the accepted norm of the group.

Some form of evaluative process is also associated with the achievement of successful outcomes. This again speaks to the goal focused approach that successful user organisations possess. As mentioned earlier, the evaluation mechanisms used vary from organisation to organisation. However, one common factor is that evaluation is always to some extent inclusive; it involves either gathering data from or sharing data with organisational stakeholders. Evaluation also involves a continuous determination of the cost/benefits of VET engagement. Changes in training subsidies or changes in qualifications structure may impact continued VET investment.

This mirrors aspects of the strategic HRD and resource based view of HRD which advocate for the rational HRD decision making model of assessment, delivery and evaluation, as well as the alignment between HRD and other organisational functions to achieve favourable outcomes (Beatty et al., 2003; Wright et al., 2003). This is where the HRD literature can better inform VET policy literature. In the VET policy literature, there is a great emphasis on funding incentives to drive HRD investment in workplaces (Gorg \& Strobl, 2005). What is seen here is that this, while important, is insufficient; other organisational characteristics are equally necessary. The importance of HR champions also echoes some of the arguments in the Critical HRD literature. The decision making power within organisations with regards to VET investment lies in the hands of managers, in fact, possibly a few managers. These managers are also the ones who guide the extent of that investment, in terms of organisational resources that will be dedicated to it, what training programmes will be undertaken, etc. Individual employees' agency as it relates to VET engagement is limited by organisational strictures, key among them being the values and attitudes of managers in relation to VET investment.

The implications of these findings will be discussed in the concluding section. 


\section{CONCLUSION}

So what are the implications of the research findings for future VET policy practice and evaluation, and for theory and research?

An important finding from the data is that managers and workplace culture play critical roles in supporting VET and creating value for multiple stakeholders, particularly at the organisational level. One implication of this is that the provision of funding to encourage investment in nationally recognised workplace training can be insufficient to incentivise desired training behaviours. Funding only stimulates desired behaviours, particularly benefits for a range of stakeholders, when key managers/employers at the organisational level place value on training and development as an integral part of the workplace culture, and where the technical expertise to utilise the training either resides within the organisation or is accessed via external consultants or an ITO. Where this valuing of VET and technical expertise is limited, it results in limited benefits for stakeholders.

The question then for policymakers is how to encourage the management of skill formation through VET. The empirical data in this research provides insights on this under-researched area. Further research will be needed however to test the new programme theory of creation of VET outputs and outcomes. Such research could focus on the role and characteristics of workplaces as communities of VET practice. This suggests a greater emphasis on a socio-cultural approach to VET policy research, where the multivariate nature of VET in workplaces can be further illuminated (Stasz, 2001). The challenge for VET practice however is whether policy instruments can in fact be developed and designed to enforce desired behaviour, especially in light of the findings that stakeholders' values in relation to VET are such a critical factor in a revised programme theory (Coffield, 2004). One recommendation that could be explored is the inclusion of a requirement of organisations to submit to a monitoring body such as an ITO, proof of implementation of minimum requirements to support VET implementation in their workplace, such as provision for assessment and trainee support, in order to access training subsidies. This runs the risk of creating additional paperwork and bureaucracy. However, it can be argued that participation in VET, and the receipt of training subsidies constitutes an implicit agreement to participate in 
public policy implementation (Buchholz \& Rosenthal, 2004). Such a reporting requirement could be seen as attempting to assure benefits for a wider range of stakeholders. Additionally, the role of ITOs and similar organisations in other countries may need to be expanded to provide capacity building to organisations to improve their capability to successfully implement VET initiatives. At the organisational level, the recognition and assessment of the internal infrastructure required to successfully engage in VET initiatives ought to be clearly understood prior to engagement. Successful engagement requires expertise in the management of competency based training and knowledge of assessment methodology, quality assurance processes, as well as an appreciation of how to align Industry Training, in particular the experiential component with the wider organisational and HR systems and processes. For trainees, the data revealed VET engagement is initiated by employers/managers. However, employees seeking developmental opportunities such as access to VET through work, should appreciate that the quality of workplace affordances directly impacts their ability to successfully engage in VET, in particular the quality of the management of training and the extent to which managers are required to provide learning support. The data also suggests that trainees would need to be mindful that engagement in upgrade VET training may not directly impact their level of employability in the wider labour market, as this training is often context specific, and may not be recognised by other employers.

Another major implication of the research findings for VET evaluative practice is the need for the management of meaning of performance data (Funnell, 2000; Thiel \& Leeuw, 2002). The assumption of consensus among stakeholders must be eliminated from VET policy dialogue. The analysis of the data reveals that among stakeholders, there can be areas of consensus, but also areas of disagreement in how some critical factors in VET policy implementation are defined and evaluated, for example VET quality. The multiple stakeholder approach of this research has assisted in unearthing some of these disagreements. This then can be viewed as furthering the dialogue on gaming behaviour and perverse incentives in the VET policy arena. The research reveals that from a multiple stakeholder perspective, perceptions of gaming and perversity are value-laden, and are constructed through political struggles and interests, particularly at the industry interest group levels. The research is however limited in scope in terms of the number of stakeholder groups included. Future 
research would benefit greatly from a similar multiple stakeholder approach, but with greater emphasis on analyses based on sectoral, ethnic, gender, occupational, and organisational differences. Such analyses could reveal important differences in definitions and importance of a variety of VET outputs and outcomes, and may lend themselves to more tailored policy action that is reflective of stakeholders' needs and values.

The use of the analytical framework where the data was analysed through two programme theories - the strategic HRD/VET logic and the Critical HRD/Stakeholder logic, proved a useful heuristic for analysing the various stakeholder perspectives presented. One of the important findings from using this analytical framework is that stakeholders' perceptions are not always as polarised, as Critical HRD theorists postulate (Fenwick, 2005). Rather, the two programme theories represent tensions within VET policy, rather than charged dichotomies (FitzSimons, 2002). It is however an analytical framework that should be subjected to further empirical testing in VET policy research, given the limited nature of this research, in terms of scope and range of stakeholders.

Further research opportunities include, testing this new VET policy evaluation and outcome creation model in the context of other industries, and VET systems in other countries. This would allow comparative examination of the approaches to value creation and evaluation of VET engagement used by these different sectors and systems. Using a wider range of case studies, the logic can also be tested across organisations of varying size. This could be particularly beneficial in countries with a proliferation of SMEs, which invariably limited internal capacity, a factor identified in the model as critical to VET success. The model can be tested to examine different kinds of employees, particularly disadvantaged groups such as women and other minorities, in order to examine inter-relationships between VET and characteristics leading to labour market disadvantage, an issue that was beyond the scope of this research. The data here revealed some advantages to the logic in creating value for second chance learners; however, the selection strategy used did not intentionally target specific types of trainees. It is posited however that the new model as well as the wider research findings provide a new and more robust heuristic for researching VET evaluation practices from a multiple stakeholder perspective. 
Appendix A: List of Respondents

\begin{tabular}{|c|c|}
\hline \multicolumn{2}{|c|}{ LIST OF RESPONDENTS } \\
\hline \multicolumn{2}{|l|}{ Policy Makers } \\
\hline Respondent 1 & Tertiary Education Commission \\
\hline Respondent 2 & Department of Labour \\
\hline Respondent 3 & Department of Labour \\
\hline Respondent 4 & Department of Labour \\
\hline \multicolumn{2}{|c|}{ Industry Interest Groups } \\
\hline Respondent 5 & State Services Commission \\
\hline Respondent 6 & Business New Zealand \\
\hline Respondent 7 & $\begin{array}{l}\text { Tourism Industry Association of New } \\
\text { Zealand }\end{array}$ \\
\hline Respondent 8 & Ministry of Tourism \\
\hline Respondent 9 & Industry Training Federation \\
\hline Respondent 10 & Industry Training Federation \\
\hline Respondent 11 & Learning State \\
\hline Respondent 12 & $\begin{array}{l}\text { Aviation, Travel, Tourism Training } \\
\text { Organisation }\end{array}$ \\
\hline Respondent 13 & $\begin{array}{l}\text { Aviation, Travel, Tourism Training } \\
\text { Organisation }\end{array}$ \\
\hline Respondent 14 & New Zealand Council of Trade Unions \\
\hline Respondent 15 & Hospitality Standards Institute \\
\hline Respondent 16 & New Zealand Qualifications Authority \\
\hline \multicolumn{2}{|l|}{ Company A } \\
\hline Respondent 17 & Owner/Trainer \\
\hline Respondent 18 & Line Manager A/Learner \\
\hline Respondent 19 & Trainee A \\
\hline Respondent 20 & Trainee B \\
\hline \multicolumn{2}{|l|}{ Company B } \\
\hline Respondent 21 & Operations Manager/Assessor/Trainer \\
\hline Respondent 22 & HR Manager A \\
\hline Respondent 23 & Line Manager B \\
\hline Respondent 24 & Trainee C \\
\hline Respondent 25 & Trainee D \\
\hline Respondent 26 & Trainee E \\
\hline \multicolumn{2}{|l|}{ Department X } \\
\hline Respondent 27 & HR Manager B \\
\hline Respondent 28 & Line Manager C/Former Assessor \\
\hline Respondent 29 & Line Manager D \\
\hline Respondent 30 & Line Manager E \\
\hline Respondent 31 & Line Manager F \\
\hline Respondent 32 & Trainee F \\
\hline Respondent 33 & Trainee $\mathrm{G}$ \\
\hline Respondent 34 & Trainee $\mathrm{H}$ \\
\hline Respondent 35 & Trainee I \\
\hline
\end{tabular}




\begin{tabular}{|l|l|}
\hline \multicolumn{2}{|c|}{ LIST OF RESPONDENTS } \\
\hline Ministry Y & \\
\hline Respondent 36 & HR Manager C \\
\hline Respondent 37 & HR Manager D \\
\hline Respondent 38 & Line Manager G \\
\hline Respondent 39 & Line Manager H/Assessor/Leaner \\
\hline Respondent 40 & Line Manager I \\
\hline Respondent 41 & Line Manager J \\
\hline Respondent 42 & Trainee J \\
\hline Respondent 43 & Trainee K \\
\hline Respondent 44 & Trainee L \\
\hline Respondent 45 & Trainee M \\
\hline Respondent 46 & Trainee N \\
\hline Respondent 47 & Trainee O \\
\hline Respondent 48 & Trainee P \\
\hline Respondent 49 & Trainee Q \\
\hline Respondent 50 & Trainee R \\
\hline
\end{tabular}


APPENDIX B: RESEARCH QUESTIONS MAP

\begin{tabular}{|c|c|c|c|c|c|c|}
\hline Policymakers & $\begin{array}{l}\text { Industry Interest } \\
\text { Groups }\end{array}$ & $\begin{array}{l}\text { General } \\
\text { Manager/Owner }\end{array}$ & $\begin{array}{l}\text { Training Manager (if } \\
\text { existing) }\end{array}$ & Line Manager & Trainees & $\begin{array}{l}\text { Research } \\
\text { Questions }\end{array}$ \\
\hline
\end{tabular}




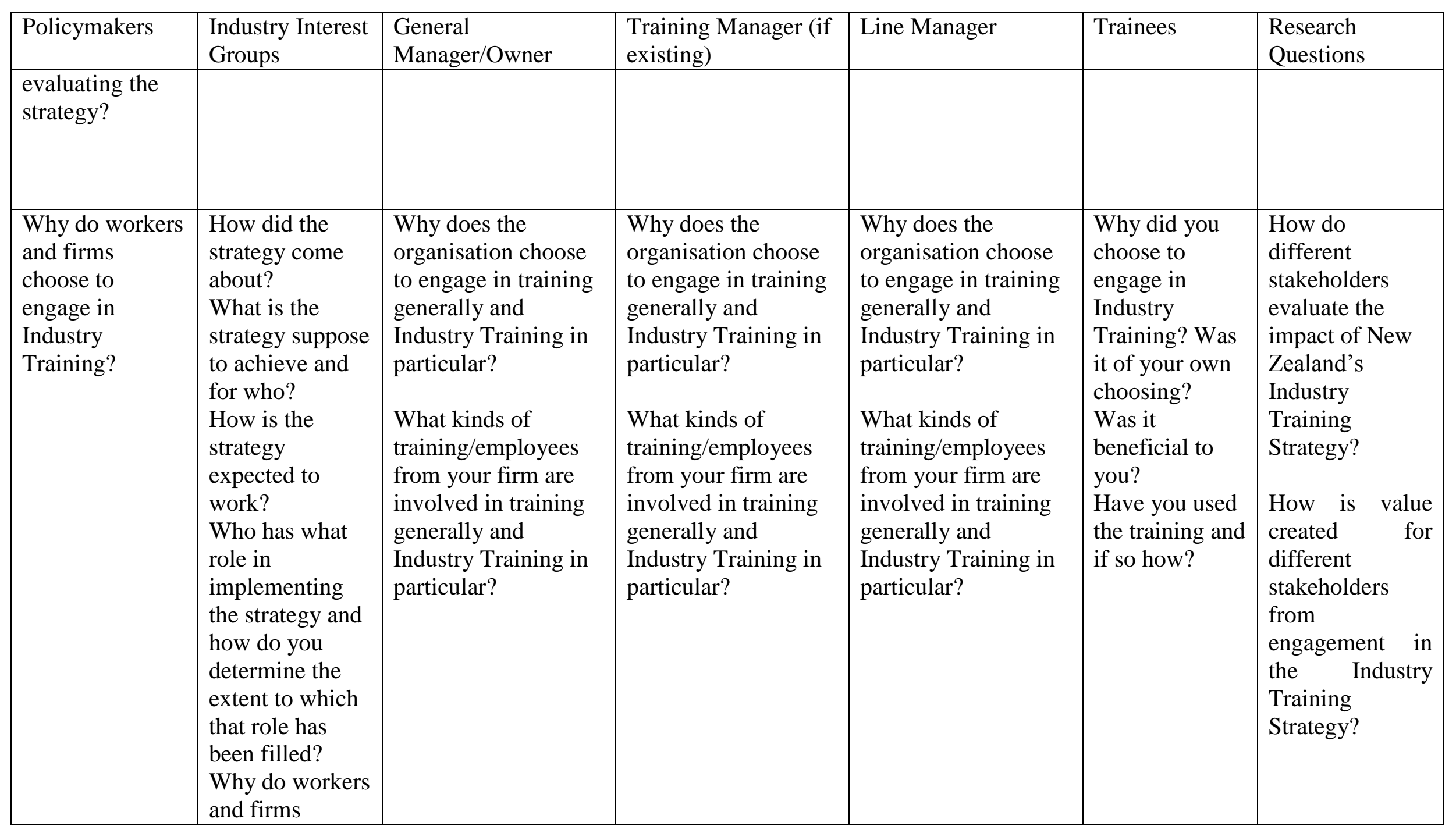




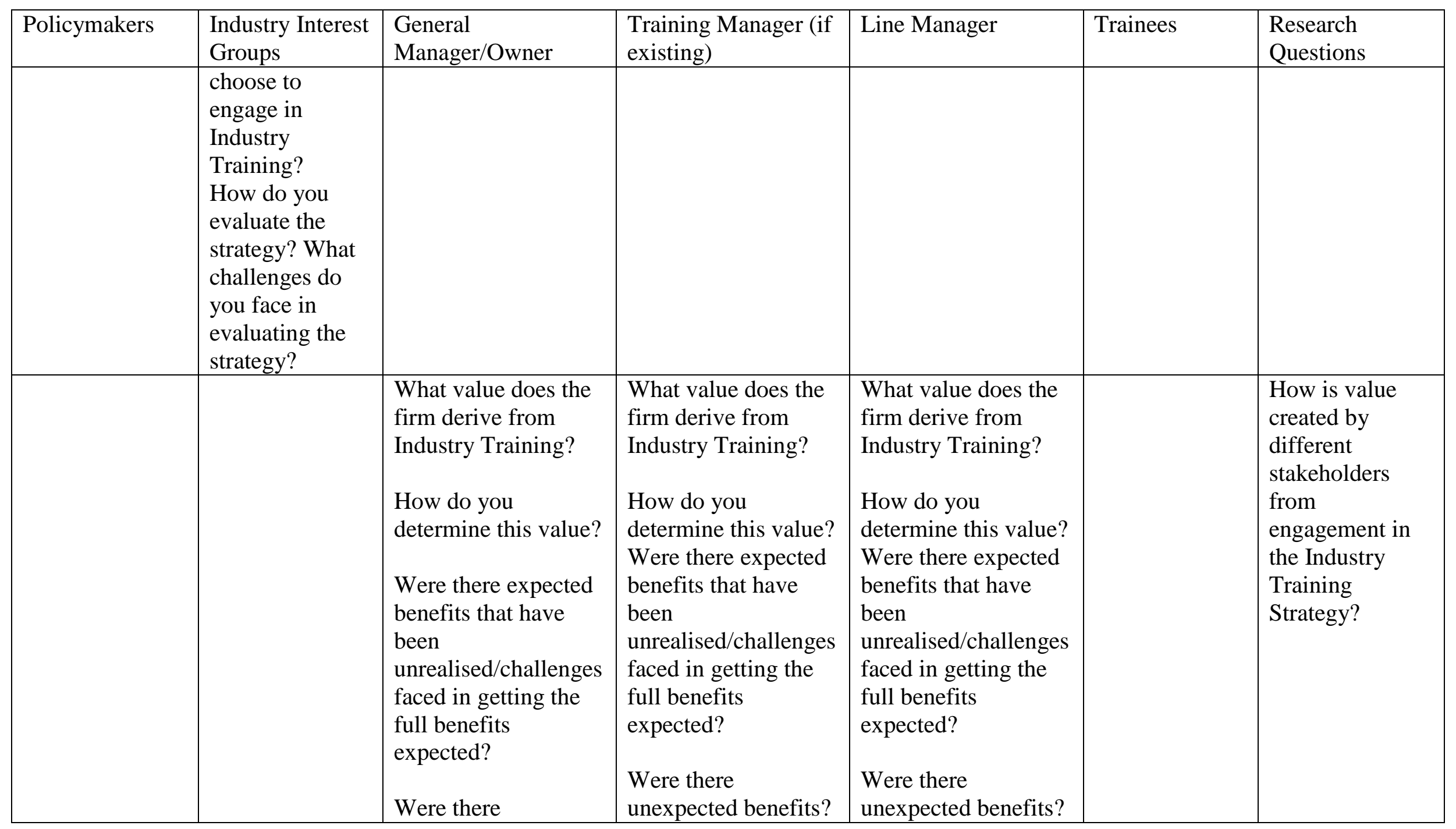




\begin{tabular}{|l|l|l|l|l|l|l|}
\hline Policymakers & $\begin{array}{l}\text { Industry Interest } \\
\text { Groups }\end{array}$ & $\begin{array}{l}\text { General } \\
\text { Manager/Owner }\end{array}$ & $\begin{array}{l}\text { Training Manager (if } \\
\text { existing) }\end{array}$ & Line Manager & $\begin{array}{l}\text { Trainees } \\
\text { Questions }\end{array}$ \\
\hline & & $\begin{array}{l}\text { unexpected benefits? } \\
\text { What are these and } \\
\text { what in your view } \\
\text { caused them? }\end{array}$ & $\begin{array}{l}\text { What are these and } \\
\text { what in your view } \\
\text { caused them? }\end{array}$ & $\begin{array}{l}\text { What are these and } \\
\text { what in your view } \\
\text { caused them? }\end{array}$ & \\
& & & & \\
\hline
\end{tabular}

For cases, I will also be asking questions and collecting secondary data in relation to the following:

- Organisation history (recent changes, size, structure, competitive/operational challenges)

- Organisation environment (the wider sector of which it is a part)

- Organisational learning climate

- Skill development activities, motives

- Participation of employees in skill development

- Role of specific actors such as managers, supervisors 


\section{REFERENCES}

Abbot, B. (1993). Training strategies in small service sector firms: employer and employee perspectives. Human Resource Management, 4 (2), 70 - 87.

Acemoglu, D. (1997). Training and innovation in an imperfect labour market. Review of Economic Studies, 64 (3), 445-464.

Acemoglu, D. (2003). Human capital policies and the distribution of income: a framework for analysis and literature review. Wellington: New Zealand Treasury Department.

Agriculture ITO Annual Report - partners in productivity. (2008). Wellington: Agriculture ITO.

Aldcroft, D. (1992). Education, training and economic performance 1944-1990. Manchester: Manchester University Press.

Alkin, M. (Ed.). (2004). Evaluation roots: tracing theorists' views and influences. Thousand Oaks: Sage Publications.

Alkin, M., \& Christie, C. (2004). An evaluation theory tree. In M. Alkin (Ed.), Evaluation roots: tracing theorists' views and influences. Thousand Oaks: Sage Publications.

Antonacopoulou, E. (1999). Training does not imply learning: the individual's perspective. International Journal of Training and Development, 3 (1), 14-33.

Armstrong, M. (2009). Armstrong's handbook of human resource management practice $\left(11^{\text {th }}\right.$ ed.). London: Michael Armstrong.

Ashton, D. (2002). The dynamics of workplace learning: the role of work organisations. In K. Evans, P. Hodkinson \& L. Unwin (Eds.), Working to learn: transforming learning in the workplace. London: Kogan Page.

Ashton, D. (2004). The political economy of workplace learning. In H. Rainbird, A. Fuller \& A. Munroe (Eds.), Workplace learning in context. London: Routledge.

Ashton, D., Green, F., Sung, J., \& James, D. (2002). The evolution of education and training strategies in Singapore, Taiwan and South Korea: a development model of skill formation. Journal of Education and Work, 15 (1), 5- 29.

Attride-Stirling, J. (2001). Thematic networks: an analytic tool for qualitative research. Qualitative Research 1 (3), 385-405.

ATTTO Annual Report: setting the standard for training in aviation, tourism, travel and museums. (2007). Wellington: ATTTO.

Avery, G. Everett, A., Finkelde, A. \& Wallace, K. (1999). Emerging trends in Australian and New Zealand management development practices in the $21^{\text {st }}$ century. Journal of Management Development, 18 (1), 94-108.

Baehler, K. (2002). Intervention logic: a user's guide. Public Sector, 25 (3), 14-20.

Baehler, K. (2003). 'Managing for outcomes': accountability and trust. Australian Journal of Public Administration, 62 (4), 23-34.

Bailey, T., \& Merritt, D. (1995). Making sense of industry-based skill standards. Washington D.C.: Office of Vocational and Adult Education.

Baker, J. (2007). Industry training investment out of step with skill shortages - media release 17 May 2007. Wellington: Industry Training Federation.

Ball, R. \& Halwachi, J. (1987). Performance indicators in higher education. Higher Education, 16 (4), 393-405.

Barbour, R. (2008). Introducing qualitative research: a student guide to the craft of doing qualitative research. Sage Publications Limited. 
Barnetson, B. \& Cutright, M. (2000). Performance indicators as conceptual technologies. Higher Education, 40 (3), 277-292.

Barney, J. (1991). Firm resources and sustained competitive advantage. Journal of Management, 17 (1), 99-120.

Bassanini, A., Booth, A., Brunello, G., Paola, M.D., \& Leuven, E. (2005). Workplace training in Europe: Discussion paper No. 1640. Bonn: Institute for the Study of Labour.

Baxendine, S., Cochrane, B., \& Poot, J. (2005). Description and spatial analysis of employment change in New Zealand regions 1986-2001: Discussion paper No. 57. Hamilton: Population Studies Centre, University of Waikato.

Beatty, R., Huselid, M., \& Schneier, C. (2003). Scoring on the business scorecard. Organisational Dynamics, 32 (2), 107-121.

Becker, G. (1962). Investment in human capital: a theoretical analysis. Journal of Political Economy, 70 (5 Part 2), 9-49.

Becton, S. \& Graetz, B. (2001). Small business - small minded? Training attitudes and needs of the tourism and hospitality industry. International Journal of Tourism Research, 3, 105-113.

Beer, M., Spector, B., Lawrence, P., Mills, D., \& Walton. R. (1985). Human resource management: a general manager's perspective - text and cases. New York: The Free Press.

Behn, R. (1981). Policy analysis and policy politics. Policy Analysis, 7 (2), 199-225.

Beierle, T. (2002). Quality of stakeholder-based decisions. Risk Analysis, 22 (4), 739749.

Benson, G. (2006). Employee development, commitment and intention to turnover: a test of 'employability' policies in action. Human Resource Management Journal, 16 (2), 173-192

Bickman, L. (2000). Summing up program theory. New Directions for Evaluation, 87, 103-112.

Billett, S. (2000). Guided learning at work. Journal of Workplace Learning, 12 (7), $272-285$.

Billett, S. (2004a). Learning in the workplace: reappraisals and reconceptions. In G. Hayward \& S. James (Eds.), Balancing the skills equation: key issues and challenges for policy and practice. Bristol: The Policy Press.

Billett, S. (2004b). Workplace participatory practices. Journal of Workplace Learning, 16 (6), 312-324.

Billett, S., \& Hayes, S. (2000). Meeting the demand: the needs of vocational education and training clients - an overview. National Centre for Vocational Education Research.

Blalock, A. (1999). Evaluation research and the performance management movement. Evaluation, 5 (2), 117-149.

Blundell, R., Dearden, L., Meghir, C., \& Sianesi, B. (1999). Human capital investment: the returns from education and training to the individual, the firm and the economy. Fiscal Studies, 20 (1), 1-23.

Bolton, S., \& Houlihan, M. (2007). Beginning the search for the H in HRM. In S.

Bolton \& M. Houlihan (Eds.), Searching for the human in human resource management: theory, practice and workplace contexts. New York: Palgrave Macmillan.

Boshier, R. (1980). Towards a learning society. Vancouver: Learningpress Limited.

Boxall, P. (1996). The strategic HRM debate and the resource-based view of the firm. Human Resource Management, 6 (3), 59-75. 
Boxall, P. (2003). HR strategy and competitive advantage in the service sector. Human Resource Management, 13 (3), 5 - 20.

Briggs, C. \& Katay, J. (2000). Vocational education and training, skill formation and the labour market. Sydney: NSW Board of Vocational Education and Training.

Brinkerhoff, R. (1989). Using evaluation to transform training. New Directions for Program Evaluation, 44, 5 - 19.

Brinkerhoff, R. (2003). The success case method: find out quickly what's working and what's not. San Francisco: Berrett-Koehler Publishers Inc.

Brinkerhoff, R. (2005). The success case method: a strategic evaluation approach to increasing the value and effect of training. Advances in Developing Human Resources, 7 (1), 86-101.

Brinkerhoff, R. (2006). Telling training's story: evaluation made simple, credible and effective. San Francisco: Berrett-Koehler Publishers Inc.

Brosnan, P., \& Rea, D. (1992). Government policy on restructuring the labour market: New Zealand Working Paper 16. Sydney: ACIRRT, University of Sydney.

Brown, P., Lauder, H., \& Ashton, D. (2008). Towards a high skills economy: higher education and new realities of global capitalism. In R. Boden, R. Deem, D. Epstein, F. Rizvi \& S. Wright (Eds.), World Year Book of Education 2008. Geography of knowledge, geometrics of power: high education in the $21^{\text {st }}$ century. London: Routledge.

Bryant, K. (2007). Reporting value added to training project. Paper presented at the Industry Training Federation Conference.

Bryson, J. (2006). How national learning and training strategies are implemented at the workplace level through industry training organisations. Paper presented at the APEC HRD Forum: Increasingly vital role of enterprises in HRD.

Bryson, J. (2007). Human resource development or developing human capability? In S. Bolton \& M. Houlihan (Eds.), Searching for the human in human resource management. New York: Palgrave MacMillan.

Bryson, J., \& O’Neil, P. (2008). Developing human capability: employment institutions, organisations and individuals - an overview of findings on developing human capability. Wellington: Industrial Relations Centre, Victoria University of Wellington.

Bryson, J., Pajo, K., Ward, R., \& Mallon, M. (2006). Learning at work: organisational affordances and individual engagement. Journal of Workplace Learning, 18 (5), 279-297.

Buchanan, J., Briggs, C., Considine, G., Schofield, K., \& McIntyre, J. (2000). Vocational education and training and the changing nature of work: overview of work in progress. NWS Board of Vocational Education and Training.

Buchanan, J., Schofield, K., Briggs, C.,Considine, G., Hager, P., Hawke, G., et al. (2001). Beyond flexibility: skills and work in the future. Sydney: NSW Board of Vocational Education and Training.

Buchanan, J., Watson, I., Briggs, C., \& Campbell, I. (2006). Beyond voodoo economics and backlash social policy: where next for working life research and policy? Australian Bulletin of Labour, 32 (2), 183-201

Buchholz, R., \& Rosenthal, S. (2004). Stakeholder theory and public policy: how governments matter. Journal of Business Ethics, 51, 143-153.

Career maps and pathways report. (2008). Wellington: HSI/Projects International/ATTTO. 
Career progression and development survey: results for the New Zealand public service. (2005). Wellington: State Services Commission.

Case studies: workplace productivity in practice. (2004). Retrieved September 27, 2008 from http://www.dol.govt.nz.

Chalofsky, N. (1992). A unifying definition for the human resource development profession. Human Resource Development Quarterly, 3 (2), 175-182.

Chappell, C., Hawke, G., \& Schofield, K. (2002). An industry-led system: issues of policy practice and practitioners. Sydney: University of Technology.

Chelimsky, E. (1996). Auditing and evaluation? Whither the relationship? New Directions for Evaluation, 71, 61-67.

Christie, C. (2003). What guides evaluation? A study of how evaluation practice maps onto evaluation theory. New Directions in Evaluation, 97, 7 - 35.

Christopoulos, D. (2007). Explaining country's efficiency performance. Economic Modelling, 24, 224-235.

Coffield, F. (2004). Alternative routes out of the low skills equilibrium: a rejoinder to Lloyd and Payne. Journal of Education Policy, 19 (6), 733-740.

Combs, J., Liu, Y., Hall, A., \& Ketchen, D. (2006). How much do high performance work practices matter? A meta-analysis of their effects on organisational performance. Personnel Psychology, 59, 501-528.

Cooksky, L., Gill., P., \& Kelly, P.A. (2001). The program logic model as an integrative framework for a multimethod evaluation. Evaluation and Program Planning, 24, 119-128.

Correa, H. (2004). A game theoretic analysis of public/government interactions in human capital formation. Journal of Socio-Economics, 33, 409-425.

Cousins, J., \& Earl, L. (1992). The case for participatory evaluation. Educational Evaluation and Policy Analysis, 14 (4), 397-418.

Cox, A. (2007). Re-visiting the NVQ debate: 'bad' qualifications, expansive learning environments and prospects for upskilling workers: SKOPE Research Paper No. 71: Centre on Skills, Knowledge and Organisational Performance.

Crichton, S. (2009). Does workplace-based industry training improve earnings? Wellington: Statistics New Zealand and New Zealand Department of Labour.

Crocombe, G., Enright, M., \& Porter, M. (1991). Upgrading New Zealand's competitive advantage. Auckland: Oxford University Press.

Crouch, C., Finegold, D., \& Sako, M. (1999). Are skills the answer? The political economy of skill creation in advanced industrial countries. New York: Oxford University Press.

Culpepper, P. (1999). The future of the high-skill equilibrium in Germany. Oxford Review of Economic Policy, 15 (1), 43-59.

Daly, A., Hitchins, D., \& Wagner, K. (1985). Productivity, machinery and skills in a sample of British and German manufacturing plants. National Institute Economic Review, 111, 48-61.

Dalziel, P. (2007). Integrating employment, skills and economic development: New Zealand: Report to the OECD: LEED Programme, OECD.

Dalziel, P., \& Saunders, C. (2003). Regional economic development planning in New Zealand: who owns it? Canterbury: Agribusiness and Economics Research Unit, Lincoln University.

David, P., \& Lopez, J. (2001). Knowledge, capabilities and human capital formation in economic growth. Wellington: New Zealand Treasury Department.

Davies, I. (1999). Evaluation and performance management in government. Evaluation, 5 (2), 150-159. 
Davis, N. (2006). Business $R \& D$, innovation and economic growth : an evidencebased synthesis of the policy issues. Wellington: New Zealand Ministry of Economic Development.

Delivering value: the contribution of ITOs to New Zealand vocational education and training. (2010). Retrieved November 12, 2010, from http://itf.org.nz.

Denzin, N., \& Lincoln, Y. (Eds.). (2005). The Sage Handbook of qualitative research $\left(3^{\text {rd }}\right.$ ed.): Sage Publications Inc.

Developing the second tertiary education strategy: Industry Training Federation submission to the Ministry of Education. (2006). Wellington: Industry Training Federation.

Devins, D., \& Johnston, S. (2003). Training and development activities in SMEs: some findings from an evaluation of the ESF objective 4 programme in Britain. International Small Business Journal, 21 (2), 213-228.

Dieckhoff, M. (2008). Skills and occupational attainment: a comparative study of Germany, Denmark and the UK. Work, Employment and Society, 22 (1), 89108.

Dillingham, W. (2002). New Zealand's workforce: qualifications and evidence of upskilling. Wellington: Labour Market Policy Group, New Zealand Department of Labour.

Dixit, A. (2002). Incentives and organisations in the public sector: an interpretative review. Journal of Human Resources, 37 (4), 696-727.

Dockery, A. (2001). Training, innovation and business performance: an analysis of the business longitudinal survey. Australian National Training Authority.

Donaldson, S., \& Gooler, L. (2003). Theory-driven evaluation in action: lessons from a \$20 million statewide Work and Health initiative. Evaluation and Program Planning, 26, 355-366.

Downey, J., \& Zeltmann, S. (2009). The role of competence level on the self-efficacy skills relationship: an empirical examination of the skill acquisition process and its implications for information technology training. International Journal of Training and Development, 13 (2), 96-110.

Dunn, C. (2006). The benefits of completing a retail industry qualification. Wellington: Retail ITO.

Dunn, C. (2007). Retail ITO employer survey report. Wellington: Retail ITO.

Dunn, W. (2004). Public policy analysis: an introduction (3 ${ }^{\text {rd }}$ ed.). New Jersey: Pearson PrenticeHall.

Dunning, J. (1992). The competitive advantage f countries and the activities of transnational corporations. Transnational Corporations, 1, 135-168.

Durbin, S. (2004). Workplace skills, technology adoption and firm productivity: a review. Wellington: New Zealand Treasury Department.

Dyson, C., \& Keatin, J. (2005). Skills, knowledge and employability: recognition of prior learning - policy and practice for skills learned at work. Geneva: International Labour Office.

Edgar, F. \& Geare, A. (2005). Employee voice in human resource management. Asia Pacific Journal of Human Resources, 43 (3), 183-196.

Edgar, F. \& Geare, A. (2007). Legislating for best practice in HRM: the New Zealand approach. Public Personnel Management, 36 (3), 183-196.

Edwards, P., Sengupta, S., \& Tsai, C. (2007). Managing work in the low-skill equilibrium: a study of UK food manufacturing: SKOPE Research Paper No. 72. Centre on Skills, Knowledge and Organisational Performance.

Edwards, R., \& Boreham, N. (2003). 'The centre cannot hold': complexity and 
difference in European Union policy towards a learning society. Journal of Education Policy, 18 (4), 407-421.

Elkin, G. (1998). New Zealand human capital development and structural reform. International Journal of Training and Development, 2 (1), 42- 60.

Elliot, C., \& Turnbull, S. (Eds.). (2005). Critical thinking in human resource development. Leicester: Routledge.

Eraut, M., Alderton, J., Cole, G. \& Senker, P. (2000). Development of knowledge and skills at work. In F. Coffield (Ed.), Differing visions of a learning society. London: The Policy Press, Economic and Social Research Council.

Eraut, M., \& Hirsh, W. (2007). The significance of workplace learning for individuals groups and organisations. ESRC Centre on Skills, Knowledge and Organisational Performance.

Evans, K., \& Rainbird, H. (2002). The significance of workplace learning for a 'learning society'. In K. Evancs, P. Hodkinson \& L. Unwn (Eds.), Working to learn: transforming learning in the workplace. London: Kogan Page.

Evans, L., Grimes, A., Wilkinson, B., \& Teece, D. (1996). Economic reform in New Zealand 1984-95: the pursuit of efficiency. Journal of Economic Literature, 34, 1856-1902.

Fabling, R., \& Grimes, A. (2006) Practice makes profit: business practices and firm success. Wellington: New Zealand Ministry of Economic Development.

Fabling, R., \& Grimes, A. (2007). HR practices and firm performance: what matters and who does it? Wellington: New Zealand Ministry of Economic Development.

Fenwick, T. (2004).Toward a critical HRD in theory and practice. Adult Education Quarterly, 54, 193-208.

Fenwick, T. (2005). Conceptions of critical HRD: dilemmas for theory and practice. Human Resource Development International, 8 (2), 225-238.

Fenwick, T. (2006). Learning as grounding and flying: knowledge, skill and transformation in changing work contexts. Journal of Industrial Relations, 48 (5), 691-706.

Fenwick, T., \& Hall, R. (2006). Skills in the knowledge economy: changing meanings in changing conditions. Journal of Industrial Relations, 48 (5), 571-574.

Fetterman, D., \& Wandersman, A. (Eds.) (2005). Empowerment evaluation principles in practice. New York: The Guilford Press.

Field, J. (1991). Competency and the pedagogy of labour. Studies in the Education of Adults, 23 (1), 41-66.

Finegold, D. (1999). Creating self-sustaining, high-skill ecosystems. Oxford Review of Economic Policy, 15 (1), 60-81.

Finegold, D., \& Soskice, D. (1988). The failure of training in Britain: analysis and prescription. Oxford Review of Economic Policy, 4 (3), 21-51.

Fischer, F., Miller, G., Sidney, M. (Eds.) (2007). Handbook of public policy analysis: theory, politics and methods. Boca Raton: CRC Press.

FitzSimons, G. (2002). What counts as mathematics? Technologies of power in adult and vocational education. Dordrecht: Kluwer Academic Publishers.

Fleetwood, S., \& Hesketh, A. (2006). HRM-performance research: under-theorised and lacking in explanatory power. International Journal of Human Resource Management, 17 (12), 1977-1993.

Fleetwood, S., \& Hesketh, A. (2007). Theorising under-theorisation in research of the HRM-performance link. Personnel Review, 37 (2), 126-144.

Flude, M., \& Siemenski, S. (Eds.) (1999). Education, training and the future of work 
(Vol. 2). New York: Routledge.

Frey, L., Botan, P., Friedman, P., \& Kreps, G. (1991). Investigating communication: an introduction to research methods. EnglewoodCliffs: PrenticeHall.

Fuller, A., Ashton, D., Felstead, A., Urwin, L., Walters, S., \& Quinn, M. (2003). The impact of informal learning at work on business productivity: final report to the Department of Trade and Industry. Centre for Labour Market Studies, University of Leicester.

Funnell, S. (2000). Developing and using a program theory matrix for program evaluation and performance monitoring. New Directions for Evaluation, 87, 91-101

Garavan, T., Gunnigle, P., \& Morley, M. (2000). Contemporary HRD research: a triarchy of theoretical perspectives and their prescriptions for HRD. Journal of European Industrial Training, 24 (2/3/4/), 65-93.

Gerring, J. (2007). Case study research: principles and practices. New York: Cambridge University Press.

Gilbert, J. (2005). Catching the knowledge wave? The knowledge society and the future of education. Wellington: New Zealand Council for Educational Research Press.

Gorg, H., \& Strobl, E. (2005). Do government subsidies stimulate training expenditure? Microeconometric evidence from plant level data: Discussion Paper No. 1606. Bonn: Institute for the Study of Labour.

Gray, A. (2006). Upskilling through foundation skills: a literature review. Wellington: New Zealand Department of Labour.

Green, D., \& Riddell, W.C. (2003). Literacy and earnings: an investigation of the interaction of cognitive and unobserved skills in earnings generation: Labour Economics, 10, 165-184.

Green, F., Ashton, D., James, D., \& Sung, J. (1999). The role of the state in skill formation: evidence from the Republic of Korea, Singapore and Taiwan. Oxford Review of Economic Policy, 15 (1), 82-96.

Green, F., Mayhew, K., \& Molloy, E. (2003). Employer perspectives survey. London: Department of Education and Skills.

Green, N., Hopkins, C., Williams, P., \& Murdoch, C. (2003). A brief history of government funding for industry training 1989-2002. Wellington: Industry Training Federation.

Gregory, R. (2004).Political life and intervention logic: relearning old lessons? International Public Management Journal, 7 (3), 299-315.

Grubb, W.N.,\& Ryan, P. (1999). The roles of evaluation for vocational education and training: plain talk in the field of dreams. Geneva: International Labour Office.

Grugulis, I. (2003). The contribution of national qualifications to the growth of skills in the UK. British Journal of Industrial Relations, 41 (3), 457-475.

Guest, D. (1999). Human resource management - the workers' verdict. Human Resource Management Journal, 9 (3), 5 -25.

Hager, P. (2000). Know-how and workplace practical judgement. Journal of Philosophy of Education, 34 (2), 281 - 295

Hager, P. (2004). Lifelong learning in the workplace? Challenges and issues. Journal of Workplace Learning, 16 (12), 22-32.

Hager, P., \& Beckett, D. (1999). Making judgements as the basis for workplace learning - preliminary research findings. Sydney: UTS Research Centre for Vocational Education and Training. 
Hales, B. (2004). Let's not dumb down workplace learning. New Zealand Management, 15 (7), 22-23.

Hall, D. (2004). Modern apprenticeships. Wellington: Industry Training Federation.

Hall, R., Buchanan, J., \& Bretherton, T. (2000). "It's not my problem": the growth of non-standard work and its impact on vocational education and training in Australia. Sydney: ACIRRT.

Hall, R., \& Jones, C. (1999). Why do some countries produce so much more output per worker than others? Quarterly Journal of Economics, 83-115.

Hall, R., \& Lansbury, R. (2006). Skills in Australia: towards workforce development and sustainable skill ecosystems. Journal of Industrial Relations, 48 (5), 575592.

Hanberger, A. (2001). What is a policy problem? Methodological challenges in policy evaluation. Evaluation, 7 (1), 45-62.

Hansson, B. (2008). Job-related training and benefits for individuals: a review of evidence and explanations. OECD Education Working Papers, 19, 1- 48.

Hanushek, E., \& Wobmann, L. (2007). The role of education quality in economic growth. World Bank.

Harbison, F. (1973). Human resources as the wealth of nations. New York: Oxford University Press.

Hardy, F. (2008). Measuring the value of training by quantifying the return on investment of training in both economic and non-economic terms. Paper presented at Evaluating Workplace Learning - Identifying Success Conference.

Harris, K. (2007). Interview on the topic: the history and development of industry training organisations in New Zealand.Wellington.

Harvey, O., \& Harris, P. (2008). The skills-productivity nexus: connecting industry training and business performance. Wellington: New Zealand Department of Labour/Industry Training Federation.

Hawke, G. (1988). Report on the working group on post compulsory education and training in New Zealand. Wellington: New Zealand Ministry of Education.

Hawke, G., Ross, B., \& Smythe, D. (1986). Labour market flexibility. Wellington: New Zealand Planning Council.

Hayward, G., \& James, S. (Eds.) (2004). Balancing the skills equation: key issues and challenges for policy and practice. Bristol: The Policy Press.

Heise, W. (1998). Portability of qualifications: an answer to the qualifications demands of globalisation? Journal of European Industrial Training, 22 (7), $289-298$.

Heyes, J., \& Stuart, M. (1996). Does training matter? Employee experiences and attitudes. Human Resource Management Journal, 6 (3), 7-21.

High Performance ITOs. (2009). Wellington: Industry Training Federation.

Hillage, J., \& Pollard, E. (1998). Employability: developing a framework for policy analysis. Institute for Policy Studies.

Hodkinson, P., \& Bloomer, M. (2002). Learning careers, conceptualising lifelong work-based learning. In K. Evans, P. Hodkinson \& L. Urwin (Eds.), Working to learn: transforming learning in the workplace. London: Kogan Page.

Holtom, B., Mitchell, T., \& Lee, T. (2006). Increasing human and social capital by applying job embeddedness theory. Organisational Dynamics, 35 (4), 316331.

Holton, E. (2005). Holton's evaluation model: new evidence and construct evaluations. Advances in Developing Human Resources, 7 (1), 37-54. 
Holton, E., \& Naquin, S. (2005). Critical analysis of HRD evaluation models from a decision-making perspective. Human Resource Development Quarterly, 16 (2), 257-280.

Hoque, K., \& Bacon, N. (2006). The antecedents of training activity in British small and medium-sized enterprises. Work, Employment and Society, 20 (3), 531552.

House, E. (1978). Assumptions underlying evaluation models. Educational Researcher, 7 (3), 4-12.

House, E. (2001a). Responsive evaluation (and its influence on deliberative democratic evaluation). New Directions for Evaluation, 92, 23-30.

House, E. (2001b). Unfinished business: causes and values. American Journal of Evaluation, 22 (3), 309-315.

House, E. (2003). Stakeholder bias. New Directions for Evaluation, 97, 53-56.

Human capital and the inclusive economy: Treasury Working Paper 01/16. (2001). New Zealand Treasury Department.

Human resource capability survey of public service departments as at 30 June 2007. (2007). Wellington: State Services Commission.

Industry Training 2003. (2004). Wellington: New Zealand Tertiary Education Commission

Industry Training 2005. (2005). Wellington: New Zealand Tertiary Education Commission.

Industry Training Act, (1992).

Industry training and modern apprenticeship statistics as at 30 September 2006. (2007). Wellington: New Zealand Ministry of Education.

Industry Training skills leadership: the role of industry training organisations in shaping skills in the New Zealand economy. (2006). Wellington: Industry Training Federation.

Industry Training: file specification for industry training organisation performance measurement system. (2005). Wellington. Retrieved 30 March 2010 from http://www/tec/govt/nz.

Ingram, B., \& Neumann, G. (2006). The returns to skill. Labour Economics, 13, 3559.

Inkson, K. (2006). Protean and boundaryless careers as metaphors. Journal of Vocational Behaviour, 69, 48-63.

Investing in a plan. (2007). ITP Update (1), 1-14.

Jesson, B. (1999). Only their purpose is mad: the money men take over NZ. Palmerston North: Dunmore Press.

Johnston, G. (2004). Adult literacy and economic growth. Wellington, New Zealand Treasury Department.

Julian, D., Jones, A., \& Deyo, D. (1995). Open systems evaluation and the logic model: program planning and evaluation tools. Evaluation and Program Planning, 18 (4), 333-341.

Junor, A. (1992). Emerging training patterns: productive, equitable? Paper presented at the Training for the Workplace: Developing and evaluating programmes. University of Sydney.

Kaplan, R., \& Norton, D. (1996). The balanced scorecard: translating strategy into action. Boston: Harvard Business School Press.

Kaplan, R., \& Norton, D. (2001). The strategy-focused organisation-how balanced scorecard companies thrive in the new business environment. Boston: Harvard Business School Publishing Corporation. 
Kaplan, S., \& Garrett, K. (2005). The use of logic models by community-based initiatives. Evaluation and Program Planning, 28, 167-172.

Katz, E., \& Ziderman, A. (1990). Investment in general training: the role of information and labour mobility. Economic Journal, 100 (403), 1147-1158.

Keep, E. (2007). Key future labour market and skills issues in Scotland (and beyond). Glasgow: Futureskills Scotland.

Keep, E. (2009). Internal and external incentives to engage in education and training - a framework for analysing the forces acting on individuals? Cardiff: ESRC Centre on Skills, Knowledge and Organisational Performance, Cardiff University.

Keep, E., \& Mayhew, K. (1999). The assessment: knowledge, skills and competitiveness. Oxford Review of Economic Policy, 15 (1), 1 - 15.

Keep, E., \& Mayhew, K. (2004). Can employers be persuaded that training pays? Glasgow: Futureskills Scotland.

Keep, E., \& Payne, J. (2004). 'I can't believe it's not a skill”: the changing meaning of skill in the UK context and some implications. In G. Hayward \& S. James (Eds.), Balancing the skills equation: key issues and challenges for police and practice. Bristol: The Policy Press.

Key facts about industry training. (2008). Retrieved September 22, 2008 from http://www.itf.org.nz

Key steps forward for workforce literacy. (2008). Wellington: Business NZ/NZCTU/ Workbase.

King, J. (2003). The challenge of studying evaluation theory. New Developments for Evaluation, 97, 57-67.

Kirkpatrick, D. (1998a). Evaluating training programs: the four levels $\left(2^{\text {nd }}\right.$ ed.). San Francisco: Berrett-Koehler Publishers Inc.

Kirkpatrick, D. (Ed.) (1998b). Another look at evaluating training programs. American Society for Training and Development.

Kis, V. (2005). Quality assurance in tertiary education: current practices in OECD countries and a literature review on potential conflicts. Paris: OECD.

Kitching, J. (2007). Regulating employment relations through workplaces learning: a study of small employers. Human Resource Management, 17 (1), 42-57.

Kitching, J. (2008). Rethinking UK small employers' skills policies and the role of workplace learning. International Journal of Training and Development, 12 (2), 100-120.

Kitching, J., \& Blackburn, R. (2002). The nature of training and motivation to train in small firms. Department for Education and Skills.

Knowledge at Work. (2001). Wellington: Skill New Zealand.

Knuckey, S., Johnston, H., Campbell-Hunt, C., Carlaw, K., Corbett, L., \& Massey, C. (2002). Firm foundations: a study of New Zealand business practices and performance. Wellington: New Zealand Ministry of Economic Development.

Kock, H., Gill, A., \& Ellstrom, P.E. (2008). Why do small enterprises participate in a programme for competence development. Journal of Workplace Learning, 20 (3), 181-194.

Korczynski, M. (2005). Skills in service work: an overview. Human Resource Management, 15 (2), 3-14.

Kotter, J. (1996). Leading change. Massachusetts: Harvard Business School.

Kulvisaechana, S. (2005). The rhetoric and reality of developing human capital in the organisation: a case study. University of Cambridge.

Lamm, F., Massey, C., \& Perry, M. (2006). Productivity indicators and challenges in 
New Zealand workplaces. Wellington: Labour Employment and Work in New Zealand.

Lamm, F., \& Rasmussen, E. (2008). Employment relations. In K. Macky (Ed.), Managing human resources: contemporary perspectives in New Zealand. New South Wales: McGraw-Hill Australia.

Lange, T., Ottens, M., \& Taylor, A. (2000). SMEs and barriers to skills development: a Scottish perspective. Journal of European Industrial Training, 24 (1), 5-11.

Laughlin, R., \& Broadbent, J. (1996). Redesigning fourth generation evaluation: an evaluation model for the public sector reforms in the UK? Evaluation, 2 (4), 431-451.

Le, T., Gibson, J., \& Oxley, L. (2005). Measures of human capital: a review of the literature. Wellington: New Zealand Treasury Department.

Learner perceptions of industry training. (2007). Wellington: Industry Training Federation.

Leeuw, F. (1996). Auditing and evaluation: bridging a gap, worlds to meet? New Directions for Evaluation, 71, 51-60.

Lennie, J. (2006). Increasing the rigour and trustworthiness of participatory evaluations: learnings from the field. Evaluation Journal of Australasia, 6 (1), 27-35.

Liaise report: a forecast of skill needs and training priorities for the New Zealand Hospitality Industry to 2012. (2007). Wellington: Hospitality Standards Institute.

Literacy, language and numeracy action plan 2008-2012. (2008). Wellington: Tertiary Education Commission.

Livingstone, D. (2005). Exploring adult learning and work in advanced capitalist society. Retrieved April 2, 2007 from http://www.obs-pascal.com/

Lloyd, C., \& Payne, J. (2003). The political economy of skill and the limits of educational policy. Journal of Education Policy, 18 (1), 85-107.

Lloyd, C., \& Payne, J. (2005). High performance work organisation-a driver for the high skills vision? SKOPE Issues Paper 6.

Logic model development guide. (2004). Battle Creek: W.K. Kellogg Foundation.

Logic model for the evaluation of the 10-year strategic plan for early childhood education: pathways to the future. (2003). Wellington: CIRCLE RMIT University.

Lunt, N. (2003). Knowledge for policy: the emergence of evaluation research within New Zealand. In N. Lunt, C. Davidson \& K. McKegg (Eds.). Evaluation policy and practice: a New Zealand reader. Auckland: Pearson Education New Zealand Limited.

Lunt, N., \& Davidson, C. (2003). Introduction. In N. Lunt, C. Davidson \& K. McKegg (Eds.). Evaluation policy and practice: a New Zealand reader. Auckland: Pearson Education New Zealand Limited.

Mahoney, P. (2010). Industry training - exploring the data. Wellington: New Zealand Ministry of Education.

Martin, G., Pate, J., \& Beaumont, P. (2001). Company-based education programmes: what's the pay-off for employers. Human Resource Management, 11 (4), 5573.

Mason, G., \& Osbourne, M. (2007). Productivity, capital-intensity and labour quality at sector level on New Zealand and the United Kingdom: Treasury Working Paper 07/01. Wellington: New Zealand Treasury Department.

McGoldrick, J., Stewart, J., \& Watson, S. (2001). Theorising human resource 
development. Human Resource Development International, 4 (3), 343-356.

McLaughlin, C. (2006). Achieving efficiency with equity: a labour market analysis of Denmark, Ireland and New Zealand. Unpublished $\mathrm{PhD}$, University of Cambridge.

McLean, G., Bartlett, K., \& Cho, E. (2003). Human resource development as national policy: Republic of Korea and New Zealand. Pacific Asian Education, 15 (1), 41-59.

McQuaid, R., \& Lindsay, C. (2005). The concept of employability. Urban Studies, 42 (2), 197-219.

Miller, D., Sen, A., Malley, L., \& Owen, E. (2007). Comparative indicators of education in the United States and other G-8 countries - 2006. National Centre for Education Statistics: US Department of Education.

Modernising vocational education and training: fourth report on vocational education and training research in Europe: synthesis report. (2009). Luxembourg: Publications Office of the European Union.

Mohan, R., Tikoo, M., Capela, S., \& Berstein, D. (2006). Increasing evaluation use among policymakers through performance measurement. New Directions for Evaluation, 12, 89-97.

Moore, P. (2009). UK education, employability and everyday life. Journal for Critical Education Policy Studies, 7 (1), 243-274.

Mournier, A. (2001). The three logics of skill in French literature: Working Paper No. 66. Sydney: ACIRRT.

Murray, N. (2004). Who gets their hands dirty in the knowledge society? Training for the skilled trades in New Zealand. Unpublished $\mathrm{PhD}$, Lincoln University.

Naswall, K., Hellgren, J., \& Sverke, M. (2008). The individual in the changing working life: an introduction. In K. Naswall, J. Hellgren \& M. Sverke (Eds.). The individual in the changing working life. New York: Cambridge University Press.

New Zealand economic growth: an analysis of performance and policy. (2004). Wellington: New Zealand Treasury Department.

New Zealand Skills Strategy Action Plan. (2008). Wellington: New Zealand Government/Business NZ/NZCTU/Industry Training Federation.

New Zealand Skills Strategy Discussion Paper. (2008). Wellington: New Zealand Government/Business NZ/NZCTU/Industry Training Federation.

Nielson, S., \& Ejler, N. (2008). Improving performance? Exploring the complementarities between evaluation and performance management. Evaluation, 14 (2), 171-192.

Noe, R., Hollenbeck, J., Gerhart, B., \& Wright, P. (2000). Human resource management: gaining a competitive advantage. McGraw-Hill Publishing.

Nolan, A., \& Wong, G. (2004). Evaluating programmes for local economic and employment development: an overview with policy recommendations. In Evaluating local and economic and employment development: how to assess what works among programmes and policies. OECD.

Nonaka, I. (1991). The knowledge-creating company. Harvard Business Review, July - August, 2007 reprinted, 162-171.

Nordman, C., Hayward, P., \& Hayward, G. (2006). Returns to on-the-job training: do skill usage, tasks and workstation matter? Evidence from British workers: SKOPE Research Paper No. 63. Centre on Skills, Knowledge and Organisational Performance.

O'Donoghue, J., \& Maguire, T. (2005). The individual learner, employability and the 
workplace: a reappraisal of relationships and prophecies. Journal of European Industrial Training, 29(6), 436-446.

O’Donnell, D., McGuire, D., \& Cross, C. (2006). Critically challenging some assumptions in HRD. International Journal of Training and Development, 10 (1), 4-16.

Owen, J. (1998). Towards an outcomes hierarchy for professional university programs. Evaluation and Program Planning, 21, 315-321.

Pahl-Wostl, C. (2002). Participative and stakeholder-based policy design, evaluation and modelling processes. Integrated Assessment, 3 (1), 3-14.

Patton, M. (2002a). Qualitative research and evaluation methods $\left(3^{\text {rd }}\right.$ ed.). Thousand Oaks: Sage Publications.

Patton, M. (2002b). Utilisation-focused evaluation. Evaluation in Education and Human Services, 49 (5), 425-438.

Pawson, R. (2002) Evidence-based policy: in search of a method. Evaluation, 8 (2), 157-181.

Payne, J. (2004). The changing meaning of skill. SKOPE Issues Paper 1.

Payne J. (2007). Skills in context: what can the UK learn from Australia's skill ecosystem projects? SKOPE Research Paper No. 70. Centre on Skills, Knowledge and Organisational Performance.

Peck, J., \& Theodore, N. (2000). Beyond employability. Cambridge Journal of Economics, 24 (6), 729-749.

Pfeffer, J. (1998). The human equation: building profits by putting people first. Boston: Harvard Business School Press.

Phillips, J., \& Stone, R. (2002). How to measure training results: a practical guide to tracking the six key indicators. New York: McGraw-Hill.

Phillips, P., \& Phillips, J. (2007). The value of learning: how organisations capture value and ROI. San Francisco: John Wiley and Sons Inc.

Piore, M., \& Sabel, C. (1984). Second industrial divide: possibilities for prosperity. New York: Basic Books.

Pool, I., Baxendine, S., Cochrane, W., \& Lindop, J. (2005a). New Zealand regions 1986-2001: Incomes Discussion Paper No. 58. Hamilton: Population Studies Centre, University of Waikato.

Pool, I., Baxendine, S., Cochrane, W., \& Lindop, J. (2005a). New Zealand regions 1986-2001: Industries and Occupations Discussion Paper No. 59. Hamilton: Population Studies Centre, University of Waikato.

Pool, I., Baxendine, S., Cochrane, W., \& Lindop, J. (2006). New Zealand regions 1986-2001: Labour market aspects of human capital: Discussion Paper No. 60. Hamilton: Population Studies Centre, University of Waikato.

Porter, M. (1998). Clusters and the new economics of competition. Harvard Business Review, November-December, 77-90.

Porter, S. (2006). Conclusion. In S. Porter \& M. Campbell (Eds.). Skills and economic performance. London: Sector Skills Development Agency.

Prais, S., Jervis, V., \& Wagner, K. (1989). Productivity and vocational skills in services in Britain and German hotels. National Institute Economic Review, 130 (52).

Propper, C., \& Wilson, D. (2003). The use and usefulness of performance measures in the public sector. Bristol: University of Bristol.

Public Sector Industry Training Organisation strategic business plan 2006-2009. (2006). Wellington: PSITO.

Qualifications and lifelong learning: OECD Policy Brief. (2007). OECD. 
Rainbird, H. (2002) No rights, just responsibilities: individual demand for continuing training. In K. Evans, P. Hodkinson \& L. Unwin (Eds.). Working to learn: transforming learning in the workplace. London: Kogan Page.

Rainbird, H., Fuller, A., \& Holly, L. (2004). The employment relationship and workplace learning. In H. Rainbird, A. Fuller \& A. Munro (Eds.). Workplace learning in context. London: Routledge.

Rainbird, H., \& Munro, A. (2003). Workplace learning and the employment relationship in the public sector. Human Resource Management, 13 (2), 30-44.

Reform and change in Industry training. (1992). Paper presented at the Reform and Change in Industry Training Conference, Auckland.

Reich, R. (1992). The work of nations. New York: Vintage Books.

Richardson, S., \& Liu, P. (2008). Changing forms of employment and their implications for the development of skills. National Centre for Vocational Education Research.

Richardson, S., \& Miller-Lewis, L. (2002). Low wage jobs and pathways to better outcomes. Wellington: New Zealand Treasury Department.

Ridoutt, L., Dutneal, R., Hummel, K., \& Smith, C. (2002). Factors influencing the implementation of training and learning in the workplace. Australian National Training Authority.

Ridoutt, L., Hummel, K., Dutneal, R., \& Smith, C. (2005). The place of recognised qualifications in the outcomes of training. Australian National Training Authority.

Ridoutt, L., Smith, C., Hummel, K., \& Cheang, C. (2005). What value to employers give to qualifications? Adelaide: National Centre for Vocational Education Research.

Robertson, M. (2004). Building program theory for evaluation: the process through a political lens. Athens: University of Georgia.

Rogers, P. (2000). Causal models in program theory evaluation. New Directions in Evaluation, 87, 47-55.

Rubin, H., \& Rubin, I. (2005). Qualitative interviewing: the art of hearing data $\left(2^{\text {nd }}\right.$ ed.). Thousand Oaks: Sage Publications Inc.

Ruppert, S. (1995). Roots and realities of state-level performance indicator systems. New Directions for Higher Education, 91, 11-23.

Ryan, R. (2007). Why workplaces matter: the role of workplace practices in economic transformation. Wellington: New Zealand Department of Labour.

Sabatier, P. (Ed.). (2007). Theories of the policy process $\left(2^{\text {nd }}\right.$ ed.). Westview Press.

Salaman, G., Storey, J., \& Billsberry, J. (2005). Strategic human resource management: defining the field. In G. Salaman, J. Storey \& J. Billberry (Eds.). Strategic human resource management theory and practice: a reader. Sage Publications Limited.

Sambrook, S. (2009). Critical HRD: a concept analysis. Personnel Review, 38 (1), 6173.

Santos, A., \& Stuart, M. (2003). Employee perceptions and their influence on training effectiveness. Human Resource Management Journal, 13 (1), 27-45.

Saville-Smith, K. (2003). Power and politics: the shaping of evaluation research in New Zealand. In N. Lunt, C. Davidson \& K. McKegg (Eds.). Evaluation policy and practice: a New Zealand reader. Auckland: Pearson Education New Zealand Limited.

Scriven, M. (1967). Methodology of evaluation. In R. Tyler, R. Gagne \& M. Scriven (Eds.). Perspectives in curriculum evaluation. Chicago: Rand McNally. 
Seven pillars of growth: a New Zealand perspective. (2007). Wellington: Business NZ.

Sheldon, P., \& Thornwaite, L. (2005). Employability skills and vocational education and training policy in Australia: an analysis of employer association agendas. Asia Pacific Journal of Human Resources, 43 (3), 404-425.

Skills of improved productivity, employment growth and development. (2008). Geneva: International Labour Office.

Skills for the knowledge economy: a review of industry training in New Zealand. (2001). Wellington: New Zealand Ministry of Education.

Skills imperative: towards a learning culture for New Zealand. (1990). Wellington: New Zealand Ministry of Education.

Smart food, cool beverage: New Zealand's future in the food and beverage sector. (2006). Wellington: New Zealand Trade and Enterprise.

Smart, W. (2006). Outcomes of the New Zealand tertiary education system: a synthesis of the evidence. Wellington: New Zealand Ministry of Education.

Smelt, S. (1995). Industry training organisations. Wellington: Education Forum.

Smith, A. (Ed.). (2001). Return on investment in training: research findings. Australian National Training Authority.

Smith, C., \& Ridoutt, L. (2007). The importance employers attach to employee qualifications. Asia Pacific Journal of Human Resources, 45 (2), 180-199.

Smith, P. (2007). Formula funding of public services. New York: Routledge.

Smits, W. (2007). Industry-specific or generic skills? Conflicting interests of firms and workers. Labour Economics, 14 (3), 653-663.

Smits, W. (2008). The private benefits from vocation training: a new framework. In Modernising vocational education and training: fourth report in vocational training research in Europe - a background report. Luxembourg: Office for Official Publications of the European Communities.

Stake, R. (1975). Program evaluation particularly responsive evaluation. Chicago: University of Illinois.

Stasz, C. (2001). Assessing skills for work: two perspectives. Oxford Economic Papers, 3, 385-405.

Stasz, C., Hayward, G., Oh, S., \& Wright, S. (2004). Outcomes and processes in vocational learning: a review of the literature. Learning and Skills Research Centre.

Strategic plan for the employer of choice and excellent state servants development goals. (2006). Wellington: State Services Commission.

Strathdee, R. (2005). Globalization, innovation and the declining significance of qualifications led social and economic change. Journal of Education Policy, 20 (4), 437-456.

Stroombergen, A., Rose, D., \& Nana, G. (2002). Review of the statistical measurement of human capital. Wellington: Statistics New Zealand.

Strugeon, T. (2000). How do we define value chains and production networks? Paper presented at the Bellagio Value Chains Workshop.

Suchman, E. (1967). Evaluative research: principles and practice in public service and social action programmes. New York: Russell Sage Foundation.

Swanson, R. (1998). Demonstrating the financial benefit of human resource development: status and update on the theory and practice. Human Resource Development Quarterly, 9 (3), 238-295.

Tertiary Education Strategy 2002-2007. New Zealand Ministry of Education.

Tertiary Education Strategy 2007-2012 incorporating statement of tertiary education 
outcomes 2008-2010. (2007). Office of the Ministry for Tertiary Education.

Tertiary Education Strategy 2010-2015. (2010). Wellington: New Zealand Ministry of Education.

Thiel, S., \& Leeuw, F. (2002). Performance paradox in the public sector. Public Performance and Management Review, 25 (3), 267-281.

Thomas, P. (2006). Performance measurement, reporting, obstacles and accountability: recent trends and future directions. Canberra: Australian National University.

Tight, M. (2002). Key concepts in adult education and training ( $2^{\text {nd }}$ ed.). London: RoutledgeFalmer.

Tomorrow's standards: the report of the Ministerial working party on assessment for better learning. (1990). Wellington: New Zealand Ministry of Education.

Torvatn, H. (1999). Using program theory models in evaluation of industrial modernisations programs: three case studies. Evaluation and Program Planning, 22, 73-82.

Tourism and Hospitality Workforce Strategy. (2006). Wellington: Tourism and Hospitality Leadership Group.

Trotman, I. (2003). Evaluation in New Zealand: a founder's reflection. In N. Lunt, C. Davidson \& K. McKegg (Eds.). Evaluation policy and practice: a New Zealand reader. Auckland: Pearson Education New Zealand Limited.

Turner, D, \& Washington, S. (2002). Evaluation in the New Zealand public management system. In J. Furubo, R. Rist \& R. Sandahl (Eds.). International atlas of evaluation. New Jersey: Transaction Publishers.

Valentin, C. (2006). Researching human resource development: emergence of a critical approach to HRD enquiry. International Journal of Training and Development, 10 (1), 17-29.

Vaughan, K., O’Neil, P., \& Cameron, M. (2011). Successful workplace learning: how learning happens at work. Wellington: Industry Training Federation.

Velada, R., Caetano, A., Michel, J., Lyons, B., \& Kavanagh, M. (2007). The effects of training design, individual, individual characteristics and work environment on transfer of training. International Journal of Training and Development, 11 (4), 282-294.

Walters, L., Aydelotte, J., \& Miller, L. (2000). Putting more public in policy analysis. Public Administration Review, 60 (4), 349-359.

Ward, T. (2008). Geographical mobility. In Modernising vocational education and training: fourth report on vocational training research in Europe background report. Luxembourg: Office for Official Publications of the European Communities.

Warhurst, C., \& Nickson, D. (2007). Employee experience of aesthetic labour in retail and hospitality. Work, Employment and Society, 2 (1), 103-120.

Watson, I. (2008). Skills in use: labour market and workplace trends in skills use in Australia. Paper presented at the Jobs Australia National Conference.

Wengraf, T. (2001). Qualitative research interviewing. London: Sage Publications Inc.

What do we mean by skills. (2007). Retrieve July 10, 2008 from http://www.itf.org.nz

Whiteford, A. (2006). Skill shortages in the trades: a report card. Wellington: Labour Employment and Work in New Zealand.

Wholey, J. (1987). Evaluation assessment: developing programme theory. New Directions for Evaluation, 33, 77-92.

Wholey, J. (2001). Managing for results: roles for evaluation in a new management 
era. American Journal of Evaluation, 22 (3), 343-347.

Wilson, R., \& Hogarth, T. (2003). Tackling the low skills equilibrium: a review of issues and some new evidence. UK Department of Trade and Industry.

Wolf, A. (2002). Does education matter: myths about education and economic growth. London: Penguin Group.

Wolf, A. (2011). Review of vocational education. London: UK Ministry of Education.

Wolf, A., Jenkins, A., \& Vignoles, A. (2006). Certifying the workforce: economic imperative or failed social policy? Journal of Education Policy, 21 (5), 535565.

Wong, G. (2004). Policy learning through evaluation: challenges and opportunities. In Evaluating local economic and employment development: how to assess what works among programmes and policies. OECD.

Wood, S., \& Wall, T. (2007). Work enrichment and employee voice in human resource management-performance studies. International Journal of Human Resource Management, 18 (7), 1335-1372.

Working smarter: driving productivity growth through skills. (2008). Wellington: New Zealand Treasury Department.

Workplace productivity challenge: report of the Workplace Productivity Working Group. (2004). Wellington: Workplace Productivity Working Group.

World class skills: implementing the Leith review of skills in England. (2007). London: UK Department for Innovation, Universities and Skills.

Wright, P., Gardner, T., \& Moynihan, L. (2003). The impact of HR practices on the performance of business units. Human Resource Management, 13 (1), 21-36.

Yang, B. (2003. Political factors in decision making and implications for HRD. Advances in Developing Human Resources, 5 (4), 458-479.

Yin, R. (2003). Case study research: design and methods $\left(3^{\text {rd }}\right.$ ed.). Sage Publications Inc. 